\title{
$\mathbf{G} \mid$ oba $\mid \mathbf{S t u d i e s}$
}

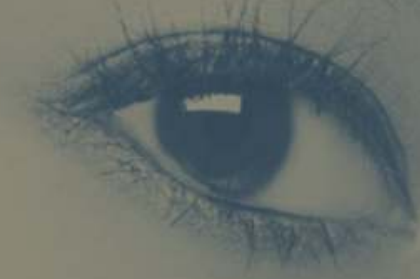

ULRICH HEI N Z E

\section{Hautkontakt der \\ Schriftsysteme}

Japan im Zeichen der

Globalisierung: Geldflüsse

und Werbetexte

旬のフェミニン顔の鍵は

ぷるんとツヤめく肌にあり

[transcript] 
Ulrich Heinze

Hautkontakt der Schriftsysteme 
Ulrich Heinze ist Soziologe und promovierte I99I in Berlin. Als Forscher und DAAD-Fachlektor war er fünf Jahre an der Universität Tokio. Seit 2004 ist er Privatdozent an der Universität Freiburg i.Br. 
ULRICH HEINZE

Hautkontakt der Schriftsysteme

Japan im Zeichen der Globalisierung:

Geldflüsse und Werbetexte

[transcript] 
Bibliografische Information der Deutschen Bibliothek

Die Deutsche Bibliothek verzeichnet diese Publikation in der Deutschen Nationalbibliografie; detaillierte bibliografische Daten sind im Internet über http://dnb.ddb.de abrufbar.

(C) 2006 transcript Verlag, Bielefeld

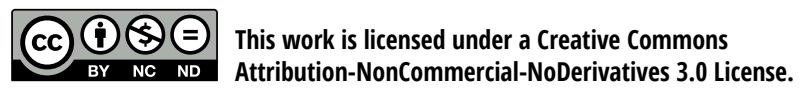

Umschlaggestaltung: Kordula Röckenhaus, Bielefeld; Rie Koiwa, Hokkaido (J) Lektorat und Satz: Ulrich Heinze

Druck: Majuskel Medienproduktion GmbH, Wetzlar

ISBN 3-89942-513-8

Gedruckt auf alterungsbeständigem Papier mit chlorfrei gebleichtem Zellstoff.

Besuchen Sie uns im Internet: http://www.transcript-verlag.de

Bitte fordern Sie unser Gesamtverzeichnis und andere Broschüren an unter: info@transcript-verlag.de 


\section{Inhalt}

Vorwort. .7

Einleitung: Weltwirtschaftssystem,

Weltwährungssystem, Weltwerbesystem. .11

\section{Geschlechterdifferenz als kulturelle Identität}

1.1 Geschlechterdifferenz als Konstituente von Kulturen.............25

1.2 Die latente Spur des Geldes im Verhältnis der Geschlechter........30

1.3 Die Zivilisierung der Liebe als Codierung ihrer Theorie. .41

\section{Japan und der Westen als differenzielle Einheit der Zivilisation}

2.1 Japan und der Westen: Moderne als Einheit der Differenz. . .49

2.2 Gabe und Geld in Japan: Dividuum und Dividende....................57

2.3 Macht und Massenmedien, Beschreibung und Beschriftung interkultureller Grenzgang zwischen System und Subjekt........66

\section{Geld und Werbung als mediale Komplemente}

3.1 Digitales Geld und seine binär schematisierte Theorie...........77

3.2 Die diabolische Spur der Versuchung in der Theorie des Geldes...................................8 87

3.3 Materialistische Matrizen: Werbung im maternellen Japan.......97 


\section{Interkulturelle Lesungen der Werbung in Japan}

4.1. Die Lust am Werbetext:

binärer Baukasten einer Theorie der Werbung...................109

\section{2. tanjô (Geburt):}

Werbung gebiert Waren und zeichnet ungezeichnete Körper...121

4.3. ubuhada (unschuldige Haut):

Hautkontakt von digitalem System und taktilem Körper.........126

4.4. ironna jibun (verschiedene Selbste):

Selbst und (In-)Dividuum in der japanischen Werbung...........136

4.5. otoko no aji (der männliche Geschmack):

Mann und Frau in der japanischen Werbung..............................148

4.6. oishii yôroppa (leckeres Europa):

exklusives Essen in der japanischen Werbung............................160

4.7. Werbung als kulturelle Beobachtung zweiter Ordnung..............171

Fazit: Interkulturelle Lesungen der japanischen Werbung................181

Literatur

zum theoretischen Teil (Kapitel 1- 3.2)...................................183

zum empirischen Teil (Vorwort, Kapitel 3.3, Kapitel 4)...........190

Anhang

Liste japanischer Schriftzeichen/Werbeglossar..

Werbeausgaben nach Branchen und

Mediamix in Japan und Deutschland...........................198

Bildanhang..............................................200 


\section{Vorwort}

Nur Subjekte lieben. Nur Subjekte schreiben. Nur Subjekte (unter-) zeichnen. Der vorliegende Text versucht, ein Schriftsystem zu beschriften und Zivilisation als Kultur der Selbstbeschriftung zu lesen. Er versteht sich als eine Art des paradoxen Body-Paintings eines Theoriesystems: Objekt des Pinsels ist die körperlose, digitale Systemtheorie, genauer: ihr autopoietisch verfaßtes Weltwirtschaftssystem. Indem es sich von der Logik des äquivalenten Tauschs, von der Ware Arbeitskraft und dem durch sie bezeichneten Widerspruch emanzipiert hat, indem sein digitales Geld das materielle Äquivalent in Gold abgeschüttelt hat, indem es schließlich seine Währungen universell konvertibel verfaßt, scheint es alle kulturellen Differenzen in der Globalisierung zu verschlucken. Indem sich das Funktionssystem selbstrefenziell verschließt und informative Kommunikation an die Stelle materiellen Austausches setzt, fügt es sich ideal in die Selbstbeschreibungsmuster der zivilisierten Systemtheorie. An dieser Stelle erst breitet sich wieder eine kultursoziologische Schreibfläche vor dem Leser aus, ein Raum für einen sanften Diskurs der Zeichen. Wie die Zivilisation sich über ihre Differenz zur Wildnis selbst beschreibt, so muß auch ihr Wirtschaftssystem mit seiner Umwelt in einen Diskurs der Zeichen eintreten, der den kulturellen Hautkontakt wiederherstellt. Diese Körperzeichnung leistet das Massenmedium Werbung weltweit.

Die Systemtheorie hat Systeme nur beschrieben. Es kommt aber darauf an, ihre Selbstbeschriftung zu lesen. Sie unterscheidet die Akte vom Buch und generiert erst die Lust am Text. Das vorliegende Papier ist keine Verpackung für rohe Fische, sondern plädiert für das Außen, für die Fremde, für das Andere. Gerade selbstreferenzielle Theoriesysteme sind nur von dort zu verstehen und nachzuzeichnen. Nur von außen ist zu erkennen, wie Systeme sich selbst beschriften, nur von außen ist ihr 
Diskurs der Zeichen vorsichtig umzuschreiben. Und wenn das Massenmedium Werbung die Ökonomie kommunikativ verpackt, so abstrahiert es zugleich vom Diskurs der Ware, des Werts, des Preises und der Warenästhetik. Die Werbung verführt zu der Frage, was nun auf den identitätslogischen Ansatz der Werttheorie und das differenztheoretische Dogma der Systemtheorie folgt.

Die Umschrift japanischer Werbetexte liefert eine Spur: weder auf das Wertgesetz noch auf das Medium Geld, sondern auf die Latenz von Körper, Subjektivität und Bedürfnis sollte die Soziologie wetten. Nicht die Geldscheine, sondern die Systemtheorie ist gegen das Licht zu halten. Ihrem Begriff des selbstreferenziell geschlossenen Wirtschaftssystems fehlt das Wasserzeichen. Soziale Systeme, so komplex sie immer sein mögen, sind hervorgebracht von sozialisierten Individuen. „Soziale Systeme bilden und erhalten sich durch die Aktivitäten der Subjekte. Sie sind deshalb keine autopoietischen Systeme. ${ }^{1}{ }^{1}$ Und weiter im Text:

„Es ist im wesentlichen dieses Dogma, auf das die Mängel des systemtheoretischen Denkens auch bei Luhmann zurückzuführen sind. Der Irreduzibilitätsgedanke blockiert nämlich nicht nur jede individualistische Erklärung sozialer Systeme und damit jede tiefergehende erklärende Analyse sozialer Zusammenhänge überhaupt, sondern er ist auch verantwortlich für jene begriffliche Abgrenzung von sozialen und psychischen Systemen, deren Ungereimtheiten besonders in den Überlegungen Luhmanns sichtbar geworden sind. Eine Perspektive, in der das Verhältnis von Mensch und Gesellschaft als eine Beziehung zwischen zwei eigenständigen Systemen erscheint, die füreinander Umwelten sind, eine solche Perspektive kann nun einmal nicht klar machen, daß und wie gesellschaftliche Systeme Hervorbringungen von sozialisierten Individuen sind." ${ }^{2}$

Das Kommunikationssystem hat kein Gehirn. In unserem Zusammenhang wesentlich wird aber, daß es keinen Körper hat. Die indifferente Beschreibung der Differenztheorie ist daher zu ergänzen: Das symbolisch generalisierte Geld als digitales Zeichen zieht das taktile, diabolische Bedürfnis wie einen Schatten mit sich. Das Geld reguliert die Ökonomie im Innenverhältnis, doch nach außen hin kommt sie nicht ohne Body-Painting aus. Die Werbung bietet daher paradox die Möglichkeit, die funktionalistische Geldtheorie umzuschreiben und gegenzuzeichnen. Ausgerechnet das japanische Reich der Zeichen, mit seinen dividualen Psychen höchst empfänglich für die Semantik funktionaler Differenzierung, ist der ideale Ort für diese Operation am Text. ${ }^{3}$

1 Dux 1992: 71.

2 Bohnen 1994: 303. S. auch Wagner/Zipprian 1992.

3 Fuchs 1995. Vgl. Kapitel 2.1. 
Wohnadressen im Labyrinth von Tokio, besonders die von Ghostwritern, sind schwer zu finden. Doch irgendwer steckt hinter dem Text. Nur Subjekte schreiben. Nur Subjekte lieben. Nur Subjekte reflektieren ihre Bedürfnisse jenseits der ja/nein-Codierung. Nur Subjekte wissen, daß ihre Welt real ist, nicht konstruiert. ${ }^{4}$ Nur Subjekte können Widersprüche und Paradoxa erkennen und bezeichnen. Nur Subjekte sind fähig zu interkulturellen Grenzgängen - so wie Captain Picard vom Raumschiff Enterprise, der die Kultur der übermächtigen Borg auf ihrem eigenen, furchteinflößenden schwarzen Sternenschiff erforscht hat. Und deswegen erhielt der diplomatische Captain auch vom allmächtigen Q eine winzige Chance zur Aufnahme ins Kontinuum. Nicht an die äußere Komplexität und Bedrohung ist deshalb zu denken, sondern an die kognitiven Spielräume der Sprache, des Bewußtseins und der Kommunikation - im Einklang mit den Werbeslogans von Ikea und Toyota: Entdecke die Möglichkeiten! Nichts ist unmöglich!

Latenzen kommunizieren heißt: Möglichkeiten eröffnen. Das Motto dieser Arbeit ist daher nicht das des übermächtigen Borg-Schiffs: „Widerstand ist zwecklos!“ Im Gegenteil: Auch die Kultur der Borg, die Funktionssysteme der Gesellschaft, sind als Lebensform anzuerkennen, ihre Theorie ist zu unterschreiben. Auch die vorliegende Arbeit wurde durch ein postdoc-Stipendium der Europäischen Union finanziert und begann mit der Unterschrift unter einen Vertrag. Buchstaben, Zeichen und Texte sind dehnbar - genau wie die Reproduktionskosten von Forschern, wenn sie den Kursschwankungen im Weltwährungssystem unterliegen. Doch am Ende sind auch Systeme lern- und zahlungsfähig. Die Unterschrift ist daher allenfalls der erste Schritt, das Zücken der Feder, ihr Aufsetzen auf dem Papier, der Beginn des Fließtextes und des Schreibflusses. Profitieren soll davon nicht der Unterzeichnete, sondern der Steuern zahlende Leser.

Der empirische Teil dieser Arbeit (Kapitel 4) beruht auf Werbungen, die fast alle im japanischen Haushaltsjahr 1999 (1. April 1999 bis 31. März 2000) aus den Printmedien und dem Fernsehen in Japan abgegriffen wurden. Weitere Informationen flossen ein aus Interviews mit japanischen Werbemanagern sowie aus der japanischen Werbeforschung. Die Übersetzungen der japanischen Werbetexte ins Deutsche sind bewußt in Rohform gehalten: Sie sollen zeigen, wie sich die japanischen Werbestrategien in die theoretische Argumentation dieser Arbeit einfügen. Es ist also weder möglich noch notwendig, sie ohne den Verlust wesentlicher Informationen (der Begriffsassoziationen und Worthöfe) in das Genre deutscher Werbetexte zu überführen. Dennoch sind mir Hin-

4 Dux 1994: 43- 47. 
weise auf Fehler oder auf mir entgangene Anspielungen sowie Kritik an der Argumentation jederzeit willkommen.

Für meine Arbeit in Japan hat mich sage und schreibe zwei Jahre lang das Institute of Socio-Information and Communication Studies (ISICS) der Universität Tokio als Wissenschaftler beherbergt. Für die Öffnung des Akamon (roten Tores) danke ich herzlichst Prof. Hanada Tatsuro. Prof. Hermann Schwengel leistete Hilfestellung aus dem fernen Freiburg i.Br. Igari Hiromi und Koiwa Rie haben viele meiner Übersetzungen der japanischen Werbeslogans ins Deutsche verbessert und zusätzlich mein Verständnis der japanischen Sprache und Kultur vertieft. Inagaki Hideto sorgte für meine ständige digitale Vernetzung und erfaßte auch einige Werbespots per Computer. Der schönen Norika Fujiwara bin ich verbunden, weil sie sich zum richtigen Zeitpunkt ins japanische Starund Werbesystem und in mein geistiges Auge einschlich. Am meisten beigetragen zu meiner Arbeit hat jedoch meine Familie. Sie meisterte alle Belastungen mit besonderem Einsatz und hat mir nach vielen schwachen Momenten ein Leben jenseits der Zeichen und Bildschirme geschenkt.

Tokio, am Valentinstag 2005

Ulrich Heinze 


\section{Einleitung: Weltwirtschaftssystem, Weltwährungssystem, Weltwerbesystem}

\section{Autoskript der Zivilisation und kulturelle Umschreibung}

Leuchtende, bunte, bewegte Werbebilder in den öffentlichen Räumen der modernen Städte sind zugleich als Errungenschaften und als Zeichen der Zivilisation lesbar. Wie die Zivilisation ihre Grenze zur Wildnis selbst strichelt, so umhüllt, beschriftet, verpackt und identifiziert die Werbung das autopoietische Weltwirtschaftssystem, das den gegenwärtigen Prozeß der Globalisierung moderner Gesellschaft trägt. Beide sind Autoskripte geschlossener Systeme, die zur kulturellen Umschreibung herausfordern. So wie die technische Zivilisation noch von den letzten Dschungelvölkern lernt, so öffnet die Werbung das ökonomische Funktionssystem für den Zugriff der Kultursoziologie. Am Ende sind die Autoskripte der Zivilisation nur gezeichnete Varianten von Kultur.

Nur die Zivilisation kann Werbung generieren, denn sie ist eine autodeskriptive Kultur. Sie unterscheidet sich von den wilden Ethnien, indem sie jene kulturell, sich selbst aber technisch und ökonomisch identifiziert. Während primitive Gesellschaften sich an der Geschlechterdifferenz bilden, ersetzen moderne Gesellschaften den symbolischen durch den äquivalenten Tausch und Verpflichtung durch Vertrag. Die Werbung ist selbst ein unmittelbares Produkt, ein Korrektiv dieser modernen Vertragskultur. Zwar muß niemand sie kaufen oder unterschreiben, aber jeder muß sie lesen oder ansehen. Zwar überredet, beeinflußt, manipuliert sie nicht, doch gleichzeitig kann niemand sich ihr entziehen. An diesem Paradox: der kostenlosen Üppigkeit der Werbung angesichts der ewigen Knappheit des Geldes und asketischen Existenz von Otto Normalverbraucher, setzt der vorliegende Text an. Er umschreibt Werbung als Autoskript der Ökonomie und besteht zum guten Teil selbst aus 
Werbetexten. Gleichzeitig versucht er, den Spieß umzukehren und Werbung als kulturelles Zeichensystem zu lesen, das sich der einheitlichen, zivilisierten, funktionalen Logik des Geldes entzieht.

Erfordert eine Geschichte der Phantasie Phantasie, so muß eine Theorie der Werbung frei vom Funktionsbegriff geschrieben werden. Die Werbung dient nicht der Verkaufsstrategie, sondern ist zum Genießen da. Mehr als die Ware selbst ist sie zum Konsumgut avanciert und konvergiert (speziell in Zeiten der Hochkonjunktur) mit der Kunst. ${ }^{1}$ Ausgangspunkt ihrer Analyse ist daher ihre Definition als überflüssige und zweckfreie Kommunikation, als Verpackungskunst des Wirtschaftssystems. Erst indem das autopoietische Funktionssystem Ökonomie, das sich im Innenverhältnis des Mediums Geld bedient, sich nach außen hin mit Werbung selbst beschriftet, gelingt es ihm auch, sich selbstreferenziell zu schließen. Und erst indem die Soziologie diese kulturelle Selbstbeschreibung des Funktionssystems liest und zur Kommunikation von Latenz umschreibt, definiert sie Zivilisation wieder als Kultur: als Gesellschaft von Subjekten mit Körpern, Bedürfnissen, Identitäten.

Diese zivilisierende Kraft der Werbung läßt sich in erster Näherung an ihrem Widerstand gegen ihre weltweite Standardisierung und Vereinheitlichung ablesen. Obwohl in den 90er Jahren mit dem Anschluß Ostdeutschlands und der europäischen Währungsunion das Wirtschaftssystem seine Globalisierung vorantrieb und Handelsgrenzen überwand, hat gerade die Öffnung des Ostens gezeigt, wie tief die vielen kulturellen Identitäten der einen Weltgesellschaft in den Psychen und Mentalitäten verankert bleiben. Bevor ich deshalb auf die Theorie der Selbstbeschreibung der Weltwirtschaft zurückkomme, lohnt sich ein empirischer Seitenblick auf den Stand der Forschung zur interkulturellen Werbung.

\section{Kulturelle Mauern als Schreibflächen der Werbung: DDR/Rußland/China}

Kulturelle Grenzen sind, anders als Systemgrenzen, unscharf (und der Systemtheorie sind daher alle Kulturbegriffe fremd: Ihre Kultur ist die einheitliche (Beschreibung der) Einheit der zivilisierten Weltgesellschaft.). Während Systeme sich über ihre Differenz zur Umwelt selbst als Einheit konstituieren, verschwimmen kulturelle Identitäten, gleich wie man sie definiert, am Rand. Mehr noch: Kulturelle Differenzen lassen sich nicht zur Einheit reduzieren - die Differenz zwischen Ja-

1 Sylvia Meffert beobachtet diese Konvergenz vor allem in den 90er Jahren des 19. sowie in den 60er und 80er Jahren des 20. Jahrhunderts. Meffert 2001. Vgl. Schnierer 1999: 245-266. Schmidt/Spieß 1996: 39. 
pan und dem Westen bildet hier die große Ausnahme. Mögen Staatsgrenzen noch von politischen Systemen stabil gehalten werden Sprachräume, regionale Gewohnheiten und Kommunikationsstile sind ständig wechselseitigen Einflüssen ausgesetzt und immer im Fluß.

Die politische Einigung West-Europas gab vor dem Fall der Mauer Anlaß zu der Vermutung, mit dem ökonomischen Zusammenwachsen würden sich auch kulturelle Eigenheiten abschleifen. So vermaßen Kloepfer/Landbeck Ende der 80er Jahre TV-Spots aus den westlichen Industrieländern über vier Jahre nach einem eigens entwickelten empirischen Schema und konstatierten eine zunehmende Ästhetisierung und sogar Standardisierung der Werbestile. Die Spots wurden aufwendiger und emotionaler, lösten sich vom Produkt und von der sachlichen Information. Allerdings blieb die qualitative Rangfolge der Länder fast gleich. Am progressivsten war die TV-Werbung demnach in Großbritannien, am rückständigsten in den USA. ${ }^{2}$ Die Autoren folgerten, daß die Werbung sich weltweit standardisiere:

„Der entscheidende Wandel setzt damit ein, daß Dinge, Interieurs, Architekturen, Landschaften als transnationale Zeichen entdeckt werden, insbesondere, wenn mit dem hochkodierten akustischen Environment dargeboten. Dasselbe gilt für die relative Kulturunabhängigkeit vom mimischen Ausdruck elementarer Emotionen, von Basisgesten, von narrativen oder allgemein dramatischen Situationen und Konstellationen. An die Stelle der sprachlichen Intonation tritt transnational Musik, welche den Kontext in Sekunden evoziert, Einstellungen zur Botschaft orientiert, die Stimmung tönt. Die jeweils fremdartigen Reste werden zu Reizmitteln. Unverständlichkeit wird einsetzbar wie Exotik. Ebenso werden transkulturelle Symbolfelder, Metaphernnetze und Mythen als gemeinverständliche Chiffren in dem Maße brauchbar, wie die Spots selbst in steter Mehrfachkodierung diese Zeichen und ihre Übersetzung wiederholen. Zumindest für Europa werden dergestalt die historischen Gemeinsamkeiten in den nationalen Lebenswelten für eine differenzierte, transnationale Ikone der Werbung entdeckt: Eine einfache Weltsprache Werbung gibt es bereits. “3

Für einen kurzen Augenblick schien die Globalisierung der Weltwirtschaft widerstandslos auf die Kulturen der westlichen Industrieländer und ihre Werbung durchzugreifen. Doch mit dem Fall der Berliner Mauer (und dem gleichzeitigen Platzen der bubble-economy in Japan) wendete sich das Blatt. In Europa, besonders aber innerhalb des wiedervereinigten Deutschlands, brachen die kulturellen Differenzen wieder mit aller Wucht hervor. 1991 notierte der Kreative Konstantin Jacoby:

2 Kloepfer/Landbeck 1991: 111. Vgl. auch Fuchs 1992: 313.

3 Kloepfer/Landbeck 1991: 233. 
„Die Franzosen haben eine Erotik-Macke, die Engländer eine Humor-Macke, die Japaner eine Graphik-Macke. Die Deutschen haben die Macke, alles richtig machen zu wollen. Aber der Unterschied zwischen Engländern und Westdeutschen, wenn es um Werbung geht, ist zur Zeit viel geringer als der zwischen Ost- und Westdeutschen. Werbung hat im Osten einen anderen Stellenwert. Produktinformation muß im Vordergrund stehen. Die im Westen sehr erfolgreiche Kampagne für Peter Stuyvesant - ,Come Together ${ }^{6}$-, in der die Aufgeschlossenheit und das Verständnis gegenüber fremden Völkern und Ländern betont wird, kam im Osten nicht an. Die Verbraucher fragten: ,Was soll das, was hat das mit Zigaretten zu tun?' Dort muß es zum Beispiel heißen: ,Eine Top-Classe-Zigarette mit internationaler Tabakmischung': Schlagzeilen und Slogans wie bei uns in den 50er Jahren werden gebraucht - weil sie dieselbe Funktion haben wie bei uns in den 50er Jahren. “4

Geöffnet für den Weltmarkt haben sich auch Rußland und China. In Rußland ist der politisch indoktrinierende Stil von einst dem sanfteren Plädoyer für den individuellen Konsum gewichen. Wie in der Ex-DDR lösen diskrete, persuasive Techniken die plumpe Übermittlung von Produktinformationen ab. Zumindest in puncto Ästhetisierung der Produktion paßt sich der Osten den westlichen Standards an.

„Bei den Überschriften der 90er Jahre geht es also oftmals nicht mehr darum, dem Rezipienten Gebrauchswerte eines Produktes mitzuteilen. Stattdessen werden nun Behauptungen über den Konsumenten gemacht und Zusatzwerte angesprochen, die der Konsument zugleich mit dem Produkt erwerben kann. Dem Verbraucher wird also nahegelegt, daß er sich selbst durch den Konsum der Produkte aufwerten, Glück erlangen oder ein erstrebenswertes Ziel erreichen kann. Im Fließtext wird der Rezipient nun nicht mehr die Antwort auf die Frage: ,Welche Eigenschaften hat dieses Produkt?` erwarten, sondern die Frage: ,Wodurch kann ich zu einer positiv bewerteten Gruppe gehören, andere übertreffen, bestimmte Eigenschaften bekommen?““5

4 FAZ-Magazin vom 25. Oktober 1991. Der Werbeprofi erkannte früh, was inzwischen alle empirischen Daten belegen. Schon der Fernsehkonsum liegt in Ostdeutschland um rund 10\% höher als im Westen. Auch bleibt der ostdeutsche Konsument gerne seinen gewohnten Marken treu (Nickel 1996). Zwar sah eine Analyse aus dem Jahre 1991 den Anteil spezieller Fernsehspots für Ostdeutschland nur bei 5\% (Becher/Kessler 1991). Aber es fällt auf, daß die Bilder vom Fall der Mauer in Deutschland noch in keinem Werbespot zum Imagetransfer genutzt wurden, in Japan dagegen allein 1999 zweimal. In einem Spot fährt der VW Golf durch die Berliner Mauer (Kapitel 4.7), in einem anderen schlürft ein tarento inmitten der Mauerspechte seine Nudelsuppe. Diese Bilder zeitigen wohl in Deutschland selbst immer noch viele negative Assoziationen. Immerhin ergab eine Studie zur Wirkung zweier Anzeigen für Lord Extra: In beiden Landesteilen kam die westliche „Lifestyle-Version“ besser an als die nüchterne, informative Ost-Version (Mayer/Heckelsberger 1992).

5 Butterweck 1995: $56 f$. 
Seit im europäischen Werbespot der Citroën AX mit revolutionärem Slogan (Revolutionaire) über die chinesische Mauer preschte, gilt China, mehr noch als Rußland oder die Ex-DDR, als Musterland der politisch-ökonomischen Öffnung. Anfang der 80er Jahre war die chinesische Werbung noch stark politisch geprägt. Toyota eckte 1981 mit seinem ersten TV-Spot noch an, weil, wie es hieß, eben nicht (wie im Spot behauptet) auf jeder Straße ein Toyota fahre. ${ }^{6}$ Insbesondere japanische Firmen biederten sich offen bei der chinesischen Führung an, gratulierten zu Jubiläen und lobten ihren eigenen Beitrag zur Entwicklung des Landes. Die Werbung war Teil der politischen Großwetterlage und propagierte die Ein-Kind-Ehe und die Ideologie der Transformation. ${ }^{7}$

Erst ab Mitte der 80er Jahre entdeckten die Werber den chinesischen Konsumenten. Gleichzeitig wurde die Werbung emotionaler, und westliche Werte wie „Weltoffenheit“, ,fortgeschrittene Technik“, „,besondere Qualität“ und „,neues Zeitalter“ hielten Einzug in die Slogans. Ideologische Pflichtübungen wichen zurück, hartes, materialistisches Konsumdenken gewann die Oberhand. Auch das Massaker vom Platz des Himmlischen Friedens 1989 hinterließ in der Statistik der japanischen Werbung in China nur eine kleine Delle und hat die globale Einbindung Chinas nicht behindert. ${ }^{8}$ Innerhalb von acht Jahren ist China mit seinen absoluten Werbeausgaben vom 36. auf den 9. Platz (1998) in der Welt vorgestoßen.

Japan spielt beim globalen Anschluß Chinas die Vorreiterrolle, und das offensiv. Manabe zählt unter den Ausländern, die in der chinesischen Werbung auftauchen, drei Viertel Japaner. Sie spielen zumeist die Rolle von großen Brüdern, die die chinesischen Konsumenten als Manager, Vertreter oder mindestens als Office Lady in die Segnungen des Konsums einweihen und die Tücken der Technik erklären. Das befremdet selbst den japanischen Analytiker der chinesischen Werbung, Manabe Kazufumi: „Aus den Auftritten der Japaner mag man auf einen gewissen Wohlstand schließen sowie auf Ernsthaftigkeit und Fleiß. Aus der Sicht der Chinesen kommen jedoch erstaunlich selten Menschen vor, die eine gewisse Vertrautheit oder Freude spüren lassen. “9

6 Hong 1994.

7 Yamaki 1994: 38.

8 Manabe 1998: 88, 93-95.

9 Manabe 1998: 97 (Übersetzt von mir, U.H.). Die rapide Zunahme der Werbung, auch der unlauteren, in China zwang die Führung, 1993 und 1995 neue Gesetze zu erlassen, um die zahlreichen gutgläubigen, aber ungebildeten Konsumenten zu schützen (Au/Wormuth 1995, Shao 1995). Auch wenn die politische Zensur der Werbung etwas an Strenge verlor, wird sie immer noch gegängelt. Ein Werbespot mit der Freiheitsstatue im Hintergrund durfte nicht gesendet werden, auch die chinesische Flagge und Hymne sind tabu. Und um seine Pepsi zu holen, durfte Aaron Kwok, der Pop-Star aus Hong Kong, nicht im Stil eines Einbrechers durchs Fenster, 
In der interkulturellen Werbeforschung hat sich daher die Differenzierungsthese gegen die Standardisierungsthese auf allen Ebenen durchgesetzt. Schon die Produkte selbst und ihre Rezeptur unterscheiden sich von Land zu Land signifikant. Coca-Cola ist nicht überall gleich süß, Tütensuppen sind in Osaka anders gewürzt als in Tokio. Marlboro-Zigaretten, Hygieneartikel und Klebestifte haben in verschiedenen Ländern verschiedene Bedeutungen und sind im Marketing nicht über einen Kamm zu scheren. Schon die Benennung des Produktes (Naming) muß den Klang und die Bedeutung des Wortes in den verschiedensten Sprachen recherchieren: „Pajero“ als Name für einen Geländewagen ist in Spanien ungeeignet, das englische Wort „mist“ kann in Deutschland kein Parfum bezeichnen. Auch Schreibweisen, ja sogar Schrifttypen sind wesentlich: Ein süßer Sirup läuft nur als runde Welle die Kehle herunter. Auch die Vorteile des Kapitalismus macht eine Managerzeitung ihren Lesern besser mit rundem „C“ schmackhaft, selbst wenn das die deutsche Rechtschreibung verletzt. Ein Messer aus Deutschland mit dem Namen Kondor dagegen schreibt sich - anders als die Fluggesellschaft besser mit eckigem „K“. ${ }^{10}$

Identische Produkte unterscheiden sich in Abhängigkeit von ihrem kulturellen Kontext. Computer und Telefone spielen in Deutschland, wo jeder dritte Haushalt ein Single-Haushalt ist, eine andere Rolle als in Irland, wo das nur für jeden elften Haushalt gilt. Die Werbung muß auch diese kulturspezifischen Konsumstile und Assoziationsmuster berücksichtigen: Der Marlboro-Cowboy erinnert in Hong Kong und Argentinien im Aussehen an einen Menschen aus der Unterschicht. Stewardessen, die Alkohol servieren, lösen in arabischen Ländern Unmut aus. Der schokoladige Sarotti-Mohr galt bis vor kurzem in Deutschland als politisch unkorrekt. Und nicht einmal die Bildsprachen der Werbung sind interkulturell standardisierbar. Wendelin Müller stellt fest:

„Zur Vermittlung des Konsumerlebnisses ,abenteuerlich“ muß Werbung in den USA auf die Darstellung von Bergwelten zurückgreifen, Werbung in Frankreich und in Deutschland dagegen auf die ,Dschungelwelt'. Das Konsumerlebnis ,sportlich“ hat immer einen hohen Bezug zu Nationalsportarten. ,Genießen' als Konsumerlebnis ist in Deutschland mit ,Essen', ,Wein trinken' usw. verbunden, in Frankreich dagegen mit ,Desserts', denen in Deutschland wiederum etwas Verbotenes, Sündiges anhängt. ,Gesundheit‘ als Konsumerlebnis erfordert in den USA die Visualisierung von ,Sport treiben` als Ausdruck eines

über die Feuertreppe, über die rote Ampel und an der Streetgang vorbei wie sein amerikanisches Vorbild Michael J. Fox. Politisch korrekt ging er durch die Hintertür nach draußen und bei Grün über die Straße. Eine Straßengang gab es im zivilisierten China der Pepsi-Werbung nicht.

10 Zu den Regeln des internationalen Namings Matsushima 1998: 202-220. 
gesunden Lebensstils, in Frankreich dagegen die Visualisierung von ,bewußtem Ernähren`. Deutsche Konsumenten verbinden ,Gesundheit' mit ärztlicher Betreuung, was in Frankreich und in den USA genau entgegengesetzt mit Krankheit in Verbindung gebracht wird."11

Auch die Vermutung, in verschiedenen Ländern könnten demographisch oder psychographisch vergleichbare Konsumentengruppen oder Subkulturen entstehen, die sich werbetechnisch ähnlich adressieren ließen, ist empirisch nicht $\mathrm{zu}$ untermauern. ${ }^{12}$ Und sogar im Umgang mit den Massenmedien als Werbeträger lassen sich speziell im Vergleich zwischen Deutschland und Japan signifikante Unterschiede messen. So werden in Deutschland Radio und Fernsehen täglich etwa gleich lange genutzt, während das Radio in Japan nur ein Schattendasein führt (Kapitel 3.3, Abbildungen 3 und 4). Die Standardlänge für TV-Spots beträgt in Deutschland 30 Sekunden, in Japan nur 15, sodaß die japanischen Konsumenten auch in Stichproben die niedrigsten Recall-Werte erzielen. Als einzige kulturübergreifende Rahmenbedingung der Werbung in den entwickelten Industrieländern ist daher paradox die Austauschbarkeit vieler konkurrierender Produkte, die Sättigung der Märkte und die restlose Überfütterung der Konsumenten mit medialer Information zu nennen. ${ }^{13}$

\section{Zeichensystem der Zivilisation: Werbung als kulturelle Verpackung der globalen Ökonomie}

Wie die Werbung zeigt, haben sich die Kulturen gegenüber den standardisierenden, vereinheitlichenden Tendenzen der globalen Ökonomie als resistent erwiesen. Damit haben sich zwar einerseits auch die neo-marxistische Thesen des Kulturimperialismus und der Bewußtseinsmanipulation durch Werbung erledigt. ${ }^{14}$ Gleichzeitig aber stellt sich angesichts des wachsenden Weltwerbesystems auf einer abstrakten Ebene erneut die kultursoziologische Frage, warum sich die Werbung als dysfunktionales Kulturelement des ultrafunktionalen Wirtschaftssystems ausdifferenziert hat: die Frage nach ihrer Message.

Solange Kommunikation analog zum äquivalenten Tausch materieller Werte als Transfer von Information begriffen wurde, blieb die Theo-

11 Müller 1998: 86.

12 Müller 1997: 10-23. Schnierer 1999: 157-172. Müller/Kornmeier 1994: 156-161. Grunert 1990.

13 Die höchsten Recall-Werte erzielt Österreich, wahrscheinlich wegen der dort verzögerten Kommerzialisierung der Fernsehlandschaft. Müller 1997: $84,32$.

14 Manabe widerspricht insbesondere den Thesen von C.J. Hamelink und J. Tomlinson. Manabe 1994: 307-311. 
rie der Massenmedien der Manipulationsthese verhaftet. ${ }^{15}$ Das falsche Bewußtsein der Fernsehzuschauer diente aber noch immer als Folie für das richtige Bewußtsein des Philosophen. Seit die Systemtheorie nun Kommunikation nicht mehr als summenkonstanten Transfer, sondern als dreistufigen Selektionsprozeß aus Information, Mitteilung und Verstehen beschreibt, steht der Elfenbeinturm außerhalb des Kommunikationssystems Gesellschaft schief und - schlimmer noch - ist von lärmenden und knipsenden Touristen umgeben. Eine abstrakte Theorie der Werbung muß daher differenztheoretische Begriffe integrieren und sie als Massenmedium aus der Verabsolutierung des Tauschmittels Geld bei Marx erst rekonstruieren. Die Theorien der Werbung und des Geldes sind daher nicht zu trennen, nicht weil die Werbung käufliche Waren präsentiert, sondern umgekehrt: weil sie sich wie das Geld als ökonomisches Medium vom materiellen Wert gelöst hat und ein informatives Eigenleben führt. Radikal formuliert: Mit ihrem Massenmedium Werbung beschriftet sich das autopoietische System selbst und entzieht sich gerade dadurch dem Zugriff funktionaler Beschreibungsroutinen. Das Paradigma der Werbeforschung ist daher auszutauschen: Nicht die Ware, sondern der Körper steht im Zentrum ihres Zeichensystems. Erst die Schreibfläche Körper macht die Werbung wieder anschlußfähig an die Theorie der Zivilisation als derjenigen Kultur, die sich theoretisch selbst beschriftet, aber zugleich einen handschriftlichen Spielraum läßt.

Die Werbung ist, so meine These, als kulturgebundenes Massenmedium der Ökonomie ihrem internen, weltweit generalisierten und standardisierten Kommunikationsmedium Geld gegenüberzustellen. Erst die Werbung dotiert und konterkariert dieses absolute, im Rahmen funktionaler Differenzierung von Gesellschaft universal konvertible Tausch- und Kommunikationsmittel mit kultureller Individualität. Gerade weil das autopoietische Wirtschaftssystem sich selbstreferenziell geschlossen hat, muß es sich mit Werbung kulturell verpacken. Und deshalb ist die Werbung auch erst aus der Definition der Zivilisation als autodeskriptive Kultur herzuleiten.

Das folgende Schema (Abbildung 1) skizziert jene differenziellen Selbstbeschreibungsmuster, welche den Weg zu einer Theorie der Werbung als Massenmedium der Ökonomie ebnen. Das sind: der Unterschied zwischen Mann und Frau als Konstituente vormoderner Gesellschaften (Kapitel 1), das Verhältnis westlicher Kulturen zu Japan als interne Triebfeder der Zivilisation (Kapitel 2) und schließlich der

15 Nämlich bis Ende der 70er Jahre, vgl. Lindner 1977. 
Gegensatz zwischen den ökonomischen Medien Geld und Werbung als interkulturelle Kontingenz der Globalisierung innerhalb der zivilisierten Weltgesellschaft (Kapitel 3). Das Geld ist im Rahmen dieser Gegenüberstellung definiert als inneres Kommunikationsmedium der Weltökonomie, die Werbung als deren Massenmedium und Außenhaut.

Abbildung 1: Differenzielle Selbstbeschreibungen der Zivilisation

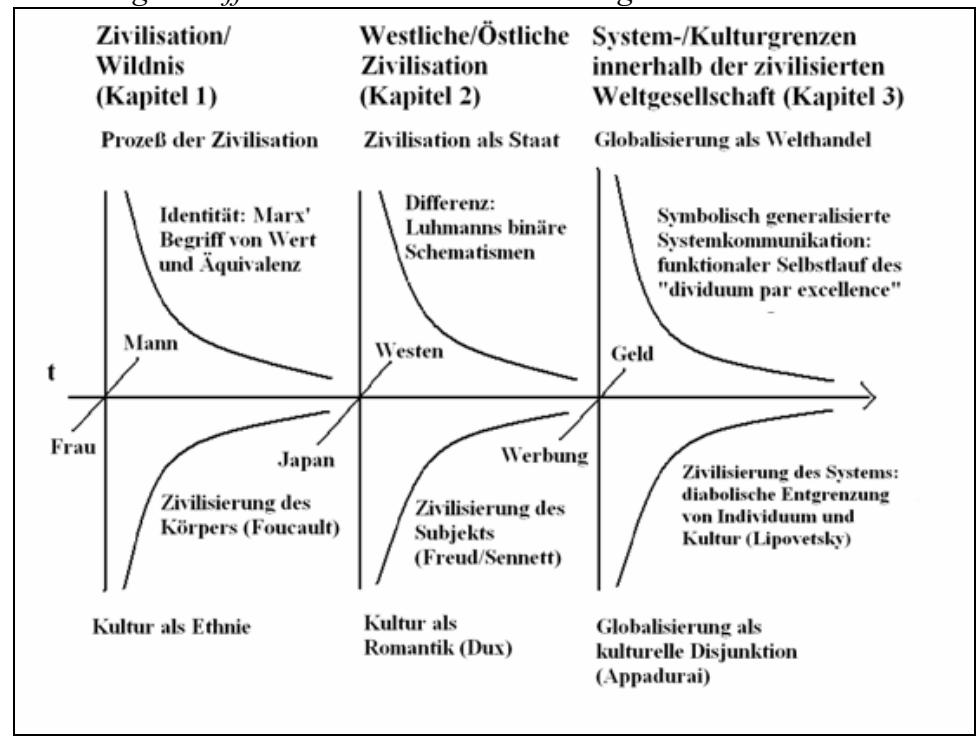

\section{Zivilisation und Wildnis}

Das erste Kapitel begreift den Prozeß der Zivilisation mit der Theorie von Norbert Elias als einen Prozeß der Beschriftung und Disziplinierung des Körpers. Er erreicht mit Foucaults Kliniken und Anstalten im 19. Jahrhundert seinen Höhepunkt. Doch die unmittelbare Zurücksetzung des Körpers in zivilisierten Gesellschaften ist harmlos, verglichen mit der anthropologischen Beschriftung des wilden Körpers zur Identifizierung vormoderner Gesellschaften. Nach allen Eroberungen und Kolonialisierungen ist die Grenze zwischen Ethnologie und Soziologie um diesen Körper und sein Geschlecht zu ziehen: Primitive Kulturen pflegen den symbolischen Tausch und nutzen die Frauen als Aktivposten in ihrem System gegenseitiger Verpflichtungen. An dieser Stelle schlägt in der Formulierung von Günter Dux die Macht in das Geschlechterverhältnis ein (1.1) und prägt es eine Geschichte lang. Erst die Zivilisation öffnet es wieder: zunächst als Diskurs des weiblichen Körpers und Charakters, dann als (Gender-)Diskurs der Gleichberechtigung. 
Dieser Befund hat dazu verführt, auch das Geld ethnologisch im Geschlechterverhältnis zu verankern. Obwohl Marx einen geschlechtsneutralen Wertbegriff schuf und in seiner Herleitung der Zivilisation aus Produktions- und Besitzverhältnissen den symbolischen durch den äquivalenten Tausch ersetzte, mußte - in der marxistischen Theorie bei Horst Kurnitzky und Jean-Joseph Goux - die Spur der Macht im Verhältnis der Geschlechter eine Spur des Geldes bleiben (1.2). Erst indem Schulte Marx' unbewußte Identifizierungen von Ware und Frau bzw. von Geld und Mann entschlüsselte und das monetäre Äquivalenzprinzip nicht mehr als alleinseligmachendes Erklärungsmuster für Gesellschaft genutzt werden konnte, wurden Liebe und Intimität wieder frei für die Theorie. Hier brachte die Systemtheorie eine neue Differenz (oder: differente Differenz) ins Spiel: Sie entkoppelte die Liebe vom Bedürfnis der Subjekte und generierte sie nicht mehr über die materielle Differenz zwischen Mann und Frau, sondern über die informative Differenz von Erleben und Handeln (1.3). Und parallel löste die Systemtheorie auch ihren medialen Geldbegriff von seiner materiellen Referenz ab und begann, die Ökonomie in ein selbstreferenzielles, informatives System von Zahlungen umzuschreiben. In Luhmanns System blühen und wuchern daher die Differenzen, nur die eine Differenz zwischen den Systemen und ihrer Theorie fällt flach. Das Autoskript der Zivilisation muß daher seine Fremde selbst entwerfen. Es findet seine einsame Insel innerlich im romantischen Hautkontakt des liebenden Subjekts, äußerlich im fernöstlichen Widerpart: im japanischen Zivilisierungs-, Industrialisierungsund Kolonialisierungsprozeß ${ }^{16}$

\section{Westliche und Östliche Zivilisation}

Japan hat sich als Kultur ohne romantische Liebe als besonders empfänglich für die Semantiken der Zivilisation erwiesen. In Japan, das nie erobert wurde, stieß die westliche Zivilisation nicht an ihre Grenze zur Wildnis, sondern zur östlichen Zivilisation. Nicht moderne und primitive Gesellschaften treten bei der erzwungenen Wiedereröffnung Japans 1869 in diplomatische Beziehungen ein, sondern Staatssysteme - und die rasche, zentralstaatlich gesteuerte Industrialisierung des Landes erntet bis heute Respekt. Daher versucht das zweite Kapitel, dieses Verhältnis zwischen dem Westen und Japan zu strukturieren. Im Rahmen der binär schematisierten Systemtheorie hat Peter Fuchs ideal den westlichen Individualismus dem japanischen Dividualismus gegenübergestellt (2.1). Damit rekapitulierte er Charakterisierungen der japani-

16 Shimada 200: 183-185. 
schen Psyche und Mentalität und schloß die Kultur zugleich begrifflich an die funktional differenzierte Weltgesellschaft an. Ein Seitenblick auf Gabe und Geld in Japan bestätigt, daß hier der Durchgriff der symbolischen Generalisierung des ökonomischen Kommunikationsmediums nicht durch kulturelle oder religiöse Schattierungen beeinträchtigt wurde (2.2). Aber gerade in Japan gedeiht die politische Korruption in einem Ausmaß, daß sie sich ihrer bewußten, öffentlichen Kommunikation in den Massenmedien nicht entziehen kann. Aus diesem Grunde bieten die Massenmedien die Chance eines theoretischen Grenzgangs zwischen System und Subjekt, Kommunikationslatenz und Bewußtseinslatenz (2.3).

\section{Kulturelle Grenzen innerhalb der zivilisierten Weltgesellschaft}

Kein Zweifel, daß in der modernen Zivilisation das Subjekt (mitsamt seiner Theorie) ins Hintertreffen geriet. Um diesen (in den Worten von Günter Dux:) Verlust der Welt scharen sich zahlreiche Theorien der Disziplinierung und des Zerfalls, die vor allem auf die Psyche der Subjekte abzielen: Sigmund Freud, Norbert Elias, Michel Foucault, Richard Sennett. Die romantische Liebe und Kultur ist selbst nichts anderes als eine Reaktion auf diesen rationalistischen Bruch zwischen Subjekt und Welt. Von hier an gewinnen Differenztheorien die Oberhand, die den Proze $\$$ der Zivilisierung produktiv umdeuten und als Emergenz komplexer Organisationen beschreiben: Max Weber, Talcott Parsons, Niklas Luhmann. Seine ausgefeilte Systemtheorie reduziert schließlich das Subjekt zum Individuum (und das Individuum in Japan zum kontextuellen Dividuum) und degradiert es zur bloßen Umwelt der Funktionssysteme.

Dieser Konflikt zwischen System und Subjekt bzw. Identität und Differenz läßt sich verdeutlichen anhand der systemtheoretischen Geldtheorie. Luhmann verwurzelt das Geld nicht wie die marxistischen Ethnologen im Machtverhältnis zwischen den Geschlechtern, sondern wie den Liebescode - im informativen Schematismus Erleben/Handeln, und zeichnet damit die Konturen eines universellen, kulturunabhängigen, symbolisch generalisierten Mediums der ökonomischen Kommunikation (3.1). Das Geld ist in dieser Fassung asexuell perfekt, die Vernunft - in der Diktion von Günter Schulte - vom Subjekt aufs System umgeschrieben. Wie er daher aus Marx' Formel latente Identifizierungen herauslas, kann er im differenztheoretischen Modell Luhmanns eine diabolische Spur der latenten Kommunikation aufdecken (3.2). Indem die sozialen Systeme Körper, Geburt und Tod verdrängen, bleibt ihre Theorie zwangsläufig als Therapieversuch lesbar. Erst diese Spur führt zum Massenmedien Werbung: Während im grassierenden Handel mit 
digitalen Werten Aktien gezeichnet werden, zeichnet die Werbung Körper. Sie bleibt als Hautkontakt zwischen dem System der Ökonomie und der Lebenswelt der Subjekte auf den Körper fixiert und ist deshalb nicht als Manipulation, sondern als Artikulation latenter Bewußtseinsmuster $\mathrm{zu}$ lesen. Aktuelle Mediendaten aus Japan laden zu einem theoretischen Tauchgang ein (3.3).

Ziel der vorliegenden Arbeit ist es, das zivilisierte Autoskript der Systemtheorie kultursoziologisch zu relativieren. Die Funktionssysteme der modernen Gesellschaft erzeugen und steuern sich nur in ihrer Theorie der Realität selbst. In Wirklichkeit bleiben sie eingebettet in die Bedürfnisse und Bewußtseinsmuster sozialisierter Individuen. Ablesbar ist diese latente Kommunikation idealiter an der Werbung als Hautkontakt zwischen System und Subjekt. Die symbolisch generalisierte Kommunikation innerhalb des komplexen Weltwirtschaftssystems zieht die diabolische Entgrenzung von Individuum und Kultur wie einen Schatten mit sich. Auch Systemgrenzen sind daher als unscharfe, kulturelle Grenzen faßbar: als umschreibbare Grenze zwischen Beschreibung und Beschriftung. Die Werbung als Autoskript und Haut der Ökonomie zivilisiert sie gerade dadurch, daß sie ihre System/Umwelt-Grenze kulturell entschärft. Der Prozeß der Globalisierung moderner Gesellschaft impliziert daher keinen funktionalistischen Durchgriff, sondern kulturelle Disjunktionen im Sinne von Arjun Appadurai: financescapes, ideoscapes, technoscapes, mediascapes und ethnoscapes überlappen sich. Gilles Lipovetsky hat schließlich die konsumtiven Spielräume des postmodernen Individuums vermessen und Sennetts Zerfallstheorie sanft konterkariert. ${ }^{17}$ Auch die Werbung als Haut der Ökonomie in der Verpackungskultur Japan entpuppt sich damit als Umschrift eines Systemimperativs und als interkulturelle Grenze innerhalb des zivilisierten Kommunikationssystems Weltgesellschaft.

\section{Japanische Werbung als interkulturelle Kommunikation zweiter Ordnung}

Zwar geht die vorliegende Schrift bei der Rekonstruktion der Werbung als Autoskript der Ökonomie den chronologischen Weg. Doch dem Leser wird ausdrücklich geraten, sie wie ein Manga rückwärts zu lesen: Ein Neger mit Gazelle zagt im Regen nie. Die empirischen Daten und Beispiele aus der japanischen Werbung der Gegenwart (Kapitel 4) vermitteln einen raschen Eindruck von ihrer paradoxen Zeichnung ungezeichneter Körper.

17 Appadurai 1990. Lipovetsky 1983. 
Die Herausforderung einer Theorie der Werbung liegt darin, sie trotz ihrer formalen Kulturgebundenheit mit einer kulturunabhängigen, reproduzierbaren Formel zu verstehen. Diese Formel schlummert im Paradigmenwechsel von der Warenpräsentation zur Körperzeichnung. Als Autoskript der Ökonomie muß die Werbung in allen entwickelten Industriegesellschaften auf Körper, Individuum und Kultur als unhintergehbare Konstituenten sozialen Zusammenlebens rekurrieren. Sie symbolisiert den paradoxen Hautkontakt zwischen dem autopoietisch geschlossenen, materialistischen Wirtschaftssystem der Weltgesellschaft und den materiellen Bedürfnissen der Individuen. Werbeanalyse ist daher zugleich ein Grenzgang der Kultur und der Theorie. Indem die Werbung die Ökonomie medial verpackt und ihre Beobachtung zweiter Ordnung kultiviert, gewährt sie zugleich Einblick in die Latenz ihrer dominanten internen Kommunikation über das Medium Geld. Diese Außenperspektive ist in folgenden Schritten zu erschließen:

Werbung verpackt Ökonomie, indem sie - parallel zur Dialektik zwischen Regierung und Opposition in den Nachrichten - binäre Schematismen zur positiven Darstellung der Produkte selbst definiert. Schon dieser binäre Baukasten ist mit Begriffen wie Traum, Natur, Gesundheit und Schönheit auf den Körper als Schreibfläche fixiert (4.1). Erneut zeigt sich, daß die Werbung neue Waren (negativ oral) gebiert (tanjô heißt Geburt) und ungezeichnete Körper zeichnet (4.2). Speziell die japanische Werbung belegt zudem eine manische Sehnsucht nach reiner, ungeschminkter Haut (4.3). Des weiteren inszeniert die Werbung - gerade im dividualen Japan - Individualität und sexuelle Identität mit äußerster Intensität. Dabei steht keineswegs das Machtverhältnis der gender-relation im Vordergrund, sondern das Wunschbild eines souveränen Selbst und sexueller Erfüllung (4.4 und 4.5). Auch die fremdkulturelle Dotierung der japanischen Werbung geht einher mit einem semiotischen Körperbezug. Insbesondere in der Werbung für Nahrungsmittel gehen fremdkulturelle Zeichen und orale Fixierung eine produktive Verbindung ein (4.6). In der japanischen Autowerbung schließlich läßt sich beobachten, wie gerade deutsche Hersteller ihre fremdkulturellen Images gezielt nutzen und ihre Strategien nur im Einzelfall dem japanischen Werbestil anpassen (4.7).

Das zivilisierte Autoskript der Weltökonomie verleiht ihr ihre Identität erst im Hautkontakt mit Körpern und Kulturen. Das Geld allein als perfekter Regulator im Innenverhältnis reicht dazu nicht aus, seine Verabsolutierung zum Dividuum par excellence muß gerade in Japan, dem Land der dividualen Psychen, gegengezeichnet werden. Die These der autopoietischen Geschlossenheit des Weltwirtschaftssystems ist daher angesichts seiner internen kulturellen Grenzen zu relativieren. Wie 
identische Subjekte, so sind auch komplexe, umweltdifferenzierte soziale Systeme auf semantische Anregungen aus ihrer (inneren) Umwelt angewiesen, um sie selbst zu bleiben. Die Individuen sind daher im Hinblick auf das identitätsstiftende Massenmedium der Ökonomie Werbung weder als Autoren noch als Marionetten, sondern als innere Umwelten der Funktionssysteme zu lesen. Die Massenmedien tun nichts anderes, als diese inneren Umwelten zu reflektieren. Die Evolution der Zivilisation als Kultur der Selbstbeschriftung dirigiert also nicht der Text oder das System (der Theorie) selbst, sondern der Leser auf der anderen Seite der Schreibfläche. In dieser Dimension der Kommunikation ist der Text eine Handlung und versteht sich von selbst. 


\section{Geschlechterdifferenz}

\section{als kulturelle Identität}

\subsection{Geschlechterdifferenz als Konstituente von Kulturen}

Der wilde Körper als Schreibfläche der Zivilisation

Das Autoskript der Zivilisation bezeichnet sich als von den Wilden unterschieden. Es beschreibt zunächst andere, um sich selbst verständlich zu werden. Die Ethnologie, sagt Lévi-Strauss, ist eine europäische Wissenschaft. Da die Strukturen der Gesellschaften sich in aller Vergangenheit über Macht gebildet haben, setzt auch die Beschreibung der primitiven Völker an am Machtverhältnis zwischen den Geschlechtern, konkret: am Körper (der Frau). Hautzeichnungen, Körperschmuck und auch seine spezifische Fähigkeit zum Gebären prädestinieren den weiblichen Körper als Schreibfläche von Kultur. Die Menstruations- und Geburtsriten der Völker (bis hin zur Debatte um Sinn und Effekt der Anwesenheit der Männer im Kreißsaal) erlauben es, eine Geschichte der Kulturen um den Körper, das Blut und die Fruchtbarkeitsrituale der fremden Frauen herumzuschreiben. ${ }^{1}$ Der Diskurs des Geschlechterverhältnisses markiert das Übergangsfeld zwischen Ethnologie und Soziologie: Der Einschlag der Macht im Verhältnis der Geschlechter bietet die Chance, primitive Kulturen wissenschaftlich zu beschreiben und diese Texte als Kontrastmittel der Zivilisation zu nutzen.

Um die Wende zum 19. Jahrhundert übernehmen die Aufklärer die Aufgabe, die Differenz zwischen Zivilisation und Wildnis auf das Geschlechterverhältnis zu projizieren. Der Göttinger Professor Christoph

1 Zwei Autorinnen: Schlehe 1987 und Hampe 1995. 
Meiners (1747-1810) schreibt zwischen 1788 und 1800 seine vierbändige „Geschichte des weiblichen Geschlechts“. Er benennt eine Reihe von Völkern, deren geringeren Entwicklungsstand er an der Ausgestaltung ihrer Ehe festmacht: Das Geschlechterverhältnis der Wilden sei das von Herrscher und Sklavin. Carl Friedrich Pockels (1757-1814) ergänzt 1805 das Werk „Der Mann. Ein anthropologisches Charaktergemälde seines Geschlechts“. Beide nutzen ausgiebig die reiseliterarischen Quellen ihrer Zeit und versuchen, mit Blick auf die primitiven Völker Leitbilder und Rollenmuster für Deutschland zu entwickeln. Dabei stellen sie das wilde, unvernünftige Denken der wilden Männer der Ratio der zivilisierten Männer und die schamlose, starke, unbekleidete, wilde Frau der grazilen, schamhaften, wohlerzogenen europäischen Frau gegenüber. Diesen Diskurs der Wildnis verankern Mediziner wie Johann Friedrich Blumenbach (1752-1840) und Thomas Soemmerring (1755-1830) schließlich in den Körpern der indigenen Völker, die sie nach dem Vorbild der Kartographie der Erde bis auf Schädel, Nerven, Haut und Geschlechtsorgane vermessen. ${ }^{2}$ Und auf der Rückseite der Schreibfläche Körper dämmert bereits seine Zivilisierung und Disziplinierung, seine Umschrift zum christlichen Gotteskörper herauf. ${ }^{3}$

Springen wir von hier aus 200 Jahre in die Zukunft, so ändert sich an der körperlichen anthropologischen Verfassung nichts. Auch in der Theorie unserer Zeit ist der Prozeß der Herauslösung der Gattung Mensch aus ihrem naturalen Kontext nicht lesbar ohne die Erfahrung und Voraussetzung des Körpers. Zwar sind weder Rasse noch Geschlecht, sondern die kognitiven Fähigkeiten der Subjekte die Determinanten der Evolution. Aber auch in der historisch-genetischen Theorie von Günter Dux durchläuft jedes nachwachsende Gattungsmitglied aufs neue seine Ontogenese und bleibt darin an seinen Körper gebunden. Aus dem intimen Verhältnis zur Mutter resultiert das Bedürfnis, sich auch als Erwachsener zu binden. Liebe zwischen den Geschlechtern gibt es daher zu allen Zeiten, in allen Gesellschaften. Ihre jeweilige Ausprägung aber umreißt das Ethnologie-Soziologie-Übergangsfeld.

Für die Struktur primitiver Gesellschaften ergibt der Befund: Die physiologischen Unterschiede zwischen Mann und Frau generieren ein Machtgefälle, welches die Frau ins Innenverhältnis zurücksetzen. Doch nicht absolut: Die Frauen bedienen sich der Männer im Außenverhältnis. Schläge und Gewalt kommen vor, an der Grundbedingung der wechselseitigen Liebe ändern sie indes nichts. Der Machtverfassung als solcher stimmen die Frauen zu. Zwar jagen sie nicht, aber auch ihre Arbeit wird geachtet. Die Wertigkeit folgte den Verhältnissen, nicht umgekehrt. Da

2 Yuge 2000: 10.

3 Kamper 1986: 205-229. 
Liebe und nicht Macht das Grundbedürfnis des Subjekts ist, schlägt die Macht von außen in das Geschlechterverhältnis ein.

Die Fissuren dieses Geschlechterverhältnisses und der Innenbereich der Familie spannen sich daher als Gegenstand vor der Ethnologie und Soziologie auf. Praktiken der Frauenleihe und des Frauentauschs, Brautgut oder Mitgift, strategische Heiratsversprechen und Vermittlungsarrangements bis hin zur männlichen Polygonie, all das findet sich bei den !Kung-Buschleuten ebenso wie bei den Eskimo und den australischen Walbiri. Und weil erst die Graduationen und Spielräume in diesem Machtverhältnis die Ethnien als Kulturen charakterisieren, mutiert der weibliche Körper mit seinen Narben zum ersten Lesezeichen der Zivilisation. ${ }^{4}$

Bei den Baule der Elfenbeinküste übten vor der Kolonialzeit auch die Frauen religiöse und politische Macht aus. Die Körpermetaphorik und die semantische Beschreibung der Geschlechter ließen auf eine annähernde Gleichberechtigung schließen. Anders als in der Medizin (und Psychoanalyse) des 19. Jahrhunderts war das weibliche Geschlecht bei den Baule nicht defizitär, sondern komplementär. Dennoch bewahrten sie sich die Differenz zwischen Mann und Frau als kulturelle Konstituente und kultivierten in Tänzen und Ritualen unterschiedliche Verhältnisse der Geschlechter zur Natur, zum Wald und zur Wildnis. ${ }^{5}$ Bei den Lio auf Flores in Ostindonesien wurden die Land- und Ehekonflikte bis ins 20. Jahrhundert hinein in eigenen Stammhäusern ausgetragen, die als weibliche Körper konzipiert waren. Sie schützten die Macht der Frauen im Haushalt sowie ihren Einfluß bei der Partnerwahl für die Kinder und beim Gabentausch zu Lebenszyklusritualen. Diese weiblichen Zeremonialhäuser, in denen alle Teile des weiblichen Körpers sowie der heterosexuelle Geschlechtsakt sich widerspiegelten, repräsentierte die komplementären Beziehungen zwischen den Geschlechtern und untermauerte ihre Machtbalance im Innen- und Außenverhältnis der Familien. ${ }^{6}$

Auch zur Charakterisierung der Kulturen auf den japanischen Inseln bietet der weibliche Körper eine geeignete Schreibfläche. Zwar waren in der zentralistischen Feudalgesellschaft stets die männlichen Samurai die Stützen der Macht, waren die Frauen von der konfuzianischen Priesterschaft ausgeschlossen, galten dem Buddhismus Menstruation, Schwangerschaft und Geburt als natürliche Strafen der Frau. Aber in allen Epochen finden sich in Japan Spuren beträchtlicher weiblicher Gegenmacht, die über das traditionelle Bestimmungsrecht der Frauen im Innenverhältnis des Haushalts hinausragen. Ruth Hampe hält fest:

4 Dux 1992: 106-136.

5 Luig 1995.

6 de Jong 1998. 
„Die Rolle der Frau im alten Japan ist nur anhand kultureller Zeugnisse nachzuvollziehen, in denen das Weibliche, ähnlich den alten GöttinnenBildnissen, eine vorrangige Stellung einzunehmen scheint. Es wird eine Besiedlung der Japanischen Inseln, soweit archäologische Funde es bis heute aufzeigen, von über 30.000 Jahren angenommen. Aus der Zeit der Jômon-Kultur von 12.000 bis 300 v. Chr. liegen einige bedeutende Funde vor. Für diese Periode, wo bereits Seßhaftigkeit mit urzeitlicher Bodenbearbeitung bestanden hat, wird von einer mütterlichen Organisation der Gemeinschaft hinsichtlich der zentralen Rolle der Frau ausgegangen. Die Organisationsform der Mutterfolge läßt sich auch in der Sprache zurückverfolgen: das Wort oya, das heutzutage für ,Eltern' steht, bedeutete ursprünglich ,Vorfahre‘ bzw. ,Mutter'. In der Verbindung mit der Mutter galt auch der Vater als oya, und erst nach der Nara-Zeit, ab 710 n. Chr., entstand die Bezeichnung für den Vater selbst. “"

Die Sonnengötting Amaterasu selbst ist im shintoistischen Urtext weiblich und seit 1911 sogar das Symbol der japanischen Frauenbewegung. Ihr Schrein in Ise wird traditionell von einer Priesterin geleitet. Noch in den 30er Jahren dieses Jahrhunderts, als das konfuzianisch geprägte Familienrecht die Frauen in Japan in formal-rechtliche Abhängigkeit zwang, fand die Ethnologin Ella Embree im ländlichen Japan einen höchst selbstbewußten, unzivilisierten, undomestizierten Frauentypus: außereheliche Geburten und auch von Frauen initiierte Scheidungen waren häufig. ${ }^{8}$ Das Ausmaß an weiblichem Selbstbestimmungsrecht überraschte auch den Ethnologen André Leroi-Gourhan, als er in derselben Dekade zu den Ainu auf Hokkaido reiste. Besonders beeindruckten ihn die den Frauen über ihre Münder tätowierten Bärte. ${ }^{9}$

\section{Austausch der Tauschzeichen -}

\section{in 10 Minuten vom symbolischen zum äquivalenten Tausch}

Das 19. Jahrhundert erlebt den Aufstieg eines differenten, geschlechtsneutralen Zeichens, das den Körper zunächst verdrängt. Normen, Regeln und Gesetze greifen um sich und konstituieren schließlich auch die Theorie des Tausches und des Geschlechterverhältnisses. Die bürgerliche Wissenschaft und Medizin ordnet dem Mann die naturgegebene Rolle des planenden Individuums zu und spricht der Frau die Fähigkeit ab, sie auszufüllen. Sie dringt mit dem Spekulum in die Dunkelheit des weiblichen Körpers vor und fahndet nach Belegen für ihre diskriminierende Theorie. Die Gynäkologie identifiziert das Weibliche mit der Natur und der unbeherrschbaren Wildnis. In der bürgerlichen Ehe finden

7 Hampe 1995: 135. Vgl. auch Immoos 1991.

8 Weber 1989: 94-95.

9 Leroi-Gourhan 1995. 
idealtypisch die männliche Individual-Identität und die weibliche Gattungs-Identität zueinander. Claudia Honegger spricht von ,polaren kulturellen Idealtypen“ von Mann und Frau und stellt diese Ideologie in die Tradition des Hexenwahns zur Kontrolle zügelloser Weiblichkeit. ${ }^{10}$ Das neue Machtverhältnis zwischen den Geschlechtern entkoppelt sich zwar von offener Gewalt, die „Geschlechterordnung“ reproduziert sich aber informativ: Bildung, Ämter und Würden bleiben den Frauen vorerst verschlossen. Diese Privatisierung, Harmonisierung, Idealisierung und Zivilisierung des Geschlechterverhältnisses als Ehe wird unmittelbar auch in der Theorie der Gesellschaft ablesbar. Denn in der Umstellung der ökonomischen Ordnung vom symbolischen zum äquivalenten Tausch rutscht die materielle Dimension des Körpers auf die latente Ebene der Kommunikation.

Die Zivilisation beginnt, ihr Autoskript vom Körper zu lösen, indem sie den Körper der Wilden selbst zum Zeichen macht. Intern gelingt der Take-off aber erst durch den Austausch der Tauschzeichen: Nicht mehr Frauen, sondern Gelder werden getauscht. Die krude ethnologische Formel „Fleisch gegen Sex“ markiert hier genau den Übergang zur Soziologie, weil sie eine Gegenwart in die Vergangenheit projiziert. ${ }^{11}$ Indem die Zivilisation also ihre Tauschpraktiken radikal in Differenz zur Wildnis setzt, ja mehr noch ihre eigenen Tauschpraktiken als von denen der Wilden different bezeichnet, löst sie sich zugleich von der Geschlechterdifferenz als Konstituente. Der Körper der zivilisierten Tochter mag zahm, schwach und zierlich sein, aber immerhin gehört er ihr, nicht ihrem Vater, Ehemann oder Arzt. Gewalt steht nun unter Strafe, der Inzest wird zur Regel der Regel bei Lévi-Strauss, bei Freud - und indirekt auch bei Marx. Mit der Einführung des abstrakten und geschlechtsneutralen Tauschmittels Geld hebt sich die Zivilisation von der Wildnis ab: Verträge ersetzen Verpflichtungen, romantische Heiratsanträge die standesvermittelten Ehen. Nicht mehr am verletzlichen, sterblichen Körper und seiner Geschlechterdifferenz bildet sich nun die neue Gesellschaft, sondern an den Produktionsformen und ihren politischen Widersprüchen, am toten Vampir, dem Kapital.

Mit seiner Formel vom äquivalenten Tausch gelingt Marx eine zivilisierte Beschreibung der Zivilisation ohne ethnologische Rückgriffe auf äußere Kulturen. Das Paradigma der Theorie wechselt vom Gebrauchswert zum materiellen Tauschwert. Und indem er die Theorie der Gesellschaft vom weiblichen Körper löst, verfällt er der Schreibfläche Körper nur umso gründlicher, weil er, wie die ethnologischen Ausläufer seiner Theorie zeigen, nun den männlichen Sexualtrieb zur Triebfeder des

10 Honegger 1987.

11 Dux 1992: 208-209. 
Kapitalismus verabsolutiert. Das 19. Jahrhundert erlebt den Aufstieg des Geldzeichens in der Theorie, das später auch die Bestattungsriten und die Liebesverhältnisse affiziert. Statt mit den Toten zu kommunizieren, kommunizieren die Lebenden nur noch - radikal weltzugewandt - mit totem, akkumuliertem Reichtum. „Auf der Ebene der modernen Gesellschaften gibt es keinen symbolischen Tausch mehr", formuliert Jean Baudrillard, nachdem das Geld seine materielle Deckung durch das Gold der Zentralbank verloren hat. Marcel Mauss hat das Verbindungsstück zwischen äquivalentem und symbolischem Tausch gelegt und damit eine neue Dimension eingeführt, die in das Geschlechterverhältnis einschlägt: die Zeit. Am Anfang trennen zwar nur 10 Minuten Gabe und Gegengabe. ${ }^{12}$ Aber am Ende dauert es rund 100 Jahre, bis die sexuellen Latenzen aus Marx' Wertgesetz wieder auftauchen.

Marx selbst weiß davon noch nichts. Er liest keine bildungsbürgerlichen Reiseberichte aus Transsylvanien an einer deutschen Universität, sondern harte Statistiken in London. Der latente Körper schleicht sich daher zunächst unbemerkt in seine Geldtheorie ein. Die Theorie der Wildnis mutiert zur wilden Theorie des Geldes.

\subsection{Die latente Spur des Geldes im Verhältnis der Geschlechter}

\section{Sexualpsychologie des Geldes: Von der manifesten Macht der Männer zur latenten Macht der Triebe}

Mit Marx' Standardtheorie des Geldes als absolutes Tauschmittel, das zum absoluten Zweck mutiert, fühlen wir uns sofort heimisch in der Zivilisation. Sie vereinheitlicht das Tauschobjekt zum meßbaren Wert, abstrahiert vom Körper und setzt das Prinzip der Äquivalenz an die Stelle der Reziprozität. Zivilisation heißt nun nicht mehr nur: die Heiratsregeln der Wilden kennen. Zivilisation heißt auch: reflexiv die konstituierenden Differenzen moderner Gesellschaft benennen, den Widerspruch zwischen Kapital und Arbeit, zwischen dem Fetischcharakter des Geldes und dem politischen Subjekt Arbeiterklasse.

Doch Marx' Versuch, einen reinen, sauberen Geldbegriff zu formen, der als Erklärungsmuster alles erhellt, mußte scheitern. Die Spur des Geldes im Verhältnis der Geschlechter und die Spur der Sexualität in der Geldtheorie sind zwei Seiten derselben Medaille. Indem Marx unbewußt Geld und Sexualität begrifflich überlagert, indem er den Fetischcharakter des Geldes so konzipiert wie Freud den Sexualtrieb, subsumiert er

12 Mauss 1975/2: 20-37. 
dem Geld zugleich das Subjekt, das sich seinen Fängen erst entwinden soll. Die Äquivalenz von Geld und Arbeitskraft beschreibt die Zivilisation als ökonomisches, substanzlogisches, inzestuöses System ohne äußeres Korrektiv. Verdeutlichen läßt sich das am besten an der Geldtheorie der Psychoanalyse: Was für Freud die inzestuöse Liebe des Knaben zur Mutter, ist für Marx die Liebe des Kapitalisten zum Geld und die Akkumulation des Kapitals. Trieb und Fetisch sind begrifflich äquivalent. Aus diesem Grunde konnte die Psychoanalyse den Ursprung des Geldes in der frühkindlichen Sexualität verankern und mit dem gemeinsamen Wunschobjekt von Mutter und Kind identifizieren.

Die psychoanalytische Formel Geld = Kot ist schließlich auch zu einer kulturellen Entstehungsgeschichte des Geldes verfeinert worden. Bevor das Geld Tauschmittel wird, muß das Gold, das keinen Gebrauchswert hat außer als Schmuck der Göttin, aus den Gedärmen der Mutter Erde ausgegraben werden. In Ägypten diente der Skarabäus, ein Mistkäfer, von dem man annahm, er sei von keinem Weibchen empfangen, als Vorlage für die Versiegelung der ersten Münzen. Die ältesten Münzen Europas wurden um 700 v. Chr. in Kleinasien geschlagen. „Das Wort Münze leitet sich von lateinisch ,moneta‘ ab; das wiederum verweist auf die römische Göttin Juno Moneta, deren Tempel als römische Münzstätte diente. So wie das Kind der Mutter seinen Kot übergibt, so wurde den Stellvertretern der Muttergöttin das zu prägende Metall übergeben. Von mütterlich-göttlicher und väterlich-staatlicher Autorität mußte es auf Reinheit geprüft, gewogen und geprägt werden. “" ${ }^{13}$ In der Südsee zirkulierte die Kaurimuschel als wertvoller Schmuck und Zahlungsmittel, und auch im chinesischen Zeichensystem trägt die $\mathrm{Mu}$ schel die Bedeutung von Geld, Wohlstand, Besitz. ${ }^{14}$ Dieses läßt sich psychoanalytisch zwar als weibliches Symbol deuten, aber als Auswurf des Meeres ebenso in die anale Wunschökonomie einfügen.

Wie Marx’ Akkumulationsthese, so läßt sich trotz (und wegen) des Börsen- und Wertpapierbooms, der die goldene Münze zum Papier- und Aktiengeld sublimiert, auch die psychoanalytische Geldtheorie mit einigem Recht bis ins 21. Jahrhundert vertreten. Im vermeintlich sauberen Zahlungsmittel weitab von der schmutzigen Fabrik mutiert das glitzernde Geld zur Plastikkarte mit Beethoven-Hologramm. Im abstrakten Auf und $\mathrm{Ab}$ der Börsenkurse ohne sichtbare Arbeitsleistung und Wertschöpfung wird der anale Narzißmus des Kreditsystems unbewußt. Wolfgang Harsch führt aus:

13 Harsch 1995: 180.

14 Die Muschel kai (貝) ist zugleich ein Kanji-Radikal, z.B. für die Worte kaufen (kau: 買 う), schenken (okuru: 贈る), Schulden (sai: 債) oder Bestechung (wairo: 賄賂). 
„Es entsteht die Illusion, daß das zinstragende Kapital sich von selbst vermehrt, ohne erkennbare Beteiligung der Arbeiter an der Produktion. Diese Phantasie ist Ausdruck eines infantilen analen Narzißmus. Das sich scheinbar selbst vermehrende zinstragende Geld oder Kapital repräsentiert, nach dem Vorbild des infantilen magischen Kots, einen Teil des Selbst, der zugleich die Eigenschaften der allmächtigen Mutter besitzt: unendliche Ernährungs- und Vermehrungsfähigkeit. Mit ihm soll die narzißstisch kränkende, infantile Abhängigkeitsbeziehung zur Mutter verleugnet und die narzißtische Ökonomie wiederhergestellt werden. [...] Meine These ist, daß sich das Kapitalwachstum oder die Kapitalvermehrung unbewußt auf das infantile Wachstum mit Hilfe und auf Kosten der Mutter zurückführen läßt.“' ${ }^{15}$

Aus psychoanalytischer Sicht ist der erste Naturaltausch des Menschen der von Kot und Muttermilch. Sie medialisieren, vermitteln das Verhältnis des Individuums zu seiner Mutter, die es über sein Privateigentum zum ersten Mal als handelndes anerkennt. Doch gleichzeitig ist die Reinlichkeitserziehung höchst ambivalent, die Haltung der Mutter widersprüchlich: Sie wartet auf den Kot des Kindes, entsorgt ihn dann aber sogleich. Diese Ambivalenz spiegelt sich in der Theorie des Geldes wider: Einerseits ist das Geld neutrales Zahlungsmittel, polierter Goldbarren, instrumentelle Meßlatte für die Warenwerte, andererseits ist es als absoluter Zweck Mittel der Herrschaft des Kapitals über die Arbeitskräfte. Aus diesem Grunde muß sich im dialektischen Materialismus die triebhafte Substanzlogik des Geldes auch jenseits der analen Phase durchhalten. Die ödipale Phase der marxistischen Geldtheorie läßt sich in ihrem ethnologischen Auslegerboot am besten beobachten.

\section{Ethnologie des Geldes:}

\section{Triebverdrängung, Brautkauf, Opferlogik}

Horst Kurnitzky hat in seiner „Triebstruktur des Geldes“ die Marxsche Theorie ethnologisch auf die vormodernen Gesellschaften zurückprojiziert. Zwangsläufig ist sein Geld männlich und entspringt dem Inzestverbot: Erst indem die Väter und Brüder auf ihre Schwestern und Töchter verzichten, indem sie einen Teil ihres Körpers opfern und die Braut freigeben, erwächst ihnen ein Anspruch auf Entschädigung durch den Bräutigam. Die Männer handeln und formen aktiv die Kultur, die Frauen schweigen und bilden passive Natur. Unterdrückt wird aber auch die Weiblichkeit im Manne. Auf dieser Verdrängung basiert nach Kurnitzky die primäre Ökonomie in agrarisch-matriarchalen Gesellschafen.

15 Harsch 1995: 245, 129. 
„Erst im Kapitalismus dringt das Geld in alle gesellschaftlichen und privaten Sphären des Menschen ein, schreibt Marx. Wir aber wissen, daß das Geld nicht nur der letzte, sondern zugleich auch der erste Fetisch war, weil es mit Beginn der Assoziation von Menschen, deren gesellschaftlich vermitteltes Naturverhältnis sich immer um den Fokus des Inzesttabus zentrierte, als erstes Substitut der geopferten Sexualität auftrat [...]. “616

Kurnitzky zitiert die Tauschpraktiken im Volk der Mbowamb, die 1933 im östlichen Neuguinea entdeckt wurden. Sie haben das Menschenopfer (Frauenopfer) an die Natur durch das Schweineopfer ersetzt. Das Schwein ist die wichtigste Währung für den Brautkauf neben Salz und Kaurimuscheln. Während das Salz teilweise bis heute als Fruchtbarkeitssymbol gilt, verkörpert die Kaurimuschel, ein Abbild der vagina dentata, die männliche Kastrations- oder Erblindungsangst.

Bei den Griechen und Römern entstehen Geldwirtschaften im Umfeld der Tempel der Mond- und Fruchtbarkeitsgöttin Hera (Juno). Ihr wurden Tiere geopfert, die nach der Zeremonie erneut gegen Münzen eingetauscht wurden. Feste, Wett- und Stierkämpfe erweiterten die Märkte. Im römischen Wort für Geld: pecunia, ist dieser sakrale Ursprung des Zahlungsmittels im Tempelopfer (pecus = Vieh) noch ablesbar. Auch das Märchen von Hänsel und Gretel läßt sich als Plädoyer für die Opferlogik lesen: Indem Hänsel (Gretel ist wie im Märchen von Brüderchen und Schwesterchen als Teil seiner Identität zu verstehen) seine Mutter ermordet und seine inzestuösen Wünsche zügelt, erlangt er Reichtum.

\section{Anthropologie des Geldes:}

\section{Phallus, Szepter, Schwert, Buchstabe}

Jean-Joseph Goux hat versucht, mit seinem Text „Ökonomie und Symbolik“ den Marxschen Wertbegriff sozial zu verfeinern. Dazu verläßt er die Ebene primitiver Gesellschaften und reflektiert strukturell den europäischen Feudalismus. Dieser Ansatz soll die mechanische Zweiteilung von Basis und Überbau mithilfe der Psychoanalyse geschmeidiger machen und in einem symbolischen Gesamtprozeß erfassen. ${ }^{17}$ Parallel zum Geld konstruiert Goux soziale Komplemente der Wertform. Deren Symbolisierungsprozeß schematisiert er auf unterschiedlichen Ebenen gesellschaftlicher Kommunikation: in der Ökonomie, der Spra-

16 Kurnitzky 1974: 157.

17 „Man erweitert so, auf der Basis, die Marx mit seiner genetischen Typologie der ökonomischen Austauschweisen gelegt hat, eine Konzeption, die Mauss und Lévi-Strauss für die primitiven Gesellschaften nur statisch und partiell haben bezeichnen können." Goux 1975: 41. 
che, der Sexualität und der Herrschaft. Seine allgemeinen Äquivalente heißen: Gold, Vater, Phallus und Monarch. Er homologisiert symbolisch die Zentralisierung des Subjekts um seinen namengebenden Vater, den Logozentrismus als Herrschaft der linguistischen Zeichen über alle sonstigen und die staatlich-zentralisierte (monarchische) Macht in der Kapitale. Aus seinem Raster deduziert Goux - wie Marx - eine gesetzmäßige Logik des Symbolisierungsprozesses: „Sexuelle, monetäre, konstitutionelle, linguistische Organisation, alle schreiten sie voran in vier Phasen, nach ein und demselben Strukturprinzip; in all ihren Funktionen und Implikationen (trotz aller Verschiebungen zwischen den Ebenen, Ungleichheiten in der Entwicklung, Fixierungen und komplexen Interaktionen) sind sie isomorph. “" 18

Ausgangspunkt dieser symbolischen Ökonomie ist einmal mehr die Ontogenese des Geldes. Natürlich entspringt sie einer sexuellen Analogie. Dem Gold und dem Penis gemeinsam ist die Eigenschaft ihrer Überflüssigkeit/des Überflusses. Sie macht das speicherbare Gold zum geeigneten Tauschmittel und erhebt den Penis zum Träger einer Funktion, zum Signifikanten der Lust, zum Phallus. Der schwellfähige Phallus und das akkumulierte Gold sind Zeichen einer überschüssigen, aufschiebbaren, unproduktiven Verausgabung. So wie sich also der kindlich-polymorphe Geschlechtstrieb (jedenfalls bei Freud) um den Penis zentralisiert, so zentralisieren sich die Zahlungsmittel Muschel, Salz, Pelz und Vieh um das Gold-Geld-Monopol. Und so wie der Phallus unmittelbaren Gebrauch (Onanie) und unmittelbaren Austausch (Inzest) verbietet, so ist das Gold als in Gewicht und Titel offizieller Goldbarren weder gebrauchsfähige Ware noch bares Zahlungsmittel.

Goux' Theorie mündet gesetzmäßig in ihre eigene Deklarierung zur Vor-Geschichte. Der Zielpunkt des Symbolisierungsprozesses soll seinen natürlichen Anfangspunkt wiederfinden, bereichert um die Erfahrungen historischer Sequenz. Aus der Theorie der Symbolisierung heraus ist dieses Ziel fast nur negativ zu fassen - ebenso wie das weibliche Geschlecht bei Freud. Während also die gesetzmäßige Geschichte selbst als technisches Räderwerk von männlicher Theorie, Philosophie und Ökonomie zu beschreiben ist, kann umgekehrt die genitale, emanzipative Phase des Symbolisierungsprozesses nur negativ am Weiblichen festgemacht werden. Erstens ist die Frau von ihrer phallischen Symbolisierung $\mathrm{zu}$ befreien und wieder der natürlichen Reproduktion des Lebendigen zuzuführen statt der Reproduktion toten Kapitals. Zweitens verschmilzt in der historischen Perspektive die natürliche, unreflektierte, gesetzmäßige Geschichte der Gesellschaft mit den bewußt gewordenen Zielen der

18 Goux 1975: 97. 
Natur bzw. die Wissenschaft vom Menschen mit der Naturwissenschaft. ${ }^{19}$ Goux bemüht sich dergestalt, die Prophezeiungen von Marx und Freud gleichermaßen einzulösen.

Goux und Kurnitzky präsentieren historische Prozesse, die sich am Ende an ihrem Ursprung wiederfinden. Eingeschlossen zwischen Inzesttabu und Revolution, sehen sie sich schließlich wieder mit dem Verdrängten konfrontiert. Wie Freud gelangen sie über die Substanzlogik des Inzestverbots nicht hinaus, sondern müssen vielmehr umgekehrt entweder konsequent das Inzestverbot in Frage stellen (Kurnitzky) ${ }^{20}$ oder in der ödipal-inzestuösen Verschmelzung mit der Mutter Natur diese umindizieren (Goux) $)^{21}$. Doch die sexuellen Identifizierungen, die die Achse bilden für das Laufrad der marxistischen Geschichtsschreibung, ragen bis in Marx' eigene Formeln hinein.

\section{Theologische Latenzen in der Marxschen Geldtheorie}

Statt Marx und Freud zu parallelisieren, hat Günter Schulte Freud auf Marx angewandt und die latenten, psychisch-sexuellen und normativ-religiösen Identifizierungen in Marx' Geldtheorie aufgezeichnet. Seine „Kritik der proletarischen Vernunft“ decodiert die Äquivalenz sexueller und monetärer Beziehungen und offenbart die inzestuöse Immanenz des marxschen Revolutionsmodells. Indem sie die Identität von Subjekt und Arbeiterklasse und das mechanische Geschichtsmodell des dialektischen Materialismus erschüttert, löst sie zugleich die Geldtheorie von ihrer materiellen Referenz ab und ebnet dem postmodernen Denken den Weg. Das verbürgte Papiergeld und schließlich der digitale Zahlungsverkehr werden differenztheoretisch, funktional und wertfrei erfaßt und binär schematisiert (Kapitel 3.1). Der Blick zurück auf Marx' alte Formeln aber offenbart ihre latenten Identifikationen, die inneren Risse in der Theorie der Ware, des Geldes und der Verwertungslogik:

19 „Die genitale Phase ist historisch, als gesellschaftlich dominierende Möglichkeit, bisher noch nicht vollzogen. Diese Produktions- und Austauschweise kann man benennen, aber sie ist bis heute kaum ausdenkbar; sie ist das Ziel heutiger revolutionärer Bewegung, der sie am tiefsten entspricht." Goux 1975: 275.

20 ,Sind Produktionsverhältnisse möglich, die eine verdrängungsfreie Sublimierung darstellen?" Kurnitzky 1974: 159.

21 „Diese Wiederanknüpfung an die Natur nach dem Zyklus der Geschichte ist jedoch der dem, vollzogenen Inzest' entgegengesetzte Standpunkt. Die Natur, die das Subjekt auf der Spitze wiederfindet, zu der es erneut stößt, ist nicht die Mutter-Natur, es ist eine ,Hyper-Natur', zu der eine genitale sexuelle Ökonomie gehört, die ihr entspricht, eine herrschende wissenschaftlich-politische Ideologie, mitsamt dem, was sie aus dem Unterschied der Geschlechter an Realem machen kann, nachdem die Symbolismen durchlaufen und überwunden sind, die diesen Unterschied nicht bezeichnen konnten." Goux 1975: $295 \mathrm{f}$. 
a) Gesellschaft/Natur = Mann/Frau: Gattungsleben als Gattenleben

Marx erkennt in der Arbeit des Proletariats den Frondienst der Israeliten wieder. Ihm entgegen setzt er den paradiesischen Zustand, in dem Produktion und lustvolle Konsumtion eine Einheit bilden. Die Arbeitsteilung ist daher der Sündenfall der Gesellschaft. Er scheidet Produktion und Genuß, trennt Vater und Tochter, und nur die Revolution kann sie wieder zusammenführen. Auch in dem Appell „Vereinigt Euch!“ blitzt daher eine sexuelle Komponente auf. Gatten- und Gattungsliebe sollen wieder ineinanderfallen. Marx ist fasziniert vom verbotenen Genuß, dem Inzest, um den seine Ökonomie kreist. Noch in seine Formel „20 Ellen Leinwand = 1 Rock" projiziert er unbewußt die infantile Beziehung zwischen Wickelkind und Mutter hinein. ${ }^{22}$

b) Kapitalist/Arbeiter(in) $=$ Geld/Ware: Ökonomie als Prostitution

Auch der Klassengegensatz ist bei Marx sexuell konnotiert. Die kapitalistische Gesellschaft ist gespalten in genießende Kapitalisten und produzierende Arbeiter. Letztere sind als ausgebeutete Arbeitskräfte zugleich Waren: weibliche Tauschobjekte. Das Verhältnis ist ein patriarchalisches: Geld besitzende Väter begatten fremde Töchter, die sich von ihren eigenen Vätern entfremdet haben und unehelichen Mehrwert produzieren. Daher ist die Prostitution das beste moralische Synonym für den Kapitalismus. ${ }^{23}$

c) Revolution $=$ inzestuöser Regreß

Oft wurde vermerkt, daß in Marx' Geschichtsmodell die Arbeiterklasse (und damit die ganze Gesellschaft) in Gestalt der Partei als Subjekt aufzutreten hat. ${ }^{24}$ Dessen Revolution erst soll wieder die absolute Subjektivität freilegen, d.h. den Zugang zu den selbstproduzierten Töchtern, zum unmittelbaren Genuß der Waren. Revolution hieße: Den Gebrauchswert zu verabsolutieren und den Tauschwert, das Geld, abzu-

22 Schulte vermutet, daß er tatsächlich ein Verhältnis mit seiner Haushälterin hatte. Ihr Tod bei einer versuchten Abtreibung markiere den wesentlichen Bruch in seinem theoretischen Schaffen. Schulte 1992: 126, 142.

23 ,Der Zeugungsvorgang von Geld durch Geld vollzieht sich also mittels der Ware. Wenn das phallisch ,harte' Geld anderes Geld begattet, so begattet das Geld sich selbst doch stets nur in der Ware, die ihm ,leiblich“ gegenübersteht. Auf deren Lebensblut ist das Leben des Geldes, also das Kapital, angewiesen. Erst durch die Warenbasis ist das Kapital , geldheckendes Geld - money which begets money ${ }^{*}$ - und führt ein geradezu ewiges Gattungsleben. Das Geld bleibt aber das Leben eines teuflischen Vampirs, der erst mit dem Blut und dem Sperma der Menschen immer neue Vampire zeugt.“ Schulte 1992: 180. Das Kapital ist tote Arbeit, Parasit des (weiblichen) natürlichen Lebens, es ist die allgemeine Hure und der allgemeine Kuppler, der Inbegriff der verdrängten Weiblichkeit, der falschen Liebe für Geld.

24 Guttandin 1980: 362-373. 
schaffen. Mit dieser Austreibung des Geldes aus der Gesellschaft würde der teuflische Frauentausch beendet, der sich im Kapitalismus in die Ausbeutung der Ware Arbeitskraft verwandelt hat. Marx' Revolution ist ein inzestuöser Regreß, ist die narzißtische Selbstliebe des Produzenten zu seinem Produkt, die Wiedervereinigung von Produktion und Genuß, Vater und Tochter. Marx kleidet seine sexuellen Identifizierungen lediglich in ökonomische Begriffe.

d) Männliches Trauma: Die emanzipierte Ware Lilith

In der Figur der Lilith schließlich konvergieren religiöse und sexuelle Latenzen bei Marx. Sie verkörpert als erste Frau Adams, die als Strafe für ihr Selbstbewußtsein und ihre Verführungskraft in die Wüste geschickt wurde, den teuflischen „FeTisch“ der Ware und des Geldes, den Sündenfall der Gesellschaft. ${ }^{25}$ Diese selbstbestimmte Frau und ihre Sexualität soll in der Revolution durch die Wiedervereinigung von Gattungs- und Gattenleben unter Kontrolle gebracht werden. Und umgekehrt: Erst als die Polarisierung von Mann und Frau in der Anthropologie des 19. Jahrhunderts auf die Spitze getrieben wird und zerbricht, erst als im 20. Jahrhundert die Frauen selbst das Wort ergreifen, werden auch die Risse in Marx' substanzlogischer Geldtheorie sichtbar. Die Universalität des Geldes dünnt aus, Latenzen schimmern durch.

Die Sprache des Geldes ist hart, unmißverständlich, gnadenlos, äquivalent, eindeutig. Das Geld ist ein phallisches Medium, „,das stehende tertium comparationis aller Menschen und Dinge' [...]. Im Kapitalleben wird es als Phallus gegenüber der Ware eingesetzt. ${ }^{\text {‘2 }}$ Doch hinter dieser ungeheuren Stärke der Marxschen Theorie des Kapitals verbirgt sich auch ihre größte Schwäche. Denn die Totalität ihrer Produktionsverhältnisse basiert auf einer männlichen Triebökonomie, in der das Weibliche nicht vorkommt. Erreichbar ist es allenfalls - wie bei Goux - inzestuös: über die Vereinigung mit der Ur-Mutter Revolution, als Versöhnung des (männlichen) materialistischen Menschen mit der (weiblichen) Mutter Natur. Die marxistische Geldtheorie beruht auf sterilen Identifizierungen, die weder über Freuds Inzesttheorie hinausführen noch über den vorgezeichneten Revolutionsbegriff. Dieses theoretische Vakuum zwischen Marx und Freud haben Gilles Deleuze und Félix Guattari treffend beschrieben:

25 Marx projiziert als Sproß einer Rabbinerfamilie die Figur der Lilith, die den Beischlaf in umgekehrter Position vollzog, in den „FeTisch“ der Ware und des Geldes. Vgl. Schulte 1992: 204ff.

26 Schulte 1992: 187. 
„Solange wir uns damit begnügen, zum einen Geld, Gold, Kapital und das kapitalistische Triangel, zum anderen Libido, After, Phallus und das familiale Triangel parallel zu setzen, liefern wir uns wohl einem angenehmen Zeitvertreib aus, nur bleiben damit die Geldmechanismen nicht weniger gleichgültig gegenüber den analen Projektionen dessen, der sich jenem Spiel hingibt. Die Parallelisierung von Marx und Freud bleibt absolut steril und irrelevant, bringt Kategorien hervor, die sich wechselseitig internalisieren oder projizieren sollen, ohne daß doch, wie aus der berühmten Gleichung Geld = Scheiße zu ersehen, ihrer Indifferenz ein Ende gesetzt wäre. “27

Luce Irigaray hat schon früh darauf hingewiesen, daß die Frau in der Definition von Freud als bloßes Komplement (Umstülpung) des Mannes fungiert, und dieses indifferente Geschlechterverhältnis findet sich auch in Marx' männlicher Geldtheorie. In der identitätslogischen Fassung der Marktökonomie erscheinen Frauen nur als Jungfrau, Mutter, Prostituierte. $^{28}$ Doch das Geschlecht, das nicht eins ist, hat eine Mundart, die sich der unmittelbaren Verständlichkeit der Hochsprache Geld entzieht: Subjektive Bedürfnisse, die beide Geschlechter haben, insbesondere das Bedürfnis nach Liebe, sind von den Effekten der Geldökonomie zu unterscheiden. Und umgekehrt ist das Geld nicht aus der Triebökonomie herzuleiten. Die wilde Geldtheorie der Zivilisation zivilisiert sich also erst dadurch, daß sie die Frau von der Ware und das Geld von der Sexualität differenziert. Nur Liebe ist ein Grundbedürfnis des Subjekts, Macht und Geld sind es nicht. Dennoch hinterläßt der Einschlag der Macht ins Geschlechterverhältnis in der Geldtheorie seine Spur.

\section{Monogamie und Kredit:}

\section{Politische Differenzierung von Intimität und Ökonomie}

Lange bevor das Geld als generelles Zahlungsmittel überhaupt gedacht ist, geraten die Frauen ins Hintertreffen. Die Männer erringen die Zuständigkeit im Außenverhältnis und beziehen die Frauen als Aktivposten in ihren Handel um Verpflichtungen und Abhängigkeiten ein. Und die Frauen bleiben auch in entwickelten Agrargesellschaften, in der Polis Athens und in der Civitas in Rom, die schwächeren. Sogar als die industrielle Geldwirtschaft den agrarischen Feudalismus im 19. Jahrhundert

27 Deleuze/Guattari 1974: 38f.

28 „Die Teilnahme am Gesellschaftlichen verlangt, daß der Körper sich einer Spiegelung unterwirft, einer Spekulation, die ihn zum Wertträger umbildet, zum geeichten Zeichen (signe étalonne), zum Währungszeichen, zum Schein, der sich auf ein Modell bezieht, welches als Autorität fungiert. Die Ware - die Frau - ist in zwei unversöhnliche ,Körper' geteilt: ihren ,natürlichen" Körper und ihren austauschbaren, gesellschaftlich wertvollen Körper: mimetischer Ausdruck männlicher Werte." Irigaray 1976: 52. 
ablöst und die patriarchalische Ordnung von (Land-)Besitz und männlicher Herrschaft zerbricht, ändert das an der Machtverteilung unter den Geschlechtern zunächst noch nichts. Im Gegenteil: Die Polarisierung der Geschlechter erreicht in der bürgerlichen Anthropologie und Medizin ihren Höhepunkt, und Geld und Ware können sich in Marx' materialistischer Argumentation als Mann und Frau gegenübertreten.

Das Geld aus dem Machtverhältnis zwischen den Geschlechtern zu erklären heißt: moderne Gesellschaften zu beschreiben mit den Mitteln der primitiven. Aber Geschlechter- und Machtverhältnisse sind eben nicht geldtheoretisch $\mathrm{zu}$ identifizieren, sondern empirisch $\mathrm{zu}$ differenzieren. Und wenn Macht und Geld einerseits und Liebe andererseits erst einmal verschiedene psychosoziale Kommunikationsmuster sind, wie ist dann die Entstehung des Geldes als universelles Zahlungsmittel zu erklären? Wo beginnt die Zivilisation, die Machtverteilung zwischen den Geschlechtern zuungunsten der Frauen zu balancieren und den Keim zur Loslösung der politischen und ökonomischen Macht vom Geschlechterverhältnis zu legen? Und wie gelingt es ihr, das Medium Geld nicht im Körper, sondern als Kredit reflexiv in sich selbst zu verankern?

Gunnar Heinsohn hat der Frage einen aufschlußreichen Aufsatz gewidmet: „Patriarchat und Geldwirtschaft“. Er analysiert die neuen Eigentumsverfassungen in Athen und Rom und zeigt, daß die Einführung der Geldwirtschaft doch mit einer Neustrukturierung des Geschlechterverhältnisses einhergeht. Zwar läßt sich keine eindeutige Ursache für diesen ökonomischen Zivilisationsprozeß ausmachen, aber zumindest werden in der Antike die gerechte Landverteilung und die patriarchale Monogamie zu notwendigen Bedingungen der neu eingeführten Geldwirtschaft. Es ist nicht das Inzestverbot, sondern der politische Rechtsakt des Eigentums an Land, der scheinbar aus dem Nichts entsteht und die Monogamie für eine eindeutige Erbfolge erfordert.

Heinsohn folgt hier strukturell der Argumentation Freuds: Sehr wohl hat es eine Revolution gegeben. Sehr wohl haben Söhne ihre Väter, kleine Landbesitzer ihren Feudalherrn, hat Romulus Remus erschlagen, sehr wohl wurde das Land neu verteilt und eine neue politische Ordnung errichtet. Sehr wohl mußten auch die Frauen verteilt, und, wenn sie nicht ausreichten, Sabinerinnen geraubt werden. Erst an dieser Stelle greift Freuds Argumentation zu kurz: Nicht das Schuldgefühl wegen des Vatermordes, sondern die Angst vor einem neuen, feudalen Über-Vater führen in Athen und Rom zur strengen Einehe der primären Grundeigentümer. Die Zivilisation erzeugt sich selbst in ihrer ökonomischen Ordnung, und nicht der Grund dafür ist entscheidend, sondern die Art und Weise. Denn Männer und Frauen gemeinsam bringen Kapital in die neue Verfassung ein (wenngleich unterm Strich die Frauen etwas mehr): Beide verzichten, 
diese auf andere Frauen, jene auf traditionelle Rechte. Neue Gesetze verbieten vorehelichen Geschlechtsverkehr, Alkoholgenuß und Kindestötungen, damit ein keuscher Frauentypus entsteht. Die Erblinie muß eindeutig sein. Und die zivilisierende Kraft dieser Disziplinierung der Frau ist kaum zu überschätzen. ${ }^{29}$

Gleichzeitig mit der Einehe, so vermutet Heinsohn, differenziert sich der Besitz gegen das Eigentum aus. Nicht allein die Revolte gegen den Patriarchen und die Landreform, erst die Kombination von neuem Besitzrecht an Land und eindeutiger Erbfolge macht es möglich, das Eigentum auf Zeit an andere Besitzer zu verleihen. Dies ist die Geburt des Zinses, der Liquiditätsprämie, die den Eigentümer für seinen zeitweiligen Zugriffsverzicht entschädigt. Da das Land nun beiden etwas einbringen muß, dem Eigentümer und dem zeitweiligen Besitzer, erzwingt die Eigentumswirtschaft einen Überschuß in der Produktion: den Profit und die Akkumulation. „In Stamm und Feudalismus werden Ressourcen lediglich beherrscht und genutzt. In der Eigentumsgesellschaft jedoch beginnt mit dem Verzinsen, Verkaufen, Verleihen und Verpfänden von Eigentumstiteln etwas gänzlich Neues. Der Begriff der Ökonomie findet erst jetzt seinen Gegenstand.“30

Schon in Griechenland haben Oikos und Nomos eine neue politische Ordnung generiert. In der Polis und später in der römischen Civitas wird die Entmachtung der Frau vorangetrieben. Sie wird in den Innenbereich des Haushalts verbannt, dem der Mann vorsteht. Die wiedergewonnene Schriftkultur fördert die Entstehung des Rechtssystems. ${ }^{31}$ Der Nomos regelt vor allem die Gesetzmäßigkeiten des Eigentums. Erst dieser rechtlich-politischen Ordnung, nämlich der verläßlichen Verpfändbarkeit des Eigentums, entspringen Zins und Geld. Das Geld ist daher nicht substanzlogisch als Wertsubstrat, als universelles Tauschmittel zu denken, sondern entsteht erst im Prozeß der Schuldverschreibung aus der Differenz von Besitz und Eigentum, aus dem Schuldverhältnis.

Die Macht wird in der zivilisierten Gesellschaft in der staatlichen

29 „Bei der gegenüber dem Manne etwa zehnfach höheren Orgasmuspotenz der Frau und bei der für alle Säugetiere biologisch fixierten weiblichen Initiierung des Sexualaktes stellt die erotische Domestikation der Frau ein ungeheures Vorhaben dar. Gleichwohl: Nur bei eindeutiger Weitergabe des heredium an Söhne, deren Erbrecht niemand durch Anzweiflung der Vaterschaft in Frage stellen kann, geht das Eigentum mehr oder weniger unangefochten in die nächste Generation über. Nur wenn die Mutter des Erbsohnes allein und ausschließlich mit ihrem Ehemann sexuell verkehrt hat, wirkt seine Vaterschaft überzeugend. Das biologisch determinierte Vorrecht der Frau auf Einleitung der Paarung paßt zu einem solchen Sexualverhalten ebenso wenig wie ihr Interesse an der Verwirklichung ihrer überlegenen orgasmischen Möglichkeiten." Heinsohn 1995: 225.

30 Heinsohn 1995: 221.

31 Dux 1992: 384-389. 
Rechtsordnung neu verfaßt. Sie bildet sich in der europäischen Antike als ökonomisches Regulativ und legt den Grundstein für den weiteren Modernisierungsprozeß. Auch dieser Staat und seine Öffentlichkeit sind und bleiben noch lange Zeit Organisationen der Männer. Doch gleichzeitig schaffen sie bereits eine notwendige Bedingung für die späte Gleichberechtigung der Geschlechter. Bevor sie mit Hilfe des Staates und der „Väter“ der Grundgesetze erreicht werden kann, wird das Verhältnis der Geschlechter - wie wir sahen: auch in Marx' Geldtheorie erst aufs äußerste polarisiert und erst dann graduiert. Spätestens aber, wenn auch die Töchter erben, ist es nicht mehr grundlegend für das Autoskript der Zivilisation. Sie diszipliniert jetzt den Körper und entmaterialisiert ihre Theorie. An diesem Punkt muß dann nicht mehr nur das Geld, sondern auch die Liebe differenztheoretisch als ein Modus der Informationsverarbeitung rekonstruiert werden. Die Systemtheorie Luhmanns befreit den Geldbegriff radikal von der Sexualität und dem Machtverhältnis zwischen den Geschlechtern und löst sogar den Liebescode radikal vom subjektiven Bedürfnis ab. Um welchen Preis?

\subsection{Die Zivilisierung der Liebe als Codierung ihrer Theorie}

\section{Der Einbruch der Zeit in die Theorie der Liebe}

Mit dem Einbruch der Zeit in die Gesellschaft der Renaissance setzt sich ein Räderwerk in Bewegung. Während Marx’ Maschinen laufen, produzieren sie auch ihre eigene Vorgeschichte. Webers Einspruch gegen Marx konnte daher nur religionshistorisch ausfallen, und Dux' historisch-genetische Theorie muß sogar bis vor die Ontogenese zurück und „vom Vorrang der Natur aus“ denken. „Es ist bei einem niedrigen Organisationsgrad der Gesellschaft nicht notwendig, ein operationales Zeitverständnis zu entwickeln; es geschieht auch nicht.“32 Die Zivilisation kennt auch die Zeitökonomie der Primitiven und verfaßt ganze Soziologien der Zeit. ${ }^{33}$ Zwar muß noch immer jedes Kind sich die Raum-Zeit-Kompetenz neu erarbeiten, aber die zehn Minuten zwischen symbolischem Tausch und Computer-Überweisung eröffnen das Zeitkonto. Der Gewinn der Weltzeit bis hin zur Relativitätstheorie zeichnet die moderne Gesellschaft aus.

Immer noch charakterisiert zwar der Umgang mit Zeit auch entwickelte Gesellschaften. Japan z.B. zeichnet sich aus durch die parallele Nutzung von unterschiedlichen Kalendern, die eigenartige Vermischung

32 Dux 2000: 365.

33 Dux 1989. Elias 1984. Ein philosphischer Meilenstein schon in den 1940er Jahren ist zweifellos „Ursprung und Gegenwart“ von Jean Gebser. 
von offizieller Arbeitszeit und Freizeit sowie einen astrologischen Aberglauben. In meinem Geburtsjahr 1966, dem Jahr des Feuerpferdes, sank die Geburtenrate von knapp 2 auf 1,58, weil in diesem Jahr geborenen Mädchen angeblich ein schlimmes Schicksal droht. ${ }^{34}$ Weitere Studien zeigen, daß Manager und Großstadtbewohner schneller zu Fuß gehen als Arbeiter oder Menschen vom Lande. Doch längst läuft auch hier die abstrakte Weltzeit parallel mit. Hatte in der primitiven Gesellschaft jede Handlung ihre eigene Zeit gehabt, hatte man in Polynesien noch mindestens 10 Minuten mit der Gegengabe warten müssen, so sind 5 Minuten in einer Warteschlange in Mitteleuropa jetzt eine halbe Ewigkeit. Und während Darwin für die Mutationen und Selektionen in der Natur diese halben Ewigkeiten erfaßt, wird die Zeit von Börsianer und Bourgeois, die Marx im Auge hat, bereits knapp.

Die historisch-genetische Theorie hat den Doppelcharakter des Zeitgewinns nachgezeichnet. Einerseits erlaubt es der Gewinn der Zeit in der Ontogenese, die Theorie der Liebe vom Naturalismus Freuds und vom Regelsystem Lévi-Strauss' zu entkoppeln. Der ödipale Konflikt: Penisneid und Kastrationskomplex, ist ein Mythos, ebenso sind die elementaren Strukturen der Verwandtschaft keine abstrakte Regel, deren Einführung im dunkeln bleibt. Auch die Theorie des Matriarchats geht über Bord. Geschichte, auch die Entwicklung des Subjekts, wird nicht länger zu Phasen mythologisiert, sondern basiert auf den Fähigkeiten, die jedes nachwachsende Gattungsmitglied neu im Prozeß der Enkulturation entwickelt. ${ }^{35}$ Diese Ausgangsbedingungen sind in allen Gesellschaften gleich. Alle Gesellschaften kennen daher das Bedürfnis nach Intimität, alle kennen eine Institution der Ehe und der familialen Organisation.

Aber der Gewinn der (knappen) Zeit in der Geschichte geht einher mit einem radikalen Verlust von Weltbild und Welt: Die industrialisierte Welt der Großstädte und Eisenbahnen generiert ein technisches Schockerlebnis und beraubt den Reisenden seiner Wahrnehmung. Auch der Zugang zur sinnfreien Zone des körperlichen Daseins wird beschnitten. Indem das moderne Weltbild auf den Menschen konvergiert, steht der Mensch auch alleine im All. Seine Arbeit wird als Lohnarbeit abstrakt und läuft ins Leere. Die Romantiker versuchen zum letzten Mal, sich ge-

34 Vgl. Coulmas 2000.

35 ,Für das substanzlogische Verständnis der Entwicklung gilt der Satz der Erhaltung. Was sich entwickelt, sind lediglich Umorganisationen naturaler Potentialitäten. Freud hat es an der expliziten Affirmation des Satzes der Erhaltung nicht fehlen lassen. Die prozeßlogische Argumentation des Satzes der Erhaltung zeichnet sich demgegenüber dadurch aus, daß sie ontogenetisch sowohl als auch historisch im Bildungsprozeß des Subjekts konstruktive Kompetenzen entstehen läßt, denen zufolge die kulturellen Lebensformen in einem anderen Stratum ausgebildet werden als dem der Natur, von dem sie ausgegangen sind.“ Dux 1994: 271. 
gen die reale Welt absolut zu setzen und in der Nähe zur Kindheit, zur Mutter, zur Natur, zur Geliebten, zum Traum und zum Tod subjektiv zu erreichen, was ihnen die reale Welt objektiv nicht mehr bietet. ${ }^{36}$ Aber der Versuch, das dauerhafte Bedürfnis nach Liebe auch in eine dauerhafte Bindung umzumünzen, ist risikobehaftet. Die reale Knappheit der Zeit ist schon bis ins Liebesverhältnis durchgeschlagen.

Zur Bedeutung der Glaubenskriege für den Modernisierungsprozeß gibt es Arbeitsthesen. Die Bedeutung der Kriege des 20. Jahrhunderts für die Liebessemantik der Gesellschaft wäre erst noch zu erforschen. Der sexuellen Befreiung der 60er Jahre steht eine Normalisierung des Eheund Beziehungsbruchs gegenüber. Sie ist historisch neu und doch nichts anderes als eine verschärfte Zeitknappheit: Die biologische Uhr (der Frauen) tickt. In den rapide alternden Industriegesellschaften steigt zwar die Lebenserwartung offenbar noch immer um drei Monate pro Jahr an (Deutschland liegt mit 77 Jahren im europäischen Mittelfeld, Japan hat die höchste Lebenserwartung der Welt). Doch die Bevölkerung schrumpft, weil die Familiengründung zusehends scheitert. Die Kinderzahl pro Frau in Deutschland ist mittlerweile die niedrigste in Europa und lag im Jahre 2000 bei 1,2. In Japan betrug sie 1,34 bei ebenfalls stetig sinkender Tendenz. Das Heiratsalter beider Geschlechter und das Gebäralter der Mütter steigt, auch die Zahl der Kinderlosen und Single-Haushalte nimmt länderübergreifend zu.

Der Befund: Das Risiko der Liebe mündet in rasant steigende Trennungs- und Scheidungszahlen. In Japan verdoppelte sich die Zahl der Scheidungen pro 1.000 Einwohner von unter 1,0 im Jahre 1970 auf 2,1 im Jahre 2000. Insbesondere lange verheiratete Paare wagen heute den Schritt. Deutschland liegt mit einer Scheidungszahl von 2,4 ungefähr gleichauf, die Ostdeutschen haben die Westdeutschen in puncto Scheidungshäufigkeit fast eingeholt. Finnland, Großbritannien und die USA weisen noch höhere Raten auf. Mehr noch: Die Akzeptanz der Scheidung nimmt sogar in Japan zu. Seit 1997 würde eine Mehrheit der Befragten ihr im Zweifel eher zustimmen. Auf diese Normalisierung des Bruchs kann die Systemtheorie naturgemäß am schnellsten reagieren: Statt der großen, lebenslangen Liebe erwartet das psychische System nur noch die zeitlich begrenzte „Lebensabschnittsbegleitung“. Ihre bloße Annahme scheint sich ex post zu bestätigen. ${ }^{37}$ 


\section{Die theoretische Liebe zur Differenz}

Schon die historisch-genetische Theorie hat gezeigt, daß Kompetenzsteigerungen im Entwicklungsprozeß der Gesellschaft von beiden Geschlechtern gemeinsam erbracht werden müssen. Auch das Bedürfnis nach Liebe ist beiden Geschlechtern eigen. Liebe will etwas vom anderen, und sie will, daß er es freiwillig gibt. Daher sind Liebe und Macht disparat. Im 19. Jahrhundert aber gerät auch die Liebe unter den Druck der protestantischen Ethik. Während die Romantiker in den romantischen zu fliehen versuchen, stehen Foucaults Anstalten und Kliniken schon bereit, um die Körper wieder einzufangen. Hier ist die Disziplinierung sichtbar, doch auch die Anforderungen des anonymisierten Alltags hinterlassen sozialpsychologische Spuren. Rigide polarisiert die bürgerliche Gesellschaft die Rollenmodelle für Mann und Frau und stellt den homo oeconomicus der femina casa gegenüber. Indem der Zivilisierungsprozeß abstrakt eben nicht nur die Frau, sondern beide Geschlechter affiziert, bewegt er sich geradewegs auf eine weitere Komplexitätssteigerung zu: die Umschrift der Liebe vom subjektiven Bedürfnis auf ein Medium der Kommunikation, vom Subjekt aufs System. Und ausgerechnet der Stoff, aus dem die Träume der Romantiker sind: Briefe, Romane und Briefromane, liefern Niklas Luhmann das Material für die theoretische Codierung der Intimität. Er nutzt die semantische Polarisierung der männlichen Individualidentität und weiblicher Gattungsidentität in der bürgerlichen Gesellschaft dazu, die physiologische Differenz der Geschlechter auszutauschen gegen informative Differenzen im Kommunikationsprozeß zwischen (geschlechtslosen) sozialen Systemen:

„Die meisten Erfordernisse seines Lebens kann der Einzelne, und das ist neu, nur noch in unpersönlichen Beziehungen sicherstellen, in Beziehungen, in denen er nicht oder nur in den engen Grenzen des jeweiligen Systems, über sich selbst kommunizieren kann. [...] Im 19. Jahrhundert hatte man angesichts der Tatsachen, die die industrielle Revolution für die bürgerlichen Schichten geschaffen hatte, annehmen können, dieses Problem betreffe nur den Mann. Nur er arbeite zu Hause. Nur er habe sich mit den Unzuträglichkeiten der Welt auseinanderzusetzen. Nur er sei der Indifferenz, der Rücksichtslosigkeit, der Bosheit von Mitmenschen direkt ausgesetzt, und die Frau entschädige ihn dafür mit Liebe. [...] Unter dieser gesellschaftstheoretischen Prämisse muß die anthropologische Differenz von Mann und Frau zunächst beibehalten, ja ins Extrem getrieben werden - bevor sie dann ganz aufgegeben wird. “38

38 Luhmann 1982: 194f. 
Die Systemtheorie entkoppelt die Liebe nicht nur vom Geschlecht, sondern vom Körper, und verschmilzt sie mit ihrem komplexen, digitalen Kommunikationssystem. Damit landet sie in der modernen Gesellschaft, welche die Geschlechter (und Völker) rechtlich und theoretisch gleich behandelt. $^{39}$ Die Frage schließt sich an, wo das Geschlecht dann überhaupt noch zu verankern ist. Judith Butler schlägt mit ihrer provokanten These, es gebe keine physiologische Determination, genau in diese Kerbe. ${ }^{40}$ Auch die Genforschung und Pränataldiagnostik gehört in diesen Kontext. Sie affizieren die Autonomie des Subjekts und seine Beziehung zu den Eltern vor seiner Geburt: Kinder als Produkt. Doch in unserem Kontext ist die Frage, was die Abstraktion vom Körper anrichten kann, zweitrangig. Wichtiger ist, daß die Codierung von Körper und Geschichte denkbar geworden ist.

\section{Der Code der Liebesgeschichte:}

\section{Erleben/Handeln statt Mann/Frau}

Zerfallsgeschichte à la Sennett und Verlustsemantik à la Dux sind Luhmann fremd. Er entwickelt ein evolutives Modell intimer Kommunikation. Paradox verwurzelt er die Liebe nicht im emotionalen Bedürfnis der Liebenden, nicht in Kategorien des Wunsches, des Bedürfnisses, des psychischen Verlangens. Vielmehr ist der Ausgangspunkt seiner Überlegung der Zustand der Indifferenz. Seine Systeme sind Monaden, die sich nicht füreinander interessieren, sondern gegen ihre Umwelt und gegeneinander abschotten. Von dieser Basis aus gelangt er über die Theorie des Tausches hinaus: In der Liebe werden nicht mehr Gefühle oder Körper getauscht, sondern sie ist als asymmetrischer Kommunikationsproze $\beta \mathrm{zu}$ begreifen, besser noch: als eigenes, symbolisch generalisiertes Kommunikationsmedium, das diesen an sich unwahrscheinlichen Prozeß erst motiviert. Sein symbiotischer Mechanismus ist nichts als ein informativer Rest des Körpers und das genaue Gegenteil der frühkindlichen Sexualität im Prozeß der Ontogenese des Subjekts. Damit ist zugleich klargestellt, daß die Asymmetrie nicht notwendig zwischen den Geschlechtern, sondern zwischen den Kommunikanten: im Kommunikationsprozeß selbst, verankert ist, was auch die Homosexualität integriert. Luhmann befreit die Liebe von der materiellen Geschlechterdifferenz wie das Geld vom Gold und setzt die informative Differenz von Erleben

39 Im Jahre 2002 schrieben sich erstmals mehr Frauen an deutschen Universitäten ein als Männer. Natürlich fungiert die mangelhafte Kinderbetreuung noch als Machthebel im Geschlechterverhältnis. Aber auch die Wahlergebnisse zeigen keine signifikante Geschlechterdifferenz.

40 Butler 1991. 
und Handeln an ihre Stelle. Mit diesem Schematismus können alle Kommunikationsmedien der Systemtheorie: Wahrheit und Macht, vor allem aber Liebe und Geld, vom Bedürfnis entkoppelt und auf der Ebene der Informationsverarbeitung neu konstruiert werden. ${ }^{41}$

Mit der (selbst schon unwahrscheinlichen) Umstellung der neuzeitlichen Gesellschaft von stratifikatorischer auf funktionale Differenzierung und der Steigerung der sozialen Komplexität wächst nicht nur die individuelle Freiheit, sondern auch die Unwahrscheinlichkeit intimer Kommunikation. Das Individuum mag seine Lebenswelt pflegen, bewegt sich aber durch eine zusehends unpersönlichere Außenwelt. Nur noch selten bestätigt ein Individuum die Weltsicht eines anderen. Daher ist Liebe im Normalfall nicht nur asymmetrisch, sondern unglücklich. Nicht Haß ist das Gegenteil der Liebe, sondern Indifferenz. Spontane Zuneigung und intensive Subjektivität unterliegen als idiosynkratische Kommunikation einem besonderen Bann. Deshalb differenziert die moderne Gesellschaft Liebe aus als semantisches Angebot und Handlungsmuster. Als symbolisch generalisiertes Kommunikationsmedium motiviert sie dazu, einen aus der Sicht der Individuen an sich langweiligen (oder umgekehrt: zu idiosynkratischen) Kommunikationsprozeß fortzusetzen.

Dazu macht sie sich die Differenz zwischen Erleben und Handeln, zwischen der Selbst- und Fremdzurechnung von Selektionen, zunutze und setzt den Liebenden unter Handlungsdruck. Der Kavalier muß seine Liebe zeigen. Wer liebt, muß seiner Geliebten die Wünsche von den Augen ablesen und sein Handeln gleichzeitig durch ihre Augen beobachten und ihren Erlebnishorizont ständig miteinrechnen. Nicht Aufrichtigkeit und Liebesschwüre beweisen Gefühle, sondern nur zuvorkommendes Handeln und (teure) Aufmerksamkeiten. Genau darin liegt die Chance, die ungeheure Bindungsfähigkeit der Liebe. Sie sorgt dafür, daß die Individuen Informationen im Hinblick auf zwei Welten beobachten. Liebende kommunizieren anders als andere, direkt, vorausahnend, mit kurzen Blicken, und nehmen ihr Beziehungssystem aus der allgemeinen Welt heraus. Diese dauernde Beobachtung zweiter Ordnung kann später in der Ehe als ständige Zumutung pathologische Züge annehmen. Dann führt nur noch die Therapie aus der kommunikativen Paradoxie heraus, indem sie psychisches Verstehen über soziales stellt. Oder umgekehrt: Die zunehmende Eheberatung (auch im Radio) bezeugt, daß die Liebe selbst einem Paradox entspringt: Bindung entsteht aus innerem Schon-Gebunden-Sein, Trennung aber ist der einfachste und häufigste Ratschlag von außen.

41 Luhmann 1997: 346. Schwanitz 1990: 80, 215. Luhmann 1982: 21-39. 
Erst von dieser Beobachtungsebene aus wird die Entstehungsgeschichte der Liebe transparent. Die Liebessemantik selbst sickert aus der Spitze der Gesellschaft in die bürgerlichen Oberschichten ein. Der erste Schritt dorthin heißt: Passion. Dabei wird im Frankreich des 17. Jahrhunderts die Liebe gegen die Ehe ausdifferenziert, denn die Individuen sind eher frei als die standesvermittelten Ehen. Die Passion setzt an die Stelle der mittelalterlichen Idealisierung der unerreichbaren Geliebten ein kommunikatives Paradox. Der Liebende muß Handeln, seine Liebe bekennen, die Angebetete dagegen mit ihrer Wahlfreiheit kokettieren. Hier konvergieren die Unterwerfung unter die eigenen Gefühle und die Eroberung der Frau. Das Paradox wird in der Kommunikation normalisiert.

Auf dieser Ebene der emotionalen Bindung, d.h. der Bindung an die eigene Emotion, gewinnt die Liebe im 18. Jahrhundert einen Sonderstatus. Jetzt konvergieren Liebe und Ehe wieder und definieren sich über die englische Häuslichkeit als Distanz zur anonymen Außenwelt. Dafür handelt sich die Liebe jedoch das Problem der Inkommunikabilität der Gefühle ein. Die Information der Liebe ist nicht mitteilbar, subjektive Aufrichtigkeit läßt sich ebensowenig ins Kommunikationssystem einspeisen wie Spontaneität. So führt Luhmanns Liebestheorie von der französischen Passion über die englische Häuslichkeit zur deutschen Individualität.

Weitere Komplexitätssteigerung im Rahmen funktionaler Differenzierung von Gesellschaft zwingen das Subjekt im 19. Jahrhundert dazu, seinen idiosynkratischen Weltbezug romantisch zu radikalisieren. Die objektive Welt bietet keinen Anhaltspunkt mehr, stattdessen werden die Liebenden füreinander zum Universum und phantasieren vom gemeinsamen Tod. ${ }^{42}$ Der Text der funktionalen Differenzierung aber fließt weiter und erreicht seinen Höhepunkt im englischen Liebesroman. Jane Austen überdreht die romantische Sehnsucht publikumsträchtig mithilfe von Anknüpfungen an den Schauerroman und der Erfindung der erlebten Rede so weit, daß die verliebte Frau ihr Selbst externalisiert und sagt: „Ich bin er.“ Darin wird das Paradox sichtbar, „daß gerade die emphatische Ausrichtung auf das Selbst die rückhaltlose Selbstthematisierung der Liebesleute voreinander so schwierig macht". ${ }^{43}$ Es kommt zum Happy End, zum Geständnis und zur Erklärung, warum das Geständnis so lange dauerte. Dieses Geständnis ist der Liebesroman selbst.

Dem romantischen Liebesroman mit dem Happy End der Heirat entspricht theoriegeschichtlich die Begegnung des philosophischen Erzählers der Geschichte (Hegel) und dem Erzählten (Napoleon) während der 
Schlacht von Jena im Jahre $1806{ }^{44}$ Staat und Philosophie verschmelzen wie Mann und Frau. Doch die Realität - und auch die Theorie - ist komplexer. Während Hegel Widersprüche im Rahmen des dialektischen Materialismus serviert bekommt, landet die romantische Liebe im hochkontingenten Kommunikationssystem der Zivilisation (wie Luhmann formuliert: im Auto). Wenn Männer ihre Arbeit $\mathrm{zu}$ sehr lieben und Frauen autoaggressiv zur Klinge greifen, ist der Rat Dritter sicher hilfreich, Trennungen müssen erwogen und finanziell durchgerechnet werden. Aber die Systemkommunikation Luhmanns ist selbst nach dem Vorbild der Ehe-Hölle verfaßt. ${ }^{45}$ Und aus diesem Kommunikationssystem gibt es kein Entrinnen, selbst wenn man den Code wechselt.

Die moderne Gesellschaft, soviel ist klar geworden, bildet sich nicht mehr am Geschlechterverhältnis. Das Bedürfnis nach Liebe hält sich gleichwohl durch - die Massenmedien aller Schattierungen legen davon tagtäglich Zeugnis ab. Der Einschlag von Macht, Zeit und Geld ins Verhältnis der Geschlechter ist ein empirisches Faktum, aber wie bei vielen anderen Problemen auch sind die Individuen als Subjekte und psychische Systeme auf sich selbst verwiesen. Hier liegt zugleich die Stärke und die Schwäche des Codes: Einerseits steht im Rahmen der Differenzierung von Erleben und Handeln die Liebe auf derselben Stufe wie die nüchterne Wahrheit und das harte ökonomische Geld. Das Medium wirkt systemerhaltend. Andererseits fallen die Bedingungen der Liebe, die von außen in ihre Intimität einschlagen, durch das Beobachtungsraster hindurch.

Die Zivilisierung der Liebe und Codierung ihrer Theorie bis hin zur Gleichbehandlung der Geschlechter ist aber nur die Innenperspektive der Modernisierung moderner Gesellschaft. Während der Ökonom Karl Marx noch am Wertgesetz feilt, geht 1859 im fernen Nagasaki der deutsche Arzt Philipp Franz von Siebold an Land und sieht nach 30 Jahren seine Frau und Tochter aus erster Ehe wieder. 1829 war er wegen des Schmuggels von Landkarten des Landes verwiesen worden. Japan, der weiße Fleck der Zivilisation, hat sich der christlichen Mission und Eroberung widersetzt. Jetzt öffnet es sich wieder als Außenperspektive der westlichen Zivilisation. Der europäische, bürgerliche Staat und seine Verschmelzung von Politik und Philosophie vollenden also keineswegs den Zivilisationsprozeß. Vielmehr stößt er im fernen Osten auf ein Widerlager, ein zentralistisches und hierarchisches Staatssystem, ein kulturelles Korrektiv, das sein Selbstbild verfeinern soll. Wie wird die fremde Schrift des Ostens in das Autoskript der Zivilisation integriert? Und erneut: Wer zivilisiert wen? 


\section{Japan und der Westen als differenzielle Einheit der Zivilisation}

\subsection{Japan und der Westen: Moderne als Einheit der Differenz}

Schamgrenzen der Zivilisation: Verpackung von Körper und Raum

Als die schwarzen Schiffe (kurofune) des amerikanischen Kommodore Perry 1853 vor Uraga auftauchen, erzwingen sie militärisch den politischen und ökonomischen Anschluß Japans an die westliche Zivilisation. Ihre Okzidentierung stößt hier an die pazifische Mauer, an ihre Grenze zur Wildnis zweiter Ordnung, ihre Grenze zur fernöstlichen Zivilisation, zum asiatischen, nie eroberten, isolierten Feudalstaat. Kurz nur überlegt die japanische Seite, dem Kommodore und seinen Offizieren Frauen zu schicken, um sie in ihrem aggressiven Anliegen zu besänftigen. Doch nach kurzem Ringen fällt in der Spitze der Gesellschaft eine andere Entscheidung: Japan wird sich die westliche Zivilisation zum Vorbild nehmen und sich technisch, politisch und sozial mit atemberaubender Geschwindigkeit modernisieren. In den 140 Jahren bis zum Platzen der japanischen bubble-economy wird eher Japan den Westen zivilisieren als umgekehrt: Die Insel wird immer neue kulturelle Rätsel aufgeben und Beschreibungsmuster provozieren. Festmachen läßt sich das am besten an den Japan-Diskursen, die aus seiner Gegenüberstellung mit dem Westen eine differenzielle Einheit der Zivilisation entwickeln.

Macht ist in Japan schon seit der Einigung des Landes durch Oda Nobunaga und Toyotomi Hideyoshi im Jahre 1590 zentralstaatlich verfaßt. Obwohl die überhandnehmende katholische Mission die Toku- 
gawa-Regierung 1635 zur Isolation des Landes bewog, ist der Außenkontakt auf der Ebene des Handels 220 Jahre lang nicht abgebrochen. Die ostindische Kompanie, die erste Aktiengesellschaft der Welt, gegründet in den protestantischen Niederlanden, schlägt auf der künstlich aufgeschütteten Insel Deshima vor Nagasaki in jedem Jahr mehrere Schiffsladungen um. So gelangen nicht nur Waren, sondern auch westliche Wissenschaft und Medizin nach Japan. Als 1858 auf Druck der USA die (noch) „ungleichen Handelsverträge“ abgeschlossen werden, geht es aber nicht mehr nur um Kohle für Dampfschiffe auf ihrem Weg durch den Pazifik. Vielmehr wird die fremde Kultur und unbekannte Subjektivität dem „Selbstverständigungsdiskurs“, der „Meta-Erzählung“ (Lyotard) der Moderne einverleibt. Zwar ist die japanische Kultur in besonderem Maße rezeptiv: Sie hat bereits den Buddhismus aus Indien, die Schrift aus China, den Reisanbau aus Korea und die Waffentechnologie aus den westlichen Ländern integriert und all diesen fremdkulturellen Elemente im eigenen Kontext eine neue Färbung verpaßt. Nun aber sickern auch noch die Begriffe zur Konstruktion kultureller Identität nach Japan ein und generieren eine kulturelle Umschrift zweiter Ordnung, die Spuren am Körper hinterläßt.

Die Zivilisation bricht ein in die Vorstellungen von Gesundheit und Mode, von weiblicher Schönheit und von textiler Schichtung des Körpers und Raumes, Schamgrenzen geraten in Bewegung. Das öffentliche Gemeinschaftsbad in Yokohama und Osaka wird nach Beschwerden westlicher Besucher unterbunden. Mit der Meiji-Restauration und der Begeisterung für die westliche Medizin beginnt bei Geburten die Rückenlage die Sitz- oder Hocklage zu verdrängen. Nebenfrauen werden gesetzlich verboten. Äußerlich ist also der Einfluß westlicher Normen stark. Aber die importierten Regeln schlagen nicht wirklich auf die emotionale Tiefenschicht der japanischen Kultur durch. Shimada Shingo verdeutlicht das am japanischen Verhältnis von Sexualität und Scham. ${ }^{1}$

In christlichen Kulturen sind Sexualität und Scham unmittelbar miteinander verknüpft. Sexualität impliziert Schuld und Sünde, sie öffentlich zu praktizieren, ist schamlos. In Japan jedoch steht sie nicht im moralischen Kontext, sondern impliziert - unbeschadet der Tabuisierung der weiblichen Menstruation - körperliches Wohlbefinden und Gesundheit. Scham resultiert daher in Japan nicht unmittelbar aus der Wahrnehmung von Nacktheit, sondern hat selbst zwei Ebenen (bzw. Schichten). Erstens ist die japanische Toleranz gegenüber Nacktheit selbst vom Ort der Nacktheit abhängig. So kann ein Vermieter seinen Mieter im eigenen Haus durchaus in Unterwäsche empfangen. Zweitens aber löst scham-

1 Shimada 1994: 181-188. 
lose Nacktheit in der Öffentlichkeit, z.B. im heißen Bad (sentô oder onsen), als Regelverletzung bei den Anwesenden, nicht beim nackten Ethnologen, Scham (zweiter Ordnung) aus. Diese Scham entspringt also keinem Bewußtsein individueller Schuld, sondern einer situativen Wahrnehmung der Regelverletzung durch andere. ${ }^{2}$

Wenn nicht das Verletzen fester Kleiderordnungen oder Verhaltensregeln, sondern erst der Kontext der Situation oder die Umstände eines Auftritts Schamgefühle hervorrufen, so ist die Definition, Beschriftung und Verpackung des Raumes von besonderer Bedeutung. Das traditionelle japanische Haus weist seinen Räumen keine klare Funktion zu, sondern ist flexibel geschichtet und umbaubar. Die Grenze zwischen Privatleben und Öffentlichkeit ist verschiebbar wie die japanischen Türen, welche das Haus in drei Schichten verpacken: amado (Regentüren) schützen gegen Taifune, die weißen shôji (Papierschiebetüren) begrenzen die Zimmer und die bemalten fusuma schmücken ihn weiter aus. Bis heute verfügt jede japanische Wohnung über ein Zimmer mit einem Fußboden aus tatami (Reisstrohmatten) mit einem niedrigen Tisch, an dem man knieend seinen Gästen den Tee serviert.

Schon die traditionelle japanische Stadt kennt keine identifizierende, klare Stadtmauer. Ihr Raum ist nicht auf ein politisches Zentrum hin strukturiert, sondern unübersichtlich, die Hausnummern sind nach Baujahr vergeben, die Adressen ohne Wegbeschreibung des Hausherrn kaum zu finden. Zwar wurde mit der Industrieausstellung von 1878 versucht, die Idee der Perspektive, der Sichtbarkeit der Stadt, nach Japan zu importieren. Aber auch der zwölfstöckige Turm von Asakusa, das erste Hochhaus Japans, das beim Erdbeben von 1923 zerstört wurde, oder der 1958 dem Pariser Eiffelturm nachempfundene, rote Fernsehturm Tokyo Tower sind lediglich Zitate der europäischen Raumordnung. Tokio ist bis heute eine Ansammlung von Dörfern. Seine sakariba (Vergnügungsviertel) an der Ringlinie Yamanote generieren keinen fixen politischen Raum, sondern historisch wandernde Orientierungspunkte der Zirkulation: Ginza war das Zentrum der 1920er Jahre, Shinjuku stieg während der Hochwachstumsphase der 1960er Jahre zum Zielpunkt der Migranten auf, Shibuya ist erst seit den 1980er Jahren der Treffpunkt der pendelnden Vorstadtkids. ${ }^{3}$ Während für die westliche Kultur die klare Differenz zwischen Öffentlichkeit und Privatsphäre grundlegend ist und ihr massenmediales Aufweichen zur Diagnose des Narzißmus berechtigt, wird die japanische Achsialisierung des Soziallebens über mehrere Begriffspaare umrissen.

2 Shimada 1994: 199-207.

3 Yoshimi 2002. 


\section{Privat/öffentlich versus uchi/soto,} honne/tatemae, ura/omote, giri/ninjô

Der Psychologe Kimura Bin hat in Anlehnung an Herder und den japanischen Philosophen Watsuji Tetsurô versucht, die japanische Subjektivität im Klima und in der Natur der Inseln zu verankern. Weil die Japaner sich von Anfang an einer übermächtigen Natur mit Erdbeben, Vulkanen und Taifunen ausgeliefert sahen, mußten sie, anders als die Menschen im milden Klima Europas, eine duldende, einfühlsame, rezeptive Haltung zu ihrer Umwelt entwickeln. Mehr noch: sie waren für ihre tägliche Arbeit in der Agrargesellschaft elementar aufeinander angewiesen. Aus dieser Notwendigkeit heraus bildeten sich in Japan weiche psychische Strukturen aus, deren temporäre Muster in jeder Situation in der sozialen Kommunikation neu ausgehandelt werden müssen. So hat die japanische Sprache bekanntlich zahlreiche Personalpronomen sowie Präund Suffixe, die Geschlechterverhältnisse, soziale Hierarchien und Höflichkeitsgrade ausdrücken und nuancieren. Das japanische Wort für Mensch: ningen, ist selbst zusammengesetzt aus den Kanji (chinesischen Schriftzeichen) für „Mensch“ und „Zwischenraum“. Japan erlebt sich als den Naturgewalten schutzlos ausgesetzt und bringt wechselhafte, spontane, planlose Menschen hervor. Wichtiger als die westliche, zentralisierende Kategorie des freien, festen, individuellen Willens ist daher in Japan die der sozialen Reziprozität. Diese soziale Verpflichtung des Einzelnen (giri) im Rahmen der hierarchisch gegliederten Gesellschaft Japans läßt sich seinem subjektiven Gewissen, seiner Sittlichkeit (ninjô), begrifflich entgegensetzen. ${ }^{4}$

Dieser „Zwischenmenschlichkeit“ der Japaner entspringt eine kommunikative Kultur, welche den Konversationsstil stark am Empfänger ausrichtet. Das japanische Wort dafür: omoiyari, ist zu übersetzen mit „Empathie“, „Feingefühl“ oder „Mitleid“. Gruppen- oder Familienmitglieder reden daher untereinander völlig anders als mit Außenstehenden. Mit seiner wirklichen Meinung (honne) wird sich ein Japaner einem Fremden gegenüber zurückhalten, genauer: er wird an ihn denken und ihn deshalb nicht mit seinen eigenen Sorgen und Problemen belasten. Ihm gegenüber genügen Höflichkeiten und Floskeln (tatemae). Meinungen und Urteile müssen im Rahmen bleiben, so daß beide Seiten das Gesicht wahren können. Die harten Diskussionen finden anderswo und mit anderen statt, nicht in der Öffentlichkeit. Auch Vertragsverhandlungen werden ungern in der formalen Atmosphäre des Büros geführt, sondern lieber in die ungezwungene Umgebung der sakariba verlegt.

4 Kimura 1995: 31-35. Shimada (2000: 115) kritisiert, daß Kimura ein blutsverwandtschaftliches Verhältnis zwischen allen Japanern unterstelle. 
Hier, im vertrauten, informellen Innenbereich, kommen die wirklichen Meinungen (honne) zur Sprache. Die Vorstellung einer repräsentativen, klaren, offenen und öffentlichen Sprache ist der japanischen Psyche fremd. Sie wechselt mit dieser Schichtung des sozialen Raumes und Priorisierung von Kommunikation im vertrauten Kreis nicht nur die Wertigkeit von Öffentlichkeit und Privatsphäre, sondern bereichert sie auch um eine flexible, weiche, weibliche Tiefendimension.

Auch das Begriffspaar uchi/soto (innerhalb/außerhalb) gehört in diesen Zusammenhang. Das Wort uchi bezeichnet das eigene Haus bzw. seine Innenseite und kann daher auch für die erste Person Plural stehen. Der Begriff soto meint die Außenseite des Hauses. Die Dichotomie omote/ura (Vorderseite/Rückseite) ist im wesentlichen äquivalent. Die sichtbare Vorderseite (omote) generiert eine andere Kommunikation als die rückwärtige Seite (ura) des Hauses. ${ }^{5}$ Außen- und Innenbereich des Hauses lassen sich in erster Näherung als die traditionellen Sphären der Männer und der Frauen beschreiben. Das Wort oku ist zu übersetzen mit „Tiefe“ (oder „hinten“), okusan kann daher sowohl „Hausfrau“ als auch „Ihre Frau“ heißen. In der Tat hat die japanische Sprache bis heute kein Wort für „Ehefrau“, das mit dem Wort „Ehemann“ (goshujin) auf einer Stufe stünde. Infrage käme allenfalls das dem Englischen entlehnte pâtonâ (Partner). Die Brüche im japanischen Raum springen also auf die Psychen, Denkweisen und Weltbilder der Individuen über und verleiten dazu, den weichen Kontextualismus der fernöstlichen Insel der harten Identitätslogik der westlichen Kultur polar gegenüberzustellen.

\section{Imperfekte Psyche, perfekte Funktion:}

japanisches Dividuum (kanjin) und westliches Individuum (kojin)

Die japanische Niederlage im Zweiten Weltkrieg läutete erneut einen Modernisierungsschub ein. Das Schulsystem und der Volkssport Baseball wurden aus Amerika übernommen, und auch die moderne Wohnhausarchitektur hielt in Japan Einzug. Sogar die Institution des Badehauses geriet unter Druck. Dennoch hat sich die maternelle Prägung als Erklärungsmuster der japanischen Kultur gerade in den Jahren des wirtschaftlichen Aufbaus als resistent und nützlich erwiesen.

Der Arzt Kosawa Heisaku und sein Schüler Okonogi Keigo haben versucht, komplementär zum Ödipus-Komplex der westlichen Psychoanalyse einen japanischen Ajase-Komplex zu definieren. Dieses grob als Sehnsucht nach der Mutter umschriebene psychische Muster greift zurück auf den amae-Begriff von Doi Takeo und versucht zugleich, maso-

5 Shimada 1994: 126-132. 
chistische Tendenzen in Japan aus der traumatischen Erfahrung der Trennung von der Mutter zu erklären. Tiefenpsychologisch betrachtet, gleicht das intensive Mutter-Kind-Verhältnis in Japan einer sukinshippu (vom englischen Wort skinship). Die Kleinkinder werden zumeist auf dem Rücken getragen und wachsen in einer Umgebung ohne Vater auf. Die Haltung der Mutter ist weitestgehend permissiv. Aber gerade weil sie unter den Taten ihres Kindes leidet, sie erduldet und ihm verzeiht, kann sie ihm ein spontanes Schuldgefühl einpflanzen und es an sich binden. Folgt man diesem Erklärungsmodell, so versucht das Kind später als Erwachsener, diese Schuld als Schuld gegenüber seiner Arbeitsgruppe abzutragen. ${ }^{6}$ So ist auch der japanische Firmenkrieger, der sarariiman, eben nicht hart und durchsetzungsfähig, sondern schwach und unfähig, seinem Vorgesetzten zu widersprechen.

In der japanischen Gesellschaft bewegen sich noch heute Männer und Frauen meist in getrennten Welten. Die Büroarbeit der Männer und die Hausarbeit der Frauen sind räumlich, zeitlich und sozial weitgehend entkoppelt. $^{7}$ Sogar dem Männertheater Nô steht seit 1912 das in Takarazuka gegründete gleichnamige Frauenrevuetheater gegenüber, das im Jahre 2001 mitten in Tokio ein neues Gebäude bezog. Diese getrennten Räume von Mann und Frau implizieren keine normative Einheit von Liebe, Ehe und Sexualität. Viele Ehemänner liefern noch immer brav ihr Geld zuhause ab und erhalten von ihrer Frau nur ein Taschengeld zum Pachinko-Spielen, Karaoke-Singen und Entspannen. ${ }^{8}$ Mädchen werden schon in ihrer Erziehung stark auf ihre Rolle als Hausfrau und Mutter verpflichtet und scheiden zumeist nach der Geburt des ersten Kindes aus dem Erwerbsleben aus. Die japanische Gesellschaft enttraditionalisiert sich nur langsam. Während das Gesetz die Gleichberechtigung formal garantiert, erschweren die steigende Arbeitslosigkeit und die rasante Alterung der Gesellschaft den Prozeß.

Der japanische Sozialpsychologe Hamaguchi Eshun entwickelte schließlich für die japanische, kontextuelle Fassung von Subjektivität den Begriff kanjin, indem er die Kanji für das japanische Wort Mensch (ningen) umdrehte, und setzte es dem japanischen Wort für Individuum (kojin) entgegen. ${ }^{9}$ Durch diese begriffliche Polarisierung von ,individual“ und „contextual“ wurde das Verhältnis zwischen Japan und dem Westen umschreibbar in einen binären Schematismus der Systemtheorie. Peter Fuchs hat die japanische Psyche im Kontext funktionaler Differen-

6 Pörtner 1995. Kersten 1997: 76f. Okonogi 1990. Elschenbroich 1996: $21 \mathrm{f}$.

7 Lenz/Mae 1997: 7-14. Weber 1997.

8 Duerr berichtet, daß japanische Männer in ihren schwachen Momenten keine Oben-ohne-Bars bevorzugen, sondern einen Kult der Vulva in LoveHotels und Unten-Ohne-Bars pflegen. Duerr 1990: 235-243.

9 Hamaguchi 1990. 
zierung als perfekte Imperfektion beschrieben. Indem die japanische Kultur die Semantik des Subjekts ausspart und den Einzelnen nicht isoliert, sondern in unterschiedlichen Kontexten immer wieder aufs neue sozialisiert, erzeugt sie ein Milieu psychischer Systeme, die sich ideal den Anforderungen unterschiedlicher Funktionssysteme anpassen.

„Die Notwendigkeit der Umstellung auf dividuale Kommunikation (bei Entwicklung einer gleichsam daran unentwegt zweifelnden Semantik) unterscheidet den Anlauf der funktionalen Differenzierung in Europa vom Andocken Japans an diese (dann entwickelte) moderne Differenzierungsform. Die japanischen Einzelexemplare waren - auf Grund der dort entwickelten kommunikativen Strukturen - dividual, waren (und sind dem Vernehmen nach), contextuals‘. Sie fügen sich nahtlos in die Polykontexturalität der modernen Gesellschaft ein. Symptomatisch dafür ist die Hilflosigkeit, mit der in Japan selbst das gesucht wird, was es dort so noch nie gab: das Individuum und seine Einzigartigkeit. Man glaubt, in der Übernahme westlicher Beobachtungsroutinen, die Individuen bezeichnen, dem so Bezeichneten nicht nur einen semantischen, sondern einen Realitätswert zusprechen zu müssen, von dem her gesehen Japan defekt ist, wohingegen es, von den Erfordernissen funktionaler Differenzierung her, sich als perfekt erweist: Es präsentierte ein Tableau von nicht-idiosynkratischen (sich nicht singularisierenden) Bewußtseinen und stößt, traut man dem Hörensagen, erst dann auf Probleme, wenn es so sein will, wie westliche Unterscheidungen es nahelegen. “ ${ }^{10}$

\section{Kulturelle Fremdbeschreibung versus Autoskript der Zivilisation}

Auch der Anschluß Japans an die Weltgesellschaft ist als (Export der) Umstellung von stratifikatorischer auf funktionale Differenzierung beschreibbar. Autor dieser Formulierung jedoch ist die Systemtheorie. Damit ergänzt sie lediglich eine lange Kette von Begriffstransfers, mit deren Hilfe wir seit seiner Öffnung seine kulturelle Identität zu erfassen versuchen. Shimada hat diesen Effekt auf allen Ebenen als „Erfindung Japans" historisch durchgerechnet. Er zeigt anhand der Gegenüberstellung von westlichem Individuum und japanischem Kollektiv, von westlichem Monotheismus und japanischer Naturreligion, von westlichem Nationalstaat und japanischer Staatsreligion, wie Japan mithilfe entlehnter, fremder, übersetzter und integrierter Begriffe eine eigene Identität konstruierte und sich gerade damit dem Gesamtsystem der Zivilisation einfügte. Dem diplomatischen Öffnungsdruck aus dem Westen folgten Auslandsreisen japanischer Delegationen. In diesem abstrakten Prozeß des Austausches und der Angleichung sind Kultur und

10 Fuchs 1995: 73f. 
System, sind Japan und der Westen nicht mehr zu unterscheiden. ${ }^{11}$ Das (selbst-)konstruierte Japan gehört zum Programm der Moderne.

Indem die Systemtheorie Zivilisation und funktionale Differenzierung ineinanderschreibt, mündet die polare Gegenüberstellung von westlicher und japanischer Psyche in die deskriptive Einheit der modernen Weltgesellschaft. Von hier aus erübrigen sich Theorien der Kultur und der Liebe. Die systemtheoretische Umschrift des Bewußtseins von einem Subjekt mit materiellen Bedürfnissen $\mathrm{zu}$ einem psychischen System der Informationsverarbeitung findet ausgerechnet in Japan ihre weiße Schreibfläche mit weißem Kragen und weißer Weste. Die imperfekten Dividuen passen perfekt zum Dividuum par excellence, dem Geld. Alteuropäische Semantiken gehen über Bord und das Weltwährungssystem bestimmt das Thema. Sein Paradigma ist die Konvertibilität, es saugt alle kulturellen Differenzen auf. Man muß weder Karl Marx noch Fukuzawa Yukichi lesen, um bezahlen zu können. ${ }^{12}$ Man muß sie nur in der Hand haben, sei es auf dem alten 100-Mark-Schein der DDR oder auf der neuen japanischen 10.000¥-Banknote. ${ }^{13}$ Die Individualität, die sich ziert, verschwimmt mit den Geldzeichen im Meer der Liquidität.

„Im Wirtschaftssystem der modernen Gesellschaft wird die mitlaufende Selbstreferenz durch kommunikative Verwendung von Geld realisiert. Die Quantifikation des Geldes macht dieses beliebig teilbar in Anpassung an jeden Teilungsbedarf. Dadurch wird das Geld universell verwendbar, wie kompakt auch immer Wirtschaftsgüter gegeben sein mögen. Es kann jede Wirtschaftsoperation ausdrücken, insbesondere auch bei unteilbaren Objekten, für die man sonst schwer ein passendes Gegenstück zum Tauschen finden könnte. Geld ist das Dividuum par excellence, das sich jeder In-dividualität anpassen kann. “14

11 Shimada weist dem japanischen Philosophen Maruyama Masao (19141996) eine Schlüsselrolle zu: „Der begriffliche Widerspruch im Werk Maruyamas spiegelt aber auch die historischen Konstellationen innerhalb Europas wider. Denn seine Vorstellung eines japanischen Volkes als der Grundlage der Nation entspricht dem deutschsprachigen Konzept der Kulturnation [...]. Und dies ist aufgrund der welthistorischen Situation durchaus plausibel, denn wie im Fall der deutschsprachigen Länder wurden die Industrialisierung und die Rationalisierung auch in Japan als ein Hereinbrechen der fremden Zivilisation in die eigene Sphäre empfunden. Es ist verständlich, daß die konzeptuelle Entgegensetzung, die im deutschsprachigen Raum kurz zuvor ausgearbeitet worden war, von einer anderen Kultur in einer vergleichbaren Situation willig übernommen und zum eigenen Selbstverständnis verarbeitet wurde." Shimada 2000: 33.

12 Fukuzawa verfaßte 1875 eine Art japanischer Zivilisationstheorie. Asien sollte sich gegen den Westen abgrenzen, dabei aber sollte Japan die Führungsrolle übernehmen. Shimada 2000: $220 \mathrm{f}$.

13 Luhmann hat also an der Kasse die falsche Frage gestellt. Nicht das Preisschild interessiert, sondern das Design des Geldscheins. Meine Kassiererin kannte allerdings Nitobe Inazo auf dem 5.000¥-Schein auch nicht. Immerhin: Die Rückseite ziert der Berg Fuji. Das versteht jeder.

14 Luhmann 1984: 625. 
Ist Japan zivilisiert? Ist das Reich der Zeichen autodeskriptiv? Kann eine Kultur sich mit westlichen Begriffen und chinesischen Zeichen selbst beschriften? Ist 1 eine Primzahl? Um die Indifferenz der Differenztheorie zu überwinden, müssen die Rechnungen vom und die richtigen Fragen auf den Tisch. Japan ist in den „Selbstverständigungsdiskurs“ der Zivilisation hüben und drüben feierlich aufgenommen. Wenn aber die Differenzen zwischen den Kulturen schrumpfen, taucht eine neue Frage auf: Wo wandern sie hin? Welche latente Geheimschrift offenbart das Autoskript der Zivilisation? Die Theorie muß daher an der Geschichte des „Dividuums par excellence“ im dividualen Japan die systemtheoretische Probe aufs Exempel machen. Erst aus der wechselseitigen Verschränkung des Geldes als einheitliches Zeichen mit der dividualen Psyche als kommunikativer Einheit wird das Autoskript der Ökonomie in Japan lesbar. Erst die Werbung entlarvt die einheitliche Indifferenz des dividualen Systems und inszeniert paradox die unendliche Differenzierung der Individualität.

\subsection{Gabe und Geld in Japan: Dividuum und Dividende}

\section{Geld, Schuld, Verpflichtung: Reziprozität statt Äquivalenz}

Die soziologische Formel von Nakane Chie, die Japan als ,vertikal strukturierte Gesellschaft“" (tateshakai) beschrieben hat, ist in letzter Zeit brüchig geworden. Die Kritik an ihrer Eindimensionalität kommt nicht nur aus Japanologenkreisen. Schon Kimura benutzt ein um $90^{\circ}$ verschobenes Koordinatensystem. Für ihn prägt den abendländischen Menschen seine vertikale Beziehung zu Gott, den Japaner aber seine horizontale Beziehung $\mathrm{zu}$ den Mitmenschen. ${ }^{15}$ Zweifellos enttraditionalisiert sich auch Japan, geraten auch hier alte Gewohnheiten und stereotype Denkweisen unter Modernisierungsdruck. Doch die psychischen Muster, die im Rahmen der Theorie des Tausches und des Geldes für Japan relevant werden, sind keine äußerlichen Höflichkeitsregeln oder kognitiven Erwartungen, sondern tief in der japanischen Gefühlswelt, Mentalität und Höflichkeitsprache (keigo) verankert. Schon für die Verben „,geben“" und „bekommen“ hält das Japanische in Abhängigkeit von der sozialen Beziehung der Akteure verschiedene Zeitworte bereit, die Höflichkeit, Respekt oder Bescheidenheit ausdrücken. Die Interaktion des Gebens ist in Japan von Haus aus keine gönnerhafte Geste, sondern eine vornehme Bitte. Das Geschenk wird verpackt, mit beiden Händen und mit einer Verbeugung überreicht.

15 Nakane 1985. Kimura 1995: 33. 
Die psychoanalytische Theorie des Geldes ist den Dividuen fremd. Ihnen stellt sich daher weder die Frage nach seiner Unreinheit noch das Problem der Äquivalenz. Das Geld hat in Japan keine zersetzende Funktion, sondern erhöht die soziale Reziprozität. Deshalb ist die Kultur der Verpflichtung (zôtôbunka) auch dem Kalender der Inseln eingeschrieben. Zweimal im Jahr erhalten Verwandte, Bekannte, Nachbarn und Kollegen als Dank für gebotene Leistungen rituell Geschenke, nämlich in der Jahresmitte am 15. Juli (chûgen) und zum Jahresende (oseibo). Der Wert der Geschenke hängt dabei durchaus ab vom Ausmaß der erhaltenen Unterstützung. Manche ältere Japaner führen deshalb noch Buch über erhaltene und gegebene Geschenke und ihre Preise. ${ }^{16}$ Sogar Bargeld kann - frisch gedruckt und im Umschlag verpackt - zur Gabe werden. Im gleichen Kontext steht das System der halbjährlichen, im Einzelfall festgelegten Bonuszahlungen in den japanischen Firmen, das die Angestellten auf ihre Rollen im sozialen Gefüge verpflichtet. Auch die Angestellten selbst, die z.B. wegen einer Dienstreise fehlen, vergelten ihre Abwesenheit gern mit kleinen Geschenken für die Kollegen. ${ }^{17}$ Politische Führer verteilen am Ende eines jeden Jahres an ihre loyalen Mitarbeiter Geschenke, die mochidai heißen: Geld für Reiskuchen. Und wenn das neue Jahr begonnen hat, wird zuerst den Kindern die Logik der Verpflichtung nachhaltig vor Augen geführt. Auch sie erhalten ein bares Geldgeschenk, das otoshidama, von ihren Eltern und Verwandten.

Die positive Besetzung hierarchischer Beziehung steht in Einklang mit der Philosophie des Konfuzianismus. Für sie begründen sie kein Machtverhältnis, sondern das von Lehrer und Schüler. Bis heute bilden überall, wo Wissen vermittelt wird, asymmetrische, aber vertrauensvolle Beziehungen zwischen sempai und kôhai die Elemente der Interaktion und Organisation. Das Prinzip der gegenseitigen Verpflichtung bildet den Rahmen für das Lernen des Lernens, die Dankesschuld (on) ist dabei die verbindlichste Norm, die den Empfänger eines Gefallens langfristig zu Gegenleistungen und Loyalität anhält. Das Prinzip gilt auch zwischen Gleichrangigen und Gleichaltrigen in abgeschwächter Form: giri verpflichtet die Mitglieder einer Gruppe zu gegenseitigem Respekt z.B. am Arbeitsplatz (uchi) sowie zu geschlossenem Auftreten nach außen hin (soto). ${ }^{18}$ In diesem dichtgeflochtenen Netzwerk konnten sich keine betriebsübergreifenden Gewerkschaften bilden.

Ohnehin ist die Grenze zwischen Arbeitsplatz und Privatleben in Japan - wie die zwischen Öffentlichkeit und Privatsphäre - unscharf. Bis heute arrangieren zahlreiche Firmen Verlobungstreffen (omiai) für ihre

16 Brumann 1998.

17 Shimada/Gabbani 1998.

18 Blechinger 1998: 82-86. 
eingespannten Mitarbeiter. In den letzten Jahren gab es einen starken Trend zur Heirat im Ausland, weil die Hochzeitspaare sich nur dort der Verpflichtung zur Einladung aller Verwandten und Chefs entziehen können - und sogar noch Geld sparen. Auch nach der Hochzeit ist die gegenseitige Bescherung der Geschlechter nicht zu umgehen: Am Valentinstag, dem 14. Februar, erhalten die Männer Schokolade von ihren Frauen und Kolleginnen. Ein Kaufhaus soll diese Tradition nach dem Krieg eingeführt haben. Die Männer revanchieren sich dafür genau einen Monat später am white day.

Wie die Systemtheorie festgestellt hat, begünstigen die dividualen Psychen, die Ordnung des Dividuums par excellence. Das psychosoziale Milieu Japans transportiert die Semantik der verpflichtenden Zahlung nur noch tiefer in die Gesellschaft hinein als die westliche Vertragskultur. Die Partner betrachten sich nicht als Individuen, losgelöst von der Gesellschaft, sondern tauschen, geben und erhalten im Rahmen eines sozialen Netzes stets mehr als äquivalente Gegenwerte - und auch wirklich bedankt hat sich nur, wer es zweimal tut. Hier wird die ternäre Struktur des Geldes sichtbar: Es involviert auch die Umstehenden, weil sie alle die Legitimität des Geldes garantieren. ${ }^{19}$ Geschenkkultur, Verpackungskultur und Handel ergänzen sich. Auch ein Blick in die Geschichte des Geldes in Japan zeigt, daß sich ihm keine religiöse Ethik und kein philosophierendes Subjekt in den Weg gestellt hat.

\section{Kulturelle Gemeinsamkeiten in der ökonomischen Kommunikation: Geld als sakrales Mittel der Säkularisierung}

Die Frage nach der Rolle des Geldes in Japan überschreitet die Schamgrenze der Zivilisation. Niklas Luhmann hat auf den primär moralischen Schematismus des dialektischen Materialismus hingewiesen. ${ }^{20}$ In der Tat läßt sich im Hinblick auf Marx' Identifizierung von Kapitalismus und Prostitution (Kapitel 1.2) und im Hinblick auf die psychoanalytische Grundformel zum Geld eine moralische Komponente seiner Argumentation nicht übersehen. Doch real sind in der modernen Gesellschaft nicht nur die Reichtümer, sondern auch die Gefühle ungleich verteilt: Armut beschämt überall, Reichtum nicht. ${ }^{21}$ Ethik und Moral bilden daher nicht unbedingt den Kern der Kritik der politischen Ökonomie. Vielmehr schuf gerade die Religion in Europa und Japan die organisatorische Basis, um das Geld als allgemeines Zahlungsmittel zu etablieren.

19 Paul 2002: 121.

20 Luhmann 1988: 242.

21 Neckel 1991. 
Im christlichen Mittelalter stieg die Kirche zum Vorläufer des modernen Staates auf. Im 11. und 12. Jahrhundert griff sie in das System der Gottesgabe ein, entwickelte den Ablaßhandel und akkumulierte damit selbst Reichtum. Die Entdeckung der Perspektive Anfang des 15. Jahrhunderts leistete der Quantifizierung des Geldes Vorschub. Der Templerorden, der sich ihr widersetzte, wurde unterdrückt. Die Kirche entzog so den einzelnen Handel dem totalen Leistungssystem von Gabe und Geschenk à la Mauss. Dieser Handel bekam nun den Charakter eines individuellen Vertrages, und in der Folge konnte auch das Rechtssystem umgestellt werden. Die Zeugen und Verwandten wurden aus der Verhandlung ausgeschlossen, unpersönliche, schriftliche Regeln traten an ihre Stelle. Die Reformation schließlich überführte diese neue Vertragskultur in das diesseitige, säkulare Wirtschaftssystem. Im Protestantismus entfällt der Mittler zu Gott, damit wird der einzelne zum geschäftsfähigen, nur sich selbst und seinem Gewissen gegenüber verantwortlichen Individuum.

Wie heute noch zu beobachten, hat der schwunghafte Handel im Umfeld der Tempel die Verbreitung des Geldes beschleunigt. Anfang des 16. Jahrhunderts erlaubten die Shogune eine „Zettelbank“ in Ise, am shintoistischen Nationalheiligtum Japans. Der Handel mit Geschenken und Opfergaben, den die riesigen Pilgerströme auslösten, erforderte moderne Zahlungsmittel, deren Wert in Gold, Silber und Grundstücken abgesichert war. Nach Miyashita Koichi bedeutet das Wortes harau (bezahlen) ursprünglich: reinigen, eine Schuld durch Gaben an einen Gott abbüßen. Christoph Deutschmann resümiert:

„Manches spricht dafür, daß sich die Transformation des Geldes in eine säkulare Ersatzreligion in Japan noch rascher und ungehinderter vollziehen konnte als in Europa. Der Konflikt zwischen dem religiösen und dem profanökonomischen Heilskalkül scheint im japanischen Buddhismus und Shintoismus von vornherein geringer als im Christentum gewesen zu sein. Miyashita erwähnt in seiner schon zitierten Untersuchung, daß sich die buddhistischen Tempel schon in der Kamakura-Zeit selbst als Handelszentren und Darlehensinstitute betätigten. R. Bellah und in seinem Gefolge verschiedene japanische Autoren haben auf die Parallelen zwischen der diesseitsorientierten Wirtschaftsethik des asketischen Protestantismus und der verschiedener Sekten des japanischen Buddhismus (genannt werden immer wieder die Namen Suzuki Shôzan und Ishida Baigan) hingewiesen.“22

22 Deutschmann 1998: 19. 


\section{Monetäre Grenzen des feudalen Japan in der Tokugawa-Zeit}

Nach der Abschließung (sakoku) Japans 1639 schufen die TokugawaShogune ein gesellschaftliches System höchster Stabilität. Seine zentralistische, feudale Ordnung kannte vier Statusgruppen, die bereits Toyotomi Hideyoshi (1536-1598) festgeschrieben hatte: Krieger (shi), Bauern (nô), Handwerker (kô) und Händler (shô). Die zentrale Macht der Shogune wurde zwar von der relativen Autonomie der Domänen konterkariert. Allerdings hielten die nationalen Herrscher ihre Lehensfürsten (daimyô) mit dem sankinkôtai-System unter Kontrolle. Es zwang die daimyô, einen Teil ihrer Familie stets als Geiseln in der Hauptstadt zu lassen und sich selbst alternierend in ihren Domänen und in der Hauptstadt aufzuhalten. $^{23}$

Aus diesem Grunde hatte der Adel der Tokugawa-Zeit einen immensen Geldbedarf, den die Agrargesellschaft auf Dauer nicht befriedigen konnte. Viele daimyô und samurai verschuldeten sich und gerieten in Abhängigkeit. Sie behielten allerdings das Recht auf willkürliche Selbstjustiz, was manche Handelshäuser in den Ruin trieb. Auch gab es Generalamnestien durch die Zentralregierung. Im Rahmen dieser feudalen Gewaltherrschaft konnte sich das Geld noch nicht als allgemeines Tauschmittel durchsetzen. Reis blieb bis zum Ende der Tokogawa-Zeit das wichtigste Zahlungsmittel für Pachten und Steuern. Zwar durfte das Daimiat Fukui schon im Jahre 1661 seine ersten eigenen Noten emittieren, auf Reisen in andere Daimiate mußte man aber mit Kupfermünzen zahlen. Auch im Alltag der Bevölkerung waren hauptsächlich Münzen aus Kupfer, Silber und Eisen in Gebrauch. Das Preisverhältnis zwischen diesen Metallen wurde bis 1868 regierungsamtlich festgesetzt. Berechnungsbasis war das ryô-Gewicht. Geldwechsel heißt bis heute ryôgae.

Während Edo (Tokio) das politische (und konsumtive) Zentrum des Landes war, war Osaka das Zentrum des Handels mit dem Silberland China. Die großen Wechselhäuser (ryôgaeya) gewährten sich untereinander Kredite und versorgten auch die Regierung mit frischem Geld. Diese Kredite wurden mit Reiswechseln (komegitte) abgesichert. Aus dem Handel mit diesen Reiswechseln entwickelten sich im 17. Jahrhundert die ersten Warentermingeschäfte in Japan. So wurde 1730 in Dôjima die erste Börse amtlich anerkannt und 1871 in eine moderne Warenbörse umgewandelt. ${ }^{24}$ Auch im japanischen Feudalismus war also der Durchbruch vom Metallgeld zum Bankpapier schon angelegt.

23 Heise/Pörtner 1995: 238-250.

24 Schaede 1990. 
Der ständige Geldbedarf des Adels und die geringe Emissionsdisziplin der Daimiate führten im 18. Jahrhundert zu einer nachhaltigen Inflation des japanischen Geldes. Zusehends wurde das Kupfer in den Münzen durch billiges Eisen ersetzt, mehrere Abwertungsschübe setzten ein. Vereinzelt kam es zu Aufständen und Plünderungen, die Bevölkerung wurde sensibel für die disziplinlose Geldpolitik des Adels. Diese frühen Skandale im feudalen Japan sind als innere Ursache des Zusammenbruchs des Shogunats zu lesen, das sich schließlich nach außen hin mit den schwarzen Schiffen aus Amerika konfrontiert sah.

\section{Sekundäre Akkumulation in der Meiji-Zeit}

Als Karl Marx im Londoner Exil seine Kapitalanalyse vollendete, öffnete sich Japan dem Welthandel. Im Zuge der Meiji-Restauration wurde 1868 wie zuvor in Rußland auch in Japan das Eigentum an Grund und Boden eingeführt, vier Jahre später auch eine neue Währung. Der Yen unterlag dem Dezimalsystem $(100$ sen $=1 ¥)$ und wurde statt in Silber in Gold geprägt. Japan ging also de facto zum Goldstandard über, gleichzeitig mit Deutschland. Und während das Deutsche Reich aus seinem Krieg mit Frankreich 1870/71 Reparationen in Gold erhielt, zogen die Japaner ihren Nutzen aus ihrem gewonnenen Krieg gegen China 1894. Beide Länder folgten damit dem Beispiel des klassischen Industrielands England, dessen Goldwährung auch die Grundlage für Marx' Theorie lieferte. Die Bank von Japan, 1881 gegründet, mußte ab 1899 ihre Noten in Gold einlösen. Nur in China hielt sich die Silberwährung noch bis in die 30er Jahre des 20. Jahrhunderts.

Die neue Meiji-Verfassung von 1889 war der deutschen Reichsverfassung von 1871 nachempfunden, und auch die neuen ökonomischen Rechtsformen waren der westlichen Vertragskultur entlehnt. Das neue Handelsgesetz von 1893 schuf die Grundlage für Kapitalgesellschaften. Städtische Kaufleute konnten nun industrielle Konglomerate zusammenkaufen. Gleichzeitig fanden traditionelle Regeln und Werte Eingang in den modernen Geschäftsbetrieb. Zwar war die Metalldeckung des japanischen Yen von Anfang an großen Schwankungen unterworfen: Sie fiel insbesondere zur Finanzierung der Kriege gegen Rußland 1905 und gegen die asiatischen Länder 1940, sie stieg im Ersten Weltkrieg, als Japans Exportindustrie profitierte. Aber gerade diese Instabilitäten der Währung in Kriegszeiten begünstigte die Entstehung der großen Firmenkonglomerate und Finanzcliquen (zaibatsu), die sich bis über den Zweiten Weltkrieg retten sollten. 
„Nach 1900 boten diese Familien, jetzt in Form der zaibatsu-Industriellen, das Bild des kultivierten Geldadels. Sie häuften Reichtum an, bauten Villen, sammelten Kunstschätze. Aber diese Gruppe von Reichen unterschied sich ganz deutlich von den sogenannten Neureichen, die im ersten Viertel des 20. Jahrhunderts auftraten. Kriegsgewinnler und Spekulanten nach dem RussischJapanischen Krieg von 1904/05 wurden erstmals als narikin, als ,Neureiche“, bezeichnet. Ihre große Zeit brach aber erst mit dem Ersten Weltkrieg an. Mit narikin verband man dann bald den rasch erworbenen Geldreichtum, aber auch Extravaganz, ausschweifenden Lebenswandel und Verschwendungssucht sowie Mangel an Kulturverständnis. Die Neureichen hatten auch keine Skrupel, ihr Geld in die Politik einzubringen. ${ }^{“ 25}$

In der Zwischenkriegszeit boomte die Literatur, die zur Börsenspekulation anhielt. Der Schwarze Freitag hielt die Japaner nicht von ihrer Spielsucht ab. Die Gier nach individuellem Reichtum stand im Konflikt mit den Regeln des traditionellen ie-Systems, in dem Reichtum immer an ein Haus gebunden war. Während die narikin oft ihr erworbenes Vermögen schnell auch wieder verloren, investierten die zaibatsu es vorausschauend immer wieder in Immobilien und Grundstücke. Schon im 19. Jahrhundert hatten die Kaufmannsfamilien Mitsui und Mitsubishi die Meiji-Reformer großzügig unterstützt. Dabei war der Öffentlichkeit der Einfluß dieser zaibatsu bewußt. Spöttisch sprach man von der MitsuiPartei (seiyûkai) und der Mitsubishi-Partei (minseitô). Ihr politischökonomisches Interesse galt vor allem den Rohstoffen und Märkten der von Japan eroberten - und zu erobernden - Länder. Im Jahre 1914 kam die „Siemens-Affäre“ ans Licht. Vertreter der deutschen Firma hatten „Kommissionen“ an Marineoffiziere gezahlt, um Rüstungsaufträge zu erhalten. Doch damit nahm die Geschichte der politischen Korruption im Japan des 20. Jahrhunderts erst ihren Anfang.

\section{Dividuum und Dividende:}

\section{Strukturelle Koppelung als strukturelle Korruption}

Die Bestechung von Politikern ist auch nach dem verlorenen Weltkrieg aus dem politischen System Japans nicht wegzudenken. Bei den Protesten gegen die Verlängerung des japanisch-amerikanischen Sicherheitsvertrages 1960 stellte die yakuza, die japanische Mafia, den Konservativen Geld, Schlägertrupps und sogar Wählerstimmen zur Verfügung. Kishi Nobusuke, Nachfolger des berühmten Nachkriegspremiers Yoshida Shigeru, des ,japanischen Adenauer“, peitschte den Vertrag im Alleingang durchs Parlament und trat zurück. 1976 wurde der ehemalige

25 Pauer 1990: 48 und 1998. 
Regierungschef Tanaka Kakuei verhaftet. Er hatte von der Firma Lockheed zwei Millionen Dollar erhalten. In seiner Amtzeit kaufte die All Nippon Airways das Lockheed-Flugzeug Tristar. Der ehemalige Repräsentant von Lockheed in Japan, der notorische Rechtsradikale Kodama Yoshio, erhielt sogar sieben Millionen Dollar, die in der Regierungszeit Tanakas offenbar in einen Geheimfonds der LDP flossen.

Eine ganz neue Größenordnung der politischen Korruption eröffnete allerdings der Recruit-Cosmos-Skandal 1988. Im Juni wurde bekannt, daß der Medien- und Immobilienkonzern Recruit ausgewählten Vertretern aus Politik und Verwaltung Aktien seiner Immobilien-Tochter Recruit Cosmos zum Vorzugspreis überlassen hatte. Ein Dutzend LDPund fünf Oppositionsabgeordnete griffen $\mathrm{zu}$ - die meisten natürlich mit einem Kredit der Recruit-Finanzierungsgesellschaft First Finance. Aber auch ehemalige Staatssekretäre, Arbeitgebervertreter und einflußreiche Journalisten standen auf der Liste des Recruit-Chefs Ezoe Hiromasa. Die Insidergeschäfte waren legal, die Gewinne daraus großenteils steuerfrei.

Im Zuge der Ermittlungen offenbarten sich Ezoes Interessen, einerseits als Aufsteiger, Gönner und Partner in führenden Kreisen akzeptiert zu werden, andererseits aber auch konkrete Gesetze zu beeinflussen. Der Kreis der durch Aktiengeschenke Begünstigten erwies sich als so weitreichend, daß der politische Druck Regierungschef Takeshita Noboru im April 1989 zum Rücktritt zwang. Seine LDP verlor nach 38 Jahren ununterbrochener Regierungszeit (55er System) die Mehrheit im Unterhaus. Der Recruit-Skandal ist deshalb ein Meilenstein in der politischen Geschichte Japans. Erstmals machte eine Firma mit Aktien statt mit Geld ihren Einfluß geltend. Er belegt daher die Umstellung der japanischen Korruption von der Industrieförderung auf die staatliche Protektion der Finanzspekulation.

Die japanische Öffentlichkeit ist gegenüber politischer Korruption tolerant. Auch der Recruit-Cosmos-Skandal hat daran nichts geändert. Die LDP hat ihre Mehrheit im Unterhaus schon 1997 wiedererlangt. Die Parteien selbst finanzieren sich im wesentlichen aus „Spenden“ der Privatwirtschaft, und auch die Abgeordneten sind nicht nur individuell gewählt, sondern „erben“ in gut einem Fünftel der Fälle (1994) ihren Wahlkreis von ihren Vätern oder Schwiegervätern. Dabei greifen der Regionalismus des Wahlsystems, der ländliche Gebiete begünstigt, und der Finanzbedarf der Kandidaten im Wahlkampf ineinander. Gewonnen wird nach dem sanban-Prinzip: Der Sieger braucht eine lokale Hochburg (jiban), ein bekanntes Gesicht (kanban) und eine prallgefüllte Geldtasche (kaban).

Die japanische Politik ist fest in der Hand des „Eisernen Dreiecks“ aus Wirtschaft, Politik und Ministerialbürokratie. Als fixe Kanäle 
der effektiven Kommunikation dienen paipu (vom englischen pipe) oder kone (von connection), die oft zurückreichen bis zur gemeinsamem Hochschulzeit der Beteiligten, zumeist an der renommierten Universität Tokio. Politiker werben auf Fund Raising-Parties nach amerikanischem Vorbild offen um das Geld der Firmen in ihrem Wahlkreis für ihren Wahlkampf. Auf nationaler Ebene verteilt die keidanren (keizai dantai rengôkai, Vereinigung der Wirtschaftsorganisationen) indirekt erhebliche Mittel an die LDP. Auch für ausscheidende Spitzenbeamte ist gesorgt: Wenn sie schon mit Anfang 50 in Pension gehen, wechseln sie oft als amakudari (vom Himmel Herabgestiegene) zu Privatunternehmen und nutzen weiterhin ihre persönlichen Kontakte bei der Vergabe öffentlicher Aufträge. Auftraggeber und Bieter treffen sich zur Preisabsprache (dangô), hebeln den Wettbewerb aus und teilen den Markt unter sich auf. Daß alle bescheid wissen und damit erpreßbar sind, stabilisiert das Eiserne Dreieck zusätzlich. ${ }^{26}$

Die Geschichte der Skandale in Japan geht weiter. Die Pleite des Wertpapierhauses Nomura 1997 war der letzte Höhepunkt. Gleichzeitig stehen die Weichen im internationalen Geldhandel auf Akkumulation und Fusion. Das japanische System des Austauschs zwischen Wirtschaft und Politik mag man daher beklagen. Es bietet aber auch die Chance, eine systemtheoretische Formel zu korrigieren - und die Aufdeckung des politischen Finanzskandals um die deutsche Regierung Kohl leistet dabei Hilfestellung. Die These der Systemtheorie, die strukturelle Koppelung zwischen Wirtschaft und Politik werde in erster Linie durch Steuern und Abgaben erreicht, läßt sich nicht empirisch untermauern. ${ }^{27}$ Die Schwarzkonten sind der blindeste Fleck der Systemtheorie. Gerade in der globalisierten Gesellschaft, in der zahlreiche Unternehmen und Aktienbesitzer sich ihrer Besteuerung entziehen, ist vielmehr die strukturelle Korruption der wichtigste Kommunikationskanal zwischen Politik und Wirtschaft. ${ }^{28}$ Damit gelingt es der modernen Gesellschaft, ihre interne Machtverfassung von der materiellen Ebene der physischen Gewalt auf die informative Ebene des bezifferbaren Geldbesitzes zu ver-

26 Zur Funktionsweise des Eisernen Dreiecks s. Blechinger 1998: 196-218. Sogar der Standardausdruck für Korruption in Japan wurde nach dem Krieg nachweisbar „,neutralisiert“: Der Oberbegriff seijioshoku (politische Korruption) ersetzte in den 70er Jahren zusehends das ältere, noch moralisch anrüchige Wort seijifuhai. Er markiert also den Übergang zur normalisierten, tolerierten und strukturellen Korruption. A.a.O. 62.

27 Luhmann 1997: 781.

28 Die Soziologie darf hier nicht das Reflexionsniveau der Massenmedien unterbieten. Die Japan Times vom 20. Februar 2003 schreibt auf Seite 2: „Talks may focus on but won't solve fundraising scancals. [...] Yet lawmakers in the ruling camp seem to be reluctant to implement reforms. Prime Minister Junichiro Koizumi, president of the LDP, is no exception. ,No matter how many laws you draw up, politicians will violate them.““ 
lagern. Das heißt im Umkehrschluß: Die Theorie darf sich nicht auf die kasuistische Beobachtungsroutine der Massenmedien herablassen, sondern muß auf das latente Rauschen in ihrem Beobachtungsmodus ein forensisches Team ansetzen.

\subsection{Macht und Massenmedien, Beschreibung und Beschriftung - interkultureller Grenzgang zwischen System und Subjekt}

\section{Politische Verpackungskultur: das Autoskript des Leviathan}

Die Massenmedien beobachten und kontrollieren nicht einfach, sondern verpacken das politische System. Sie stellen symbolisch seine Einheit auf informativer Ebene her, sie regulieren die Balance zwischen System und Subjekt kommunikativ. Sie entschärfen den politischen Diskurs, dämpfen ihn ab, verwandeln die Gewalt in Kommunikation und bestätigen damit den Triumph der Knappheit: Obwohl es Güter und Ereignisse im Überfluß gibt, sind Geld und Nachrichten immer knapp. Das demokratische Ritual der Mediendialektik macht den Zuschauern ihre Entmündigung auf Zeit schmackhaft. Das politische Funktionssystem legt sich eine aufwendige, regelmäßige Hülle zu, auf der die politischen Zeichen entlangfließen können. Sie bestehen eben nicht nur aus Nachrichten: BBC, CNN, ZDF, sondern auch aus Worthülsen, Festakten und repräsentativen Bauten. Deshalb wird auch der Reichstag in Berlin jeden Tag zum Objekt der Verpackungskunst.

Besser noch als im alten Europa ist diese mediale Schrift in der japanischen Verpackungskultur zu lesen. Schon Ende des 19. Jahrhunderts bemühte sich die Meiji-Regierung um die Revision der „ungleichen Verträge" und den raschen Anschluß an zivilisierte Standards des Politischen. Sie errichtete 1883 das Rokumeikan, ein Gebäude für Feste und Empfänge im westlichen Stil, um die Fortschrittlichkeit des Landes zu demonstrieren. Im Jahre 1886 wurden dann die Berliner Architekten Hermann Ende und Wilhelm Böckmann mit dem Bau eines Parlamentsgebäudes samt Kuppel nach dem Vorbild des Reichstags in Berlin beauftragt. Realisiert wurde jedoch nur eine vereinfachte Version aus Holz, die 1891 niederbrannte. Die Deutschen bauten später auch den Tokioter Justizpalast und planten weitere Ministerien. ${ }^{29}$ Doch während sich das politische System einen fortschrittlichen Anstrich gab, wurde das allgemeine Wahlrecht für Männer erst im Jahre 1925 eingeführt.

Das politische System Japans agierte also von Anfang an in relativer

29 Heinze 1999. 
Abgeschiedenheit von der Öffentlichkeit. Weder haben Stadtmauern aus „Fleisch und Stein“ (Sennett) einen politischen Entfaltungsraum aus seiner Feudalgesellschaft herausgeschnitten, noch haben Kirchen, Rathäuser oder Marktplätze das Volk ins Zentrum der Gesellschaft projiziert. Auch steht dem Privatleben am Stadtrand kein öffentliches Leben im Zentrum gegenüber. Öffentlichkeit und Privatleben sind in Japan nicht durch formale, kontextunabhängige Regeln polarisiert. Schon der Begriff „öffentlich“ ist gespalten: ôyake heißt „öffentlich“ (oder draußen auf der Straße) als Gegensatz zu ,privat“, ,persönlich“ (kojinteki), kôkyôteki heißt „öffentlich“ (oder staatlich) im Gegensatz zu ,privatwirtschaftlich“(shiritsu). Und aufgrund dieser Spaltung des Begriffs der Öffentlichkeit und der Schichtung des Raumes konnte in Japan keine Ideologie der Öffentlichkeit als Souverän des Staates Platz greifen.

Politische Entscheidungen fallen in Japan nicht nur unter Ausschluß der Öffentlichkeit, sondern unter Ausschluß der normativen Vorstellung öffentlicher Kontrolle. Für diese Art der Geheimgespräche gibt es einen eigenen Ausdruck: dangô (Geheimgespräche). Der erreichte Konsens (gôi) hat Bestand, und darauf kann sich die Öffentlichkeit verlassen. Zwar sind die Aussagen und Spots der Parteien und Politiker völlig unverbindlich, zwar stagniert die Wahlbeteiligung bei 63\% (bei den Wahlen zum Unterhaus im Juni 2000), zwar blüht die politische Korruption. Aber die Öffentlichkeit hat dieser Machtverteilung und Einparteiendemokratie - ebenso wie die Frauen der Machtverschiebung zugunsten der Männer in den pristinen Gesellschaften - im entscheidenden Augenblick zugestimmt. ${ }^{30}$ Die Thesen der Systemtheoretiker Luhmann und Fuchs: die Irreduzibilität des Sozialen und die japanische Dividualität, greifen hier exakt ineinander. Der Reiz, den die Massenmedien auf die Theorie ausüben, liegt daher in ihrer dezidierten Dysfunktionalität. Ihr diskursiver Spielraum weist über die selbstreferenziellen Zirkel der Systeme (und der Nachrichten) hinaus.

\section{Vom Outsourcing der Öffentlichkeit zum Outing des Intimen - vom Verlust der Einheit der Welt zum Gewinn ihrer Medialität}

Schon Marx hat gezeigt, wie das Prinzip des äquivalenten Tausches die Ware Arbeitskraft subsumiert und gerade dadurch die Gerechtigkeit des Tausches unterminiert. In der Informationsgesellschaft aber vollzieht

30 Das weiß sogar die Campari-Werbung, auf der neben der Flasche eine Frau in rot posiert. Ihr Text arbeitet mit der doppelten Bedeutung des Wortes gôi, das „Besprechung“ oder „Konsens“ heißt, aber auch das Gegenteil von sekuhara (sexual harrassment) meinen kann: einvernehmlichen Sex. カンパリは、合意の上で。Red Sensation. Campari.

Auf die Einigung (zwischen den Verhandlungspartnern)!! Red Sensation. 
sich eine Enteignung zweiter Ordnung: Die Medialisierung des einheitlichen Weltbildes. In der Romantik wird dieser Verlust der Welt zum ersten Mal offenbar. Die Liebe zur Natur, zur Mutter und zur Geliebten erfährt eine Aufwertung, sie muß das Bedürfnis nach jener Einheit der Welt stillen, die real zerbrochen ist. Aber kann sie das? Saugt sich ihre romantische Idealisierung nicht vielmehr selbst an Medien der Kommunikation fest: Briefen, Romanen, Briefromanen? Und hat nicht eben jener Textstoff zugleich der Systemtheorie die Chance geboten, Liebe vom Bedürfnis des Subjekts zum Medium der Kommunikation zwischen psychischen Systemen umzuschreiben (Kapitel 1.3)? Und: Wie sollen sich Subjekte politisch vereinigen, die sich kaum in ihren intimen Beziehungen der Einheitlichkeit ihrer Welt rückversichern können? Wie interagieren Dividuen auf der Bühne der Öffentlichkeit?

Solange man die bürgerliche Gesellschaft alteuropäisch als eine Gesellschaft von selbstbewußten Subjekten beschreiben konnte, mußten auch die Massenmedien als ihr verlängerter Arm zur Kontrolle der politischen Machtausübung definiert werden. Folgt man dem Ideal der Medienethik und des investigativen, aufklärenden Journalismus, so finden sich z.B. im Hinblick auf den Watergate-Skandal sogar in den USA Wurzeln einer Semantik der ,vierten Gewalt“. ${ }^{31}$ Aber gerade in Amerika hat sich mit dem Wahlkampf von 1980 das politische System radikal selbst seines Erscheinungsbildes in den Massenmedien angenommen. Mediaplanung und Public Relations sind in den Fernsehwahlkämpfen an die Stelle des Investigative Reporting getreten, meßbare Beliebtheitsund Bekanntheitsgrade von Politikern bestimmen das Barometer, professionell konstruierte Images von Produkten und Logos schieben sich über die klassische, neutrale Information.

Weder ist die Normativität von Moral und Ethik im System der Massenmedien durchzuhalten, noch erlauben sie einen summenkonstanten Transfer aufklärender Information. Seit der nationalen Debatte um den weißen Fleck auf dem Kleid der Praktikantin im Weißen Haus läßt sich auch umgekehrt argumentieren: Die Potentiale der Empörung sind gering, der Programmwechsel häufig, das Gedächtnis des Pub-

31 Redelfs 1996. Für die japanische Seite ergänzt Abe: „Das wichtigste und wirksamste Mittel gegen Korruption ist die öffentliche Meinung. Und um diese Meinung deutlich vertreten zu können, bedarf es wohl einer gründlichen Selbstreflexion in der Bevölkerung. Aufgrund der Erfahrungen in Japan möchte ich sagen, daß die Korruptionsaffären eines Landes tief in der Mentalitätsstruktur der Gesellschaft verwurzelt sind. Es ist evident, daß das Geschenk- und Gegengabesystem nicht abgeschafft werden kann. Wenn sich aber die Bevölkerung der Problematik des Geschenk- und Gegengabesystems bewußt ist, wird es nicht schwer sein, über den Geschenkaustausch zwischen der Wirtschaft und den Politikern eine strenge Aufsicht zu führen." Abe 1992: 247. 
likums kurz, der ökonomische Druck auf das Medium selbst nicht zu hintergehen. ${ }^{32}$ Der Schematismus Wissen/Nichtwissen ist zu einfach, um den Zusammenhang zwischen Bewußtsein und System zu beschreiben. Mehr noch: In diesem neuen Mediensystem können gerade Skandale die Medienpräsenz erhöhen und den Bekanntheitsgrad steigern: Politiker müssen Stehvermögen haben. Die Grenze zwischen Kritik und Werbung zerfließt, beide verschmelzen im kommunikativen Brei der PR-Plattformen. ${ }^{33}$ Kosequent definieren Merten/Westerbarkey PR als Konstruktion wünschenswerter Wirklichkeiten für die medialisierter Öffentlichkeit der postindustriellen Informationsgesellschaft:

„PR unternehmen kommunikative Anstrengungen aller Art zur Erzeugung und Verbreitung von Kommunikation, sie betreiben Dialog, um damit Dialoge anzustoßen. Diese Funktion stellt sie - verglichen mit anderen, professionellen Kommunikatoren in Journalismus und Werbung - a priori und definitiv auf eine hierarchisch höher angesiedelte Meta-Ebene, die von anderen Kommunikatoren gar nicht eingeholt werden kann: Sie sind Meta-Kommunikatoren, die entscheiden, was, wann, wo, wie und mit welcher gewünschten Wirkung kommuniziert werden soll. Dafür steht eine Fülle von Strategien zur Beeinflussung von Öffentlichkeit und von Teilöffentlichkeiten zur Verfügung: Neben der klassischen Werbung und dem Vertrieb eigener Medien vor allem die vorgeschaltete Ansprache von Journalisten, die Verfassung von Pressematerialien, das Abhalten von Pressekonferenzen, die Einbindung und Darstellung von Meinungsführern, Multiplikatoren und Trendsettern, Aktions-PR, Sponsoring und anderes mehr.“34

Während in der feudalen Agrargesellschaft der Transport materieller Güter das wichtigste Problem war und in der Industriegesellschaft die Gewinnung von Energie, stößt die postmoderne Informationsgesellschaft auf die mediale, immaterielle Ebene vor. Sie „switcht“ von Warenproduktion und Äquivalenz auf Kommunikation und Differenz, ihre Systemlogik verfaßt die Macht neu. Nicht mehr Stände oder Klassen oder wahlberechtigte, männliche Bürger üben sie aus, sondern ein abstraktes politisches System, das sich im Rahmen funktionaler Differenzierung selbstreferenziell gegen seine Umwelt abschließt und von den unmittelbaren Zielen, Wünschen und Gedanken seiner Umwelt (und seiner Mitglieder) emanzipiert. Am Ende können Kandidaten Präsident werden, obwohl die Mehrheit der Wahlberechtigten nicht gewählt hat und die Mehrheit der Wähler einen anderen Bewerber.

32 Deutsche Zeitungsverlage z.B. erzielen mit dem bloßen Abdruck einiger Bingo-Zahlen auf der ersten Seite immense Steigerungen der Auflage.

33 Neckel 1989: 76.

34 Merten/Westerbarkey 1994: 209. 
Wer sich heute beim Kaufen und Bezahlen den Codes der Scheckkarten, dem virtuellen Geld ohne materielles Äquivalent verschreibt, muß sich auch als Wähler für Programme entscheiden, deren Finanzquellen im dunkeln bleiben. Und selbst wenn eine Parteispende öffentlich zum Skandal wird, ist ihre massenmediale Verarbeitung längst Routine. War die bürgerlich-städtische Öffentlichkeit noch einheitlich definiert, so zerfällt die Öffentlichkeit heute in Teilbereiche, Subgroups, juristische, politologische und ökonomische Definitionen: Wähler, Kunden, Demonstranten, Meinungsforscher und Image-Berater, die den demoskopischen Spiegel halten. Das Internet wird diese Teil-Öffentlichkeiten weiter zersplittern. Das Subjekt Öffentlichkeit, das sich aus der Bleiwüste der Tageszeitung informiert und Werbung nicht mag, stirbt auf der Datenautobahn. An dieser Stelle greift die Systemtheorie mit ihrer These von der Uneinheitlichkeit der Welt zu.

Während sie triumphierend Emergenz und Autopoiese beobachten kann, laufen die Kosten dafür in der Subjekttheorie auf. Daß das psychische System in einer komplexen Welt lebt, ist selbstverständlich. Aber dem Subjekt bereitet sie Kopfzerbrechen. Zunehmend einer unpersönlichen Umgebung ausgesetzt und im urbanen und globalen Kontext von Medien umzingelt, ist es gezwungen, sich zusehends mit sich selbst zu beschäftigen. Logischerweise kombiniert daher Richard Sennett die Zerfallstheorien der Öffentlichkeit mit der Sozialpsychologie des Narzißmus. ${ }^{35}$ Der massenmediale Diskurs ist selbst höchst personalisiert und intimisiert: Was die Leute am meisten interessiert, sind Leute. Dieses narzißtische Muster schlägt bis in die politischen Nachrichten durch. Statt politischer Ziele und Programme wird die Glaubwürdigkeit der Kandidaten und ihr Privatleben erörtert. Die Massenmedien lösen sich von ihrer ursprünglichen Funktion der politischen Kontrolle und investigativen Recherche und widmen sich in Teleromanzen und Talkshows den psychischen Mustern von auf sich selbst verwiesenen Individuen. Diese innere Zivilisierung der Gesellschaft überschreitet schließlich jede kommunikative Schamgrenze. ${ }^{36}$ Wenn das Outing des Intimen an die Stelle der politischen Debatte tritt, ist das Outsourcing der Öffentlichkeit perfekt. Hier schließt die systemtheoretische These an, daß komplexe Funktionssysteme sich selbstreferenziell abschotten und die psychischen Systeme als bloße Umwelt oder Turbulenzquellen behandeln.

35 Sennett 1983, 1995. Das belegt auch der weltweite Siegeszug der TV-Serie „Dallas“. Nur in Japan fiel sie interessanterweise durch.

36 Das Buch zur Sendung eines der populärsten nächtlichen Hobbytherapeuten der deutschen Medienlandschaft trägt einen bezeichnenden Titel. Jürgen Domian: Jenseits der Scham. Köln 1998. 
Mediendualismus zweiter Ordnung: Hausmacht und Außenhaut

Diese Klage über den Verlust der Einheit der Welt rückwärts lesen hieße: den Gewinn der medialen Einheit der Welt verbuchen. Mit anderen Worten: Die Massenmedien bergen die Möglichkeit zu einem medientheoretischen Grenzgang zwischen Subjekt und System. Zwar müssen die systemtheoretischen Ansätze zur Beschreibung der Massenmedien auch angesichts der Kommerzialisierung der Medienwelt immer wieder auf die Logik der Ökonomie und die Differenz von Zahlung und NichtZahlung zurückgreifen:

„Weil Werbung in entscheidender Weise an die Ausdifferenzierung des Wirtschaftssystems gekoppelt ist und wie die Wirtschaft die ,Sprache des Geldes' spricht, wird sie zum einen als eigenständiges Subsystem des Wirtschaftssystems modelliert (so bei Schmidt und Spieß 1996). Legt man dagegen den Hauptakzent der Beobachtung auf die Funktion ausdifferenzierter Sozialsysteme, der modernen Gesellschaft Informationen über sich selbst zu erlauben, dann bietet sich als Theorieentscheidung an, die Werbung als ein eigenständiges und autonomes gesellschaftliches Funktionssystem zu konzipieren (so bei Zurstiege 1998). Wie immer die theoretische Entscheidung ausfällt: Unbestritten ist in beiden Ansätzen, daß Werbung - ob als Produktwerbung oder als Sozialwerbung - nach ökonomischen Gesichtspunkten operiert. Werbung, für die nicht bezahlt wird, verfehlt die Systembedingungen des Werbesystems. “37

Aber genau dieser Weg soll hier nicht beschritten werden. Vielmehr liegt die Theorieentscheidung dieser Arbeit darin, die Massenmedien samt Werbung als äußere Häute und Verpackungen der Systeme ihren inneren Kommunikationsmedien Macht und Geld gegenüberzustellen. Die Erkenntnis, daß auch Werbung (vom Auftraggeber) bezahlt werden muß, ist geschenkt. Theoretisch läßt sie sich aber gerade aufgrund ihrer kommunikativen Entropie auch als Geschenk begreifen.

Diese Chance ergibt sich strukturlogisch aus der Radikalisierung der Grundannahmen der Systemtheorie selbst. Denn sie führen im Falle der Massenmedien in ein Dilemma. Von außen besehen: Hätten sich die Systeme tatsächlich ganz von den Subjekten in ihrer Umwelt entkoppelt (Irreduzibilitätsthese), dann hätten sich die Massenmedien nicht ausdifferenzieren müssen. Die Gesellschaft wäre dann allein über Macht verfaßt, ohne jede Kontrolle oder Gegenmacht. Eine solche Annahme ist aber schon auf der untersten Ebene der Systembildung: für das intime Verhältnis der Geschlechter, abwegig. Von innen betrachtet: Gerade weil

37 Schmidt 1996: 234f. 
es den Funktionssystemen gelungen ist, sich selbstreferenziell gegen Irritationen aus ihrer Umwelt abzuschließen, brauchen sie ein Autoskript, eine Verpackung, eine Schrift der Identität, um sich zu den Subjekten und ihrem Bewußtsein in Differenz zu setzen. Dann aber ist dieses Autoskript auch medientheoretisch zu entziffern.

Solange die Massenmedien lediglich als ein System unter vielen fungieren, führt ihre Analyse selbstreferenziell ins Theoriesystem der Systemtheorie zurück. In diesem Fall bleibt ihre Besonderheit bescheiden: Sie können beobachten, aber nicht ihren Beobachtungsmodus reflektieren. Begreift man sie jedoch als äußere Schreibfläche der Funktionssysteme Politik und Ökonomie, erschließen sie eine theoretische Anschlußstelle. Indem die Massenmedien nicht nur als ein weiteres Funktionssystem unter anderen oder einfach als Teil des Wirtschaftssystems begriffen werden, eröffnen sie den theoretischen Spielraum fürs Subjekt, der ihm auch den Zugang zu den Systemen und ihrer Theorie freihält.

Wenn sich das Funktionssystem von den Idiosynkrasien der Subjekte emanzipiert, dann bezahlt es dafür einen kommunikativen Preis. Es kann den blinden Fleck seiner Autopoiese nicht intern kommunizieren und muß ihn daher externalisieren. Die verdrängte Grundbedingung der komplexen Systembildung schlägt nach außen durch. Luhmann hat daher vordergründig recht: Den Massenmedien selbst als System ist ihre Funktion nicht einsichtig. ${ }^{38}$ Aber diese Aussage wirft einen subjekttheoretischen Schatten, denn für Subjekte gibt es keine solche kognitive Grenze. Will das System sich daher gegen die Subjekte stabilisieren, muß es ihrem Bewußtsein eine Latenz einschreiben. Diese Funktion erfüllen die Massenmedien im tagespolitischen Diskurs. Das Autoskript des Funktionssystem wird daher auch lesbar als Bewußtseinslatenz der Subjekte.

Die Theorie der Massenmedien als subtile Grenzmarkierung des politischen Systems gerät daher automatisch auch zu einem paradoxen Grenzgang der Theorie autopoietischer Systeme. Die massenmediale Inkommunikabilität der autopoietischen Geschlossenheit der Funktionssysteme artikuliert auf der latenten Schattenseite zugleich die Grenze der Funktionssysteme als Grenze subjektiver Handlungshorizonte. Die Massenmedien stabilisieren das Funktionssystem, eröffnen aber auch diskursive Spielräume nach beiden Seiten. Die Bewußtseinslatenz der Subjekte ist die Kommunikationslatenz der Systeme. Aber noch einmal: Während die Kommunikationslatenz der Systeme ihre Struktur schützt und (außer durch Luhmann selbst) inkommunikabel ist, schuldet sich die

38 Luhmann 1996: 188. 
Bewußtseinslatenz der Subjekte äußeren, objektiven Faktoren, die sich nicht von selbst der Kommunikation entziehen.

Statt daher am Ideal des unbeschädigten Lebens und der Öffentlichkeit der Subjekte festzuhalten, muß die Medientheorie diese Latenzen in ihren Text integrieren: lesen. Sie muß Luhmanns Medientheorie hinter sich lassen und die systeminternen Kommunikationsmedien Macht und Geld ergänzen um die systemexternen politischen Massenmedien samt Werbung. Dann wird sich zeigen, ob die latente Kommunikation der Massenmedien, ihre Unfähigkeit, ihre eigenen Beobachtungsmuster zu reflektieren, nicht zu einer Kommunikation dieser Latenz herausfordert, die dem Protokollanten (nicht Autor) des Theoriesystems sanft den Griffel führen kann.

\section{Kommunikationslatenz und Bewußtseinslatenz: Grenze zwischen Autopoiese und Autonomie}

Der Verlust der Welt hat sich mit der fortschreitenden funktionalen Differenzierung der Gesellschaft potenziert. Die Einheit der Welt oder Gesellschaft ist in der systemtheoretischen Argumentation unerreichbar. Jedes System muß sie jeweils für sich selbst herstellen. Politik und Wirtschaft reproduzieren diese Einheit in ihren internen Codes: Zahlen und Entscheiden, Geld und Macht. Auch kommunizieren können die Systeme nicht mehr miteinander, sondern nur noch mit dem System der Kommunikation, das seine eigene Realität schafft. ${ }^{39}$ Öffentlichkeit, in viele Teile zersplittert, ist nurmehr als Reflexion gesellschaftsinterner Systemgrenzen definierbar.

Diesem Verlust der Einheit der Welt steht jedoch der Gewinn ihrer Medialität gegenüber. „Was wir über unsere Gesellschaft, ja über die Welt, in der wir leben, wissen, wissen wir durch die Massenmedien“, sagt auch Luhmann. ${ }^{40}$ Ohne dieses Wissen ist keine komplexe Gesellschaft zu betreiben. Gerade im Fall der Massenmedien treffen daher die kommunikative Machtgrenze des politischen Systems und seine massenmediale Grenze zur Öffentlichkeit aufeinander: Sie bilden den Hautkontakt zwischen System und Subjekt, Kommunikation und Bewußtsein. Luhmann nennt ihn Interpenetration: Der Operationsbereich einer Organisation übernimmt die Grenzen des Bewußtseins seiner Mitglieder, umgekehrt können diese operativen Grenzen eines Systems in das Bewußtsein eines beobachtenden, psychischen Systems hineinfallen. Das Bewußtsein kann demnach die Grenzen sozialer Systeme entweder tragen oder unterlaufen, gerade weil die psychischen keine sozialen

39 Fuchs 1992: 89-100. Fuchs 1993: 34-36.

40 Luhmann 1996: 9. 
Systemgrenzen sind. Luhmann resümiert: „Das Gleiche gilt im umgekehrten Fall: Die Grenzen psychischer Systeme fallen in den Kommunikationsbereich sozialer Systeme. Kommunikation ist geradezu dazu gezwungen, sich laufend daran zu orientieren, was psychische Systeme in ihr Bewußtsein bereits aufgenommen haben und was nicht. “41

Für die Massenmedien potenziert sich daher das Problem des blinden Flecks. Sie sind in besonderem Maße auf Beobachtung spezialisiert und beobachten auch mit besonderer Aufmerksamkeit das Bewußtsein ihrer Rezipienten, um deren Aufmerksamkeit zu erlangen, die immer knapp ist. Aus subjekttheoretischer Sicht gibt es dagegen keinen Grund, den Massenmedien von vornherein die Fähigkeit abzusprechen, die das Wissenschaftssystem hat und die auch dort auf den kognitiven Fähigkeiten der Subjekte beruht. Vielmehr beruhen die kommunikativen Grenzen des Systems der Massenmedien auf den kognitiven Grenzen der Subjekte. Aus der Systemtheorie heraus läßt sich daher die Kommunikationslatenz der Massenmedien schlechterdings nicht erklären, sondern allenfalls beschreiben. Der Strukturschutz, über den die Systeme ihre Autopoiese sicherstellen, ist im Falle der Massenmedien Kommunikationslatenz und Bewußtseinslatenz zugleich.

Die Systemtheorie gerät daher im Falle der Massenmedien in ein fatales Dilemma. Entweder: Sie erklärt die Welt zum Text, zur Kommunikation ohne handelnde Autoren. Dann bewegt sich die Theorie durch den digitalen Raum der Software: Blindflug. Oder mit Baudrillard: „La guerre du golf n'a pas eu lieu.“ Aber das ist empirisch falsch, und auch die Computer-Kids landen über kurz oder lang auf dem harten Boden der Realität: Game over. Um im Text zu bleiben, werden die Übeltäter dem Rechtssystem überstellt und können sich dort wie de Sade als Literat betätigen. ${ }^{42}$ Oder: Die kommunikativ latent gehaltene Autopoiese muß auch im Bewußtsein der Subjekte eine Spur hinterlassen, eine Spur der latenten, unbewußten Kommunikation zwischen System und Subjekt. In diesem Falle aber dürfen die Massenmedien nicht als soziales System beschrieben werden, sondern sind als Autoskript der Systeme zu lesen. Die Theorie ist dann nicht mehr der universelle Autor des Kommunikationssystems Gesellschaft, sondern der lauschende Parasit eines histori-

41 Luhmann 1984: 295. Vgl. daher auch Fuchs 1993: 33-38.

42 Fälle virtuellen Wahns sind häufig und werden gerade von den Medien gerne zitiert, man denke nur an den Film „Matrix“. Am 23. Juli 1999 betätigte sich der 31 jährige Nishizawa Yuji als Matthias Rust zweiter Ordnung. Er entführte einen Jumbo-Jet der ANA, setzte sich ans Steuer und wollte unter der Tokioter Rainbow-Bridge hindurchfliegen. Er habe am Simulator geübt und Selbstvertrauen, sagte er. Leider enden solche Fälle virtuellen Wahns oft tödlich, in diesem Falle starb der Pilot. Hinter dem Spiel steckt also eine reale Pathologie, die der unterkomplexen Beobachtung der Medien zumeist entgeht. 
schen Rendezvous'. Damit ist die theoretische Grundannahme des vorliegenden Protokolls umrissen: Indem die Massenmedien sich zwischen System und Subjekt ansiedeln, lassen sie sich auch als Autoskript, als Schreibfläche, als Haut systemischer Identität verstehen.

Die Massenmedien, insbesondere die kommerziellen, lügen und manipulieren nicht, sondern spiegeln genau das Reflexionsniveau und die kognitiven Grenzen der Subjekte. Ihre Kommunikation ist tatsächlich eingebettet in die Lebenswelt, sie sind wie die Wissenschaft auf das Bewußtsein der Subjekte angewiesen und kulturabhängig. Doch die kognitiven Grenzen dieser Kommunikation sind Machtgrenzen. „Alles, was wir über die Welt wissen, wissen wir durch die Massenmedien“, meint Luhmann. Wichtig ist jedoch nur, was wir noch nicht wissen, was also zwischen den Zeilen der eingeblendeten Schriftzüge zu lesen ist. Hier weiß die Boulevardzeitung mehr als Luhmann: Interessant ist nur das, was irgendwer irgendwo vertuschen will. Das schließt den blinden Fleck von Wissenschaftlern ein. Während die „Pisa-Studie“ von dieser Bewußtseinslatenz nur die Spitze des Eisbergs sein dürfte und die weitere empirische Forschung an die Bildungs- und Wissenssoziologie $\mathrm{zu}$ delegieren ist, beschreitet diese Arbeit den medientheoretischen Weg.

Macht ist nicht einfach ein Medium der Kommunikation, sondern eine reale Grenze subjektiver Autonomie. Deshalb ist ihr Einschlag ins Geschlechterverhältnis in allen frühen Gesellschaften offenbar. Macht verschwindet aber nicht, wenn sie zum Medium der Kommunikation umgeschrieben wird. Politische und militärische Machtverteilung ist vielmehr auch in modernen Gesellschaften Bedingung und Grenze sozialer Evolution. Schärfer noch als in der Politik zeichnet sie sich jedoch in der Ökonomie ab als Differenz zwischen bloßer Reproduktion und Luxus. Zwar hat sich auch das Weltwirtschaftssystem in seiner systemtheoretischen Beschreibung um das Geld als Kern herum ausdifferenziert, das alle beruhigt und alle unterschreiben läßt. Aber auch dieses Funktionssystem kommt um seine Selbstbeschriftung nicht herum, will es sich gegen die unmittelbaren Bedürfnisse der Subjekte abgrenzen. Sein Massenmedium Werbung ist daher der ideale Gegenstand der soziologischen Medientheorie. Und nicht erst die Knappheit des Geldes, wie in materialistischen Argumentationen, beschädigen das Subjekt in seiner Autonomie, sondern schon die Latenz, die sich in seinen Körper einschreibt, wenn es den kommunikativen Gesellschaftsvertrag billigt. Die Einheit des Weltwirtschaftssystems verlangt eine zustimmende Unterschrift, die paradox erst an der Grenze zur Inkommunikabilität lesbar wird. In der Theorie des digitalen Geldes als diabolisch generalisiertes Kommunikationsmedium nehmen wir die Spur nach Japan wieder auf. 



\section{Geld und Werbung als mediale Komplemente}

\subsection{Digitales Geld und seine binär schematisierte Theorie}

Die sexuelle Befreiung des Geldes: von Paris über Bielefeld nach Berlin

Das Geld, das Marx vor Augen hat, kann seine psychischen, religiösen und sexuellen Latenzen nicht verbergen. Der Versuch des dialektischen Materialismus, den Wertbegriff zu verabsolutieren, dotiert, kontaminiert ihn zugleich mit einer ursprünglichen Substanz, die er selbst nicht sehen kann. Das Äquivalent zum glitzernden Gold im Keller der Zentralbank entwickelt einen Fetischcharakter, dem die Ware mit ihrem Gebrauchswert als wehrlose Frau gegenübersteht. Harte Währung zeugt weiche, nachgiebige Körper, die Ethnologie des Geldes schreibt über diese konstante, tiefenpsychologische Identifizierung sogar die menschliche Geschichte in ein Buch aus inertem Edelmetall.

Günter Schulte hat Marx' Identifikation von Geschichte und Heilsgeschichte sowie von Revolution und Inzest erörtert (Kapitel 1.2). Bei Marx wird hinter dem Schatten des Warentausches: Leinwand gegen Rock, die Frau als Ware sichtbar. Freuds Theorie regrediert schließlich auf die infantile Formel Geld = Kot. Deutschmann dreht mit seinem neomarxistischen Ansatz auch diese Formel noch einmal um ihre Achse und weist dem Fetischcharakter des Geldes eine quasi-religiöse Funktion zu: Geld = Gott. So führen alle Gleichungen zu Marx zurück: Das Geld steht für alles. Noch bis 1971 werden die Wechselkurse der Weltleitwährung Dollar über das Abkommen von Bretton Woods an die abstrakten Goldbarren gekoppelt. Und erst nachdem James Bond 007 zum letz- 
ten Mal die Goldreserven von Fort Knox gegen den deutschen Gauner Goldfinger verteidigt hat, können Weltwährungssystem und Theorie einen anderen Verlauf nehmen, ist der Weg frei von der Goldmünze (Original) über den gedruckten Schein (Kopie) zur digitalisierten Kreditkarte (Kopie ohne Original).

Wenn die Strategie der Identifizierung des Geldes X mit irgendeiner sozialen Größe Y mit seiner Entkopplung vom Zentralbankgold an ihre Grenzen stößt, dann werfen die digitalisierte Kreditkarte und das Internetbanking das alte Problem der Legitimität auf. Sicher ist Geld Vertrauenssache, Vertrauen aber reduziert Komplexität nur, statt sie zu erfassen. Die Theorie hat zwei Möglichkeiten: Entweder sie ersetzt Geld durch Macht und hält ihre Argumentation durch, alles werde einer absoluten Substanz subsumiert. Diesen Weg beschreitet Foucault. Doch das Problem wiederholt sich nur: Die Macht und die Kontrolle müssen immer wieder in sich selbst verankert werden, ohne sich erklären zu können. ${ }^{1}$ In dieselbe Kerbe schlägt Aldo J. Haesler mit seiner Theorie der Entwicklung von der Souveränitäts- über die Disziplinar- zur Selbstkontrollgesellschaft. Auch seine Argumentation mündet in eine eigenwillige Reflexivität, in der das Subjekt negativ als passives Opfer seiner selbst erscheint. ${ }^{2}$

Ähnlich argumentiert sein Landsmann Pierre Klossowski, dessen „lebende Münze“ zwischen den Sphären der Normen und der Anomalien vermittelt: Das Geld repräsentiert, was existiert, und bezeichnet, was nicht existiert. Für Klossowski ist die Utopie des Frühsozialisten Fourier zugleich die Utopie und Antriebskraft der Konsumgesellschaft. Entlarvt hat diese Ambivalenz des Geldes ausgerechnet de Sade, indem er die Unentgeltlichkeit des fremden Körpers forderte. Wer diese eigene Einheit einfordert, so Klossowki, muß diese Unentgeltlichkeit hundertfach „durch die äußere Perversion der Bedingungen, in welcher die individuelle Einheit sich zu versichern aufgerufen ist", bezahlen. ${ }^{3}$ Und das kann nur heißen: Geburt des Gefängnisses. An dieser Stelle tritt dann der Körper in die Geldtheorie wieder ein, nämlich als Ort der Verhandlung, des Feilschens um den Preis für die Befriedigung der Lüste.

Klossowski entwirft ein Magnetfeld, in dessen Zentrum die „lebende Münze“" steht. Der Perverse, der offen den universellen Tausch der Körper fordert, enthüllt nur eine größere, noch verdeckte Monstrosität, nämlich die objektive Ökonomie der Bedürfnisse, welche die subjektiven Affekte übertönt. Bei aller Negativität, die er im Schatten Foucaults auf-

1 Foucault wird das schon von Baudrillard aufs Brot geschmiert. Vgl. Jean Baudrillard: Oublier Foucault. Paris 1977.

2 Haesler 1995.

3 Klossowski 1998: 63. Hervorhebungen gelöscht. 
fängt, gelingt Klossowski hier der Anschluß an die Subjekttheorie, weil er die Ökonomie der Bedürfnisse und der Affekte, Geld und Lust, trennt und die Identifikation von Waren- und Frauentausch beendet.

„Wir laufen Gefahr, zwischen der ,Ökonomie“ der Affekte und der Ökonomie der Bedürfnisse, die durch den Tausch definiert wird, eine rein analoge Beziehung herzustellen. Dies aber führt zu nichts, wenn man nicht vom Blickwinkel der Objekte und der Bedürfnisse ausgeht, um von hier aus den Kampf der Affekte gegen ihre inadäquate Formulierung ans Licht zu bringen, die sich materiell in den Stand einer Güternachfrage umgeformt hat, die ihnen nur auf eine erzwungene Weise entspricht." ${ }^{4}$

Sexuelle Befreiung des Geldes und seiner Theorie heißt genau das: Ökonomie und Affekte (= subjektive Bedürfnisse), Tausch und Geschenk, Geld und Liebe, System und Subjekt sind verschieden. ${ }^{5}$ Der Ursprung des Geldes ist nicht im Triebverzicht zu verankern, sondern das Geld und die Warenwerte überlagern die Gebrauchswerte, affizieren sie von außen. Das Geld schlägt sozusagen in das Verhältnis zwischen Subjekt und Gebrauchswert ein. Und diesem Einschlag sind natürlich alle, Männer wie Frauen, ausgesetzt. Deutlicher sieht diese Befreiung der Geldtheorie von der Sexualität noch, wer den Rhein überschreitet und die französische Küche gegen die deutsche Bibliothek eintauscht. Denn Simmel und schließlich Luhmann treiben die Geldtheorie in Richtung des absoluten Mittels voran, das, bar seiner materiellen Deckung, nun seine eigenen Grenzen selbst zu produzieren beginnt.

\section{Geld als absolutes Mittel und seine soziale Relativität}

Geld und Sexualität unterhalten keine Beziehung zueinander. Theoretisch parallelisiert, bleiben sie steril. Aber eine Gemeinsamkeit haben sie doch: nämlich ihre absolute Relativität. Beide sind zwar absolut unabdingbar für die menschliche Existenz, aber keiner von beiden ist sich selbst genug. Geld und Sexualität sind eben nicht alles, allerdings ist ohne sie alles nichts. Nicht irgendein abstraktes Selbstbefriedigungsverbot wertet sie auf, sondern umgekehrt: beide sind an sich subjektiv unbefriedigend. Es gibt keine Intimität des Subjekts mit sich selbst, auch gibt es keine absolute Logik des äquivalenten Tauschs. ${ }^{6}$

4 Klossowski 1998: 22f. Hervorhebungen gelöscht.

5 Paul betont, daß schon Simmels Tausch aus dem Gabentausch à la Mauss hervorging. Aber eben nicht, um ihn komplett zu ersetzen. Vielmehr tritt das Geschenk als Institution (besonders in Japan, Kapitel 2.2) neben den äquivalenten Tausch. Paul 2002: 111, 113.

6 Heinsohn 1995: 236-238. 
Wie die Triebe über ihre kalte Abfuhr, so weist das Geld über seine bloße Akkumulation hinaus. Die Ökonomie wird nicht über den symbiotischen Mechanismus der Bedürfnisbefriedigung, die Liebe nicht über den symbiotischen Mechanismus der Sexualität an die Körper angebunden, sondern umgekehrt: Menschliche Gesellschaft entsteht aus dem subjektiven Bedürfnis nach Liebe, nach der Einheit von Intimität und Sexualität. Dieses Bedürfnis (zumindest) hält sich auch in modernen Gesellschaften durch. Mehr als je zuvor ist in der heutigen Zeit, zumal in den Massenmedien, die Sexualität von der Liebe getrennt und käuflich. Aber eben nur sie. Aus dieser Erfahrung heraus mußte sich aber auch die Geldtheorie von der Sexualität lösen und die absolute Relation des Geldes ergänzen um einen Begriff der Lebenswelt, des Stils, des Sozialen, einen Spielraum jenseits der Grenzen des autopoietisch geschlossenen ökonomischen Funktionssystems. Axel Paul schreibt:

„Das heißt, das Geld ist nicht nur die Sprache der Ökonomie, in der sich (fast) alle Wünsche artikulieren müssen, um zumindest die Aussicht auf Befriedigung zu erheischen, sondern umgekehrt stachelt das Geld die Wunschproduktion allererst an. Einerseits, weil jeder in Geldform gegossene Wunsch diesen entstellt und stets ein Rest bleibt, der nicht gestillt werden kann, und andererseits, weil Geld als absolutes Mittel das Subjekt auf Zwecke verweist, an die es zunächst gar nicht dachte. “7

Georg Simmel hat mit seiner „Philosophie des Geldes“ die Theorie des Mediums aus ihrer ideologischen, identitätslogischen Klammer gelöst und seine Doppelgesichtigkeit, Ambivalenz, seinen Januskopf scharf abgebildet. Seine Welt wird zur Metapher, zur Warenwelt, zur Parade der Possibilitäten. Er pflichtet zunächst Marx' ethischer Kritik bei: Indem die bürgerliche Gesellschaft sogar religiöse Autorität, sexuelle Beziehungen, Besitz an Grund und Boden und ständische Hierarchien in die Sprache des Geldes übersetzt, verwandelt sie es vom absoluten Mittel zum absoluten Zweck. Unter der Herrschaft des Geldes gedeihen (weibliche) Prostitution und (männliche) Korruption. Doch auch hier mißt die Gesellschaft mit zweierlei Maß: Mögen auch Prostitution und heimliche Bestechung Mißbilligung erfahren, so werden doch umgekehrt die umtriebige Schauspielerin und der Millionär, der sie unterhält, toleriert. Und während die sozialen Beziehungen vom Geld affiziert werden, verlieren Ehre, Aufrichtigkeit und Liebeserklärungen ihre Grundlage. Das Geld zersetzt die Familie, die Gemeinde, die Nation. Das unabhängige, aber isolierte Individuum wird zum dominanten Archetypus. Abhängig ist dieser Großstadtmensch allenfalls noch abstrakt und ano-

7 Paul 2002: 116. 
nym: von seinen Lieferanten, Arbeitern, Hausangestellten, Kunden und natürlich von der Funktionstüchtigkeit seines Geldautomaten. ${ }^{8}$

Simmels Theorie entlastet das Geld von seinem "Substanzwert" und billigt ihm stattdessen einen neuen „Funktionswert“ zu. ${ }^{9}$ Er leistet sich den Luxus, von Marx' Formel semantisch zu abstrahieren. Indem sich das Geld nicht nur als universelles Zahlungsmittel, sondern als absoluter Zweck durchsetzt, produziert es selbst jene Grenze, die es zur Selbstdefinition braucht. In den Begriffen des 20. Jahrhunderts erleben wir die autopoietische Schließung des ökonomischen Funktionssystems, das sich zu anderen Systemen in seiner Umwelt in Differenz setzen muß. Aber der Flaneur des 19. Jahrhunderts pflegt noch einen gemächlichen, großzügigen Umgang mit den Begriffen. Noch sind feine Unterschiede wichtiger als scharfe Differenzen, noch leistet sich sogar die Geldtheorie den Luxus der Ambivalenz. Das Geld induziert mehr als (nur) die Schere zwischen arm und reich, Reproduktionskosten und Luxus, und das Subjekt ist selbstbewußt genug, sich als solches zu beschreiben. Gerade indem das Geld die Ökonomie als System versiegelt, gibt es - auf der anderen Seite der Medaille - Spielraum frei für den subjektiven Stil der Lebensführung. Damit wird zugleich auch das Subjekt von seiner Absolutheit entlastet und zum sozialisierten, kultivierten Individuum umgeschrieben.

Konsequent hat daher Hermann Schwengel als Theoretiker des Lebensstils Simmels Philosophie des Geldes als Komplement zu Marx gelesen. Um 1900 ist Gott tot, sind die Könige entmachtet, haben weder das Heilige noch die Elite mehr Autorität. Bei Marx bilden die Waren-Fetische und das Geld den Schatten des toten Königs. Simmel dagegen entläßt das Heilige in die Mythen des konsumtiven Alltags. Er kontert Marx' Arbeitsbegriff mit dem Begriff des Tausches als neo-klassische Lebensform: Lohn versus Stil. Statt zur Revolution und zur Abschaffung des Geldes ermuntert Simmels soziologischer Impressionismus die Jongleure der feinen Unterschiede zu einer konsumtiven Kultur des Wählens.

Schwengel projiziert die Theorien von Marx und Simmel auf das Parsons'sche Vierfunktionen-Schema, das AGIL-Schema. Zwar lassen sich die Funktion der Umweltanpassung des Systems (A-daptation) dem materiellen Stoffwechsel der Ökonomie und die Funktion der Zielerreichung (G-oal-Attainment) der Politik zuordnen und perfekt in Marx' Konzept der politischen Ökonomie einfügen. Aber die Funktionen Latenz (L-atency) und Integration (I-ntegration) sind zu Simmels Zeiten noch nicht - wie später in Luhmanns Medientheorie - durch die Syste- 
me Ehe und Wissenschaft begrifflich besetzt. Diese indikative Lücke nutzt Schwengel, um Simmels selektiven Geldbegriff in die moderne Gesellschaft $\mathrm{zu}$ integrieren (I-ntegration) und einen latenten Prozeß (L-atency) der Bildung von Lebensstilen aus seiner Theorie herauszuschreiben:

„Wo Simmel besorgt nach einer Möglichkeit sucht, könnte man erwartungsvoll sagen, dem verobjektivierten Lebensstilprozeß, der nicht schon von vornherein Teil der Kultur ist, Maßstab, Bewegungsform und Selbstdistanz zu verschaffen, könnte er auf Marx' von Kultur, Geschichte und Natur getrennten Begriff der abstrakten Arbeit und maschineller Produktion zurückgreifen. Wo die klassische politische Ökonomie und Marx, wie Foucault zeigt, die Historizität in das Tableau der Ökonomie einführt, aber nur, um sie dann in der Analyse der Produktion stillzustellen, öffnet Simmel wieder die Geschichte als Stilwandel und Mode, als eine Geschichte des als-ob. Genau das könnte der von Simmel beschworene Sinn der Distanzierung, Temporalisierung und Rhythmisierung des Lebensstilprozesses sein.“10

Die Projektion des Marx/Simmel-Verhältnisses auf das AGILSchema ist zwar nur eine Hilfskonstruktion. Doch indem sie Ökonomie und Soziales voneinander entkoppelt, indem sie die Möglichkeit schafft, Geld, Frauen, Vespas, Designermöbel und Differenztheorie zu lieben, ebnet sie zugleich den Weg zu Niklas Luhmanns Standardtheorie des Geldes an der Nahtstelle von Kapitalismus und Moderne. Erst die Definition eines autopoietischen Wirtschaftssystems, das sich um das Geld herum bildet, kann den Begriff der Ökonomie radikal enttraditionalisieren, d.h. nicht nur sexuell befreien, sondern entsexualisieren. Erst die Systemtheorie kann den religiösen und normativen Ballast der Geldtheorie abschütteln und gleichzeitig im Rahmen ihrer Kommunikationsmedien Sinnanschlüsse in nicht geld-vermittelte Sphären des Daseins vermitteln. Wie seine Theorie der Liebe, so löst Luhmann seine Theorie des Geldes zunächst radikal vom taktilen Körper und Bedürfnis ab und digitalisiert sie. Mithilfe des selektiven Schematismus Erleben/Handeln kann er dann sogar auf der informativen Ebene die mediale Koexistenz von Geld und Liebe theoretisch bestätigen. Eine aufregendere Operation als Sex im Speicher der Zentralbank. ${ }^{11}$

10 Schwengel 1987: 484f.

11 Während James Bond die amerikanische Zentralbank noch beschützen mußte, hat der österreichische CIA-Agent Prinz Malko Linge in der 149bändigen Agentenserie „Malko“ (Cora Verlag) des Franzosen Gérard de Villiers die Zentralbanken von Suriname und Simbabwe ausgeraubt und dabei auch erotische Abenteuer nicht ausgespart. Das Geld motiviert also auch wilde Komplexitätssteigerungen literarischer Texte. 


\section{„Erleben/Handeln statt Mann/Frau“ zweiter Ordnung: Luhmanns Geldbegriff}

In Luhmanns Medientheorie: im Milieu seiner Theorie, fühlt sich jeder moderne Soziologe alsobald heimisch. Der Grund ist denkbar einfach: Seine Theorie ist im Ansatz medienvermittelt. Sie argumentiert nicht vom Subjekt, seinem Bedürfnis, seiner Identität oder vom Widerspruch zwischen Tausch- und Gebrauchswert her, sondern rationalisiert und vereinheitlicht die Differenz zur System/Umwelt-Grenze autopoietischer Systeme. Diese müssen sich nicht nur in einer komplexen Umwelt stabil halten, sondern sind zudem in jeder Operation stets selbstreferenziell an sich selbst verwiesen. Einzige Richtlinie ihrer Umweltbeobachtung ist ihre eigene System/Umwelt-Differenz, die sie in ihre Umwelt projizieren. So macht sich die Systemtheorie selbst als System die Differenz von Erleben und Handeln, externer und interner Zurechnung, zueigen. ${ }^{12}$

Im Fall der Liebe mag die Verwandtschaft von Subjekt und System und die Nähe der Körper den Beobachter noch stören. Doch in der Kommunikation komplexer Funktionssysteme findet er Ruhe vor der lärmenden Idiosynkrasie der Verwandtschaft. Gewiß war die Umstellung der Gesellschaft von stratifikatorischer auf funktionale Differenzierung, oder aus der Sicht der Theorie: von Handlungen auf Kommunikationen und von Normen auf Medien, unwahrscheinlich und kontingent, ihr Take-Off gelang nur in Europa und nur in einem kurzen Zeitfenster. Doch ist sie erst einmal geglückt, müssen und können sich die komplexen Systeme eben nicht mehr laufend mit der Frage nach ihrem Ursprung und ihrer Letztbegründung belasten. Einsichtig ist diese soziale Evolution dann allenfalls noch dem Wissenschaftssystem, das allerdings den Kommunikationscode Wahrheit benutzt, der, obwohl ähnlich entmaterialisiert, nicht mit dem des Geldes kompatibel ist.

Die Systemtheorie enttraditionalisiert, entabsolutiert das Geld und löst es von der materiellen Geschlechterdifferenz. Das ethische Problem der Prostitution erledigt sich dadurch: Sie ist wirtschaftliches Handeln, Liebe nicht. ${ }^{13}$ Und so wie die Liebe strukturell unwahrscheinlich ist wieso sollte Alter sie erwidern? - so unterliegt auch das Medium Geld dem Paradox, seine eigene Anwendung mitmotivieren zu müssen. Im Geld spiegelt sich daher idealiter das Paradox komplexer Systembildung: Es muß erstens als allgemeines Zahlungsmittel anerkannt werden,

12 Luhmann 1997: 334f.

13 „Die Kommunikationen der Wirtschaft müssen sich als wirtschaftlich ausweisen, damit man sie nicht falsch interpretiert, etwa als auf Intimität zielenden Annäherungsversuch auffaßt. Für Prostituierte ist diese Differenz besonders in ihrer Lehrzeit ein Problem. Sie müssen daher in Erscheinung und Verhalten sichtbar machen, was gemeint ist." Luhmann 1988: 15. 
es muß zweitens als Schuldverschreibung reflexiv auf sich selbst anwendbar werden und muß drittens die wachsende reich/arm-Differenz in sich aufnehmen, d.h. zugleich universelles Interesse an Gütern und ihre universelle Knappheit abbilden. ${ }^{14}$

Hier gelingt Luhmann eine elegante Wendung im Rahmen seines Schematismus Erleben/Handeln. Zur Erinnerung: Liebe zwingt zum Handeln: Wer liebt, muß es seiner Geliebten zeigen, wer vom Liebescode affiziert und gesteuert wird, muß ihr idiosynkratisches Verhalten akzeptieren, ja sogar selbst übersteigern und vorausschauend reagieren. Liebe verwandelt Erleben in Handeln, den Beobachter in den Verehrer. Geld aber funktioniert andersherum, es beruhigt. Die Banken sedieren sogar die, die kein Geld haben.

„Der wichtigste Effekt des Mediums Geld ergibt sich auf gesamtgesellschaftlicher Ebene dadurch, daß die Zahlung Dritte beruhigt. Sie können, obwohl sie auch selbst an den Gütern und Leistungen interessiert sind (oder: in Zukunft interessiert sein könnten) zusehen, wie jemand auf knappe Güter zugreift, weil der dafür zahlt. Und sie können auch akzeptieren, daß dies zu Bedingungen geschieht, die von Vertragspartnern ohne ihre Beteiligung ausgehandelt werden, weil die Gegenleistung in Geld erfolgt, also in einer Form der Weitergabe nutzbar ist. Die Selektion einer Handlung, nämlich des Zugriffs auf knappe Güter, wird durch den Code des Mediums Geld in ein bloßes Erleben Dritter transformiert. Sie nehmen es hin wie eine Information über ein Faktum, an dem sie nicht beteiligt sind. Das Medium stellt mithin sicher, daß im Bereich der Wirtschaft trotz latenter Interessendivergenz das Handeln für die Beobachter ungefähr den gleichen Sinn hat wie für die Handelnden selbst. Die Divergenzen werden nicht ausgereizt, und das Aufbrechen älterer kommunaler Bedingungen führt nicht sogleich zum Konflikt. “'15

Geld motiviert nicht nur zu wirtschaftlichem Handeln, sondern zuallererst zur Akzeptanz der Spielregeln. Und es reinigt das Gewissen. Der ferne Aktienbesitzer erlebt nur noch via Satellit und ist nicht weiter verantwortlich. Nur Alter, der bezahlt wird, handelt auch. Das Geld macht alle, im Endeffekt auch die Bezahlten, zu passiven Zuschauern der wirtschaftlichen Prozesse. Andere arbeiten für das Geld, das man hat und ausgibt oder nicht, und vor allem: ob man es hat und ausgibt oder nicht. Hat das Geld erst einmal die Eigeninteressen Dritter neutralisiert, kann es die doppelte Kontingenz der Kommunikation mithilfe der Duplikationsregel Zahlen/Nichtzahlen überwinden. Auf der informativen Ebene der Bits, im internationalen Handel und Zahlungsverkehr, geht es

14 Am Begriff der Knappheit in der Überflußgesellschaft setzt Ganßmann mit seiner neo-klassischen Kritik an. Ganßmann 1996.

15 Luhmann 1988: 69. 
nun nicht mehr um die Auflösung von sozialen Widersprüchen oder die Kooperation von Erster und Dritter Welt. Gerade die Differenz stiftet Sinn. Und das Dividuum par excellence überbrückt sie immer nur fallweise und hebt sie nicht auf. Sogar die Zahlung ist nur scheinbar positiv, die Nicht-Zahlung nur auf Alltagsebene negativ besetzt. In Wirklichkeit stellt auch die Nicht-Zahlung einen neuen, anschlußfähigen Zustand im System her. So kann Luhmann schlicht und einfach formulieren: „Die Wirtschaft ist eine Menge notwendiger/ nichtnotwendiger Zahlungen. “16

Die Systemtheorie abstrahiert von der materialistischen, ethischen Ebene der Kritik an der Reichtumsdifferenz und verortet den Diskurs der Bedürfnisse, der Interessen und der Gerechtigkeit in der Vergangenheit. Preise oszillieren nicht mehr um den Wert, sondern sind Erwartungsprogramme, vor allem die für den deutschen Liter Benzin. Und gerade wenn sie schwanken, sind die Anschlußstellen für die kommunikativen Autobahnen schon gepflastert und die weißen Begrenzungslinien schon aufgetragen. Auch schiebt das universelle Medium Geld die Frage nach den Gründen für die Nicht-Zahlung in den Hintergrund. Und selbst wenn gezahlt wird, bleibt die Differenz bestehen. Sauer verdientes Geld kann genauso verwendet werden wie geliehenes. Es kann sogar für karitative Zwecke ausgegeben werden, vorausgesetzt, die Alternativen werden ökonomisch abgewogen, nicht philosophisch. Der Code des Geldes kennzeichnet alle Zahlungen/Nichtzahlungen als ökonomische Handlungen. Daher hat das moderne Weltwirtschaftssystem seine Einheit im Geld. Komplexe Kreditverschachtelungen und Umschuldungsverhandlungen binden die Dritte Welt in den Globalisierungsprozeß ein.

Die Versuchung ist groß, dem Geld eine totalisierende Tendenz oder gar „Imperialismus“ zu unterstellen. ${ }^{17}$ Doch Luhmann widerspricht im Rahmen seiner Theorie. Die Universalität des Mediums greift nur innerhalb seines ökonomischen Funktionssystems. In der Politik, in der Wissenschaft, in der Liebe werden andere Codes benutzt. Zwar akzeptiert der Arme die Kürzung seiner Unterstützung, wenn der Geldcode benutzt wird. Aber ob der Liebende über die hohe Telefonrechnung hinwegsieht oder ob der Wissenschaftler seine Finanzierung (eher noch als der Politiker) offenlegt, das wird im Rahmen anderer Systemcodes diskutiert und entschieden. Gerade weil symbolisch generalisierte Kommunika-

16 Luhmann 1988: 243.

17 Paul formuliert: „Die Schwäche der systemtheoretischen Beschreibung der Geldwirtschaft besteht nicht nur und schon gar nicht an erster Stelle darin, daß sie das Problem der Einbettung weitgehend ausspart - die Kritik so anzusetzen, hieße, offene Türen einzutreten -, sondern darin, daß Luhmann die Autopoiesis der Wirtschaft zugleich als zu selbstverständlich und nicht radikal genug auffaßt und damit den Imperialismus des Geldes herunterspielt." Paul 2002a: 259. Dazu mehr in Kapitel 3.2. 
tionsmedien Systemgrenzen ziehen, stoßen sie zwangsläufig auf andere Codes, mit denen sie nicht vermischt werden dürfen. Funktionieren sie, dann leisten sie eine harmonische, konfliktarme Arbeitsteilung zwischen den Systemen. Dietrich Schwanitz faßt zusammen:

„Wissenschaftliche Erkenntnisse darf man nicht durch Rechtsurteile unterdrücken (vgl. das Urteil gegen die Evolutionstheorie), Liebe darf man ebensowenig kaufen (Prostitution) wie Recht (Korruption), und Politik darf man nicht durch Liebe beeinflussen (Mätressenpolitik). Alle Codes binden aspekthaft an die psycho-physische Individualität des Menschen an und formen so die ,symbiotischen Mechanismen' der Gewalt (Recht/Macht), des Konsums (Wirtschaft), der Sexualität (Liebe), der Wahrnehmung (Wissenschaft) etc. Diese mit unterschiedlichem Erfolg operierenden, phasenverschoben entwickelten Kommunikationsmedien setzen die gesamte kulturelle Semantik unter einen andauernden Änderungsdruck, der erst in der Systemtheorie selbst endgültig durchschaut wird. An dieser Stelle konvergieren dann die Theorie der Systemdifferenzierung und die Kommunikationstheorie mit der Theorie gesellschaftlicher Evolution. “18

Das Rendezvous von Theorie und Weltgeschichte wiederholt sich auf einer höheren Ebene. Diesmal hört nicht Hegel das Donnern der Schlacht von Jena, das seinem vernünftigen Staat den Weg freikämpft, sondern Luhmann beobachtet die Emergenz seiner System/UmweltDifferenzen als Systeme im unmarked space - und setzt sich selber als Beobachter, als eingeschlossener, ausgeschlossener Dritter, besser: als allwissender Autor, unsichtbar. ${ }^{19}$ Das System der Differenz hat (fast) kein Außen, und jeder Versuch, Ethik, Moral, (Inter-)Subjektivität, Identität oder die Identität von Identität und Nicht-Identität dagegenzusetzen, perlt ab. Zwar hat Jürgen Habermas versucht, in seinem begrifflichen Dualismus die Medien Geld und Macht an das Medium Sprache sowie an lebensweltliche Interaktionen, Motivationen und Normen rückzukoppeln. ${ }^{20}$ Aber aus Luhmanns Perspektive macht sich die Umstellung der gesellschaftlichen Organisation von Handlungen auf Kommunikationen gerade die Differenz der nackten ja/nein-Codierung der Sprache zunutze: Konsens wäre fatal. Man kann im wissenschaftlichen Diskurs allenfalls am Medium Wahrheit entlang weiterdebattieren. Zwar sollten alle Teilnehmer ihre Kongressgebühr entrichten, wer es aber nicht tut, muß nur mit ökonomischen Konsequenzen rechnen. Und nach der Veranstaltung dürfen auch Wissenschaftler ins Etablissement gehen. Kurz: Auf der binären Ebene der Informationsverarbeitung hat jedes

18 Schwanitz 1990: 80. Vgl. auch Luhmann 1997: 330, $366 f$.

19 Luhmann 1997: 1081.

20 Habermas 1981: 413, 419. 
Medium seine eigene Sphäre, jede Datei ihren Ordner, und diese synthetische Kommunikation ist gegen nichts so allergisch wie gegen Synthesen. Sie ist auto-immun.

Luhmanns Definition und Deduktion des Geldes lebt gerade von ihrer moralischen und sexuellen Befreiung, ihrer Abstraktion vom Körper und vom Geschlechterverhältnis. Für seine blutleere Kommunikation ist auch der unsichtbare Mehrwert nur ein sinnstiftender Parasit, z.B. eine Differenz zwischen systemintern hergestellter Information (Ware) und Mitteilung (Preisschild). Das Problem, das er sich einhandelt, beschränkt sich auf den (erwartbaren) kollegialen Widerspruch in seinem Wissenschaftssystem: Ist das Medium Geld kommunikativ eingebettet? Wie stellt es seine Legitimität sicher? Wo liegen und wie organisieren sich die Grenzen zwischen den Medien und den Funktionssystemen? Und mutieren Subjekte tatsächlich zu psychischen Systemen, bloß weil das ökonomische Funktionssystem sich weitgehend von ihnen entkoppelt hat? Setzt nicht gerade diese ökonomische Dynamik den Spielraum für die Individuen frei, der sie auch zu ihren Bedürfnissen und zum Stil zurückfinden läßt? Ist es nicht gerade die massenmediale Selbstbeschriftung des autopoietischen Wirtschaftssystems: die Werbung, die diesen Diskurs des Geschmacks latent sogar in Luhmanns eigener Fassung wieder eröffnet? ${ }^{21}$ Die Alternative zu seiner Beschreibung der Ökonomie ist daher aus seinem eigenen System heraus zu entwickeln, aus seinem blinden Fleck, aus seiner Latenz. Die Frage lautet: Wie beschriften sich die Systeme selbst? Wie stricheln sie ihre Grenze? Welche Geheimnisse bergen ihre Zwischenräume? Und die Antwort ist zum Greifen nah im Spiegel von Luhmanns Medientheorie: in der Ergänzung der symbolisch generalisierten durch die diabolisch generalisierte Kommunikation, im teuflischen Paradox der Beobachtung zweiter Ordnung.

\subsection{Die diabolische Spur der Versuchung in der Theorie des Geldes}

\section{Von der Latenz der Kommunikation zur Kommunikation der Latenz}

Noch für Marx wurde Geld zum Ein und Alles des gesellschaftlichen Lebens, sein Fetischcharakter überzog die sozialen Beziehungen mit einem klebrigen Film aus eigennützigem Kalkül. Seine Kritik war im Kern moralisch: Alles wird käuflich, der Zugriff der Kapitalisten auf die Waren (und Töchter) ist außer Kontrolle. Diese Verabsolutierung des

21 Luhmann 1997: 1105. 
Geldes sowie die Verabsolutierung der Triebe in der Psychoanalyse Freuds haben bis in die 70er Jahre die Parallelisierung beider Theorien vereinfacht. Luhmann dreht diesen kommunikativen Spieß um: Systeme sind keine Subjekte, ihre Triebe sind keine ernstzunehmenden Bedürfnisse, sondern lediglich symbiotische Mechanismen. Psychische Systeme aber sind sich gegenseitig ohnehin nie vollständig transparent: Aufrichtigkeit ist inkommunikabel. Liebe ist ein bloßes Medium der Kommunikation, Vertrauen nur ein Mechanismus zur Reduktion von Komplexität (Kapitel 1.3). Erst auf dieser Grundlage der stetigen Möglichkeit von Betrug ist ein Liebesspiel möglich. Ehevertrag, Gütertrennung und schließlich die „Lebensabschnittsbegleitung“ schließen sich an. Wenn im kontingenten Trennungsfall ein Partner den kürzeren zieht, gelangt ein anderes Medium zur Anwendung. In einem rauhen ökonomischen Milieu überleben subjektfreie Theorien besser: Digitales Geld stinkt erst recht nicht mehr. Wer dagegen an der materiellen Referenz des Geldes und der Liebe festhält, macht sich nur zum Sklaven seiner eigenen unbewußten Bedürfnisse.

Von wenigen Fissuren abgesehen, herrscht in der soziologischen Theorie Einigkeit darüber, daß Macht (bzw. soziale Vernunft) und Geld die zentralen kommunikativen Medien zur Organisation der modernen Gesellschaft sind. Auch die historisch-genetische Theorie, welche die Liebe nicht als Medium, sondern als elementares Bedürfnis des Subjekts in seiner Ontogenese verankert, muß in puncto Macht der Systemtheorie beipflichten. $^{22}$ Doch in bezug auf das Geldmedium kommt Luhmann nicht kostenlos davon. Gerade weil sich am Geld das Konstitutionsproblem moderner Gesellschaft kristallisiert, transportiert und kommuniziert es Paradoxien und Latenzen in Gesellschaft und Theorie. Zurecht konstatiert Paul daher eine Unschärferelation in der Geldtheorie:

„Es sei hier nur daran erinnert, daß Geld die disparatesten Leistungen Einzelner kompatibel und so den Aufbau von hochdifferenzierten, von den Einzelinteressen ihrer Mitglieder entkoppelten Organisationen möglich macht. Dieses in sich bewegliche Geflecht von Einflussmöglichkeiten und Interdependenzen, dieses verworrene Labyrinth von Schutzwällen und Neutralisierungsbädern läßt sich theoretisch modellieren, aber ebensowenig abbilden oder widerspruchslos darstellen wie der Elektronenmantel eines Atoms. [...] Wüßte man um die Probleme, den (inneren und/oder äußeren) Geldwert stabil zu halten, beziehungsweise verdrängte man sie nicht, geräte die auf Wachstum abonnierte und dabei inhärent und notwendig instabile Geldwirtschaft in Gefahr zu stagnieren. Denn das Gleichgewicht ist ihr Tod.“23

22 Dux 2000: 463-473.

23 Paul 2002: 122f. 
In der Münze spiegelt sich das Grundproblem der Reflexivität. Da das Geld die Reflexivität des Subjekts umgeht, weil es akzeptiert wird, ohne daß seine Deckung in Gold überprüft worden wäre, stellt es seine eigene, mediale Reflexivität her. Das Geld, so Paul, ist als Wert der Werte immer schon reflexiv: Indem es vom Gütertausch abstrahiert und seine eigene abstrakte Akkumulation als Eigenwert motiviert, setzt es an die Stelle sozialer Klassenverhältnisse das von Gläubiger und Schuldner. Das Geld sichert dadurch nicht nur die Einheit des ökonomischen Systems, sondern belegt es mit einem Zinsmotiv und einem Wachstumszwang. Nicht auf Märkten, also berechenbaren Angeboten und Nachfragen, sondern auf Börsen und Spekulationen beruht daher die Dynamik der Ökonomie. Indem die Autopoiese des Geldsystems andere Funktionssysteme affiziert, überschreitet das Geld zugleich die Grenzen der Luhmann'schen Systemtheorie. $^{24}$

Der blinde Fleck, die Unschärfe, die unreflektierte Reflexivität in Luhmanns Defensivsystem hat viele Beschriftungen. Am ehesten läßt er sich jedoch im Bereich des Mediums Liebe beobachten, denn das Intimsystem schließt den einen Akteur ein und die große soziale Organisation aus: Die Liebe fokussiert auf den Körper der Frau und schmuggelt den Kavalier samt seiner Motive und Bedürfnisse wieder in die Theorie der Gesellschaft hinein. Begeben wir uns deshalb dort zuerst auf die Suche nach der systemtheoretischen Einheit der Welt.

\section{Die Einheit der Welt als blinder Fleck} ihrer systemtheoretischen Selbstbeschreibung

Luhmanns Theorie ist in der Formulierung von Schulte ein Versuch, die Vernunft vom Subjekt aufs System umzuschreiben. Sie entkoppelt die Beobachtung der Welt vom Subjekt und vom Körper und beschreibt sie stattdessen wertfrei und bedürfnislos auf der Ebene der Informationsverarbeitung. Die Systemtheorie ist Theorie der Zivilisation und zivilisierte Theorie, weil sie sich jenseits der Scham situiert: Subjektive Motive zu offenbaren, wäre beschämend. Stattdessen muß Aufrichtigkeit inkommunikabel werden. Systeme müssen anders als Subjekte füreinander intransparent sein, sie dürfen sich keinesfalls verstehen. Erst auf dieser Grundlage wird die Beobachtung zweiter Ordnung nötig und möglich. Der blinde Fleck gerät also durch die Anfangsunterscheidung der Systemtheorie in ihr System: Indem Systeme sich selbst produzieren, verdrängen sie Geburt und Tod in die Latenz. Luhmanns blinder Fleck entspringt also nicht wie der von Marx einer sexuellen Projektion, son-

24 Paul 2002a: 252-255, 259. 
dern dem Ödipus-Komplex des Beobachters, der das re-entry des Systems in sich selbst zwar beschreiben, nicht aber in seiner eigenen Schrift dulden kann. ${ }^{25}$

Durch die Verdrängung ihrer Geburt und ihres Todes, ihre Daseins-Lüge, werden die Systeme von der Notwendigkeit erlöst, ihr Leben mit Sinn zu versehen, ihr Leben, wie Subjekte, vom Tode her zu leben. Sinn heißt dann nur noch: Anschlußfähigkeit. Dieser „BaudrillardEffekt" schlägt bis in die Kommunikation der Systeme durch: Wenn der Golfkrieg nur digital ist, dann ist auch kein Soldat gestorben. Er hat nicht stattgefunden. Die ungeborenen Systeme sind gezwungen, im Schatten des Todes alle Informationen umzudeuten, selbst wenn es um Leben, Tod oder Liebe geht. Ihre Kommunikation bleibt ein Versuch der Kommunikation, ihre Geräusche dringen allenfalls vor bis zum Kommunikationssystem, erreichen aber nicht den Geliebten. Luhmann definiert seine Systeme als Black Boxes (oder Monaden), die ihre Wahrnehmungen selbst produzieren. Der andere bleibt fremd und intransparent, jedes Verstehen ist in das System hineinverlagert, nur dort wird die Differenz zwischen Information und Mitteilung konstituiert. Gleichzeitig garantiert diese dreistufige Fassung der Kommunikation den ewigen Fortbestand der Differenz und des Gesellschaftssystems als Kommunikationssystem.

Luhmanns soziale Systeme sind nicht auf die Bedürfnisse, Erfahrungen, Entscheidungen und Handlungen von Subjekten reduzibel. In den Augen des Kunsthistorikers Schulte schließt sein Theoriesystem daher den Körper aus dem Bewußtsein der psychischen Systeme aus und bietet ihnen dann erst kompensativ eine Theorie zur Informationsverarbeitung an: Systemtheorie als Systemtherapie. ${ }^{26}$ Gerade auf der Ebene der Paarbeziehungen bekommen die Systeme die Folgen der theoretischen Regeln ihrer Kommunikation zu spüren. Schulte sieht im Mini-System Ehe Luhmanns Idealmodell für die Beobachtung zweiter Ordnung. Wo sich die Eheleute gegenseitig als Beobachter belauern und dem Erleben des Partners laufend vorzugreifen versuchen, ist jede Subjektivität und Spontaneität dahin. Gerade weil die beteiligten Black Boxes sich nicht verstehen können, entwickeln sie Bilder und Vorstellungen voneinander und produzieren ,order from noise“. Um unter dem

25 „Luhmanns re-entry-Definition ist die rationalisierte, auf den Begriff gebrachte Nacherzählung des klassischen Ödipus-Mythos. Denn Ödipus begibt sich bei der Mutter an den Ort seines Entstehens, um sich eigenmächtig zu wiederholen und damit autonom und autopoietisch zu sein. Er ,erkennt ${ }^{\prime}$ die Mutter, insofern er sie begattet, und hat sie dennoch vergessen als die bereits von seinem Vater erkannte. Das ist tragisch und komisch zugleich." Schulte 1993: 233f.

26 Schulte 1993, 23-27. 
dauernden Zwang zum Liebesbeweis nicht verrückt zu werden, müssen die Liebesleute ihn schließlich lockern und eben das als Liebesbeweis akzeptieren - oder zur Sexualtherapie gehen. Systeme lieben nicht. Aus ihrer Sicht ist Liebe ein symbolisch generalisiertes Kommunikationsmedium, das sie allererst dazu motiviert, den Grundzustand ihrer Indifferenz zu verlassen (Kapitel 1.3).

Kommunikation zwischen Systemen im Stil der Kommunikation zwischen Subjekten ist unmöglich. Möglich ist lediglich die strukturelle Koppelung von Bewußtsein und Kommunikationssystem als Beobachtung zweiter Ordnung. Und genau diese Isolation und Vereinsamung der Monaden muß in Luhmanns Theoriesystem latent werden, sonst wäre sie unerträglich. Damit ist die Theorie reif für die Umschrift ins unreine: „Kommunikation ist ein Betrug, indem das als Kommunikation erscheint, was eigentlich deren Ausbleiben ist. Luhmanns Kommunikation ist die Latenz der Kommunikation. Die Menschen betrügen sich selbst. So bleiben sie frei im Kontakt miteinander - und einsam. “27 Damit aber ist der binäre Schematismus freigelegt, der aus Luhmanns System herausführt: die Differenz zwischen symbolischer und diabolischer Generalisierung der Kommunikation. Nicht Ehebruch oder Sexualtherapie führen weiter, sondern nur der Ehewitz, der komplexe Latenzen kommunizieren kann. Dieser verführerische Übergang von der Latenz der Kommunikation zur Kommunikation der Latenz läßt sich am besten anhand unseres Lieblingsmediums Geld nachzeichnen.

\section{Die diabolische Dividualität des Dagobert Duck}

Wenn Luhmanns Kommunikationssystem der Hölle gleicht, dann sind die symbolisch generalisierten Kommunikationsmedien ihr Zerberus. Nur sie stellen in der Einheit von Selektion und Motivation sicher, daß die an sich unwahrscheinliche Kommunikation zwischen Systemen überhaupt stattfindet. Und ihr Erfolg liegt darin, daß sie den dauerhaften Erfolg gerade verhindern. Nicht Konsens ist das Ziel der Kommunikation, sondern neue Differenz. So gehen Symbolik und Diabolik Hand in Hand. Die Äquivalenz von Ware und Arbeitskraft ist nicht der Widerspruch der Ökonomie, sondern schafft lediglich im System der Zahlungen eine von vielen neuen Differenzen. Löst sich das Geldzeichensystem von der Wertreferenz Gold und erweitert es sich sogar digital um elektronischen Zahlungsverkehr und Internetbanking, kennt die globale Zirkulation keine Grenze mehr. Auch Onkel Dagoberts Bad im Geldspeicher dient nur der Produktion neuer, verrückter Ideen.

27 Schulte 1993: 111. 
„Symbolisch generalisierte Medien transformieren auf wunderbare Weise Nein-Wahrscheinlichkeiten in Ja-Wahrscheinlichkeiten - zum Beispiel: indem sie es ermöglichen, für Güter oder Dienstleistungen, die man erhalten möchte, Bezahlung anzubieten. Sie sind symbolisch insofern, als sie Kommunikation benutzen, um das an sich unwahrscheinliche Passen herzustellen. Sie sind zugleich aber auch diabolisch insofern, als sie, indem sie das erreichen, neue Differenzen erzeugen. Ein spezifisches Kommunikationsproblem wird durch ein Neuarrangieren von Einheit und Differenz gelöst: Wer zahlen kann, bekommt, was er begehrt; wer nicht zahlen kann, bekommt es nicht.“ ${ }^{28}$

Luhmann ersetzt moralisch-ethische Geldkritik oder den Widerspruch im äquivalenten Tausch durch die Einheit der Differenz zwischen symbolischer und diabolischer Differenzierung. Im allgemeinen Zahlungssystem verweist selbst die Divergenz der Zumutung von materieller Not reziprok immer noch auf die Möglichkeit von finanzieller Konvergenz. Die Leistung des Geldes, den Widerspruch zu glätten und Handeln in Erleben $\mathrm{zu}$ transformieren, ist in diesem Schematismus formelhaft zusammengefaßt. Ganz sachlich gleich sich die Systemtheorie dem Kommunikationsstil ihrer Systeme an: Sie liebt nicht nur die Differenz, sondern auch die Latenz. Indem sie sich wie ihre Systeme selber erzeugt, reinigt sie sich zugleich von schädlichen Umwelteinflüssen, von Geburt und Tod, von lästigen Kunden und Wählern, von subjektiven Idiosynkrasien und Motiven. Die Wahrheit der Systeme gleicht der Wahrheit des Geldes.

„Am Anfang mag es Sünde gewesen sein - etwa der Biß in die verbotene Frucht oder der Diebstahl des Feuers. Und es gibt in der Gesellschaft Beobachtungskontexte oder sogar Systeme, etwa Religion, die das nicht, oder nur schwer, verzeihen können. Wissen ist und bleibt für sie hybris. Der Beobachter des Systems ist und bleibt der Teufel. Im autopoietischen System des Wissens gibt es jedoch keinen Anfang; und schon gar nicht einen Anfang, der als Argument in das System selbst eingeführt werden könnte. Entsprechend hat das als wahr bezeichnete Wissen eine selbstreinigende Kraft - so wie das Geld. “29

Doch diese Selbstreinigung hinterläßt eine latente, lesbare und kommunikable Spur im Bewußtsein des Subjekts - nicht nur bei Karl Max. Wie der Witz über die Ehe die Kommunikationslatenz des Ehesystems punktiert und gleichzeitig das latente Bewußtsein ihres bisweilen höllischen Charakters artikuliert, so hat auch das Geld im System der Massenmedien eine Galionsfigur ausgebildet, die keine Scham kennt. Zweifellos spiegelt sich in den Geldspeichern von Dagobert Duck - und

28 Luhmann 1997: 320. Luhmann 1988: 258.

29 Luhmann 1988: 593. Vgl. Schulte 1993: 254. 
in der Armut seines Neffen - ein latentes, alltägliches Bewußtsein von der Negativität des Geldes. Onkel Dagobert zieht mit seinem täglichen Bad im Geldspeicher, seiner Sterilität, seiner „Lieber reich und gesund als arm und krank"-Philosophie und seinem notorischen Geiz die unbewußte Trennlinie zwischen Luhmanns theoretischer Knappheit und dem realen Reichtum der Gesellschaft. Und: Er sammelt Kunst - ganz wie die reichen Japaner, die speziell in der bubble-Zeit die Picassos und van Goghs aus der ganzen Welt auf ihre Insel holten. Die Kommunikation der Ökonomie ist also doch nicht ganz so rein, wie Luhmann gerne hätte.

Die Latenzen der Beobachtungs- und Kommunikationsmodi der Systeme fließen in einen informativen Speicher, nämlich in die Massenmedien. Und diese Daten über Grenzen, d.h. Latenzen der Kommunikation, stammen nicht vom System oder seiner Theorie, sondern wurzeln ausschließlich im Bewußtsein der Subjekte. Denn nur Subjekte können lachen. Und erst der Zugriff auf die Schrift der Massenmedien macht das akkumulierte, blockierte Wissen als Bewußtseinslatenz kommunikabel. Noch einmal: Massenmedien sind Verpackungskunst. Die Theorie muß daher nur, statt das (Geld-)Geschenk anzunehmen, die Schrift auf der Verpackung lesen.

\section{Latente Kommunikation zwischen Subjekt und System: (Verpackungs)Kunst als Kommunikation der Latenz}

Für den Beobachter des blinden Flecks der Systemtheorie erscheint Luhmann als sinnstiftender Teufel, der erst die Göttlichkeit der Systeme erkennen läßt. Gott und Teufel brauchen sich, erzeugen sich gegenseitig und vollführen ein Double-Bind im Rahmen ihres dualen Codes. Die Frage nach dem Ursprung löst sich daher auf in der Differenz, die zugleich den gemeinsamen Ursprung von Identität und Differenz und von Subjekt und System latent macht. Schulte, der Luhmanns Theorie als Umschreibung der Vernunft vom Subjekt aufs System würdigt, verhält sich daher zu Luhmann wie der Teufel zu Gott. Erst indem er die Züge des Autors im autopoietischen Theoriesystem sichtbar macht, erhebt er die Systemtheorie zur Kybernetik zweiter Ordnung. Schulte und Luhmann bestätigen sich gegenseitig. Der Leser braucht nur noch zu unterschreiben.

Doch auch die Umschrift der Systemtheorie ins unreine der Subjekttheorie kommt an einer Erkenntnis nicht vorbei: Soziale Systeme gibt es. Und sie sind stets (wesentlich) mehr als die Summe ihrer Mitglieder. Und umgekehrt: Systeme entkoppeln sich zwar weitgehend von ihnen, sind aber gleichzeitig auf humane Turbulenzquellen angewiesen. Aus 
Sicht der Systemtheorie sind Bewußtsein und Kommunikation strukturell gekoppelt, aus Sicht der Subjekttheorie ist diese Kommunikation lediglich ihre eigene Latenz: die Hölle. Um sich ihr zu entziehen und das Paradox in Luhmanns Wahrnehmungstheorie zu erläutern, nutzt und zitiert der Kunsthistoriker Schulte in seinem Buch zahlreiche Gemälde: „Die Gesandten“ von Holbein d.J., „Bathseba im Bade“ von Bordone und Eschers optische Labyrinthe. Kunst ist (wie Adornos Theorie) das Refugium des Subjekts.

Auch der Systemtheorie selbst ist der subjektive, kommunikative Sonderstatus der Kunst bewußt: Luhmann sieht den Zweck der Kunst in der „Reaktivierung ausgeschalteter Possibilitäten“, was die Möglichkeit der Subjekttheorie einschlösse. ${ }^{30}$ Kunst soll, genau wie Geld, zum Erleben anregen - aber doch ganz anders, nämlich subjektiv. Wer Kunst konsumiert, soll nicht stillhalten, sondern bewegt werden. Fuchs sieht die Besonderheit des Kunstsystems in der Unschärfe seiner Grenzen: „Die System/Umwelt-Differenz, die durch den Code Kunst/Nichtkunst bezeichnet ist (und darin lag ja die Raffinesse dieser Unterscheidung. Sie nutzt diese Differenz selbst), ist grenzdiffus. “31 Es muß Kunstwerke als solche definieren können, aber wenn es das erst einmal kann, dann kann auch Nicht-Kunst als Kunst etikettiert werden, z.B. die Autos und der Müll von H.A. Schult oder Christos Verpackung des Berliner Reichstags. Schulte nutzt in seiner Argumentation die Nähe der Kunst zur Theorie bzw. konzipiert seine Theorie als Kunst: Beide Weltbeschreibungssysteme bleiben der Subjektivität ihrer Autoren verhaftet. Das eine liebt die Kunst, das andere verankert den Ursprung seiner Argumentation im Fluchtpunkt der informativen Kybernetik außerhalb des Bildes.

Der schriftliche Grenzgang zwischen Subjekt und System stößt hier an seine diffuse Grenze, nämlich an die Grenze zwischen Theorie und Kunst, Beschreibung und Beschriftung. Wer entscheidet, was Kunst ist? Der Künstler? Das Publikum? Die Putzfrau? Das Fernsehen? Der Sponsor? Der Käufer? Der Soziologe oder seine Frau? Die Systemtheorie sagt: das System. Aber der Subjekttheoretiker Schulte nutzt die Kunst zur optischen Verdeutlichung des paradoxen Beobachtens. Solange es Künstler (und Theoretiker) gibt, die das Paradox der systemischen Selbstdefinition durchschauen und kommunizieren, ist es auch nicht universal. Gleiches gilt für die Kommunikation zwischen Systemen: Wenn das Bewußtsein wissen kann, daß Liebe ein Code ist, ist es vielleicht wieder ganz anders. Diese Verwirrung, diese diffuse Grenze zwischen

30 Luhmann 1997: 351-352.

31 Fuchs 1993: 176. Zur Grenzdiffusion Werbung/Kunst im systemtheoretischen Weltbild vgl. Schmidt/Spieß 1994: 81-99. 
Theorie und Kunst eröffnet einen Spielraum, der soziologisch zu nutzen ist. In der postmodernen Gesellschaft müssen alle mitentscheiden bei der Frage, was Kunst ist - und mitentscheiden können. Die ökonomische Kunst der Werbung ist gerade die, auf den Mehrwert kreativ zuzugreifen: Auch wenn das Leben asketisch ist, ist die Werbung üppig. Sie umgeht als Kunst die Debatte um ihren Status (und ihre Finanzierung) und ist dennoch offen für den Gebrauch künstlerischer Mittel. Werbung ist die Kunst, paradox unter dem Vorwand eines ökonomischen Zwecks subjektiv zu kommunizieren.

Das Massenmedium Werbung ist zu lesen als Schriftsystem zwischen System und Subjekt. Noch einmal: Es gibt soziale Systeme, die sich selbst produzieren und selbstreferenziell reproduzieren. Und es gibt Subjekte, die ihre Bedürfnisse reflektieren. Aber wollen komplexe soziale Systeme sich gegen die Bedürfnisse der Individuen abgrenzen, so bedürfen sie einer Kultur der Selbstbeschriftung. Nicht die Systemtheorie etikettiert die Kunst oder die Ökonomie als Systeme: Sie beschriften sich selbst. Und deshalb ist die ökonomische Verpackungskunst Werbung als einheitsstiftende Haut des Funktionssystems zu begreifen. In ihr berühren sich die Machtgrenzen des symbolisch generalisierten Kommunikationsmediums Geld und die unhintergehbare Versuchung subjektiver, körperlicher Existenz. Die Werbung ist die Grenzerfahrung des Systems, das einschneidend die Autonomie der Individuen limitiert und ihre materiellen Bedürfnisse kommunikativ umgeht.

Sie ist als äußere Schreibfläche der Ökonomie ihrem inneren Kommunikationsmedium Geld à la Parsons/Luhmann/Habermas entgegengesetzt und siedelt an der Nahtstelle zwischen Ökonomie und Lebenswelt. Sie ist nicht dem Konsens verpflichtet, sondern - wie die Liebe - dem Paradox der Aufrichtigkeit: Je mehr sie die Ware lobt, desto unglaubwürdiger wird sie. Werbliche Kommunikation ist daher weibliche, „weiche“ Kommunikation, komplementär zum „harten“ Geld. Sie ist die diabolische Versuchung und Verführung der Warenwelt. Die Soziologie der Medien der Kommunikation muß daher den Teufel tun und, statt die systemtheoretische Geldtheorie fortzusetzen, aus dem Bodypainting der Werbung die kommuzierte Latenz des Subjekts herauslesen.

Wenn die Systemtheorie der blinde Fleck der Weltbeobachtung in einem System selbstproduzierter Systeme ist, so ist die Werbung der blinde Fleck der Abstraktion der Geldökonomie von den materiellen Bedürfnissen der Konsumenten. Werbung bildet sich reflexartig in dem Augenblick, in dem sich das Wirtschaftssystem autopoietisch verschließt, sie ist die latente Kommunikation zwischen System und Subjekt und deshalb „die zarteste Versuchung, seit es Schokolade gibt“, für die Theorie. Die Grenze des Funktionssystems Ökonomie ist vom Geld auf die 
Verpackungshaut der Ware, die Werbung, umzuschreiben. Denn wenn die Grenzen dieser Massenkommunikation nicht im System gezogen werden, sondern im subjektiven Bewußtsein, dann muß das Subjekt seine materielle Körperlatenz in sie einspeisen. Und wenn es eine latente, dezente, humorvolle, platonische Beziehung gibt zwischen System und Subjekt, so kommuniziert sie sich in gezeichneten Körpern. Diese Körperlatenz, d.h. die Zeichnung der Körper durch Arbeit, ist daher nicht nur ein theoretischer Terminus, sondern wie die Ontogenese des Subjekts selbst eine empirische Realität. Aus der Arbeitsmedizin und Dermatologie ist bekannt, daß sich die Zeichnung der Körper im wesentlichen auf ihren Schreibflächen manifestiert: den Häuten, Schleimhäuten und Atemwegen (Abbildung 2): ${ }^{32}$

\section{Abbildung 2: Häufigkeit der Verdachtsanzeigen auf Berufskrankheiten} in Deutschland

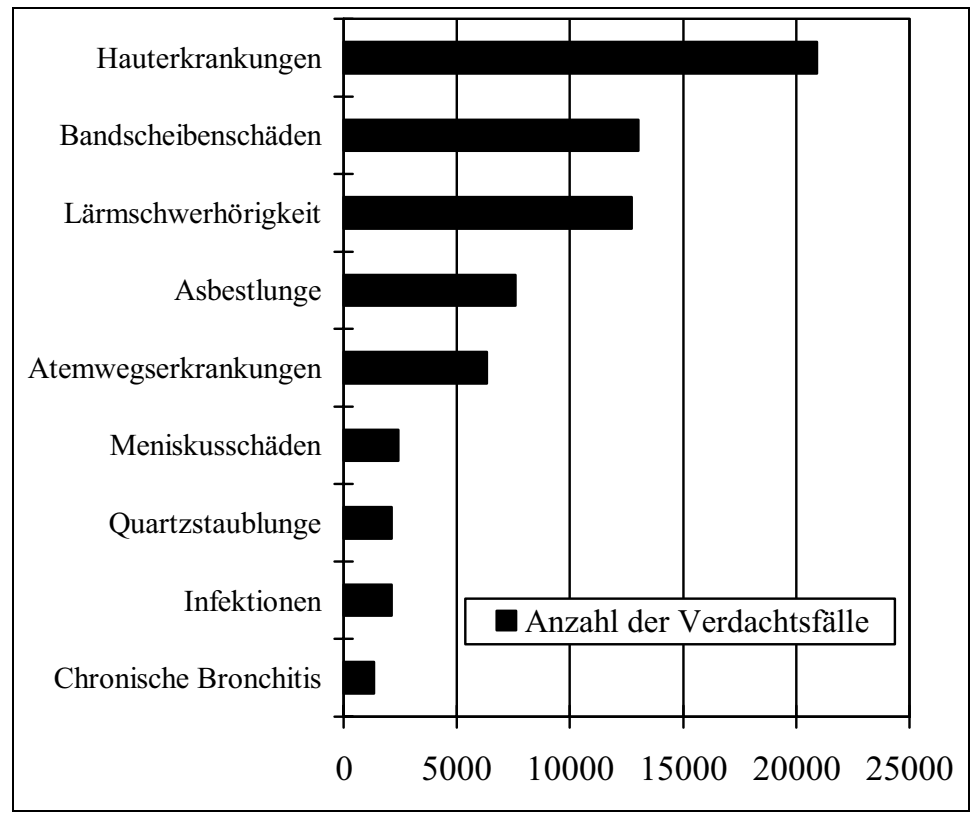

Quelle: Die Zeit vom 21. März 2002

32 Chronische Allergien sind auf breiter Front auf dem Vormarsch. In Westdeutschland leiden rund 33\% der männlichen und 47\% der weiblichen Bevölkerung daran. Referenz: Hermann-Kunz, E. (1999): „Häufigkeit allergischer Krankheiten in Ost- und Westdeutschland". Gesundheitswesen 61, S. 100-105. Von den in den 70er Jahren geborenen Japanern leiden $86 \%$ an einer Allergie. Die Rate hat sich damit in 20 Jahren verdoppelt. Japan Times vom 25. Februar 2003, S. 3. 
Während die Körperlatenz ein medizinsoziologisches Faktum ist, das sich wie das Ozonloch der Erdenhaut jährlich besser erhärten läßt, ist es Aufgabe der Theorie, die paradoxe Zeichnung ungezeichneter Körper als absolute Grenze der Autonomie des Subjekts aus dem Massenmedium Werbung herauszulesen. Ihre Umschreibung beginnt im Reich der Zeichen, das die Systemtheorie selbst als perfekt geeignet für die Semantik funktionaler Differenzierung beschrieben hat: in der ökonomischen Verpackungskunst Werbung in der Verpackungskultur Japan.

\subsection{Materialistische Matrizen: Werbung im maternellen Japan}

\section{Werbung als mediale Grenze des Wirtschaftssystems und seiner Theorie}

Die Werbung zieht die durch das Geld präzise definierte ökonomische Systemgrenze unscharf. Auch historisch. Wenn die Werbung die unmittelbare Reaktion auf die autopoietische Schließung des Funktionssystems Wirtschaft ist, so rätseln die Forscher bis heute über den Zeitpunkt ihrer Entstehung. Zwar lassen sich erste Werbekampagnen schon in der ersten Hälfte des 19. Jahrhunderts beobachten, aber das Medium scheint sich erst in der zweiten Hälfte wirklich durchgesetzt zu haben, und zwar zuerst im industrialisierten England und in Amerika. ${ }^{33}$ Alteuropa (und auch Japan) leisteten (mit Adorno) noch bis nach dem Zweiten Weltkrieg Widerstand.

„Die einsetzende Verallgemeinerung der Werbekonkurrenz schlägt sich im stürmischen Wachstum der Werbeausgaben, sowohl der Werbebudgets einzelner Kapitale wie der Werbeausgaben insgesamt, nieder. Baran gibt z.B. an, daß sich allein die Ausgaben für Zeitungs- und Zeitschriftenreklame (nicht gerechnet Werbemittel wie Plakate, Handzettel, direct mail usw.) in den USA im Zeitraum von 1867 bis 1890 nahezu verzehnfachten; von ca. 8 Millionen Dollar im Jahre 1867 auf ca. 76 Millionen Dollar im Jahre 1890. Diese historische Phase kann als die Durchsetzungsphase des Markenwarenwesens im Konsumgütersektor angesehen werden, die sich in entsprechend sprunghafter Form in Deutschland erst in den fünfziger Jahren vollzog. “ ${ }^{34}$

Nachdem sich Adorno von seinem Schrecken angesichts der gesungenen Werbesprüche erholt hatte, geriet zwar Ende der 70er Jahre endlich auch die altehrwürdige Manipulationsthese ins Wanken. Zwar wird die Wer-

33 Schnierer 1999: 22-27.

34 Lindner 1977: 45. 
bung seitens der Medienethik immer noch als teuer und nutzlos lieber kritisiert als goutiert; so errechnete Hans J. Kleinsteuber eine „Werbesteuer" von knapp 900 Mark, die jeder Haushalt in Deutschland im Jahr bezahle. ${ }^{35}$ Aber schon Marx merkte an, daß die Werbung den Wert der Ware und damit auch ihren Preis nicht erhöht. ${ }^{36}$ Schon seine Werttheorie begreift also die Werbung als informative Dreingabe zur Ware, genauer: als Geschenk oder Ausnahme vom Tausch, der soziale Bindung und Verpflichtung symbolisiert. Trifft das zu, dann ergibt sich für die Systemtheorie ein pikantes Problem. Denn wenn im Falle der Werbung keine materiellen Äquivalente getauscht und vom Konsumenten oder Rezipienten kein Preis (direkt) bezahlt wird, dann ist die Werbung im Rahmen ihres funktional operierenden Wirtschaftssystems überflüssig. Seine Grenze verschwimmt.

Die wichtigste Eigenschaft der Werbung ist daher ihre Dysfunktionalität im Rahmen funktionaler Differenzierung. Sie markiert die subjektive Grenze der Macht des ökonomischen Funktionssystems. Wer in harter (männlicher) Währung bezahlt wird, muß handeln, wer sanft (weiblich) umworben wird, nicht. Die Werbung unterstellt ihren Rezipienten - wie das Bürgerliche Gesetzbuch - Zahlungsfähigkeit und adressiert sie nicht als Arbeitskräfte, Konsumenten, Bürger o.ä., sondern als Subjekte mit klaren Vorstellungen zur Lebensgestaltung. Systemtheoretisch ist die Theorie der Werbung daher nicht anschlußfähig. Luhmann hat sie folglich in seinem Buch „Die Wirtschaft der Gesellschaft“ negiert, dann allerdings in seinem Text „Die Realität der Massenmedien“ die Paradoxie der Werbung eingeräumt: „Wie können gut situierte Mitglieder der Gesellschaft so dumm sein, viel Geld für Werbung auszugeben, um sich ihren Glauben an die Dummheit anderer zu bestätigen? Es fällt schwer, hier nicht das Lob der Torheit zu singen, aber offenbar funktioniert es, und sei es in der Form der Selbstorganisation der Torheit." 37

Siegfried J. Schmidt und Brigitte Spieß haben versucht, die Werbung als Teilsystem der Ökonomie zu begreifen. Sie analysieren deutsche TV-Werbespots aus vier Nachkriegsjahrzehnten und führen aus, daß die Werbung die Leitwerte des Wirtschaftssystems vertritt: jung, dynamisch, erfolgreich. Schmidt/Spieß folgern, daß sich die Werbung vom Produktwettbewerb zum Kommunikationswettbewerb entwickeln muß. Die materiellen Produkte, die sich ohnehin immer stärker ähneln, geraten ins

35 Für die Werbewirtschaft widersprach Jean-Pierre Wilwerding mit dem unvorhersehbaren, unvermeidlichen Argument, ohne Werbung sähen die Bildschirme aus wie in Nordkorea. Zu lesen in der Süddeutschen Zeitung vom 11. und 16. September 1997, jeweils S. 19.

36 Marx 1975: 131ff.

37 Luhmann 1996: 85. 
Hintertreffen, und die Kommerzialisierung der Kommunikation gräbt sich selbst das Wasser ab. ${ }^{38}$ Während sich in der universellen Akzeptanz des Zahlungsmittels Geld die ewige Knappheit materieller Güter spiegelt, belegt analog die informative Werbung die unaufhebbare Knappheit der medialen Aufmerksamkeit. Damit stößt aber auch die Systemtheorie auf eine begriffliche Tautologie. Denn die materiellen Güter sind für die Konsumenten knapp, die Knappheit der Aufmerksamkeit bzw. Knappheit an Zuschauern und Zuhörern ist dagegen eine Folge kommunikativer Übersättigung.

Das Dilemma der Systemtheorie, das sich schon anhand der massenmedialen Einbettung des politischen Systems verdeutlichen ließ, liegt daher auf der Hand. Von außen betrachtet: Hätte sich die Ökonomie tatsächlich ganz von den Subjekten in ihrer Umwelt entkoppelt (Irreduzibilitätsthese), dann hätte sich die Werbung nicht ausdifferenzieren müssen. Die Ökonomie wäre dann allein über Geld verfaßt, ohne jeden Diskurs über Gebrauchswerte. Die Theorie muß dann auch Werbung und Massenmedien als System verfassen und kreiert eine sterile Wucherung des Gleichen: Werbung vertritt konservative Leitwerte. Von innen betrachtet: Gerade weil es dem ökonomischen Funktionssystem gelungen ist, sich selbstreferenziell gegen Irritationen aus seiner Umwelt abzuschließen, braucht es ein Autoskript, eine Verpackung, eine Schrift der Identität, um sich zu den Subjekten und ihrem Bewußtsein in Differenz zu setzen. Dann aber ist dieses Autoskript auch medientheoretisch zu entziffern.

Die Annahme, Aufmerksamkeit sei knapp, ist daher ebensowenig plausibel wie die Annahme, Liebe sei unwahrscheinlich. Vielmehr liegt der empirische Grund für das meßbare Desinteresse am Werbekonsum im kommunikativen Überfluß. ${ }^{39}$ Werbung ist hochentropisch, ihre Ausblendungsregeln sterilisieren sie kommunikativ, auch hat die Mehrheit ihrer Empfänger keinen Bedarf nach dem umworbenen Produkt. Aber gerade das hochkomplexe System der Ökonomie kann nicht umhin, an einer Stelle seinen kommunikativen Durchlauf durchs Subjekt zu nehmen. Deswegen ist die Werbung nicht systemtheoretisch zu beschreiben: Sie spricht eben nicht die Sprache des Geldes, sondern ist nur als Beschriftung zu lesen, als latente Kommunikaton zwischen System und Subjekt. Werbung ist kein Teilsystem der Ökonomie, sondern das informative Äquivalent der Knappheit des Geldes selbst, sein nicht totzukriegender, lauschender und saugender Parasit der Kommunikation über

38 Schmidt/Spieß 1996: 35-52 und 358-361. Schmidt 2000: 270.

39 Aus der empirischen Werbeforschung ist bekannt, daß Werbepausen im Fernsehen zumeist zum Telefonieren oder zum Händewaschen genutzt werden. Die attraktivsten Plätze im Werbeblock sind daher die erste und die letzte Position nahe am Programm. 
das Medium Geld. ${ }^{40}$ Die Systemtheorie beschreibt das Wirtschaftssystem nur, für seine Beschriftung sorgt es selbst. Die Verpackungskunst Werbung trägt seine Zeichen. Und hier liegt ihre Affinität zum vielschichtigen menschlichen Bewußtsein: Werbung transportiert (wie die Nachrichten) immer auch eine Kommunikationslatenz. Nichts wäre falscher, als diese im subtilen Kaufzwang zu suchen. Vielmehr produziert der Materialismus des Geldsystems, analog zur Bewußtseinslatenz der Massenmedien des politischen Systems, materielle Körperlatenz. ${ }^{41}$

In das Medium zwischen Subjekt und System muß daher die Differenz zwischen Subjekt und Arbeitskraft einfließen. Das System, das die Individuen als Umwelt benutzt, muß die Latenz des Körpers kommunikativ verpacken. Das leistet das Massenmedium Werbung. Lesbar ist es nicht als eine warenbezogene, warenähnliche „message“ fürs Bewußtsein, die ohnehin in der Differenz von Information und Mitteilung verschwände, sondern als Einschrift in die Ware Arbeitskraft, als Grenzstein ihrer subjektiven Autonomie. Werbung ist zu begreifen als Engführung, als Haut-Kontakt zwischen Ökonomie und Lebenswelt, als semantisches Angebot für eine „body-based technology of the self“. Sie findet in der Wrapping Culture des maternellen Japan ihr ideales Milieu.

\section{Kulturelles Milieu eines materialistischen Mediums: Maternalität, Wrapping Culture, Konsumgesellschaft}

Die Anthropologin Joy Hendry hat Japan als Verpackungskultur umschrieben. ${ }^{42}$ In ihrem Buch läßt sie Geschenktraditionen, Grußkarten, die Auslagen an Gemüseständen, Sitzordnungen in japanischen Büros, Kimonos und Yukatas, Höflichkeitspräfixe und -suffixe der japanischen Sprache sowie ihre Kontaktaufnahme zum japanischen Thronfolger revue passieren und faßt den Kontextualismus, die Empathie und Wahrnehmung der japanischen Psyche in eine ethnographische Formel. Die Verpackung - bis hin zum bewußten Verdecken von Rissen in Kühlbehältern von Atomkraftwerken - ist eine Strategie der harmonischen Konfliktvermeidung. ${ }^{43}$ Ihren konkreten Nutzen darf die Kundschaft in Japan

40 Heinze 1994.

41 In diesem Latenzschatten versteckt sich zugleich die offene Anschlußstelle an die Geldtheorie von Klossowski: „Aber derjenige, der letztendlich die Kosten trägt, der auf die eine oder andere Weise, bezahlen wird - das ist der Komplize, der sich durch den Ort konstituiert, wo sich der Kampf abspielt, wo um einen möglichen oder unmöglichen Kompromiß gefeilscht wird: der eigene Körper." Klossowski 1998: 63.

42 Hendry 1993.

43 Risse im Kühlkreislauf des AKW Fukushima wurden seit den 80er Jahren vor Inspektionen mit Farbe, Plastikplanen und Metallteilen verdeckt. Asahi Shimbun vom 13. September 2002, S. 1. Der Amerikaner Homer Simpson dagegen hätte aus einem Leck im Kühlkreislauf keinen Hehl gemacht. 
Tag für Tag erfahren: Das Land ist ein Serviceparadies, das Personal stets diensteifrig, vor den Parkhäusern und in den Kaufhäusern nicken freundliche Hostessen. Jeder eilt für die Zufriedenheit der Kunden. Sogar die zahlreichen Getränkeautomaten funktionieren immer, und auf manchem Display verbeugt sich eine Animation. In diesem interaktiven Milieu kann auch die Kommunikationsform Werbung nur gedeihen.

Brian Moeran vertritt im Anschluß an seine einjährige Feldstudie in der japanischen Werbewirtschaft die These, daß die kulturellen Unterschiede im Weltwerbesystem schwinden. Überall mache die Werbung aus der Ware eine Marke und füge ihr einen nicht-materiellen Wert hinzu - früher den Verweis auf den Gebrauchswert, heute den Verweis auf den Statusgewinn für die Konsumenten, auf Internationalität, Jugendlichkeit, In-Sein, Gesundheit oder Genuß. Mehr noch: Der Konsumismus (consumerism) ersetze Kultur. „To my mind, consumerism makes the category of ,culture' irrelevant in societies like those of the United States and Japan, since - thanks to global marketing practices and the workings of advertising in the media - all objects are potentially released into a floating world of signification and values from the cultural prisons in which they were formerly incarcerated."44 Moeran sieht speziell in der Empfänglichkeit Japans für das westliche Waren- (Alkohol, Reisen, Jazz, Kunst) und Wertesystem (Individualismus, Statusdenken) der Werbung eine neue, kleinbürgerliche Kultur der Distinktion entstehen. Heißt das, daß die Japaner sich dem Geschmacksdiktat der Werbung à la Luhmann beugen und ihre psychisch-dividuale Imperfektion auch als Konsumenten in funktionalistische Perfektion umwandeln?

Einiges spricht dafür. Betrachtet man die Werbedichte in der Großstadt Tokio, die Plakate und Taschentuch-Verteiler, die Beschallung auf den öffentlichen Plätzen und die Großbildschirme in Shinjuku und Shibuya, so entpuppt sich die japanische Hauptstadt schon architektonisch als eine der kommerzialisiertesten Städte der Welt. Die Bahnhöfe der Yamanote-Ringlinie mit ihren großen Kaufhäusern und die zahlreichen Einkaufspassagen (shôtengai) voller 24-Stunden-Läden kreieren eine zirkulative Innenwelt für Flaneure. Auch Tokyo Disneyland ist kein Simulakrum wie sein amerikanisches Original in der Analyse von Jean Baudrillard, sondern ein realer Bestandteil der Stadt, der sich wunderbar in ihre Atmosphäre einfügt. Mit Dornröschenschloß, Space-Center, Westernstadt und Toontown löst es sich vom alteuropäischen Ideal der Überschaubarkeit des urbanen und politischen Raumes. Disneyland zieht jeden Besucher emotional in seinen Bann, es ist lediglich ein weiterer sakariba (Vergnügungsviertel) von Tokio. ${ }^{45}$ 
Der öffentliche Raum in Japan ist nicht politisch, sondern kommerziell konnotiert. Im kommunikativen Milieu der maternellen Gesellschaft ohne normative Ethik gedeiht ein sanfter, konfliktscheuer Stil. Anders als in Amerika, wo die Werbung ohne Gespür, als offensiver, marktschreierischer und lästiger Versuch der Belehrung daherkommt und oft noch Konkurrenzprodukte niedermacht, arbeiten die japanischen Werber gern mit Andeutungen, Emotionen, Witzen, und lösen sich von der Ideologie der „message“. Als Japanese Railways im Winter 1999 mehr Autofahrer in den Zug locken wollten, zeigte ihr Spot lange Staus und zwei geplagte Fahrer, deren Wagen beim Anlegen von Schneeketten einen Abhang herunterglitt und in Flammen aufging. Doch auf den Zug wollte niemand umsteigen. Stattdessen wurde die Musik zum Film ein großer Hit. ${ }^{46}$

Die notorische Irrationalität der japanischen Käufer, ihre Empfänglichkeit für Moden, technische Neuerungen und Spielereien machen den japanischen Binnenmarkt zum idealen Feld für Marketing-Tests und zum Referenzmodell für postmoderne Konsumsemantiken. Während der bubble-economy in den 80er Jahren, als die Banken aufgrund der Überbewertung der japanischen Grundstücke riesige ungesicherte Kredite vergaben, träumte Japan den Traum immerwährender Prosperität und sah sich auch mit einem neuen, radikalen, selbstreferenziellen Typus von Werbung konfrontiert. Er hat dazu verführt, Japan und den Westen zum letzten Mal in einem binären Schematismus gegeneinanderzusetzen.

\section{Soft-selling/hard-selling: Kulturspezifische Werbestrategien}

Die Prosperität der 80er Jahre brachte in Tokio eine ganz neue Architektur hervor, deren Spuren heute noch jeder bewundern kann. Das teuerste Gebäude Japans, das Tokyo International Forum in Yûrakuchô, oder das Edo Tokyo Museum in Ryôgoku, erhoben sich wie Raumstationen aus der Stadt und ihrer sozialen Umgebung. Und parallel dazu löste sich die japanische Werbung nachhaltig vom Produkt. Statt seine Vorzüge zu preisen, begann die Werbung, sich als Kunst selbst zu zelebrieren. Im Jahre 1990, als die japanische bubble-economy zur höchsten Ausdehnung aufquoll, erreichte auch die japanische Werbewirtschaft einen maximalen Anteil von 1,29\% am Bruttosozialprodukt. ${ }^{47}$ Ganz im Einklang mit diesem Konjunkturzyklus entstand die These von der japanischen Werbung als „soft-selling“ im Gegensatz zum westlichen „hard-selling“. Sie schloß an zwei Beobachtungen an: Erstens denkt das

46 Asahi Evening News vom 4. Dezember 1999, S. 4.

47 Haehling von Lanzenauer 1998: 9. 
japanische Management stärker in Kategorien des Marktanteils und der Corporate Identity als in denen des kurzfristigen Profits, und zweitens folgen die Kommunikationsmuster in den Massenmedien weitgehend denen der alltäglichen Interaktionen.

Mit dem Begriff ,hard-selling“ war daher vor allem der amerikanische, vergleichende und teilweise diskriminierende Werbestil gemeint, mit dem Begriff „,soft-selling“ u.a. der typisch japanische Adhortativ („Lassen Sie uns...") der japanischen „Manner-Poster““. ${ }^{48}$ Kishii ging dabei so weit, die häufige Einschätzung von der Unverständlichkeit der japanischen Sprache und Kultur in seine Analyse zu übernehmen: Japanische Werbung sei ,,insider-oriented“ und für Ausländer auch mit Übersetzung oft nicht zu verstehen. ${ }^{49}$ Die einschlägigen Stichworte zur Beschreibung des japanischen Werbestils lauteten: soft-sell, collectivism, dependancy, nature, indirect, harmony, entertaining, mood commercial. Und das Standardbeispiel lieferte ausgerechnet Coca-Cola: Während sich die Firma in den USA mit Pepsi eine Werbeschlacht mit Häme und unlauterer Kritik lieferte, lautete der animistische Werbeslogan für Japan schlicht: „I feel Coke.“ ${ }^{650}$

Mehrfach wurde versucht, die soft-selling-These empirisch zu untermauern. Vielfach konnte sie belegt werden, insbesondere in den Printmedien und im Segment der Frauenzeitschriften. ${ }^{51}$ Katharina Dallmann hat mit ihrem Vergleich deutscher mit japanischer Zeitschriftenwerbung die Unterschiede präzisiert. Die japanische zeigt eine besondere Vorliebe für das Motiv Natur, auch ist ihr Text oft nach dem Vorbild der Rollbildmalerei in das Bild verwickelt. Die deutsche dagegen behandelt den Text nur als eine monotone, informative Dreingabe. Vertikaldruck und Flattersatz sind in Japan häufiger, auch treten wesentlich mehr Stars und Heroen auf, die mit Gestik, Mimik und Kleidung kommunizieren. Deutschland bevorzugt der Reihefolge nach die Farben blau (kalt und

48 Poster mit klaren Verhaltensanweisungen z.B. in der U-Bahn: Ihre Zeitung piekst den Nachbarn! Wir wollen doch lieber nicht in die U-Bahn hineinspringen! Grabschen ist ein Verbrechen!

49 „There is a cultural difference between the way Americans and Japanese communicate. Americans, perhaps because they have built a single nation from a multitude of ethnic groups, favor detailed explanations. Japanese believe that the most desirable method is to be able to understand each other without having to say a word. [....] Ambiguous expressions such as probably, if compelled I would lean toward and may (as a verb inflection) are part of everyday Japanese conversation, underlining the value of harmony and mutual dependence in human relationships. Likewise, there is a tendency in advertising to aim for a good reception by adopting this kind of speaking style." Kishii 1994: 54f.

50 Mooij 1997, Inoue 1996, Tanaka 1992, Müller/Kornmeier 1994: 156.

51 Gould/Minowa 1994, 198-199. Haehling von Lanzenauer hat den Stand der Forschung zum soft-sell-Paradigma zusammengefaßt und weitere Studien zitiert. Haehling von Lanzenauer 1998: 302-316. 
nüchtern), grün, rot, gelb, Japan dagegen grün (warm und natürlich), rot, blau, gelb. Die deutsche Werbung zentralisiert das Produkt. Die japanischen Anzeigen dagegen präsentieren in vielen Fällen gar nicht mehr das Produkt, nennen dafür aber eher seinen Preis als seine Eigenschaften. Auf der Ebene der Erlebnisinhalte arbeitet Japan mehr mit Appellen an den sozialen Status oder an kollektivistische Anpassung, Deutschland mit dem Angebot von Erotik. Allerdings war die japanische Werbung insgesamt nicht wesentlich emotionaler, die deutsche nicht wesentlich informativer als ihr Gegenstück. ${ }^{52}$

Im Bereich der elektronischen Medien ist es zwar viel schwerer, die soft-selling-These zu belegen. Z.B. arbeitet die japanische TV-Werbung stärker mit Sprecherinnen als die westliche, aber ihre überzogenen, quietschenden Stimmen sind meist alles andere als sanft oder soft. Aber auch ihre kulturelle Einbettung läßt sich untermauern. In ihrem Vergleich von mehr als 3.000 Spots aus Japan, Korea und Amerika maßen Taylor/Miracle/Chang deutliche Unterschiede schon in der üblichen Spotlänge. In Japan waren zwei Drittel der Spots nur 15 Sekunden lang, in den USA 30 Sekunden. In Korea war dagegen auch das 20 Sekunden-Format stark vertreten. Auch das Timing der Spots, d.h. die Dauer, bis das Produkt, der Markenname oder der Produktname im Bild erschienen, war von Land zu Land verschieden. Obwohl man also vor dem Hintergrund der Amerikanisierung der Weltfilmindustrie eine Vereinheitlichung und kulturelle Homogenisierung der Bildsprache annehmen könnte, bestätigte auch dieser Drei-Länder-Vergleich zur Fernsehwerbung die Ergebnisse des 19-Länder-Vergleichs von Yamaki Toshio: Eine interkulturelle Standardisierung von Werbestrategien ist weder zu beobachten noch zu empfehlen. ${ }^{53}$ An der Kulturgebundenheit der Werbung hat also auch der Globalisierungsprozeß nichts geändert. Zwar gibt es immer wieder internationale Kampagnen, Übernahmen, Anpassungen. Doch diese sind in den meisten Fällen als solche erkennbar und erhalten daher den Charakter von fremdkulturellen Zitaten. Die Kulturgebundenheit der Werbung muß daher noch tiefer verankert werden: Sie steckt bereits im kulturspezifischen Umgang der Konsumenten mit den Massenmedien selbst.

Betrachtet man die Reichweiten von Radio und Fernsehen in Japan und Deutschland im Tagesverlauf, so zeigt sich noch deutlicher die kulturspezifische Nutzungsweise der elektrischen Unterhaltungsmedien (Abbildungen 3 und 4).

52 Dallmann 1997.

53 Taylor/Miracle/Chang 1994. Yamaki 1990. 
Reichweiten im Tagesverlauf von Hörfunk und Fernsehen in Japan und Deutschland

Abbildung 3: Hörfunk- und Fernsehreichweiten im Jahre 1999 in Tokio im Tagesverlauf in Prozent

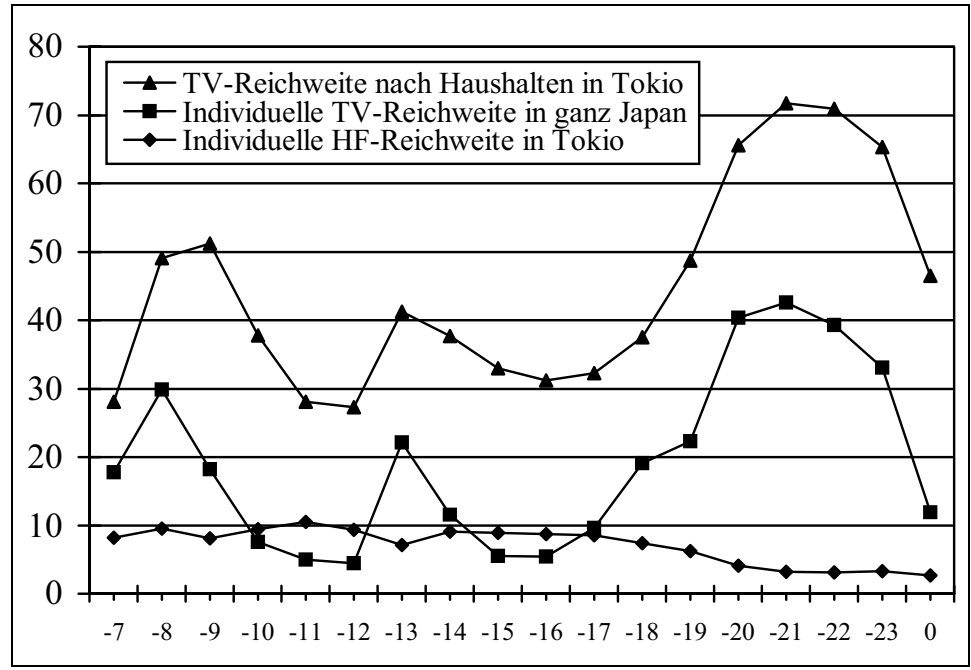

Quellen: Video Research, Tokio sowie Saito/Ida/Endo 2000

Abbildung 4: Hörfunk- und Fernsehreichweiten im Jahre 1999 in Hamburg im Tagesverlauf in Prozent

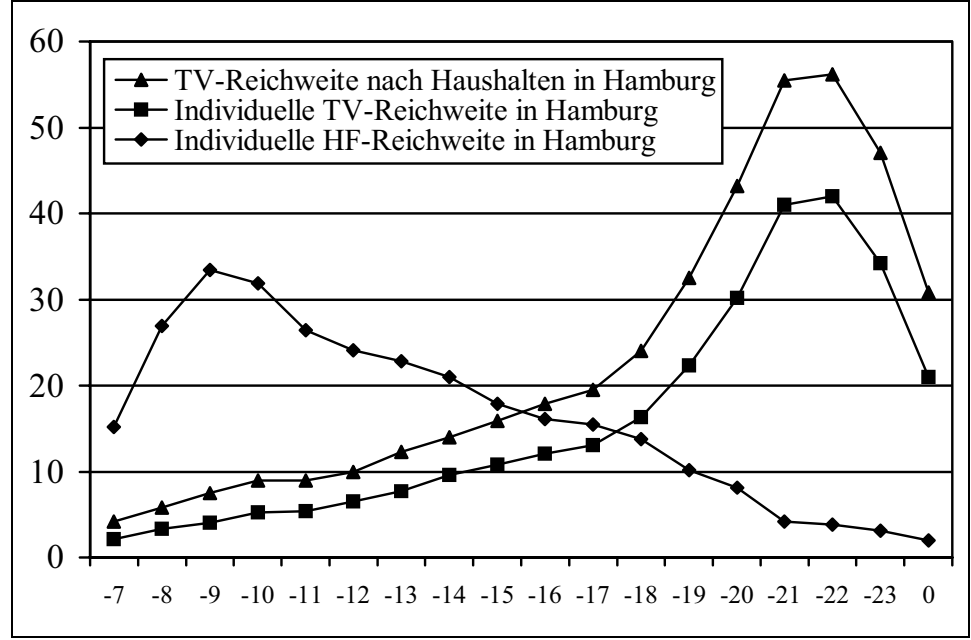

Quelle: GfK-Fernsehforschung. Norddeutscher Rundfunk, Hamburg 
Kulturspezifischer Medienkonsum: empirische Daten aus Deutschland und Japan

Das Fernsehen ist mit Abstand das wichtigste Medium für die Werbung in Deutschland und Japan. In Japan hat es seit dem Krieg einen kometenhaften Aufstieg hinter sich und mit seinen Werbeeinnahmen im Jahre 1975 schließlich die Zeitung überholt. Als Bildmedium kann es auch die chinesische Kanji-Schrift integrieren: $\mathrm{Zu}$ Werbespots, zu den Nachrichten und in Interviews werden häufig die O-Töne und Antworten zum Mitlesen eingeblendet, sodaß eine kulturspezifische Bildsprache entsteht. Auch die Kanji selbst sind schließlich im Ursprung eine Bilderschrift, die einen rasanten Zugriff auf Text und Sinn erlauben. Vielleicht deshalb sind in Japan Anzeigen in Zeitungen und vor allem Farbanzeigen in Zeitschriften auffallend häufig bildlich und textlich mit den TV-Spots gekoppelt. Das Fernsehen verschlingt in Deutschland rund $45 \%$, in Japan mehr als 50\% des nationalen Werbeetats (Abbildung $5 \mathrm{im}$ Anhang). Sponsoring für komplette Sendungen oder Filme sind häufig, aber nur in den Filmspots können die japanischen Werber ihren Hang zu digitalen Tricks und Simulationen ausleben.

Das Fernsehen erreicht fast alle Japaner und Deutsche jeden Tag. Die individuelle Sehdauer pro Tag liegt im Schnitt in Japan bei rund 225 Minuten, in Deutschland bei rund 185 Minuten (Ostdeutschland: etwa 210 Minuten. Westdeutschland: etwa 180 Minuten). Dabei nimmt die Sehdauer in beiden Ländern mit dem Alter stetig zu und erreicht im Segment der über 60jährigen mehr als fünf Stunden. In Japan schauen die Frauen in allen Altersgruppen mehr als die Männer. ${ }^{54}$ In Umfragen bekunden die männlichen Zuschauer unter 35 am Fernsehen mehr Interesse als an den Printmedien. Auch trauen sie seinen Informationen, während die Älteren eher der Zeitung glauben. Nach ihrem Interesse an Werbung befragt, antworten jedoch alle, das Fernsehen sei die wichtigste Quelle. Böse Zungen behaupten, der Fernseher habe im modernen Japan die Rolle der traditionellen Hausschreine übernommen. Bildeten jene früher eine zeitliche Brücke zu den Vorfahren, schließe der Flachbildschirm nun die Familie simultan an das Weltgeschehen an. ${ }^{55}$

In Deutschland dominiert das Radio den Vormittag und Mittag, seine Reichweite sinkt erst am Nachmittag unter die des Fernsehens. In Japan dagegen spielt das Radio nur eine untergeordnete Rolle - es erreicht nicht einmal die Hälfte der Bevölkerung. Die durchschnittliche individuelle Hördauer liegt seit Jahren unter 40 Minuten am Tag, das ist nur ein Fünftel des deutschen Werts von über 200 Minuten. Die Fernseh- 
kurve erreicht in Deutschland nur am Abend ein Maximum, in Japan aber dreimal am Tag: morgens, wenn die Fernsehserie von NHK ausgestrahlt wird, mittags, wenn die Privatsender ihre Serien verbreiten, sowie am Abend gegen $21 \mathrm{Uhr}$. Allerdings läuft das japanische Fernsehen sehr häufig auch nur als „Bilderradio“ nebenbei oder wird sogar während alltäglicher Unterhaltungen als Geräusch- und Bildkulisse hinzugezogen.

Wohl auch deshalb sinkt die Reichweite der Fernsehprogramme in Japan während der Werbeblocks (angeblich) nur um 10\%. Die Werbefilme, deren Ausstrahlung während der Prime Time eine runde Million Yen kostet, sind zwar mit 15 Sekunden meist knapp bemessen, etablieren sich jedoch immer wieder erfolgreich als Teil der alltäglichen Populärkultur. Das gelingt ihnen schon mit einfachen Wortspielen, für die das Japanische mit seinen zahlreichen Homonymen unendliche Möglichkeiten bietet. So sagt z.B. der Sprecher in einem Spot für den Kurierdienst Takkyûbin: Wenn die schwarze Katze (das Symbol der Firma auf ihren grünen Lieferwagen) kommt, ist alles einfach (kuro nekoga kaeru nara, raku da). Da jedoch kaeru auch Frosch heißt und rakuda Kamel, laufen hintereinander eine schwarze Katze, ein Frosch und ein Kamel durchs Bild. Auch die Firma Suntory kann in ihrer Werbung für den Whisky Hibiku (zu deutsch: tönen, erklingen) dem Wortspiel nicht widerstehen. Das Plakat zeigt ein ganzes Orchester im Konzertsaal, alle Musiker genehmigen sich ein Gläschen: Was ertönt für 100 Menschen? Tschaikowsky? Strawinsky? Whisky? ${ }^{56}$

Ein weiteres beliebtes Stilmittel der japanischen Werbung sind Filmzitate. Bevorzugt zieht sie amerikanische Action-Filme durch den Kakao. Ein Fußpilzmittel zielt wie in „High Noon“ auf der staubigen Straße vor dem Saloon auf seinen Feind. Das Haargel Bolty verschwindet im Werbespot im Oberschenkel seines Benutzers wie die automatische Pistole von „Robocop“. Ein Mann, dem eine junge Dame die letzte Nudelsuppe vor der Nase wegkauft, mutiert zum „Terminator" und rennt ihrem Wagen mit eisernen Krallen nach. Und im Spot der Firma J-Phone muß wie in dem Film „Blade Runner“ ein Polizeiwagen vor dem Großbildschirm in Shibuya landen - auf dem das japanische Supermodel Fujiwara Norika Produkt und Zeitalter preist.

Das japanische Werbesystem ist personell nicht zu trennen von der Glitzerwelt des Films und Fernsehens. Fast zwei Drittel der Spots ar-

56 Noch ein schönes Beispiel: Der Werbeslogan für den Epson-Farbdrucker: Ich bin Herr Rôru. Das Kanji für die Anrede Herr (shi: 氏) wird dann ausgetauscht gegen das Papier-Kanji (shi: 紙), dann heißt der Satz: Ich bin die Druckpapierrolle. In den Spot-Text geschickt eingeflochten sind die Worte koresuterôru (Cholesterol), patorôru (Patrouille), kurôru (Kraulschwimmen), kontorôru (Kontrolle), rôrukyabetsu (Weißkohlrolle). 
beiten mit sog. „Celebrities“. 57 Viele ausländische Stars geben sich in Japan für Werbefilme her, für die sie in ihrem Heimatland nur Spott ernten würden: Arnold Schwarzenegger für das Bier Hop's, Oliver Kahn für Autoreifen, Kevin Kostner für Subaru, Naomi Campbell für Shiseido, der Regisseur Spike Lee für einen Kleinwagen und die Simpsons für das anregende Getränk C.C. Lemon. Auch treten grundsätzlich alle japanischen Schauspieler in der Werbung auf. Einige beginnen sogar ihre Karriere erst mit ihrer Entdeckung als tarento, denn japanische tarento können alles. Auf dem jährlich erstellten tarento-Ranking war im Jahre 1999 Frau Fujiwara die unbestrittene Nr. 1 der Werbewelt, gefolgt von Hirosue Rryôko und Tanaka Reina. Fujiwara Norika warb für mehr als 10 Firmen gleichzeitig. Das Kaufhaus Tôbu in Ikebukuro widmete ihr eine eigene Ausstellung. Die Zeitung Asahi Shimbun sprach vom „Norika-Effekt" der Werbung. Obwohl die angepriesenen Produkte wie das Handy von J-Phone sich durch nichts von denen der Konkurrenz unterschieden, stiegen die Absätze (angeblich) um bis zu 30\%. ${ }^{58}$

Die Komiker sind schließlich das wichtigste Gewürz der japanischen Werbung. Kein anderes mediales Genre muß derart auf Humor setzen, kein anderer kommunikativer Modus markiert in diesem Maße Latenz. Nicht nur die einheimischen Komiker wie Tokoro George oder Kitano Takeshi hetzen durch die Fernsehshows und die Werbung, auch die ausländischen werden unweigerlich vom System aufgesogen. Mr. Bean (Rowan Atkinson) wirbt in seiner unnachahmlichen Art für ein Modell von Nissan. Im Spot führt er es einer englischen, unbeweglichen Palastwache mit Bärenfellmütze vor, die sich endlich erweichen läßt, ihre Augen dem Wagen zuzuwenden. Und auch der sympathische Nicht-Seßhafte, den Charly Chaplin verkörperte, wird in der japanischen Werbung verewigt. Natürlich wirbt er für einen Fernseher, den neuen Flachbildschirm von NEC: Es war ein Traum, ihn an die Wand zu hängen. Plasma $\mathrm{X}$. Die Zukunft ist dünn, groß und schön. ${ }^{59}$ Damit ist das Feld abgesteckt, in dem eine allgemeine Theorie der Werbung als Verpackung der Ökonomie sich empirisch zu bewähren hat.

57 Fields 2000: 212.

58 Asahi Shimbun vom 29. Dezember 1999: hayasugite gomennasaaai (zu schnell? pardon!). Dabei genügte es offenbar, sie mit dem Produkt zu zeigen oder ihren Namen mit dem des Produkts zu verschmelzen wie der rhythmisch-dadaistische Slogan für die Dosenlimonade Dekitate: Trinken wir Dekitate? Fujiwara Norika (dekitate nomuka. fujiwara norika). Auch der Bekleidungshersteller Wacoal engagierte Fujiwara Norika und textete hautnah: Fujiwara läßt nur angenehme Dinge an ihren Körper heran. Das Fujiwara-Prinzip (fujiwarawa, kimochi ii mono shika mini tsukenai. fujiwarashugi). Im Jahre 2001 erschien das Buch fujiwarashugi von Fujiwara Norika mit 61 Prinzipien für das Gesund-, Fit- und Glücklichsein.

59 壁に掛けるのが夢だった。

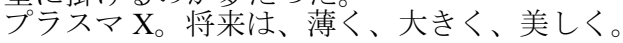




\section{Interkulturelle Lesungen}

\section{der Werbung in Japan}

\subsection{Die Lust am Werbetext: binärer Baukasten einer Theorie der Werbung}

Werbung ist Verpackungskunst. Sie lehnt sich als ökonomisches Massenmedium zunächst eng an das Argumentationsmuster der politischen Nachrichtensendungen an. Das politische System benutzt den Schematismus Regierung/Opposition zur Selbstbeschriftung. Dagegen ist nichts einzuwenden, solange die Journalisten tatsächlich den Politikern auf den Leib rücken und auf den Zahn fühlen. Aber wie jeder Image-Berater, jeder Soziologe, jeder Arzt und jeder Fernsehzuschauer weiß, kann Sprache, insbesondere die Sprache der Bilder, unangenehme Fakten, Gedanken und Assoziationen abmildern und Negatives ausblenden. Die „Bundesschuldenverwaltung“ erhält plötzlich den unverfänglichen Namen „Bundeswertpapierverwaltung“, Kürzungen von Sozialleistung sind nur „Kostendämpfungen“, Entlassungen „Anpassungsmaßnahmen (im Beschäftigtenbereich)" und die Tötung von Soldaten durch Kollegen im Krieg "friendly fire“. Schon in der Wortwahl steckt eine latente Wertung, die gerade deshalb eine große Wirkung entfalten kann. Wer erst einmal das Thema „Wirtschaftsstandort“ definiert hat, läuft keine Gefahr mehr, divergierende Interessen zu diskutieren. Und Benzinpreise sind zweifellos wichtiger als Atemwegserkrankungen.

Während die Nachrichtensendungen der Massenmedien in der Differenz zwischen Regierung und Opposition eine hinreichende operative Basis haben, um die Komplexität harter Interessengegensätze zu reduzieren, müssen die Akteure im Wirtschaftssystem sich mehr einfallen lassen, um ihre kommunikative Geschäftsstrategie zu verfeinern. Weder darf der Umgangston harter Geldgeschäfte und Vertragsverhandlungen 
in der Werbung durchschimmern, noch garantieren bloße Produktinformationen eine minimale Aufmerksamkeit. Daher muß das ökonomische Massenmedium mehr noch als die Nachrichten mit künstlichen Differenzen arbeiten. Die Werbung muß nicht nur alles Negative aus ihrer Kommunikation ausblenden, sondern die negative Kontrastfolie ihrer Präsentation selbst definieren. ${ }^{1}$ Daher findet jeder Leser von ökonomischer Selbstbeschriftung in der Werbung sein gefundenes Fressen und entdeckt seine Lust am Text. Ihre soziologische Dechiffrierung beginnt deshalb vorschriftsmäßig: mit der Identifikation ihrer binären Handschrift.

\section{Traum - Realität}

Im Gegensatz zur Realität des Schwarzenegger-Films „Total Recall“" gibt es noch keine Technologie des Traums. Gerade weil das menschliche Bewußtsein die Realität von der Realität der Massenmedien unterscheiden kann (Kapitel 2.3), tendieren sie zum Überzeichnen. Das besagt der Begriff „Traumfabrik“, der zum Leidwesen Adornos der Filmindustrie in Hollywood offenbar nicht geschadet hat. Man kann wissen, daß Filme fiktiv sind, und man kann wissen, daß die Werbung die Wahrheit dehnt. Gerade deshalb rutschen alle Manipulationsthesen ab, ist das Schema Wissen/Nicht-Wissen zu simpel, um die Kommunikation zwischen Massenmedien und Bewußtsein zu beschreiben. Das zeigt gerade das Beispiel des Traums. Alle Subjekte träumen. Aber sie träumen, vor allem wenn sie vor dem Fernsehen einschlafen, unbewußt. Und dennoch können sie grundsätzlich ihre realen Träume von denen der „Traumfabrik“ unterscheiden. Die Vorliebe der Werbung für den Begriff Traum ist daher nicht als Manipulation, sondern eher als Image-Transfer zu deuten. Die Realität dient dabei implizit als negative Kontrastfolie.

Das weiß auch der Disney-Konzern, dessen Disney-Resort in Tokio größer ist als sein amerikanisches „Original“. Er warb zusammen mit den Japanese Railways für ein Kombiticket mit dem Slogan:

・夢が、ほんとうになる。クリスマス・ファンタジー。

- Der Traum wird wahr. Christmas Phantasy.

Wo Disney ist, dürfen Popcorn und Coca Cola nicht fehlen. Die Werbestrategie für den Sirup ist kompatibel: Zu den Strandbildern im TV-Spot lesen wir folgende Zwischentitel:

1 Zur „Ausblendungsregel“" s. Schmidt/Spieß 1996: 38. 
・ 3 秒で恋におちた。ビーチボーイになった。同じ夢を見てた。 ココロが踊りだす。

- In drei Sekunden habe ich mich verliebt. Ich wurde ein Beachboy - träumte ich, und mein Herz beginnt zu tanzen.

Die girlie-group Speed aus Okinawa erfreute sich großer Popularität. Im Werbesystem empfahlen die vier jungen Damen alle möglichen gesunden Leckereien: Hamburger, Pizza und Schokoladenpralinen. Auf dem Plakat für die Pralinen dansu der Firma Meiji zeigten sie sich als gute Feen verkleidet im Aschenputtel-Look.

・ちりばめたのは夢でした。ダンスチョコレート。

- Es war unser Traum, sie auszustreuen. dansu Schokolade.

Auch die Werbung für den Lippenstift T'Estimo 2000 mit den drei Schönheiten Fujiwara Norika, Matsuyuki Yasuko und Inamori Izumi (vgl. Kapitel 4.6) geht den direkten Weg. Der Sprecher liest die Einblendung vor:

・テステイモがあなたを夢中にさせる。

- T’Estimo läßt Sie träumen.

Die japanische Autofirma Toyota nahm den Traum verbal in ihren Slogan auf: Drive Your Dreams. Mercedes allerdings ging noch einen Schritt weiter und konzipierte seine Werbespots für die C-Klasse in Japan gleich selbst als Tagtraum. Eine Frau drückt mit verträumtem Blick ihre ganze Zahnpastatube leer, ein Mann träumt von seinem neuen Wagen und verschüttet traumverloren seinen Kaffee. Was der Sprecher sagt, läßt sich auch in der doppelseitigen Anzeige nachlesen, die das Auto gleich als Subjekt des Satzes benutzt:

・[C-Klasse] の 夢をみましたね。あなたを夢中にさせる、こ んどのCクラス。

- Sie sahen die C-Klasse im Traum. Sie läßt Sie träumen, die nächste C-Klasse.

Der Traum von der Mobilität und die Realität des Staus bedürfen keines weiteren Kommentars. Doch der Traum ist resistent, weil er immer den anderen Ort und die andere Identität einschließt: die Freiheit vom Ich. Der Traum vom Fahren ist in der Werbesemantik ein Traum vom Abenteuer. 


\section{Freiheit/Abenteuer - Langeweile}

Der Geschmack von Freiheit und Abenteuer - Dieser deutsche Slogan für Marlboro ist in veränderter Form auch in Japan anzutreffen. Der Begriff der Freiheit, restlos überstrapaziert auch in der politischen Auseinandersetzung, eignet sich als Standardeuphemismus perfekt für die Werbung. Bekanntlich stammt die Musik der deutschen Marlboro-Werbung aus dem Western „Die glorreichen Sieben“. Als Vorlage diente ihm der Film „Die sieben Samurai“ des japanischen Altmeisters Kurosawa Akira. Zwar reitet der Marlboro-Cowboy auch in Japan durch die Prärie, nicht aber auf seinem typischen Slogan. Allerdings finden sich zahlreiche andere Kampagnen, die sich bei der Freiheit und dem Abenteuer wortwörtlich bedienen. Und immerhin lockt die Marlboro Adventure-Tour auch in Japan mit Abenteuerlust. Zum Photo mit den roten Jeeps im verschneiten Grand Canyon lesen wir:

・冒険心で、手に入れる。屝を開くのは、あなたの冒険心だ。

- Mit Abenteuerlust, zugreifen. Die Tür aufstoßen, das ist Ihre Abenteuerlust.

Auch die japanische Werbung ordnet also assoziativ dem männlichen Geschlecht die maschinelle (PS-starke) Penetration des Raumes à la Virilio zu. So zeigt die Zigarettenwerbung für die japanische Marke Parliament ein weißes New Yorker Paar in einem roten Sportwagen (Ford Mustang?). Er fährt. ${ }^{2}$

・自由とやすらぎの香り。Parliament.

- Der Duft von Freiheit und Ruhe.

Offenbar ist die Assoziation von Freiheit nicht zu trennen von der Assoziation des Fahrens. Auch in Japan. In ihren Anzeigen argumentieren Toyota (New Windom), Honda (Import Premium) und Cadillac im Chor:

・その自由、実力、美学、ウインダム。

- Freiheit, Leistung, Ästhetik. Windom.

・日本という枠をはずすと、走りはもっと自由になる。

- Wenn Sie den engen Rahmen Japans sprengen, wird das Fahren noch mehr zur Freiheit.

-もっと自由八。

- Hin zu mehr Freiheit.

2 Möglicherweise ist der Begriff Abenteuer in der deutschen Autowerbung tabu wegen des entsprechenden frauenfeindlichen Verses. 
Auch die neuen digitalen Produkte halten den Geist der Freiheit wach. Universelle kommunikative Freiheit verspricht NEC in Japan. Gleichzeitig lanciert das Plakat mit der schönen Frau einen individualistischen Appell:

・わたしは、どうでも、どこでも、自由です。

- Ich bin wie auch immer, wo auch immer frei.

・自由は、私のスタイルです。

- Freiheit, das ist mein Stil.

Neu(geboren) - Alt

Die Kraft des Neuen - dieser Slogan aus dem deutschen Wahlkampf mußte 1998 zurückgezogen werden, weil eine Industriefirma ihn schon benutzt hatte. Die Redundanz der Werbung ist in puncto Neuigkeit nicht zu überbieten. Allenfalls Japan schafft das. Hier ist grundsätzlich jedes Produkt neu geboren, neu im Verkauf, neu entwickelt, neu auf dem Markt oder zumindest neu konzipiert. Kein Werbetext ohne die Zeichen

- 誕生。新発売。新登場。新発想。

- Neu geboren. Neu im Verkauf. Neu auf dem Markt. Neues Konzept.

Kanji-Kenner sehen im Wort für Geburt zugleich das Wort für Industrie (産業) und für neugeboren/unschuldig (産, vgl. Kapitel 4.3). Das japanische Wort für Zeitung heißt wörtlich übersetzt: neues Hören. Daher ist die Idee der Werbung für die Tageszeitung Asahi Shimbun, die Neuigkeit zu betonen, logisch: die Quadratur des Kanji mit der Bedeutung neu läßt sich auch im Rahmen des westlichen Schriftsystems verstehen.

- 朝日新聞

- Asahi Shim²bun (Neue ${ }^{2}$ Asahi-Zeitung)

Auch Zigaretten sind kein neues Produkt, aber man kann sie immerhin neu verpacken und neu benennen. Z.B. die Zigarettenmarke Golden Bat (All New).

・吸いやすさが、新しい。コーモリ、変身する。 Golden Bat (All New).

- Die neue Leichtigkeit beim Inhalieren. Die Fledermaus, sie verwandelt sich. Golden Bat (All New). 


\section{Schön - Häßlich}

Schönheit ist ein weiteres Paradigma des Werbesystems. Sowohl die der Waren als auch die der Körper. In Japan springt sie über ihr Kanji direkt ins Auge des Betrachters. Zwei Beispiele: Das Werbeplakat in Ikebukuro für ein neues NEC-Notebook beschriftete eine schöne Japanerin mit einem Text, auf dessen Deutung ich verzichte.

- 美・アクセス

- Schön. Access (Zugang).

Ein schönes weißes Model rekelt sich im Stile der maja vestida auf dem Plakat von Lauré Parfage. Es trägt die Unterwäsche, die es empfiehlt:

・美しい下着は、魔法をつかう。 その美しさ、スウイート・エレガンス。

- Diese schöne Unterwäsche verzaubert. Diese Schönheit, sweet elegance.

Schön ist auch die Werbung für den Kalender der Japanese Railways.

・ 日本の美しさは、列車が知ってる。

- Die Schönheit Japans, der Zug kennt sie.

Schön und Kraftvoll zugleich ist der Alfa Romeo 156. Sein italienischer Slogan lautet: Cuore Sportivo. Der japanische Text:

・ パワー意のままに、フォルム美のままに。

- Soviel Power, wie Sie wollen, soviel Formschönheit, wie Sie wollen.

\section{Engel - Teufel bzw. Himmel - Hölle}

Der religiöse Schematismus bietet der Werbung die Möglichkeit, ein gängiges gut/böse-Raster zu benutzen und sich gleichzeitig humorvoll davon zu distanzieren. So der berühmte Slogan von Milka: Die zarteste Versuchung, seit es Schokolade gibt. Den nämlichen Spot mit Priester und unschuldigem Kind hat Yamaki sogar als typisch deutsche Werbung zitiert. ${ }^{3}$ Ein deutscher Slogan für Ford hat die Paradoxie des Schematismus auf den Punkt gebracht: Teuflisch gut - oder einfach himmlisch?

3 Yamaki 1990: 158. 
Teufel und Gott haben aber auch im diabolischen Medium Werbung im buddhistischen und shintoistischen Japan ihre regelmäßigen Auftritte. In einer Werbung für das scharfe Bonbon Mentos erklimmt ein langhaariger Sünder den Beichtstuhl und fragt: Kann ich armer Sünder rein werden (yogoreta orega pyûa ni naremasuka)? Zur Antwort hält der Priester die Bonbonrolle in die Luft und sagt nur: Neu im Verkauf (shinhatsubai)! Der geläuterte Junge verläßt daraufhin im blauen Konfirmandenanzug und mit frischer Kurzhaarfrisur das Gotteshaus. Das schönste japanische Beispiel lieferte aber der Schauspieler Jean Reno in seiner Werbung für den Dosenkaffee Break (Vgl. Kapitel 4.6). Dort versorgte er als Teufel seine leidenden Untertanen mit kühler Erfrischung. Der Slogan:

・地獄デ天国。BREAK ブレイク 新登場！

- Das Paradies in der Hölle. Break. Neu auf dem Markt!

Offenbar hat der Teufel in Japan eine Vorliebe für Dosenkaffee. In dem Spot für Black Boss klopft er seinem Taxifahrer auf die Schulter und deutet auf die schwarze Ampel: Was bedeutet das (kurokute nanda)? Daraufhin fließt der Verkehr rückwärts. Auch eine Paradoxie.

\section{Stark - Schwach bzw. Kraft - Schwäche}

Sind sie zu stark, bist du zu schwach. Mit dieser deutschen Werbung für die Halsbonbons Fisherman's Friends nähert sich die Analyse dem Körper und seinen Schleimhäuten. Stärke und Kraft sind Produkt- und Körpereigenschaften, die jeder Cowboy, jeder Autofahrer und jeder Konsument für sich verbuchen möchte. Und der Engel, der in der Werbung für Supli von Kirin Beverages mit seinen Füßen in einer Quelle plantscht.

・まもって、あげる。サプリの、チカラ。

- Ich beschütze. Mit der Kraft von Supli (Kirin Beverages).

Der Fernsehspot für den VW Polo wurde aus den USA nach Japan übernommen. Ein starker weißer Bodybuilder steht im weiß unterblendeten Bild. Ein Polo fällt vom Himmel, und der Sprecher sagt:

・ 新しくなった、ポロ。このサイズでは、 世界でも最強のひとつです。ポロはかなり強い。

- Der neue Polo. In dieser Klasse ist er der stärkste der Welt. Der Polo ist ziemlich stark. 
Auch Audi hat für seinen Quattro eine schöne Anzeige geschaltet. Vier nackte Männer knien neben der Karosse, startbereit. Daneben heißt es:

・チカラのあるモノは美しい。チカラを操るモノは、 さらに美しい。Audi. Vorsprung durch Technik.

- Was Kraft hat, ist schön. Noch schöner ist, was die Kraft beherrschen kann. Audi. Vorsprung durch Technik.

Alfa krönt diese Strategie schließlich mit dem Werbespruch für seinen Spider. Hier heißt es schlicht und ergreifend:

- Alfa Spider. Sexy Technology.

Das erinnert an den deutschen Slogan für den Audi TT: LusTT. Und für den Alfa 166 heißt es auf dem Plakat in Japan:

・ 心駆けるパワー、最上の確信。

- Die Power, die das Herz höher schlägen läßt. Höchstes Vertrauen.

Damit sind wir bei der Kraft der Liebe, die sich in Japan besonders gut durch das Handy kommunizieren läßt. In dem Spot für die Firma Tsu-Ka ist das Wort Kraft mal wieder in Katakana gesetzt. Wir lesen und hören:

・メールのチカラで恋をする。

- Mit der Kraft der Mail Liebe schaffen.

Kräftig und sehr groß gesetzt ist auch das Kanji für Kraft in der Werbung für das Bier Asahi Dry, das aus einer Notlage der Firma heraus gegen den großen Konkurrenten Kirin im japanischen Markt verankert werden konnte.

・ビールの力。人を讃える力。人を励ます力。人と喜びを分か ち合う力。それは、辛口の力。Asahi スーパードライ。

- Die Kraft des Bieres. Die Kraft, Menschen zu loben. Die Kraft, Menschen zu ermutigen. Die Kraft, Freude mit anderen Menschen zu teilen. Das ist die Kraft der Würze. Asahi Super Dry.

Noch ein Beispiel aus der Telekommunikation. Mitsubishi wirbt für sein tragbares Cyber Giga TH 201 mit schützendem Zubehör für Mensch und Telefon: 
・アウトドアに強い。Field Jacket 付き限定モデル。 ジャケットを着て強くなる。

- Outdoor stark. Das Field Jacket (zum Handy dazu) in beschränkter Auflage. Mit dieser Jacke werden Sie stark.

\section{Pflanze - Maschine bzw. Natur - Industrie}

Der Schematismus Natur - Industrie leitet über zum Vegetativen und zum weiblichen Geschlecht. Natürlich saugen sich die Körperbilder besser und häufiger an weiblichen Kurven fest als an männlichen Muskeln. Gerade die Werbung für Damenbinden muß die Schwächen des weiblichen Geschlechts überspielen und redet gerne von der Beweglichkeit der Frau und der Bewegungsfreundlichkeit des Produktes. Im japanischen Spot für eine solche Slipeinlage heißt es:

・自然体で暮らす発想。

- Das Konzept, mit dem natürlichen Körper (Stil) zu leben.

Am liebsten projiziert die Industrie ihre Naturnähe unmittelbar in die Namen ihrer chemischen Produkte. Wälder, Pflanzen und Natur springen in Japan schon aus deren Kanji entgegen.

・森のエッセンス。

- Waldessenz

heißt ein japanisches Shampoo mit Conditioner. Im Spot geht ein Igel hinter der Flasche her und bekommt dann weiche Stacheln. Das tarento Tanaka Reina wirbt für das Shampoo.

- 植物物語。

- Pflanzenerzählung.

Shiseido wirbt für das Parfum Eau de blanc mit einem vegetativen Fernsehbild: Frauen, die wie Blätter an einem Stengel in einer grünen Umgebung übereinandersitzen, reichen die Lotion nach unten weiter. Dabei murmeln sie in verschiedenen Sprachen den Produktnamen. Der Slogan:

・植物エキスがしみていく美白モノです。Eau de blanc.

- Es ist ein schönes Weiß, dessen Pflanzenextrakt tief eindringt. Eau de blanc. 
Auf der farbigen Anzeigenseite für Mitsukoshi Origins aus der Tageszeitung Asahi Shimbun fallen alle Stichworte in einer assoziativen Kette: Natur, Pflanze, Schönheit, Körper, Haut.

・オリジンズが、やってきた。

草木の神秘の力で肌の内側と外側から、きれいになる。 その肌に、森の力。

オリジンズの商品にはすべて、天然の草木から取ったエッセ ンシャルオイルが入っているのをご存じですか。 $[\ldots]$ 心と体がトータルで美しくなる、そんな生き方のスタイルを、 あなたに。

- Das neue Origins ist da.

Mit der wunderbaren pflanzlichen Kraft wird die Haut von innen und außen schön. Für diese Haut, die Kraft des Waldes.

Wissen Sie, daß in Origins nur natürliche, pflanzliche Essenzen enthalten sind? [...] Daß Körper und Geist komplett schön werden, diesen Lebensstil wünschen wir Ihnen.

Die Liebe zur Natur verdichtet sich traditionell in der Tierliebe und im Kauf der entsprechenden Utensilien. Im Spot für ein Hundefutter steht zu lesen:

・自然食材、という愛し方。30の自然食材をブレンド。

- Mit natürlichem Futter die Liebe ausdrücken.

Eine Mischung aus 30 verschiedenen natürlichen Futterstoffen.

Sehr schön und grün ist auch der Spot von Itôen für Gemüsesaft. Eine Konzertgitarristin spielt ihre Triller, während der Sprecher aufklärt:

・ココロ、カラダ、充実。充実野菜。 (eingeblendet:) 自然が好きです。

- Herz, Körper, Reichhaltigkeit. Reichhaltiges Gemüse. (eingeblendet:) Die Natur ist liebenswert.

Die japanische Werbung assoziiert auch zwanglos Alkohol und Natur. Eine Anzeige für Johnnie Walker Pure Malt zeigt eine englische Moorlandschaft mit einem kaminartigen Steinhaus - in Flaschenform.

・厳しい大自然から生まれるスムースな味わい。

- Geboren aus der rauhen Natur, dieser sanfte (smooth) Geschmack. 
Einen baugleichen Text präsentiert die Werbung der Japanese Railways vor einem Foto von Seehundmutter und Kind im rauhen Eis. Die eingespielte Natur auf den überfüllten Bahnhöfen Tokios spendet einen Hauch familiärer Wärme und erinnert auch an die schmerzhafte Individuation.

・アザラシの親子の時間は約二週間。あっという間にやって 来る親離れの時。大切なことが、別れによって伝えられま す。母の姿の求め鳴くことをやめる時、子供は、厳しい自 然を生きることを、覚えはじめます。

- Die gemeinsame Zeit von Seehundmutter und Kind beträgt etwa zwei Wochen. Sofort danach kommt die Zeit der Loslösung von der Mutter. Durch die Trennung wird (dem Kind) etwas Wichtiges mitgeteilt. Wenn der Lockruf der Mutter ausbleibt, beginnt es zu lernen, in der unbarmherzigen Natur zu leben.

Die japanische Werbesprache steigert die Natur (shizen) nicht nur in Richtung der Wildnis (yasei), sondern auch in Richtung der Rohheit, Ursprünglichkeit (tennen). Ihre Eigenschaft können dann gleichermaßen chemische Produkte und Nahrungsmittel annehmen. Z.B. das Haarmittel Croce oder auch die gerösteten Kastanien vom Kanebo-Konzern.

- 新天然力。Croce.

- Die neue, ursprüngliche/natürliche Kraft. Croce.

・天然甘栗の美味しさそのまま、一粒一粒むきました。 自然の甘さそのままに。

- Der Geschmack roher Kastanien, einzeln geschält. Die ursprüngliche Süße der Natur.

Die maximale, digitale Naturalisierung erreicht aber paradox die Computer-Werbung für den NEC Value Star NX Simplem. Sie schreibt das Natürliche (natchuraru) gleich in Katakana, wie das Digitale auch.

・これで私も、いよいよデビュー、かな。 デジタルはナチュラル。

- Ich frage mich, ob auch ich damit endlich anfangen (mein Debut haben) kann. Das Digitale ist natürlich. 


\section{Gesundheit - Krankheit}

Mit dem Schematismus gesund/krank verschwimmt die natürliche Grenze zwischen Produkt und Körper. Hier fließen Frische, Schönheit und Reinheit zusammen. In den 50er Jahren verkaufte sich auch die wellige Schrift von Coca Cola in Deutschland noch als gesund, inzwischen hat der Konzern seine Strategie verfeinert. Die Etikettierung von Produkten als gesund ist jedoch nach wie vor allerorten $\mathrm{zu}$ beobachten, besonders in der Werbung für die Kranken- und Pflegeversicherungen. Das alternde Japan bildet keine Ausnahme. Die Firma Glico verkauft ihre Fruchtkekse im Fernsehen mit einem typischen Slogan:

・健康フルーツ $50 \%$ 。毎日果実。おいしさと健康。Glico.

- $50 \%$ gesunde Früchte. Jeden Tag Obst. Lecker und gesund. Glico.

Auch an ermüdete und erschöpfte Büroangestellte richten sich zahlreiche Spots. Das Idiom otsukaresama deshita (Es war harte Arbeit heute! Schönen Feierabend!) beendet ganz real den japanischen Büroarbeitstag. Wenn er am nächsten Morgen wieder früh beginnt, helfen zahlreiche Energiegetränke über den Berg. Tagsüber wird dann wieder Tee getrunken, entweder chinesischer ûroncha oder grüner Tee aus Japan. Ihn gibt es auch aus der Dose, er trägt den Namen sôkenbicha. Im Werbefilm steht eine schöne Frau inmitten eines Wasserfalls und singt:

- 爽健美茶。

- Frischer, gesunder, schöner Tee.

Der Produktname erinnert an zwei morgendliche Radiosendungen des staatlichen japanischen Rundfunkprogramms NHK 1: kenkô raifu (Gesundes Leben) und furusato sawayakasan (etwa: der frische, heimatverbundene Mensch), die besonders bei alten Leuten beliebt waren und Frische und Gesundheit thematisch engführten. Aber in der Werbung ist Gesundheit eben kein Thema exklusiv für Senioren. Folgerecht heißt es in der Windelwerbung für Pampers:

・肌にすこやかに、大きくなあれ。

- Gesund zur Haut. Werde groß!

Der Diskurs der Gesundheit stößt erneut an eine Macht- und Definitionsgrenze: an die Grenze zwischen systemischer und subjektiver Identität. Indem die Werbung ihre eigenen Schematismen der Beobachtung schafft und jeder Negativität auszuweichen versucht, fällt sie der Negativität des 
Körpers anheim. Sie verpackt keine Waren, sondern gezeichnete Körper. Gerade weil das autopoietsiche Wirtschaftssystem die Individuen im Arbeitsverhältnis als Umwelt benutzt, muß sein Massenmedium Werbung diesen Vertrag gegenzeichnen. In der Werbung entfaltet sich daher der Widerspruch von Ware und Körper, von Arbeitskraft und Identität. Ihr Verhältnis ist nicht als Einheit der Differenz, sondern nur als kommunikatives Paradox nachzuzeichnen.

\section{2 tanjô (Geburt): Werbung gebiert Waren und zeichnet ungezeichnete Körper}

\section{Symbiotische Mechanismen und diabolische Kommunikation}

Im Massenmedium Werbung treffen nicht nur Ware und Körper aufeinander, sondern auch zwei verschiedene Theorieansätze. Eine Theorie sozialer Systeme, die sie lediglich bei ihrer Informationsverarbeitung beobachtet, klammert den Körper als materiellen Kern subjektiver Identität von vornherein aus. Dies wird deutlich an Luhmanns Begriff der symbiotischen Mechanismen. Sie bezeichnen im Rahmen seiner Theorie lediglich semantische Restbestände: Systeme kommunizieren über symbolisch generalisierte Kommunikationsmedien und müssen nur in Ausnahmefällen berücksichtigen, daß die Individuen auch Körper haben. Sie tun dies über vier symbiotische Mechanismen: Sexualität, Bedürfnisbefriedigung, physische Gewalt und sinnliche Wahrnehmung.

„Die Notwendigkeit, in der Kommunikation auf Körperlichkeit Rücksicht zu nehmen, kann man als Symbiosis bezeichnen und die entsprechenden Ausdrucksmittel als symbiotische Symbole. Symbiotische Symbole ordnen die Art und Weise, in der Kommunikation sich durch Körperlichkeit irritieren läßt; die Art und Weise also, in der die Effekte struktureller Koppelung im Kommunikationssystem verarbeitet werden, ohne daß dies die Geschlossenheit des Systems sprengen und eine nichtkommunizierbare Operationsweise erfordern würde. Eine Differenzierung der symbolisch generalisierten Medien legt eine entsprechende Differenzierung der im Medienbereich verwendeten symbiotischen Symbole nahe; denn die Bezugnahmen auf Körperlichkeit werden in einem jeweils hochspezifizierten Sinne erforderlich, während im übrigen außer Betracht bleiben kann, daß Menschen körperlich sind. “4

Die symbiotischen Mechanismen sind daher für Luhmann mit Selbstbefriedigungsverboten ausgestattet: Um sie zugunsten der systeminternen Kommunikation mit symbolisch generalisierten Medien zu unterdrücken,

4 Luhmann 1997: 378. 
müssen Staaten Gewalt monopolisieren und Ehen Sexualität. Auch die Wissenschaft darf sich nicht mehr auf idiosynkratische Intuition berufen. Der Körper muß aus Sicht der Systeme verschwinden. Doch gerade bei der Betrachtung des Massenmediums Werbung ist eine solche körperlose Theorie nicht anschlußfähig. Denn Werbung ist eine paradoxe Zeichnung des Körpers.

Das autopoietische Funktionssystem Ökonomie schließt sich zwar selbstreferenziell durch die symbolische Generalisierung des Geldes, doch damit entfesselt es zugleich die Diabolik der Selbstbeschriftung (Kapitel 3.2). Indem sich das System über sein massenmediales Autoskript Werbung identifiziert, kommuniziert es auch mit von ihm differenten Subjekten und adressiert sie als zahlungs-, entscheidungs- und reflexionsfähig. Gerade weil das moderne Wirtschaftssystem sich vom materiellen Stoffwechsel mit der natürlichen Umwelt der Gesellschaft und von den Körpern der Individuen entkoppelt hat, muß sein Massenmedium Werbung wieder an den Körper anknüpfen. Die Werbung ist daher der unmittelbare, kommunikative Hautkontakt zwischen der digitalisierten Geldökonomie und den taktilen Bedürfnissen der Individuen. In der Werbung wird nicht nur der Gebrauchswert der Ware wiedergeboren, sondern auch der Gebrauchswert der Ware Arbeitskraft, sie ist der paradoxe Übergang von der Beschreibung zur Beschriftung, von der Latenz der Kommunikation zur Kommunikation der Latenz.

\section{Von der Geburt der Ware zur Geburt der Körper}

Die deutsche Sprache kennt das schöne Idiom: sich wie neugeboren fühlen. In der japanischen Werbung wird dieser körperfixierte Gedanke radikal auf die Ware selbst angewandt. Überall in der japanischen Werbung werden die Waren wortwörtlich geboren. Produktion, Neuigkeit und Geburt bilden dabei eine Assoziationskette im Standardwerbetext. In der Werbung für das neue Handy von Panasonic intensiviert die Doppelbedeutung des Wortes kirei (schön bzw. sauber) noch das semiotische Spiel. Das Photo zeigt das Produkt mit Lippenstift und Nagellackflasche sowie mit dem Text:

・キレイ、すっきり。見た目もキレイな薄型 P H S 誕生。

- Schön und schnörkellos. Auch der Anblick ist schön des neuen (neugeborenen), dünnen PHS.

Und das gewundene Design des neuen Recorders von Panasonic erinnert tatsächlich an den Kopf eines Säuglings: 
・高音質の美しいIC レコーダー、誕生。美しく’ 情報 ‘を録 音。フォームが美しいICレコーダー、誕生。

- Der neue (geborene) IC-Recorder mit der schönen, hohen Tonqualität. Die „Information“ schön aufnehmen.

Der neue IC-Recorder mit der schönen Form.

Canon lobt seinen neuen Farbdrucker Wonder BJF 850:

・見えないから美しい。粒状感ゼロ。ドットが見えない。 新世代フォト面質。ウンダーBJ F 850 誕生。

- Schön, weil man es nicht sehen kann. Kein Gefühl von Körnigkeit. Keine Dots zu sehen. Die neue Generation von Foto- und Bild-Qualität. Wonder BJF 850 (Geburt).

Aber indem die Ware produziert (geboren) wird, soll auch der Konsument neu geboren werden. Im Gebrauch der Ware liegt das Glück der Identität, die Werbung argumentiert exakt auf der latenten Ebene dieser Akzentverschiebung von der Ware zum Körper. Z.B. die Firma Lion in ihrer Werbung für Shampoo:

・細くなった髪、生まれ変わる。ルネッサ。Lion.

- Empfindlich gewordenes Haar, es ist wie neu geboren. Lion.

Paradox gebiert erst der Körper(bezug) den Gebrauchswert der Ware, erhebt die Werbung den Rezipienten erst mit dem Argument zum Subjekt, daß die Ware körperlich zu konsumieren sei. So tanzt z.B. im Spot für Kirin Lager Light lediglich ein junger Mann im Bild, auf seinen schwitzenden Körper ist eine Bierdose aufgestanzt, und der Slogan: Body Needs Lager Light. Die Konkurrenz textet:

・からだに聞いて、ビールを替えた。

- Ich habe auf meinen Körper gehört und das Bier gewechselt.

Diese Körperbetonung kommt auch nicht umhin, auf den Sport und damit indirekt auf die Gewichts- und Ernährungsprobleme der Individuen Bezug zu nehmen. Das Plakat von Reebok spricht eine reine Körpersprache:

・フィットネス。Feel Your Body, Feel Reebok.

- Fitness. Fühle Deinen Körper, Fühle Reebok. 
Im Werbefilm für den Energietrunk Energen quält sich eine Leichtathletin im Training.

・絞ったカラダは、負けない。体脂肪を燃やせ。キレのあるボ ディのために。

- Der geschundene Körper verliert nicht. Verbrenne das Körperfett. Für einen ,scharfen“ Körper.

Die Werbung für das Getränk Pocari Sweat faßt den Körperbezug der Werbung idealtypisch zusammen, inden sie den Körper zum Subjekt erhebt, das nur eines fordert: Body Request. Ein junges Mädchen steht im blauen Badeanzug unter blauem Himmel. Die Worte Körper und Kopf werden erneut in Katakana gesetzt und besonders hervorgehoben.

・欲しいものがわからなくなったら、カラダに聞いてみる。カ ラダは、アタマより正直だ。生きるために必要なこと、気持 ちいいこと、楽しめること。誰に教わらなくたって、カラダ が勝手にそう動いている。

だから、カラダの声を、信じてみよう。アタマでっかちの人 生なんてつまらない。欲しがるカラタに素直に生きる、そん な時代がやってきた。

Body Request. Pocari Sweat.

- Wenn ich nicht weiß, was ich will, frage ich einfach meinen Körper.

Der Körper ist aufrichtiger als der Kopf. Das Notwendige zum Leben, gute Gefühle, Genuß: Das alles holt sich der Körper ganz von selbst, obwohl es niemand ihn gelehrt hat. Deshalb sollten wir versuchen, auf die Stimme des Körpers zu hören. Ein Leben nur aus dem Kopf ist irgendwie langweilig. Jetzt kommt die Zeit, in der wir einfach den Wünschen unseres Körpers nachgeben. Body Request. Pocari Sweat.

\section{Vom Zeichen der Wildnis zur Schreibfläche zivilisierter Identität}

Anders als psychische Systeme sind Individuen geboren, haben körperliche Bedürfnisse und eine materielle Existenz. Diese schließt die Werbung mit dem komplexen Wirtschaftssystem kurz. In Japan werden nicht nur die Waren wortwörtlich geboren, sondern sind auch Geburt und Kindheit selbst im Werbesystem lebendig. Noch einmal die Kampagne der Japanese Railways, die mit Texten und Bildern von Tiermüttern und -kindern die Grenze zwischen Zivilisation und Wildnis umschreibt. 
・ ライオンの母親は、子供が生まれると一カ月間、群れから離 れ、親子だけで 過ごす時間をもちます。自分の力で生きら れるように。決して負けはしないように。

- Die Löwenmutter verbringt, wenn ihr Kind geboren ist, einen Monat allein mit ihm, losgelöst vom Rudel. Damit es aus eigener Kraft leben kann und ihm auf keinen Fall etwas zustößt.

Der schönste Werbefilm ist aber der für die Kinderhautcreme von Bioré. 10 Sekunden läßt er dem Betrachter Zeit, in ihn einzutauchen, im Dampf eines heißen Bades alles hinter sich zu lassen. Eine Mutter sitzt mit ihrem Kindern im heißen Wasser, sie spielen und genießen. Dann, die sanfte, verwöhnende, mütterliche Stimme der Sprecherin:

・どうして弱酸性。ママの肌は弱酸性。ママから生まれた赤ち やんも弱酸性。素肌と同じ弱酸性。Bioré.

- Warum jakusansei (Schwach sauer/leicht säuerlich. Man beachte hier die Zuordnung des Kanji für schwach an das weibliche Geschlecht!)? Die Haut der Mutter ist jakusansei. Auch die Babys, die von der Mutter geboren wurden, sind jakusansei. jakusansei, wie die reine Haut. Bioré.

Umgekehrt läßt sich in der berühmten Benetton-Kampagne auch eine Nähe der Werbung zum Tod erkennen. In Japan erntete sie keineswegs Protest, sondern Zustimmung und Beifall. ${ }^{5}$ Ein Neugeborenes, Flüchtlinge, die nur ihr Leben gerettet haben, und die Uniform eines gefallenen Soldaten, ein Aidskranker, ein Kuß von Priester und Nonne, ein Kondomset - ihre Motive saugten sich ausschließlich am menschlichen Körper fest. Indem sie ihn ins Zentrum rückten, beendeten sie den Diskurs der Ware und eröffneten den Diskurs der Schreibfläche.

Die Werbung zeichnet ungezeichnete Körper. Paradox mutiert dabei die menschliche Haut zur wilden Schreibfläche der Zivilisation, zur Verpackung zivilisierter Identität.

5 Haehling von Lanzenauer 1998: 284. Falk 1997. 


\section{3 ubuhada (unschuldige Haut): Hautkontakt von digitalem System und taktilem Körper}

\section{Die Weißheit der diabolischen Verpackung der Ökonomie}

Wenn die Zivilisation eine Kultur der Selbstbeschriftung ist, so ist der Körper ihre erste Schreibfläche. Er trägt die Geschlechterdifferenz, mit deren Hilfe sich Völker und Ethnien identifizieren und beschriften lassen. Doch im Prozeß der Zivilisation wird auch der Körper diszipliniert (Kapitel 1). Die Kultur der Seßhaftigkeit produziert Rückenschmerzen, Herzinfarkte, in Japan sogar den plötzlichen karôshi, den Tod durch Überarbeitung. Der Begriff der Zivilisationskrankheiten ist also empirisch gerechtfertigt. Und diese zeichnen sich vor allem auf der Haut der Menschen ab. Die Körper melden sich nicht nur mit Teilzeit- und Körperteildesertionen aus dem Arbeitsprozeß, sondern schriftlich. Insbesondere die Allergien und der Hautkrebs befinden sich auf dem Vormarsch, ihre fulminante Zunahme ist de facto außer Kontrolle (Anmerkung 143). Doch die chronischen Allergien sind nicht einfach auf Umwelteinflüsse zurückzuführen, die sich zumindest theoretisch nach dem nächsten Umwelt-Gipfel reduzieren ließen. Vielmehr gerät die Haut in der modernen Gesellschaft mehr als je zuvor zur psycho-somatischen Schreibfläche der Individuen.

Die Haut ist zugleich Schale und Kern ihrer Identität. Sie schottet sie gegen Umweltreize ab, ermöglicht aber zugleich die sensibelste Kommunikation mit der Umwelt. Das weist der Psychoanalytiker Didier Anzieu in seinem Text „Das Haut-Ich“ speziell an der Mutter-Kind-Dyade nach. Bevor der Säugling die Welt taktil erobert, erforscht er sie mit oralen Hautkontakten. Und umgekehrt zeichnen sich zahlreiche psychische Verletzungen, Kränkungen, Masochismen und Sadismen unmittelbar auf dieser Schreibfläche ab. ${ }^{6}$ Identität und Geschichte des Individuums fließen in seine Haut ein. Die Haut vergißt nicht, sagen die Hautärzte vor dem Sonnenbrand. Und insbesondere die Werbung deutet darauf hin, daß die Sensibilität des modernen Menschen für sich selbst in der postmodernen Konsumgesellschaft kontinuierlich steigt. Mike Featherstone ergänzt: „Advertising thus helped to create a world in which individuals are made to become emotionally vulnerable, constantly monitoring themselves for bodily imperfections which could no longer be regarded as natural." 7

In der funktional differenzierten, polykontextuellen Gesellschaft bewegt sich das Individuum ständig auf einem Display, einem Präsentier- 
teller, einem Laufsteg, und ist selbst zugleich sein strengster Beobachter. Der Digitalisierung zum Trotz bleibt es mit seinem Selbst an seinen Körper gebunden. Im Gefängnis seines Körpers (Foucault) muß es seine Identität aus sich selbst schöpfen, nicht aus den Beziehungen zu seiner Umwelt. $\mathrm{Zu}$ diesem Zweck kommt dem gezeichneten Körper als Kern der Identität eine besondere Bedeutung zu. Der gezeichnete, allergische Körper muß umgeschrieben werden. Hier greift, zumal in einer Gesellschaft der White-Collar-Worker, die Mode als Technologie des Selbst. Gilles Lipovetsky hat gezeigt, daß die Mode im modernen Westen kein Medium der sozialen Klasse mehr ist, sondern das Medium der Individualität. „Le vêtement de mode est de moins en moins un moyen de distancement social et de plus en plus un instrument de distincition individuelle et esthétique, un instrument de séduction, de jeunesse, de modernité emblématique. “8 ${ }^{8}$ Und dieses Bild des Selbst schließt, insbesondere für Frauen, Karrierepläne und Styling-Beratung ein:

„To conclude, the development of a discourse on the career woman's dress throughout the 1980s and 1990s marks the emergence of a new ,technology of the self ${ }^{*}$, a self who demonstrates that she is ambitious, autonomous and enterprising by taking responsibility for the management of her appearance. The fact that so many women buy in the services of a consultant is also testimony of the extent to which this modern woman is an enterprising self. “9

Doch der Diskurs der Individualität ist auch mit Mode und Stoff nicht vom Körper selbst fernzuhalten. Spätestens in der Werbung ist die Grenze zwischen Kommunikationslatenz und Latenz der Kommunikation überschreibbar. Will die Verpackungskunst der Ökonomie schon einmal unbezeichnete Körper zeichnen, so muß sie unmittelbar auf die Haut der Individuen zugreifen. In der postmodernen Konsumgesellschaft dienen nicht mehr Handschrift oder Unterschrift zur Identifikation beide sind digital ersetzt. Stattdessen sind Tätowierungen, Piercing und Schönheitsoperationen in Mode. ${ }^{10}$ Die männlichen Stars leben es vor und stellen ihren Körper zuallererst in den Dienst der Werbung. ${ }^{11}$ Doch

8 Lipovetsky 1987: 179.

9 Entwistle 1997: 318.

10 Assmann 1993. Oettermann 1982.

11 „Der Körper des Michael Jackson war immer schon in der Verfügungsgewalt anderer, eine Fleisch, Haut und Knochen gewordene Vision. Seit die Vision zum Traumpfad wurde, auf dem jeder gehen will, ist der Körper nur noch eine Last, ein Sack Materie, den das künstliche Selbst hinter sich herschleppt und mit dem es sich nicht mehr abfinden will. Der Körper des Michael Jackson ist zum Schlachtfeld geworden, auf dem er seine symbolischen Kämpfe austrägt. Ähnlich wie jene autoaggressiven Frauen, die ihren $\mathrm{Ha} ß$ durch Selbstverstümmelung ausleben, fügt er sich Schmerzen zu. Doch er hat den $\mathrm{Ha}$ ausgelagert, dem Messer des Schönheitschirurgen 
diese Eingriffe in die männliche Souveränität dürfen nicht darüber hinwegtäuschen, daß sich die Werbung insbesondere bei ihrer paradoxen Beschriftung der Haut fast ausschließlich weiblicher Körper bedient. Denn die Haut soll in der Werbung eben nicht gezeichnet, sondern ungezeichnet gezeichnet werden. Als diabolisch generalisiertes Medium hat sie daher die Weißheit gepachtet, um die Körperlatenz der Ökonomie zu kommunizieren.

In diesem Funktionssystem begegnen sich die Kommunikanten als black boxes. Der systemtheoretische Beobachter kann das sehen und die beiden Systeme über das Medium Geld verkuppeln, das bekanntlich selbstreinigende Kräfte hat. ${ }^{12}$ Doch wie wir gesehen haben, wird eben der Körper in dieser digitalen Kommunikation latent (Kapitel 3.3). Und diese Latenz bricht sich im diabolischen Massenmedium der Ökonomie Bahn. Aus diesem Grunde ist Deutschland nicht nur das Land der Systemtheorie, sondern auch das Land von Persil und dem Weißen Riesen. Hier liegen die Ausgaben für Waschmittelwerbung an der Spitze, insbesondere im Segment Fernsehen (Abbildung 7 im Anhang). Auf den ersten Blick könnte man das mit der christlichen, vor allem protestantischen Kultur und ihrer Obsession für die Reinigung des Gewissens und die Tilgung der Schuld in Verbindung bringen. Aber auch im buddhistisch-shintoistischen Japan ist der Wunsch nach Reinheit tief im Werbesystem verankert. Mehr noch: Die Weißheit als Zeichen greift in der Werbung der maternellen Verpackungskultur schwarz auf weiß auf die Haut des weiblichen Körpers durch.

anvertraut. Unter seinem mitleidlosen Schnitt wurde er zum veränderlichen Wesen, das zwischen den Polen gesellschaftlicher und geschlechtsspezifischer Bestimmung, zwischen race, class und gender fluktuiert. Seine Haut hat inzwischen alle Schattierungen von hellbraun bis alabasterfarben durchlaufen, die Haare entwickelten sich von der Afro-Krause über einen geölten Disco-Look in Richtung einer Dallas-/Denver-Mähne.“ Thomas Mießgang: „Der Körper als Schlachtfeld“. Zitiert aus: Die Zeit vom 6. Juni 1997, S. 45.

„Dennis Rodman, der beste Rebounder der Welt, ist tätowiert, hat bunte Haare und gepiercte Genitalien. Er sagt von sich selbst: ,Mein Körper ist meine Reklamefläche. Da steht geschrieben, was ich fühle.' $[\ldots]$,Fuck it" steht in gotischen Lettern auf seiner Haut. [...] Inzwischen hat der Internationale Leichtathletik-Verband Tätowierungen von Sponsorenlogos auf Athletenhaut verboten. Der war in der Vergangenheit immer öfter von der Mütze und dem Kragen unter die Haut gewandert. Angefangen damit hatte Nike. Seine Angestellten unterschrieben seit einigen Jahren bei Arbeitsantritt, sich den berühmten Nike-Swoosh an einer gut sichtbaren Körperstelle eintätowieren $\mathrm{zu}$ lassen. Brandmarkung, Coroparate Identity, Versklavung.“ Zitiert aus: Andreas Bernard: „Die verkaufte Haut“. Süddeutsche Zeitung vom 8. Mai 1998.

12 Schulte 1993: 99-100. Luhmann formuliert: „Die schwarzen Kästen erzeugen sozusagen Weißheit, wenn sie aufeinander treffen, jedenfalls ausreichende Transparenz für den Verkehr miteinander." Luhmann 1984: 99. 
bihada, suhada, bihaku (schöne, reine, weiße Haut) Zeichen des Ungezeichneten im Reich der Zeichen

Weiße Models verkünden die Botschaft schöner Haut und schöner Haare auch in Japan. Andie McDowell und Claudia Schiffer, deren Gesichter 1999 auch den Ruinenturm der Berliner Gedächtniskirche zierten, um Spenden für den Wiederaufbau einzuwerben, warben zeitgleich auch in Japan für reines, seidig glänzendes Frauenhaar. Und die blonde und blauäugige Kim Basinger tanzte sogar mit Blume im Haar durch einen 60-Sekunden-Spot und gab Interviews zum Hautpflegeset von Vernal auf Englisch mit japanischen Untertiteln und mit differenztheoretischen Anflügen:

- Skin care should be simple. The Vernal system makes it easy. Try the Vernal skin care set. Use it every day. You'll see the difference in Your skin.

Auch die schöne Naomi Campbell trat in einem Spot für die Total Beauty Clinic von Shiseido auf. Eine weiteres Plakat für Swatch Uhren inszeniert ihre dunkle Haut und das rote Armband, im letzten Wort ist ihr Fingerabdruck zu erkennen:

- The skin of Naomi. 軽さ。薄さ。美しさ。Swatch Skin.

- Naomis Haut. Leicht, dünn, schön. Swatch Skin.

Die Kategorien gender und race sind jedoch keinesfalls zu vermischen. Die japanischen Konsumentinnen leben in einem Land mit intensiver Sonneneinstrahlung. Sie träumen nicht von der weißen Rasse, sondern von schattenfreier, gesunder, reiner, junger, natürlicher Haut ohne Flecken oder Sommersprossen. Dafür hat das japanische Werbesystem sogar drei Spezialausdrücke ausgebildet, die das Gesagte exemplarisch verdichten und auf die fast keine Kosmetikwerbung verzichten kann.

- 美白・美肌・素肌 (bihaku,bihada,suhada)

- Schönes Weiß. Schöne Haut. Reine Haut.

Die Firma Kosé dokumentierte in ihrem TV-Spot, daß auch Sonnenbräune in Japan unerwünscht ist. Haut muß weiß und blaß sein.

一美白、乳液、化粧水。夏の日やけにも。Kosé Cosmenience.

- Schönes Weiß, Flüssigmilch, (Haut-)Lotion. Auch gegen den sommerlichen Sonnenbrand. Kosé Cosmenience. 
Restlos weiß, milchig, sämig und flüssig ist auch der 30-Sekunden-Spot für Dove. Er unterzieht verschiedene Seifen dem Lackmustest.

・この p H 試験紙が、青になればアルカリ性です。

浴用石鹸。(wird getestet, Streifen wird blau)

洗顔石鹸。(wird getestet, wird blau)

ベビー石鹸。(wird getestet, wird blau)

DOVE は違います。DOVE（ダヴ）・/ 中性（p H）。

モイスチャーミルク $1 / 4$ 配合（うるおい成分）。

DOVE は石鹸ではありません。(wird getestet, wird nicht blau)

お肌を乾燥させないのです。 Nippon Lever. Your best partner.

- Wenn dieser pH-Teststreifen blau wird, ist es eine alkalische Lauge. Das ist Badeseife. (wird getestet, Streifen wird blau)

Das ist Gesichtsseife. (wird getestet, wird blau)

Das ist Babyseife. (wird getestet, wird blau)

Dove ist anders. pH-neutral. $\mathrm{Zu}$ einem Viertel besteht sie aus Feuchtigkeitsmilch.

Dove ist keine Seife. Sie trocknet Ihre Haut nicht aus.

Nippon Lever. Your best partner.

Chanel wirbt für das Makeup Teint Lift Éclat in der Zeitung Asahi Shimbun ganzseitig in Farbe und präsentiert konsequenterweise ein blondes, blauäugiges Model. Wieder wird die Natur in Katakana gesetzt. Der Text:

・ナチュラルさを極めた。リクイッドファンデーション誕生。 ハリ感のある肌を演出。若々しい肌のつやと明るさ。好 ような肌の印象。肌に軽い心地よさが持続。あなたの望む肌 の表現がタンリフトエクラなら叶えられます。

- Die (Geburt der) Liquid Foundation, die mehr ist als natürlich. Der Haut Spannkraft geben. Glanz und Helligkeit der jungen Haut. Ein Gefühl, als ob die Haut verschwindet.

Diese Leichtigkeit auf der Haut hält vor.

Die Haut, die Sie sich wünschen, läßt Teint Lift Éclat Wirklichkeit werden.

Stefany läßt endlich - ebenfalls auf einer Farbseite von Asahi Shimbun das Produkt seine Geburt durchlaufen. Die (wie japanisches Trinkwasser) mit Ionen dotierte Kosmetik mutiert zur „Total Skincare“. Diese Natürlichkeit zweiter Ordnung ist nicht zu überbieten. 
・美肌イオン化粧品。新発売。あついい感じ。

あれこれ悩ましくてもいいんです。美肌イオンでトータル・ スキンケア。

無香料、無着色指定成分ゼロの完全無添加化粧品。美肌イオ ン水誕生。銀座ステファニー化粧品。

- Ionenkosmetik für schöne Haut. Neu im Verkauf. Ein gutes Gefühl. Von jetzt an keine Sorgen mehr. Mit Ionenkosmetik für schöne Haut ,Total Skincare‘. Keine Duftstoffe, keine Farbstoffe, null künstliche Zusätze, völlig ohne Additive. Ionenkosmetik für schöne Haut. Ginza Stefany Kosmetik.

Drei weitere Beispiele aus der Frauenzeitschrift Saita (咲いた 6/1999) belegen dieses Baukastenprinzip der Kosmetikwerbung. Für den Titel posierte die schöne Takashima Reiko. Sie spielte in der Fernsehserie „Eine Frau voller Wunden“ (傷だらけの女) eine Leibwächterin, die andere starke Frauen tatkräftig beschützte.

Die Werbung für Fréshel White $\mathrm{C}$ von Kanebo zeigt ein lächelndes Model:

一毎日の、化粧水で美白ケア。これから先の白さのために。美 白お試しセット。 10,000 名様にプレゼント。 (klein:) 新しくなりました。

- Schönes Weiß mit der täglichen Pflegelotion. Für das Weiß der nahen Zukunft. Ein Probeset für das schöne Weiß als Geschenk für 10.000 Kunden. (klein:) Ich bin neu geworden.

Shiseido unterscheidet sich da nicht. In der Werbung für Whitia Day Protect steht neben dem Model mit weißer Haut und weißer Bluse:

- 一日中、 2 つの効果。美白美容液なのに SPF 30。 メラニンの生成を抑えて、強力な紫外線をカット。 素肌のままで、強力な紫外線をカット。

- Während des Tages zwei Effekte. Obwohl es eine Schönheitslotion für schöne weiße Haut ist, hat sie Sonnenschutzfaktor 30 (sun protection factor). Es unterdrückt die Bildung von Melanin und stoppt kraftvoll die UV-Strahlen. Mit natürlicher Haut die UV-Strahlen kraftvoll stoppen.

Auch die dritte Anzeige in derselben Zeitung von Yamanouchi Minon ist in demselben Stil. Wieder ist sie farbig und doppelseitig, wieder sehen wir rechts die schöne Frau und lesen links: 
・少女を卒業した肌に。眠れない夜を知っている。

ときには上手に嘘をつける。いつだって笑顔を見せられる。 大人の女性でいることは、肌にもけっこう重荷です。だから、 弱酸性・低刺激のミノンさらつとタイプ。アミノ酸系洗浄成 分配合で、気になる素肌も、すっきり洗えてすべすべ。そろ そろバスタイム・エステを始めませんか。

- Für die Haut, die ihre Prüfung als junges Mädchen bestanden hat. Du kennst die Abende, wo Du nicht schlafen kannst. Manchmal lügst $\mathrm{Du}$ geschickt. Immer kannst Du Dein lächelndes Gesicht zeigen. Eine erwachsene Frau zu sein, ist auch für die Haut eine schwere Aufgabe. Deshalb jakusansei (schwach sauer), leicht stimulierendes Minon, das sanfte. Angereichert mit der reinigenden Kraft der Aminosäuren, läßt sich auch die empfindliche Haut glatt und sauber waschen. Solltest Du nicht mit der Pflege beim täglichen Bad beginnen?

\section{Haut 2000 - Durchsichtigkeit als Strategie}

Zu Beginn des Jahre 2000 tauchten Plakate von Shiseido in Tokio auf, ergänzt um einen schönen Fernsehspot. Der Slogan war so einfach wie schön, das Kanji für Haut in klare, rechte Winkel gegossen: unschuldige Haut (ubuhada). Mit dieser Wortwahl überbot die Kampagne jede christliche Dialektik. Der TV-Spot, unterlegt mit der Musik der Oper Carmen, gesungen von Filippa Giordano, endete mit einem Kuß. Die Einblendung:

・ 2000 年あなたの肌はもう一度生まれる。うぶ肌。

- Unschuldige Haut. Im Jahre 2000 wird ihre Haut neu geboren.

Auf der Suche nach Steigerungsformeln läßt die Werbung die Weiße tief in die Haut der Models eindringen. Der Image-Transfer erfordert, daß die Kamera tief in die reine Seele der Stars blickt und sie überallhin begleitet. Die populäre Tennisspielerin Date Kimiko z.B. fuhr mit ihrem weißen Öko-Toyota Prius in die Natur. Aber sie warb auch für Teigwaren und für Shiseido. Auf dem Plakat stand unter dem Gesicht der ewig lächelnden Sportlerin:

・肌の奥まで、透明感。

- Ein Gefühl wie durchsichtig bis tief ins Innere der Haut.

Sofina verkauft sein neues Puder mit den Worten: 
・透明発色。それは、透明感をメイクするパウダー。 狙った以上にキレイになる。レイシャス誕生。

- Die Farbe der Durchsichtigkeit. Das ist das Puder, das ein Gefühl der Durchsichtigkeit schafft. Noch viel schöner als gedacht. Raycious.

Und auch die Allerschönste, das Nr. 1-Model in Japan 1999, Fujiwara Norika, ließ in ihrem Werbespot für Kanebo tief in ihr Innerstes blicken:

・時間がたつほど透明感がアップ、フィット感がアップ。 時間がたつほどきれいになる。New Revue.

- Mit der Zeit wächst das Gefühl der Durchsichtigkeit, der Fitness. Mit der Zeit werden Sie schön. New Revue.

Damit ist die Kosmetikwerbung von der Waschmittelwerbung zumindest in der Wahl der Stichworte nicht mehr zu unterscheiden. Zwei Beispiele für Produkte mit den schönen Namen Top und Blauer Diamant:

・浸透パワー。トップ。バイオの力で驚きの白さ。

- Durchdringende Power. Top. Mit Bio-Kraft eine Weißheit, die erstaunt.

・白さとハーブの香り。ブルーダイヤ。

- Weiße und pflanzlicher Duft. Blauer Diamant.

Pond's Double White übernimmt schließlich das amerikanische Wort in seine eigene Produktbezeichnung. Dieser Werbespot wurde besonders oft ausgestrahlt. Darin wird eine junge Frau in weiß von einem Fremden angesprochen und erschrickt. Der Leibwächter, Chauffeur und Ehemann handelt aber nur im Auftrag seiner Frau in der weißen Limousine und erkundigt sich nach der Foundation, die ihre Haut so schön weiß gemacht habe. Sie aber benutzt gar keine Foundation, sondern die Tages- und Nachtcreme von Pond's. In der Schlußblende des Spots, der später noch variiert wurde, schlüpft endlich auch das englische Wort white einmal in Katakana-Buchstaben.

・UVA 波、B 波 カット十美白。ダブルホワイト。

- UVA und UVB Wellen „,cut“ + schöne Haut. Double White.

Dieses Double White läßt sich noch einmal steigern. Das erledigt Grace Sofina mit einem doppelten „sehr“ im Werbetext. Zwei Spots sprechen zwei verschiedene Altersgruppen an. In der Version für die jungen Frauen heißt es einfach: 
- この美白肌 VeryVery で美白する。 Very Very 美白ジェル。とろける。しみこむ。Grace Sofina.

- Diese schöne weiße Haut mit VeryVery noch schöner und weißer machen. Very Very Schönes Weiß-Gel. Schmilzt. Zieht (sofort) ein. Grace Sofina.

Zwei weitere Version für die reife Frau treiben die Versprechungen weiter:

・にごり感のない白い素肌に。 年齢を輝きにかえる。

- Für eine weiße, reine Haut ohne Gefühl der Unreinheit. Das Alter in einen Glanz verwandeln.

- 大人の肌からくすみが消える。 これが、おとなの素肌っぽさ。

- Die Schatten verschwinden von der reifen Haut. Dies ist die reife, natürliche Haut.

Einen wunderschönen Spot schaltete auch die Firma Kanebo für ihre Schminke mit dem Namen Revue. Die kurzen Slogans wurden sanft und unscharf ins Bild neben das Model eingeblendet. Als unübersetzbares Stilmittel dient erneut das Katakana-Alphabet, dem hier sogar einige Kanji zum Opfer fielen.

・すはだより透明感。すはだよりテカらない。 スハダ的キレイ。

- Durchsichtiger als natürliche Haut. Glänzt weniger als natürliche Haut. Schön wie natürliche Haut.

Im Reich de Zeichen zeichnen Zeichen ungezeichnete Körper auf weiße Schreibflächen. Doch die Werbung wäre kein komplexes, diabolisches System, würde sie nicht auch einige negative Schattenseiten zulassen.

\section{Schattenseiten: Risse, Brüche, Trübungen der Haut als Echo des Ich}

Das japanische Werbeverpackungssystem hat einen Zug von Perfektion. Trübungen gibt es allenfalls am äußersten Rand. Doch ganz kommt die perfekte Werbung an den imperfekten Konsumenten nicht vorbei. Allergien sind häufig, gerade im insektengeplagten japanischen Sommer, in dem hemmungslos Gift zum Einsatz kommt. Aber auch eine Spülmittelwerbung räumt indirekt die Möglichkeit allergischer Reaktionen ein. 
Immerhin hält sich auch dieser 15-Sekunden-Spot an die allgemeinen Regeln: Weiße Teller und grüne Natur konvergieren vor der Melodie des deutschen Liedes ,In einem Bächlein helle“.

・アレルギーテストでも手肌へのやさしさを証明。 ヤシノミ洗剤、Power Mini.

- Auch im Allergietest wurde die Hand- und Hautfreundlichkeit bewiesen. Kokosnuß-Waschmittel. Power Mini.

Und auch im Programmheft des Takarazuka-Frauentheaters in Tokio, in dem die talentiertesten Mädchen des Landes auftreten, benannte die Firma Takeda in ihrer Anzeige ein kosmetisches Problem, das sie mit ihrer Mainstream-Werbung selbst erst verschärfte. Die Seite ist rot, wie der Pullover der Schauspielerin.

・メイクでニキビを、なかったことにしていませんか。 すぐ、のむ、肌あれ対策。ハイシーBメイト。

- Sorgen Sie nicht mit Makeup dafür, Ihre Pickel verschwinden zu lassen? Gleich nehmen als Gegenmaßnahme gegen empfindliche Haut. HICEE BMATE.

Die Schreibfläche Haut ist eine Schreibfläche des Ich. Werbung zeichnet idealisierte Identität. Kein Spot hat das deutlicher inszeniert als der für die Hautcreme von Qualité. Eine Japanerin knipst sich selbst mit Selbstauflöser, und sie will schön sein. Der Text geht narzißtisch weiter.

・きれいな素肌をつくる。カリテのティント。 (Eingeblendet:) 素肌つぽい、私っぽい。

- Schöne, natürliche Haut bekommen. Mit Qualité tinto (Name). (Eingeblendet:) Wirklich schöne Haut, ganz ich selbst.

Genauso argumentiert Shiseido für die Hautpflegeserie Taphy:

- 肌のこと、私のこと。 すばやく浸透。すぐうるおう。タフイ。

- Hautangelegenheiten sind meine Angelegenheiten. Schnelles Einziehen. Sofort feucht. Taphy.

- New. 肌のこと、私のこと。低刺激 弱酸性でうるおう。タ フィ・マイルド。

- Hautangelegenheiten sind meine Angelegenheiten. Feuchtigkeit durch leichte Stimulierung mit jakusansei (schwach sauer). Taphy Mild. 
Die Perfektion der ungezeichneten Körper eröffnet erst die Frage nach Identität und Selbst. Doch sind Selbst und Individualität im bloßen Konsum von Waren erreichbar? Die Werbung behauptet das. Auf einer Plakat-Werbung von Konica verschmelzen der Kuß von Mann und Frau mit dem Kuß der Kamera, welcher die Berührung der Lippen verdeckt. Der japanische, dividuale Narzißmus springt auf die Ware über:

・ワタシタ、撮りタイ。キレイな関係。 カンタン!クォリティーAPI. 自分撮りモード搭載。

- Ich will mich aufnehmen. Eine reine Beziehung. Einfach! Quality-API. Mit Selbstaufnahmemodus.

Eine U-Bahn-Werbung für das Ledersignet schlägt die Brücke zurück zur Mode, zur Fremdreferenz, zur Liebe. Nicht die Liebe zum Selbst, sondern die Kontingenz der Liebe zum Anderen ist das Thema. Das Foto zeigt ein schönes Mädchen mit Lederhandtasche und Lederstiefeln.

-その恋、ウソモノ? その涙、ウソモノ? その革はウソじやない。レザマーク。

- Ist diese Liebe etwa eine Lüge? Sind diese Tränen etwa eine Lüge? Dieses Leder ist jedenfalls keine Lüge. Leathermark.

Die Einschrift der Zivilisation ins Haut-Ich des Subjekts ist umschreibbar. In der äußersten Ausprägung des Narzißmus erreicht die japanische Werbung einen Punkt der Erschöpfung. Die Liebe liegt nicht im Konsum des Selbst, sondern strebt nach einem äußeren Hautkontakt. Das Haut-Ich muß unter die Leute. Daher vollführt die Werbung eine Akzentverschiebung von der materiellen Ware zur Psyche der Ware Arbeitskraft. Ihre Themen bleiben Ich, Selbst und Identität. Und nach ihrem Grenzgang über die größtmögliche Reinheit menschlicher bzw. weiblicher Haut kann sie nun wieder Männer zitieren: als Subjekte und als Zeichen von souveräner Individualität.

\section{4 ironna jibun (verschiedene Selbste): Selbst und (In-)Dividuum in der japanischen Werbung}

\section{Werbung zeichnet ungezeichnete Psychen}

Die reflexiv modernisierte Gesellschaft ist unbestreitbar eine Gesellschaft fortschreitender Individualisierung. Die normativen Bindungen an Gewerkschaften, Familien, Kirchen, Parteien, Ethnien, soziale Schichten, Berufs- oder Gehaltsgruppen oder andere Solidargemeinschaften sind 
rückläufig. ${ }^{13}$ Der „flexible Mensch“ ist auf dem Vormarsch, besser: Die Komplexität der Anforderungen an die Individuen steigt im Rahmen der ökonomisch verfaßten Globalisierung. Aus diesem Grund ist der Individualisierungsproze $ß$ nur als ein ambivalenter lesbar. Einerseits betrachten und benutzen die Funktionssysteme der Gesellschaft die Individuen lediglich als kommunikative Monaden in ihrer Umwelt. Aus diesem Blickwinkel heraus identifizierte Peter Fuchs die imperfekten Dividuen in Japan als perfekt geeignet für die funktionale Differenzierung von Gesellschaft (Kapitel 2.2). Sozialpsychologisch aber ist diese funktionale Differenzierung ein Zerfallsprozeß. Richard Sennett hat ihn als Ende des öffentlichen Lebens, als Verlust schauspielerischer Fähigkeiten und Aufstieg des Narzißmus in der westlichen Welt beschrieben. Und erst spät, nämlich in den 80er Jahren, als sich die bubble-economy in Japan abzuzeichnen begann, erntete er den postmodernen Einspruch von Gilles Lipovetsky. Das „Zeitalter der Leere“ ist ein „Zeitalter des Gleitens" (l'ère de la glisse), des Surfens im Wasser, im Netz und auch in der Theorie. Die postmoderne Konsumgesellschaft eröffnet paradox auf der Schattenseite der geschlossenen Funktionssysteme wieder subjektive Spiel- und Erlebnisräume, kommunikative Chancen und die Vielfalt der Lebensstile.

Die Ambivalenz des Individualisierungsprozesses ist schon bei Simmel angelegt. In Japan tritt sie mit besonderer Deutlichkeit zutage. Die polare Gegenüberstellung der westlichen Kultur und Japans in binären Schematismen: Individuum und Dividuum, kojin und kanjin, individual und contextual, mußte daher scheitern (Kapitel 2.1). Zum einen ist jeder Versuch, kulturelle Eigenschaften empirisch zu skalieren, aussichtslos. ${ }^{14}$ Zum zweiten sind westlicher (vor allem amerikanischer) Individualismus und japanische Gruppenorientierung nicht als inkompatible Grundformen menschlicher Existenz zu begreifen, sondern als Graduationen. Die kulturellen Differenzen entziehen sich ihrer Vereinheitlichung. In der theoretischen Argumentation ereilt sie daher dasselbe Schicksal wie die ethnologische Formel „Mann/Kultur = Frau/Natur": sie zerbricht. ${ }^{15}$ Menschliche Gesellschaften basieren auf Organisationsformen, in die sich Männer und Frauen gleichermaßen einbringen. Und kulturelle Unterschiede zwischen modernen Gesellschaften, vor allem zwischen Japan und dem Westen, verschwinden in abstrakten, digitalen, körperlosen Beschreibungsmodellen der Gesellschaft - fast. Yamazaki

13 Beck 1997: 24-32.

14 Vgl. Kersten 1997: 74-75. Er kritisiert vor allem die Studie von Hofstede (1991), die versuchte, 50 Länder in einer Rangliste nach Individualismus und Maskulinität zu ordnen. Das maternelle Japan landete in diesem ranking in puncto Maskulinität vor Österreich auf Platz 1!

15 Dux 1992: 218-221. 
Masakazu hat diesen aktuellen Stand der Diskussion auf den Punkt gebracht: „In fact, both individualism and interdependance rarely appear in pure form; there are obviously many graduations in between. This being the case, the contextual and the individual are neither two different types of social units nor two different modes of human actors; they are simply differences of degree in psychological attitudes. “16

So bietet paradox die Beschreibung der japanischen, kontextuellen Psyche und des umweltabhängigen Dividuums auch eine Möglichkeit, Systemtheorie zu konterkarieren. Denn das Dividuum konzentriert sich eben nicht nicht nur auf seine Autopoiese, seine Abschottung von der Umwelt, seine interne Informationsverarbeitung, sondern es offenbart eine elementare psychische Schwäche, die eine Formulierung Sennetts am besten einfängt: Es braucht andere, um es selbst zu sein. Hier liegt das Interesse der Soziologie an der Bezeichnung des Individuums in der Werbung. Der Hautkontakt zwischen Ökonomie und Lebenswelt balanciert zwischen Reproduktion und Konsumkultur und produziert massenhaft semantische Bauelemente für individuelle Identität. Gerade in Japan prallen daher die Semantiken der Konformität und Individualität direkt aufeinander. Konform im Rahmen polykontextueller Gesellschaft und verpflichtender Sozialstruktur ist nur, wer dafür auch Entlohnung, Geschenke und Bonuszahlungen erhält.

Wenn das Massenmedium der Ökonomie seine Körperlatenz gegenzeichnet, muß es nicht nur ungezeichnete Körper, sondern auch ungezeichnete Psychen zeichnen. Und dieser Effekt muß wiederum in Japan mit besonderer Deutlichkeit sichtbar werden. Daher ist die ,virtuelle These“ der Identität von Medienrealität und Realität falsch. Zwar verpacken, verzerren und verschreiben die Massenmedien die Realität der Systeme. Doch diese Differenz zur Wirklichkeit bleibt dem Bewußtsein der Individuen keineswegs verschlossen. Erst die Fähigkeit der Konsumenten, ihre Träume von der Realität zu unterscheiden, eröffnet auch der Werbung eine Projektionsfläche. Der Tagtraum individueller Souveränität begleitet den japanischen Büroalltag.

Die zahlreichen individualistischen Appelle in der japanischen Werbung sind daher nicht wörtlich als Spiegel der Realität zu verstehen. ${ }^{17}$ Die japanische Gesellschaft, insbesondere die Ökonomie, ist nach wie

16 Yamazaki 1991: 91, 149.

17 Gould/Minowa maßen schon im Printbereich: in der japanischen Autowerbung in Frauenzeitschriften, eine leichte Tendenz zu individualistischen Appellen. Aber sie schlossen daraus, daß individualistische Semantiken in westlichen Ländern ohnehin verankert sind, während sie in Japan erst Platz greifen. Die Werbung spiegele also nicht die Realität, sondern spiele lediglich eine Art „,cheerleader“ bei der allmählichen Enttraditionalisierung der japanischen Gesellschaft. Gould/Minowa 1994: 195. 
vor in Kleingruppen organisiert, und das japanische Wort kojinteki (individuell) kann aus dem Mund eines sempai (Gruppenleiters oder Lehrers) auch die Bedeutung von ,eigensinnig“ annehmen und einen leisen Vorwurf transportieren. Keiko Tanaka schließlich hat in ihrer Analyse der japanischen Werbesprache gezeigt, daß der Begriff der Individualität in der japanischen Werbung häufig eine andere Bedeutung und Funktion erhält als im Westen. Gerade in Anzeigen, die Frauen ansprechen sollen, wird er häufig als Anpassung an die aktuelle Mode umdefiniert und auf diese Weise seiner Sprengkraft für die japanische Gruppenideologie beraubt. Auch die häufigen Verweise der japanischen Werbung auf westliche Trends, Konsummuster und Produktnamen, häufig umgeschrieben in Katakana, bezeugen keinen Import individualistischer Semantiken nach Japan, sondern eher den Versuch der allgemeingültigen Normierung im Rahmen japanischer Konformität. „Running through most of the advertisements, which refer to individualism, is a strong association with Western culture. At first sight, this might seem to reflect the fact that the idea of individualism entered Japan from Western sources, but a close examination merely shows that the West is associated with what is expensive, fashionable and socially desirable. “18

\section{Westlicher Individualismus als Zitat: das verpackte Selbst}

Der Zitatcharakter des Werbe-Individualismus in Japan wird insbesondere dort deutlich, wo sie westliche Produkte präsentiert oder westliche Stars einspannt. So thronte z.B. Claudia Schiffer über der Geschäftsstraße Omotesandô in Tokio gegenüber dem Marlboro-Cowboy und warb mit demselben Slogan wie in Deutschland für ihr Haarshampoo.

・ロレアル・パリ。わたしにはその価值があるから。 クラウディア・シファー。

- L’Oréal Paris. Weil ich es (mir) wert bin. Claudia Schiffer.

Auch der Hersteller des Deodorants Rexona (deutscher Name) hat versucht, seine internationale Dachkampagne in Japan durchzuhalten. Das war allerdings nur mit Einschränkungen möglich. Erstens wurde Steffi Graf als Trägerin der Kampagne abgesetzt. Zweitens konnte die Kampagne nicht an die Angst vor Körpergeruch appellieren: Die japanischen Konsumenten kennen sie nicht, weil sie täglich baden. Und drittens mußte der Produktname geändert werden, weil sich das Wort „Rexona" für japanische Ohren anhört wie das Wort kuso (Exkremente).

18 Tanaka 1994: 120. 
Schließlich wurden die Konsonanten $\mathrm{R}, \mathrm{S}$ und $\mathrm{N}$ beibehalten und das Produkt in „Resena“ umgetauft. Die Fernsehspots zeigten zwei erfolgreiche Frauen. Eine Violinistin probt für ihr Konzert und führt souverän den Bogen. Eine Sportjournalistin managt eine Großveranstaltung und dirigiert die männlichen Techniker. Sie resümiert:

・私はいつでも完璧でいたいから、レセナ。私の自信。Resena.

- Weil ich immer perfekt sein will: Resena. Mein Selbstvertrauen. Resena.

Da wollte der deutsche Hersteller Beiersdorf nicht zurückstehen. Im Spot für Nivea Body lesen wir in der Einblendung:

・素肌の自信が、ボディの自信。

- Das Selbstvertrauen natürlicher Haut, das Selbstvertrauen Ihres body.

Es ist sicher kein Zufall, daß die japanische Werbung bevorzugt amerikanische Stars für ihre individualistischen Kampagnen einkauft wie die Sängerinnen Whitney Houston und Mariah Carrey oder die Schauspielerin Jodie Foster. Erstere stolziert (wie das phallische WolkenkratzerModel aus dem Amerika-Buch von Baudrillard) durch das Fernsehstudio, schnalzt mit den Fingern und empfiehlt auf Englisch (mit japanischen Untertiteln) einen Finanzdienstleister.

- Believe in Yourself. And You know, what You want. Make it happen with Nisshin.

・自分を信じて、夢に向かって、あなたならできる。 ニッシンと共に。

- Glauben Sie an sich, folgen Sie Ihren Träumen, Sie können es. Mit Nisshin.

Dieselbe Formel benutzt die Sprachschule Aeon, die Mariah Carrey für sich gewinnen konnte. Wir lesen:

・夢に近づくことは、自分に近づくこと。

- Sich dem Traum annähern heißt, sich selbst nahe zu kommen.

Etwas dezenter arbeitet die kleine Jodie Foster, ebenfalls bimedial, für eine Zeitarbeitsfirma. Auf dem Plakat heißt es: 
- Believe in Yourself. Challenge Yourself. Pasona.

- Glaube an Dich selbst. Fordere Dich selbst heraus. Pasona.

Und im Spot lesen wir:

・自分はこうなりたい。そんな思い強く願えば、 きっと実現します。

- So will ich werden. Wenn ich daran mit aller Kraft festhalte, schaffe ich es bestimmt.

Und in einer zweiten Fassung:

- 大切なのは自信。自分の可能性に挑戦すること。

- Das wichtigste: Selbstvertrauen.

Die eigenen Möglichkeiten herausfordern.

Doch diese weiche, weibliche Individualität hat auch ein männliches Gegenstück. In westlichen Gesellschaften ist traditionell der Profisport Männersache. Auch die meisten Zuschauer sind männlich, weshalb während der Sportsendungen in Deutschland gezielt für Bier geworben wird. In Japan konnte sich erst nach dem Krieg der Profi-Sport Baseball nach amerikanischem Vorbild etablieren, erst später folgte der Fußball aus Europa und die Fußball-Weltmeisterschaft 2002. Das bot dem Hersteller Adidas die Möglichkeit, in seinen 30 Sekunden-Spots weltweit ein internationales Image aufzubauen. Sie reisen in wenigen Einstellungen rund um das globale Dorf und zeigen Bilder von Sportlern aller Rassen. Auch in Japan waren die Zwischentitel, auf einer vertikalen Achse auf den Schirm gedreht, an plakativem Individualismus kaum zu überbieten.

・輝く瞬間のために。極めるために。 純粋な心のために。夢をみるために。栄誉のために。 そして、自分らしくあるために。 Adidas. スポーツの名のもとに。

- Für den Augenblick des Glanzes. Für die äußerste Anstrengung. Für die Reinheit des Herzens. Für den eigenen Traum. Für den Ruhm. Schließlich: um Du selbst zu sein.

Adidas. Im Namen des Sports.

In einer zweiten Version heißt es: 
・熱狂したい。上手くなりたい。輝いてたい。 強くなりたい。楽しみたい。そして、自分らしくありたい。 Adidas. スポーツの名のもとに。

- Ich will mich einsetzen. Ich will gut werden. Ich will glänzen. Ich will stark werden. Ich will genießen. Ich will ich selber sein. Adidas. Im Namen des Sports.

Eine dritte Version:

・地元のチャンプヘ。界のチャンプヘ。フィールドに集まれ。 シュートを放て。自分のやり方。自分のペースで。 そして、自分らしくありたい。Adidas. Forever Sport.

- Champion zu Hause. Champion in der Welt. Geh' aufs Feld. Schieß'! Auf meine Art, in meinem Tempo. Ich will ganz ich selber sein. Adidas. Forever Sport.

Die schönste individualistische Gastrolle in Japan hatte aber der Schauspieler Anthony Hopkins in seiner Werbung für den Toyota Avancier. In dem Film „Das Schweigen der Lämmer“ spielte er einen Profiler (forensischen Psychoanalytiker), der selbst zum Massenmörder wurde. Zusammen mit einer FBI-Agentin (Jodie Foster) bringt er einen anderen Mörder zur Strecke, der seine weiblichen Opfer häutet, um sich selbst eine neue Identität zu schneidern. In Anspielung auf diesen Film marschiert Hopkins mit zwei Blondinen durch den Spot und sagt: „Let's have a thrilling time." In der Print-Anzeige blickt er durchdringend mit seiner Hand an der Schläfe über den Wagen. Der Slogan der Kampagne:

・エゴイストの資格。Honda.

人と、地球に（夢・発見・ドラマ）を。 大人のわがままを充たすために。 大人たちの官能を摇さぶる。アヴァンシア誕生。Avancier.

- Die Qualifikation zum Egoisten. Honda. Für die Menschen und für die Welt: Einen Traum, eine Entdeckung, ein Drama. Um den Eigensinn eines Erwachsenen zu befriedigen. Weckt die Sinnlichkeit des Erwachsenen. Avancier (Geburt).

Natürlich ist das, was der Filmstar (und Massenmörder) Dr. Hannibal Lector, gespielt von Anthony Hopkins, sagt, nicht für bare Münze zu nehmen, sein Egoismus ist lediglich eine mediale Metapher. Aber immerhin: auch die Firma Nissan hat sich vom individualistischen Werbestil infizieren lassen. Ihre Anzeige für den Bassara Axis ziert ein Text voller Katakana-Anglizismen: cool und elegant. 
・これがおとなの、クールエレガンス。 より上質、より個性的にバサラ・アクシス。

- Das ist die coole Eleganz des Erwachsenen.

Mehr Qualität, noch individueller, Bassara Axis.

Diese Beispiele zeigen, daß die japanische Werbung individualistische Appelle westlichen Stils zwar noch intensiviert. Daraus spricht aber keine reale Individualisierung der japanischen Gesellschaft, sondern paradox ihre Lust am Zitat westlicher Stile im geschützten Rahmen des massenmedialen Kontextes. Ein Blick auf individualistische Werbestrategien ohne Celebrities und stilistische Leihgaben aus westlichen Ländern läßt das Bild wieder dividual verschwimmen.

\section{Self(s) Japanese Style: Diversifizierung der Dividuen}

Grundsätzlich muß auch die japanische Werbung ein neues Selbst durch den Konsum versprechen, konkret: einen neuen Körper. Idealtypisch tut das die Anzeige für ein Vitaminpräparat von Taishôseiyaku. Es heißt nicht nur Nature Made, sondern hilft - je nach Kombination - gegen alle geläufigen Zivilisationskrankheiten, die in „Katakana-Japlish“ treffend benannt werden: Alterung (エイジング), Gewichts- bzw. Diätprobleme (ダイエット), mangelnde Schönheit (ビューティ) und Überarbeitung (ハードワーク). Damit spannt die Anzeige den Bogen zurück zum Ursprung des Selbst im Körper. Die Überschrift:

・なりたい自分に、なるビタミン。ネイチャーメイド。 マルチビタミン。

- Die Vitamine, mit denen ich ich selbst werde. Nature Made. Multivitamin.

Doch in der Umschreibung des Selbst ist die japanische Kultur wesentlich flexibler als die westliche. Am besten lassen sich zwei Werbestrategien von Tageszeitungen gegenüberstellen. Als die Kritische Subjekttheorie in Deutschland noch en vogue war, erfand auch die konservative Frankfurter Allgemeine Zeitung für ihre Werbung den allseits bekannten klugen Kopf, der sich in der Bleiwüste der Morgenzeitung über die politische Weltlage informiert. Natürlich trägt dieses Subjekt Anzug und Krawatte. Ein Schweizer Uhrenhersteller griff in Japan auf diese Werbesemantik zurück. In seiner Anzeige hält ein Gentleman seinen Arm mit Uhr vor sein Gesicht: Who Is Behind an Audemars Piguet Watch?

Aber Japan ergänzt die harte Urteilskraft des objektiven Bewußtseins um eine weiche, weibliche Seite. Ein junges Mädchen, das tarento 
Tanaka Reina, das nebenbei auch für Dosenlimonade wirbt, abonniert nach ihrem Auszug aus ihrem Elternhaus die Tageszeitung Asahi Shimbun. ${ }^{19}$ Und sie begründet das nicht vernünftig, sondern intuitiv.

・新聞は、世界中から届く、私への手紙。

- Die Zeitung ist ein Brief aus der Mitte der Welt an mich.

Die japanische Argumentation stellt hier nicht das Subjekt ins Zentrum oder das Produkt, sondern umschreibt beide. Genau wie das Plakat für das neue Zitronengetränk C 1000 Takeda.

- C と、自分と、水分と。

- C, ich und mein/sein Wassergehalt.

Auch das Werbeplakat für das FAX-Telefon von Brother mutet japanisch an: Die weiß gekleidete Hausfrau entscheidet im Innenbereich.

・家族みんなの意見を聞いて、おたしが決めました。

- Ich habe alle in der Familie nach ihrer Meinung gefragt und dann entschieden.

Die Mutter spielt eine zentrale Rolle in der maternellen Gesellschaft der Dividuen. Ihr Kanji ergänzt das Kanji für Frau um die beiden Brustwarzen: 母. Doch es gibt auch geschlechtsspezifische, vertrauliche Anredeformen für die Mutter. Söhne nennen sie auch ofukuro (お袋). Väter werden dagegen oyaji (親父) genannt. Für Werbezwecke läßt sich naturgemäß die Positivität der emotionalen Mutterbindung besser anzapfen als die Autorität des Vaters. Auch die bereits zitierte Kampagne der Japanese Railways zur Verschönerung der Bahnhöfe arbeitete mit Tiermüttern und Tierkindern, mit Seehunden, Löwen und Känguruhs:

・カンガルーの母は、二００日以上の長時間、おなかの袋の中 で子供を育てます。母のぬくもりをとおして学ぶようにと。 自分自身のことや、世界のこと、ゆっくりと、ゆっくりと。 コミュニケーションを、JR。

- Die Känguruhmutter zieht ihr Kind im Beutel in ihrem Bauch länger als 200 Tage groß. Damit es durch die Wärme der Mutter lernt. Damit es sich selbst kennenlernt und die Welt, und alles behutsam, behutsam. Kommunikation. JR.

19 Die Bedeutung der Asahi-Zeitung für junge Leser liegt auch darin, daß ihre Artikel häufig als Vorlage für die Prüfungen zur Aufnahme in die Universität auftauchen. 
In der japanischen Sprache können Personalpronomen je nach der sozialen Beziehung zwischen den Interakteuren variieren. Die Werbung macht sich diese Dividualität auf Plakaten zunutze, indem sie das abgebildete Produkt in der ersten Person betextet. Dadurch entsteht eine Spannung zwischen Bild und Text, die das Interesse des Betrachters weckt. Auf dem Plakat für das Billigbier Bräu von der Sapporo-Brauerei z.B. sieht man chinesische Feldarbeiterinnen bei der Arbeit und liest:

・私は、無農薬です。ブロイ。

- Ich bin ohne Kunstdünger. Bräu.

Oder die Werbung für Fiona Apple in Shibuya. Auf dem Plakat nimmt sie ein brennendes Streichholz in den Mund: Ich bin Musik.

・私は音楽。フィオナ・アップル。

- Ich bin Musik. Fiona Apple.

Die Firma Shiseido hat diese Ich-Form der Warenwerbung sogar in Deutschland angewandt: Auf dem Plakat für The Skincare stand zu lesen:

- Ich bin die Energie Ihrer Haut. Vertrauen Sie mir.

Eine Drehung weiter dreht die Semantik das Super-tarento Fujiwara Norika in ihrer JAL/Okinawa-Werbung. Die Schöne steht im weißen Kleid am Pool, doch der Text benutzt ein männliches Pronomen für die erste Person: boku (Dem Plakat, das ich sah, hatte prompt jemand einen Bart aufgemalt. Die semiotische Spannung dieses kurzen Textes hatte also ihre attraktive Wirkung nicht verfehlt). Durch diesen einfachen Bruch mit den Regeln und die spielerische Verschiebung der Bedeutung wird der Text assoziativ auf verschiedenen Ebenen anschlußfähig. Spricht der Sohn?

・パパとぼくの秘密の夏休み。

- Meine heimlichen Sommerferien mit meinem Papa.

Wandlungsfähigkeit, nicht Selbstreflexion, ist die Stärke des japanischen Ich. Einer der Spots für den neuen Toyota Crown läßt einen erfahrenen Theater-Regisseur auftreten, der seinen Schülern Rollen erklärt. Sein Wagen: eine weiße Limousine. Zur Philosophie des sempai lesen wir: 
・ 21 世紀へ、人生の新しいドアを。 この道の先に、知らない自分がいる。CROWN 誕生。

- Eine neue Tür ins 21. Jahrhundert für das menschliche Leben. Auf diesem Weg gibt es ein noch unbekanntes Selbst. CROWN.

Einen baugleichen Spot, ebenfalls mit einem sanften Individualismus, schaltet Mitsubishi für seinen Diamante 2,51 GDI. Erneut dominiert eine weiße Limousine das Bild, wir hören Marvin Gaye (,Brother, brother, brother..."), und in unverhohlener sexueller Anspielung heißt es in den Zwischentiteln:

・髪をのばしていた頃の自分、クルマが欲しくてたまらなかつ た頃の自分、惚れたセダンで走りたい。Diamante 2.51 GDI。

- Ich, der ich einmal lange Haare hatte und unbedingt ein Auto haben wollte, will jetzt mit der Limousine fahren, in die ich mich verliebt habe. Diamante 2,51 GDI.

Zwei weitere Werbungen beleuchten die Realität der japanischen Arbeitswelt und offenbaren erneut ein dividualistisches Bild. In der U-Bahn mahnt ein Sumo-Ringer im Auftrag des Sozialministeriums zu verantwortlicher Lebensweise. Aus dem selbstbewußten jibun wird ein einfaches männliches boku. Der Schüler (kôhai) bedankt sich für seine Eingliederung in Familie und Gruppe. So zeigt sich hinter der Fassade des starken, Reis werfenden Mannes eine typisch japanische, schwache, weiche und geschmeidige Psyche, die ihr Ich von anderen im Akkusativ kritisieren läßt.

・誰にだって頑張れる土俵がある。 僕はある時、わけもなく、つつぱっていた。 でもそんな僕を叫び、励ましてくれる家族や先輩がいた。 みんなの声が聞こえるから、僕も、全力で頑張れるんだ。

- Jeder hat einen Ring, in dem er sich beweisen kann. Ich hatte einmal, ohne jeden Grund, eine bockige Phase. Aber es gab eine Familie und einen Sempai, die mich zurechtwiesen und aufmunterten. Weil ich alle um Rat fragen kann, kann ich mich auch mit ganzer Kraft am Riemen reißen.

Die Werbung für die Firma Tamura zieht schließlich alle Register und interpretiert selbst an der Bedeutung des Wortes selbst herum. Diese typisch japanische Umdeutung und Umschreibung von Definitionen läuft schließlich auf Harmonie, Gruppensinn und Teamarbeit hinaus. Das U-Bahn-Plakat treibt den japanischen Dividualismus auf die Spitze. 
・ タムラ製造 自分中心主義で行きましょう。わがままとか、 利己主義とかでなく、みんなの輪の真ん中に進んで入ってい くこと。中心的な役割を果たすこと。だから、タムラは自分 中心主義に質成。そんなチャレンジ精神を大切に、通信、エ レクトロニクス、宇宙など幅広い分野で、独創の技術を磨い ていきます。Tamura.

- Tamura will das Selbst ins Zentrum stellen.

Das heißt nicht: Selbstsucht oder Egoismus, sondern das bedeutet: sich mitten in den Kreis aller hineinbegeben und eine zentrale Rolle ausfüllen.

Deshalb legt Tamura Wert auf Individualität (Selbstzentrierung). Indem wir (den Geist) diese(r) Herausforderungen ernst nehmen, verbessern wir originelle Konstruktionen in der Elektronik-, Nachrichten und Weltraumtechnik. Tamura.

Die schönste Werbung, die mit dem Ich, dem Selbst, der Individualität im japanischen Sinne spielte, war aber die für den Toyota Nadia. Sie zeigte im 30 Sekunden-Spot (andere Versionen waren nur 15s lang) einen jungen Mann, der in 10 verschiedenen Aufzügen im Kreis um seinen Wagen herumsteht (sic!). In den verschiedenen Versionen verwandelt er sich dann per Knopfdruck in einen Pianisten, eleganten Gastgeber, Varieté-Zauberer, Action-Helden, Angler oder „,formal man“ und beeindruckt - in jeder Rolle aufs neue - seine weibliche Bekanntschaft. Der Spot kombiniert genial westliches Erfolgsdenken (die Frau kriegen) und japanische Dividualität. Sein Slogan überbietet elegant die Komplexität der deutschen Sprache. Hat die Soziologie bereits den Begriff Bewußtsein in den Plural gesetzt, so müßte sie das nun, um korrekt zu übersetzen, mit dem Selbst tun. Und das bei der Übersetzung eines Werbeslogans aus einer Sprache, die ursprünglich gar keinen Plural kennt.

・いろんな自分に変身ナディア。

- Der Nadia. Für die Transformation zu verschiedenen Identitäten (Selbsten).

In der englischsprachigen Japan Times zielt der Slogan der Kampagne wieder auf individuelle Perfektion ab und verliert an Eleganz und Geschmeidigkeit - schließlich sind nur imperfekte Dividuen perfekt.

- Perfect For You. Whoever You Want To Be. 
Die Inszenierung des Selbst in der japanischen Werbung hinterläßt Verwirrung und Unschärfe. Einerseits quellen Ich und Selbst aus allen Konsumempfehlungen entgegen, andererseits wird der Individualismus in der japanischen Werbung durch multiple Techniken abgeschwächt, zum Zitat zurückgestuft, relativiert. Einerseits zeichnet auch die japanische Werbung ungezeichnete Heldenpsychen. Andererseits stellt sie diese Bilder geschickt in einen kulturspezifischen Rahmen. Das scheint die Werbewelt selbst sehr gut zu wissen. Im Anzeigentext für eine neue, wöchentlich erscheinende Literatur-Enzyklopädie des Asahi-Verlages heißt es konsequent:

・自分とは何か。解答は、文学をみよ。

- Was ist das Selbst? Die Antwort findest du in der Literatur.

Die Umschrift des Selbst, die Beschriftung der Körper, geht weiter. Ein wesentliches Zeichen ist ihnen von Natur aus gegeben: das Geschlecht. Die Inszenierung von Mann und Frau in der japansichen Werbung ist daher eine weitere Spur zu ihrer Funktion als semantischer Hautkontakt zwischen ökonomischem Funktionssystem und individueller Entfaltung.

\section{5 otoko no aji (der männliche Geschmack): Mann und Frau in der japanischen Werbung}

\section{Mediale Geschlechterbilder als Selbstbilder zweiter Ordnung}

Seit der Sprinter Carl Lewis für die Pirelli-Werbung in roten, hochhackigen Schuhen an den Start ging und Claudia Schiffer ihren Citroën streichelte, springt die intensive Betonung des Geschlechts in der Werbung (und ihre Nähe zum Geschlechts-Verkehr) ins Auge. ${ }^{20}$ Sie steigert die Körperinszenierung und vergrößert erneut die Distanz zwischen Werbung, Ware und Ware Arbeitskraft. Die Werbung gesteht ein: Der Körper ist der Kern des individuellen Selbst und dieses Selbst bildet sich am Geschlechterverhältnis. Sie muß sich als zivilisierte Zeichensprache dem Körper der Frau, ihrer Haut, ihrem Haar, ihrer Kleidung einschreiben. ${ }^{21}$ Sie zeichnet ungezeichnete Körper und muß paradox die selbstbewußte,

20 Deshalb setzt die Autowerbung für Männer die Frau mit dem Auto gleich. Zur Formel „Frau = Auto" in der Werbung à la Virilio vgl. Heinze 1994.

21 „And generally the body, especially the female body, is presented either to promote the consumption or services or material objects - banks, clothes, cars, household appliances, for example - or to be consumed itself, most commonly as an image, by the gaze of the beholder, but occasionally - as in magazines promoting ,soaplands ${ }^{6}$ or massage parlours - quite literally and physically, subsequent to a reading of the magazine by those who seek out the offered services." Clammer 1995: 199. 
selbstbestimmte Frau mit der Natur in Verbindung bringen, teilweise identifizieren. Dies ist schon in Deutschland evident. ${ }^{22}$

Die Präferenz der Werbung für Weiblichkeit verleitet dazu, feministische und manipulative Thesen an ihr festzumachen. So kommt Brigitte Spiess in ihrer Bewertung von 610 deutschen Fernsehspots mit weiblichen Akteurinnen (pflichtbewußt) zu dem Ergebnis, daß sich die Werbung vom Klischee der Hausfrau aus den 50er und 60er Jahren zwar wegbewegt und auch selbstbewußte, berufstätige Frauen anspricht, daß sie jedoch gleichzeitig die normativen Paradigmen der Schönheit, Sauberkeit und Sinnlichkeit beibehält. Auch bleiben in technischen Dingen männliche Autoritäten den weiblichen Akteurinnen übergeordnet. Typisch weibliche Konflikte und Belastungsfaktoren wie Haushaltsführung neben dem Beruf, Alleinerziehung oder Partnerschaftsprobleme werden von der Werbung weitgehend ausgeblendet. ${ }^{23}$

Chuang Yi projiziert in die japanischen Frauenzeitschriften den manipulativen Versuch, ihren Leserinnen den Wunsch nach Schönheit und einem harmonischen Eheleben einzuimpfen. Insbesondere die Modezeitschriften mit ihrer Vorliebe für weiße, westliche Models propagieren den Lebensstil der Oberschicht, schreiben den Frauen männlich bestimmte Verhaltensmuster ein und degradieren sie zur ,stummen Stütze der Macht“. ${ }^{24}$ Tanaka Keiko macht das Machtgefälle zwischen den Geschlechtern in Japan am subtilen Gebrauch des Wortes ,intelligent" in der Werbung fest. Ein Werbesystem, das von ,intelligenter, weißer, natürlicher Haut", „,intelligenter Eleganz“ und „,feministischen Gasherden" redet (weil der Gasherd der Hausfrau hilft), zeugt von ungebrochener Geschlechterordnung. ${ }^{25}$ Sie zitiert eine Kosmetik-Werbung:

・やっぱり「白い素肌」が、セクシーだし、知的でしょ。 「ラ・エステ」って、女のコのことよく知ってるね。

- Weiße, ungeschminkte Haut ist doch sexy und intelligent. La Este kennt die Wünsche (Dinge/Angelegenheiten) der Frauen.

22 Zur Nutzung des Körpers als Identitätskern im deutschen Werbesystem vgl. Willems/Kautt 1999. Die Systemtheorie kommt nicht umhin, die Werbung das Geschlecht erst konstruieren zu lassen. Schmidt 2000: 242-260.

23 Spiess 1994.

24 Yi 1999.

25 „These advertisements for fashion goods are effectively suggesting that women should express their intelligence through their clothes and handbags. Intelligence is no more than a superficial quality which clothes and accessories give to a woman. It is desirable for a woman to be intelligent in her choice of clothes, but women are not encouraged to be intelligent in a general sense. Intelligence describes appearance rather than mental capacity, and seems closer in its meaning to words such as ,elegance', ,femininity ${ }^{6}$, or ,sophistication', than to words like ,brightness" and ,cleverness', which a thesaurus would suggest as synonyms." Tanaka 1994: 111-114. 
Aber manipuliert die Werbung die Realität, wenn sie sich, statt den Konflikt ihren Konsumentinnen zu suchen, sanft und unverfänglich an ihren Wünschen entlangtastet? Es ist kein Verbrechen, schön und begehrenswert sein zu wollen, sondern ein reales Bedürfnis. Auch Nancy Rosenberger hat in einer empirischen Untersuchung Leserinnen japanischer Frauenzeitschriften interviewt, deren Markt in den vergangenen 20 Jahren stark gewachsen ist. Im gleichen Zeitraum stieg das Erstheiratsalter der Japanerinnen um einen Monat pro Jahr auf 26,9 Jahre anno $1999 .{ }^{26}$ Rosenberger erkennt bei den japanischen Konsumentinnen einen ,„passiven Individualismus“: Sie reflektieren ihr Leben und ihren Lebensstil stärker als die Generation ihrer Mütter. ${ }^{27}$

Eine empirische Untersuchung der japanischen Zeitschriftenwerbung konnte sogar zeigen, daß die Frauen den Männern in der Werbung oft den Rang ablaufen. Zwar zeigen sich wie erwartet die Frauen in der Werbung signifikant häufiger als die Männer besorgt um ihre äußere Erscheinung, aber weder bewerben sie billigere Waren, noch erscheinen sie häufiger in der häuslichen Umgebung als die Männer. Auch das Vorurteil, Frauen würden häufig als bloße Dekoration der Ware beigefügt, ließ sich nicht untermauern. Die japanische Werbung kombiniert also flexibel westliche und asiatische Werte und vertritt einen ,moderate egalitarianism". Frauen treten keineswegs übermäßig bescheiden, besorgt oder bittend auf: „Our results suggest that some ethnocultural stereotypes still pervade Japanese advertising in both the surface and on more subtle levels, which is not surprising given its ethnocultural context. What is interesting is the apparent change in Japanese society in terms of women's issues and rights. “28 Elisabeth Gössmann konnte schließlich in den japanischen Fernsehserien der 90er Jahre die Enttraditionalisierung der jungen japanischen Generation unmittelbar verfolgen. Während die Frauen im Vormarsch die „Außenwelt“ erobern, entwickeln die Männer zusehends Familiensinn. ${ }^{29}$

\section{Starke Mütter, schöne Mädchen, schwache Konsumentinnen}

An zwei rituellen Ereignissen lassen sich kulturelle, geschlechtsspezifische Rollenmuster stets festmachen: an der Hochzeit und an der Geburt. In Japan hat sich das christliche Hochzeitsmodell nach dem Krieg mit großem Erfolg durchgesetzt. Die Braut trägt Weiß zum rite de passage,

26 Quelle: Homepage des Erziehungsministeriums. Diese späte Heirat (bankonka) jenseits der magischen Altersgrenze von 25 Jahren (Christmascake) bringt wie in Deutschland auch die stetig sinkende Kinderzahl mit sich.

27 Rosenberger 1995.

28 Ford/Voli/Honeycutt/Casey 1998: 122.

29 Gössmann 1997: 111. 
der Ehealltag wurde bereits umrissen (Kapitel 2.1). Auch begleiten bis heute nur wenige japanische Ehemänner ihre Frauen in den Kreißsaal: In einem Werbespot für McDonald's ziehen Vater und Sohn es vor, mit der werdenden Mutter im Krankenhaus per Telefon zu reden, während sie sich selbst einen Imbiß genehmigen. Doch auch dieses Verhalten stößt bereits innerhalb des Werbesystems auf Kritik. Das Werbeplakat von Okamoto für Kondome zeigt sechs Männer in anderen Umständen:

・男も妊娠すればいいんだ。

- Auch Männer sollten schwanger werden .

McDonald's sorgt dafür, daß die Mutterrolle dann doch den Frauen vorbehalten bleibt. Auf dem papiernen Tischtuch steht:

- 人生で、正しい手洗いを教えてくれるのは、お母さん、小学 校と、マクドナルドぐらいかもしれない。

- Die einzigen, die uns im Leben das richtige Händewaschen beibringen, sind die Mutter, die Grundschule und McDonald's.

Auch das neue Fieberthermometer für das Ohr wurde in Japan eingeführt. Im importierten Spot traten noch beide Eltern auf und das Baby kommunizierte seine Abneigung gegen das kalte Quecksilber per Pappschild. In der japanisierten U-Bahnversion ist zwar das Baby noch blond, aber für das Fieber ist nur noch die Mutter zuständig.

・お母さんの気持ちに、耳温計は「正確さ」でこたえます。さ らに性能アップ。パッケージも新たに新登場。

- Das Ohrthermometer antwortet auf die Gefühle der Mutter mit der zuverlässigen Temperatur-Messung im Ohr. Noch effektiver. Neu mit neuer Verpackung.

Die positiven Assoziationen des Begriffs Mutter nutzt auch die Werbung für die Seife Kao White. Der Spot zeigt ein junges Mädchen, das sich wäscht, Wasser, Seife, helle Kacheln und wenig Text:

・ホワイトは、お母さんのにおい。

- White ist der Duft der Mutter.

Die japanische Werbemutter putzt auch dann klaglos, wenn bei ihrem Jungen „mal was danebenging“. Die Normativität der Hausfrauenrolle wird aber dadurch besonders intensiviert, daß Mutter und Tochter gemeinsam kochen, waschen und staubsaugen. Besonders weit treibt es der 
Spot für jene sagenhaften Tücher, die noch mehr Staub als der Staubsauger aufnehmen. Im Spot säubern Mutter und Tochter den Fußboden, die Mutter saugt, die Tochter wischt hinter ihr her. Dabei singt sie die dazugehörige Werbeschnulze und ersetzt in einer Strophe „hinter dem Staubsauger" her durch, ,hinter der Mutter her". In einem weiteren Spot für Sonnenblumenöl kochen und trainieren Mutter und Tochter zusammen und überlegen sich gemeinsam, wen sie wie beschenken. Auch mit der Zubereitung von Blendy Eiskaffee vertreiben sich Mutter und Tochter in der Werbung ihre Langeweile. Der schlechteste japanische Frauenrollenwerbespot kommt aber gar nicht aus Japan, sondern aus den USA. Er wirbt für Kekse mit dem Namen Country Ma'am. Mutter, Tochter und Oma backen. Die Großmutter sitzt im Schaukelstuhl und schaut zu, wie die Enkelin Schokoladenkrümel nascht. Der Sprecher stellt befriedigt fest:

・アメリカの女の子、お母さんから最初に教わるのは、 クッキーの作り方です。

- Was die amerikanischen Mädchen zuallererst von ihrer Mutter lernen, ist das Kekse Backen.

Immerhin ist auch an die Erholung der Hausfrauen gedacht. Sie unternehmen häufig Gruppenreisen mit den Zügen der JR. Deshalb schreibt die Werbung im Waggon:

・チョット主婦を休んで行く列車の旅。 チョット主婦のリフレッシュ・トレインを計画。

- Die Bahnreise, bei der Sie mal ein bißchen von der (Rolle der) Hausfrau ausruhen. Wenn die Hausfrauen sich ein bißchen „Refresh-Train“ vornehmen. Japanese Railways.

Die japanische Ehefrau sollte stets auch an das Wohl ihres Gatten denken. Wie tief diese Rollenerwartung an die Frau in der japanischen Gesellschaft verwurzelt ist, zeigt die Telefonwerbung von Kenwood. Sie zeigt eine Kaffeetasse und das umworbene Telefon. Der Text:

・会議中の夫とメール交換する私は良妻でしょうか。

- Wenn ich mit meinem Mann, während er in einer Konferenz ist, Mails austausche, bin ich dann nicht eine gute Ehefrau?

Die These der getrennten Welten der Geschlechter in Japan läßt sich also bis in die Werbung hinein belegen. Auch versuchen die japanischen Hersteller, Produkte speziell für Frauen im Markt zu verankern, z.B. ein 
eigenes Frauenbier, das First Lady Silky. Es verspricht genau wie das Mineralwasser Minea, das ein junges Mädchen goutiert, und der Lippenstift Kate von Kanebo ein neues Ich.

・あたらしい私。あたらしいビール。 シルキーな飲みごこち。シルキ一誕生。

- Ein neues Ich. Ein neues Bier. Ein seidiges Trinkgefühl. Silky (Geburt).

・私を咲かせる水。Minea.

- Das Wasser, das mich aufblühen läßt. Minea.

- 自分の色は、自分で決める。

- Meine eigene (Lippenstift-)Farbe lege ich selber fest.

Und selbst wenn die Frauen Alkohol genießen, mahnt die Werbung sie, an ihre vegetative Zone zu denken. Shiseido empfiehlt das neue Getränk Lady Fizz gegen den Kater:

- 飲んでも元気、飲むならキレイ。Lady Fizz. お酒を飲む方用栄養補助食品。

- Gesund, auch wenn Sie getrunken haben. Schön, wenn Sie es trinken. Lady Fizz. Zur Unterstützung der Ernährung derjenigen, die Alkohol trinken.

Auch der Energietrunk Chocola BB ist für Frauen gedacht. Im TV-Spot bekämpft eine Frau damit ihre Übermüdung (tsukare) und ihre Hautflecken (hadaare). Das Plakat in der U-Bahn wird noch deutlicher:

・おんなには、顔に出せない疲れがある。 チョコラ BB ドリンク。

- Es gibt eine Müdigkeit, die Frauen nicht (in ihrem Gesicht) zeigen können. Chocola BB Drink.

Doch die Frauen befassen sich auch in der Werbung keineswegs nur mit ihrem Aussehen und ihrer Gesundheit, sondern entdecken auch den Spaß des Autofahrens für sich. Im europäischen Spot für den VW Bora streiten sich Mann und Frau darüber, wer fährt und wer trinkt. Die japanische Werbung trägt den Konflikt nicht offen aus. In der Kampagne für den Cadillac Seville (mit dem Slogan: Mehr Freiheit) entscheiden er noch über die gemeinsame automobile Freizeit. Sie stimmt noch überrascht zu: 
・ 夫が、ゴルフをキャンセルして、トライブに行こうなんて。

- Mein Mann sagte: Canceln wir das Golfspielen! Laß uns spazierenfahren!

・ 夫が、仕事を休んでまでドライブしようなんて。

- Mein Mann sagte: Laß uns spazierenfahren, bis ich mich von meiner Arbeit erholt habe!

Aber die Werbung für den Toyota Progrès dreht den Spieß um. In ihr tritt Natsume Sôseki auf, der populärste japanische Schriftsteller, der zugleich den $1.000 ¥-S c h e i n$ ziert. Denn plötzlich will die Ehefrau fahren, darf fahren und wird als gleichberechtigt in Sachen Auto anerkannt. Die Gender-Grenzen fallen.

・運転したい、と妻。どうしたんだろう。一足先に玄関をでた 妻が、なぜか運転席のほうに座って、そう言った。そういえ ば、妻も免許をもっていたんだ。そのことを忘れるくらいに、 最近はなかったことです。ただ気まぐれだろうか。それとも、 このクルマは、男とか女をこえて感じられる何かやさしさの ようなものがあるのかも知れません。どうやらこのクルマ、 主人が二人になりそうです。小さな高級車、プログレ。いい クルマに会いました。

- Ich will fahren, sagte meine Frau, als sie aus dem Flur heraustrat und sich einfach hinters Steuer setzte. Ach ja, sie hatte ja auch einen Führerschein. Da sie in letzter Zeit fast gar nicht gefahren war, hatte ich das fast vergessen. War das nur eine ihrer Launen? Dieses Auto ist offenbar so sanft, daß man regelrecht spürt, wie es die Grenze zwischen Mann und Frau überwindet. Dieses Auto wird wohl zwei Besitzer bekommen. Ein kleiner, hochklassiger Wagen: der Progrès. Ich habe ein gutes Auto gefunden.

Genausowenig wie beim Autofahren ist die Grenze zwischen der Männer- und Frauenwelt beim Biertrinken und beim Tabakkonsum durchzuhalten. In der japanischen Werbung trinken sogar mehr Frauen Bier als in der deutschen. Die Kampagne für Kirin Ichiban arbeitet ausschließlich mit einer Frau, die auf einem Plakat einen Schaumbart bekommt. Und auch der Tabakwerbung läßt sich keine Diskriminierung unterschieben. Gerade weil sie eigene Frauenmarken konzipiert, kann sie sogar besonders offensive Slogans verbreiten: Die Kampagne für Virginia Slims wirbt mit dem selbstbewußten englischen Slogan: Be You. Die Bilder zeigen starke, weiße Frauen und spielen zugleich sanft auf eine homosexuelle Beziehung an. 
・あなたと出会って、わたしになった。

- Ich habe dich getroffen und mich selbst gefunden.

・強がるのは、甘えたいから。

- Ich gebe mich stark, weil ich verwöhnt werden will.

・私を幸せにできるのは、私だけ。

- Nur ich selbst kann mich glücklich machen.

・いま、している恋が初恋。Diese Liebe ist meine allererste.

Der Werbespot für das Augenwasser Pure ging noch einen Schritt weiter im Geschlechterkampf. Ein Junge am Strand liest einem Mädchen einen frechen Satz vor, den er auf einem Schild in die Höhe hält:

・どんなに服を脱いでも、キモチはハダカにできない。 (Sie hält dasselbe Schild hoch und sagt) あたしははだか。 (Er fällt in Ohnmacht. Sie sagt:) 女の子の目はピュアがいい。 (Einblendung) スッキリ系目薬。Pure.

- Er: Wieviele Kleider ich auch ausziehe, meine Gefühle werden niemals nackt. Sie (hält dasselbe Schild hoch und sagt): Ich bin nackt (Er fällt in Ohnmacht.) Sie sagt: Mädchenaugen sollten rein sein. (Einblendung) Das klare Augenwasser. Pure.

Und noch eine Nummer härter erwischt es den ungeliebten Vorgesetzten in der TV-Werbung für den Insektenkiller Gokiburun. Seine Untergebene Office Lady kommt mit hüpfenden Brüsten im Kopierraum auf ihn zu und fordert ihn heraus. Doch die verbotene Frucht ist tödlich auch für den Chef. Während der Firmenchef dessen Versetzung verkündet, lächelt die Frau nur. So kommentiert die japanische Werbung das Problem der sexuellen Belästigung am Arbeitsplatz.

Insgesamt läßt sich festhalten, daß die japanische Werbung das Geschlechterverhältnis intensiv reflektiert. Individualistische Appelle werden an Männer und Frauen gleichermaßen gerichtet. Die Werbung begreift Geschlecht als Chance, den Körper zu betonen, sie erkennt die Verschiedenheit der Geschlechter an und fordert die Konsumenten auf, das eigene Geschlecht in ihre Identität zu integrieren. Dabei ist es nicht das andere Geschlecht, das diese Verwirklichung des Selbst behindert, sondern wesentlich eine ökonomische Grenze. Das weiß auch die Sumitomo-Bank. In ihrer Werbung für ihre Kreditkarte überspielt sie das materielle Problem elegant. Das weibliche tarento Nakayama Emiri lächelt uns vielsagend an:

・ア・レ・コ・レよくばりな、女性にぴったりのカードです。

- Genau die richtige Karte für Frauen, die gierig nach allem sind. 


\section{Schwache Männer: Väter, Biertrinker, Autofahrer, Raucher}

Auch in der Vorführung von Männern in der japanischen Werbung zeigt sich eine zaghafte Annäherung zwischen den Geschlechtern. Z.B. hat sich seit den 70er und 80er Jahren auch die Bedeutung des Wortes $k a-$ waii (süß, niedlich, cute) gewandelt. Andreas Riessland kommt in seiner Analyse zu dem Schluß, daß seine Anwendung in den 90 Jahren zu einem bewußten Stilmittel herangereift ist, das sogar auf Männer angewandt werden kann wie den Altmeister Takakura Ken. ${ }^{30}$ Entsprechend uneinig sind sich die Beobachter der kawaisa (cuteness) auch in der Bewertung des Phänomens. Für die einen ist sie ein Ausdruck weiblicher Rollenmuster und männlicher Übermacht, für die anderen eine selbstbewußte Parodie stereotyper Geschlechtsidentität. Kawasoe Noriko spricht in ihrer Betrachtung von Männerbildern in der japanischen Zeitschriftenwerbung von dem neuen, ,androgynen“ Typ Mann, der auch sensibel, traumverloren und körperbewußt sein darf. John W. Treat ging schließlich soweit, Deleuze und Guattaris Anti-Ödipus zu bemühen, um die sich auflösenden Muster von geschlechtlicher Identität in Banana Yoshimotos Roman „Kitchen“ als ,rhizomatisch“ zu beschreiben. ${ }^{31}$

In der Tat sind die schwachen Männer beliebte Vorlagen für die japanische Fernsehwerbung. Sie bildet die Realität nicht nur ab, sondern überdehnt sie humorvoll bis zur leisen Kritik. Z.B. der Spot für das Energiegetränk Regain: Ein japanischer sarariiman kommt mit Koffer von der Dienstreise nach Hause und nimmt auf dem Spielplatz - vor den Augen der Mütter - das falsche Kind auf den Arm. Peinlich! Auch dem japanischen Sozialministerium ist das Problem der abwesenden Väter bewußt. Es wollte daher das Verhältnis zwischen Eltern und Kindern, speziell Vätern und Kindern, intensivieren. Seine Werbekampagne im Gegenwert von 500 Millionen Yen für bessere Väter hatte 1999 ein Echo bis hinein in die englischsprachige japanische Presse. Zahlreiche Japaner hatten sich beschwert, weil das Ministerium ihre Arbeit nicht würdige und sich in ihr Privatleben einmische. In der Anzeige posierte der Tänzer Sam, Ehegatte der Sängerin Namie Amuro, mit Sohn:

・育児をしない男を、父と呼ばない。 家庭や子育てに「夢」を持てる社会を。厚生省。

- Männer, die nicht Babysitten, werden nicht Papa genannt. Für eine Gesellschaft, die den Traum von Haushalt und Kindererziehung lebendig hält. Ihr Sozialministerium.

30 „Cuteness is a marketing multitool, it can take on many shapes, it can appear in very different contexts [...]." Riessland 1997: 131, 151.

31 Kawasoe 1999. John W. Treat 1995. 
Einen ganz anderer Lösungsvorschlag hat dagegen der Spot für den Mazda Capella Wagon New Style. Ein weißer Vater spielt kurz mit seiner Tochter, um dann allein mit seinem Wagen auszureiten. Davonfahren heißt: ein anderer sein.

・ (Sprecher) 男には、いくつの顔があるのだろう。 父を休む日。The Super Weekend. (Schlußblende) 心を動かす新発想。

- (Sprecher) Wieviele Gesichter hat wohl ein Mann?

Der Tag, an dem ich vom Vatersein ausruhe. The Super Weekend. (Schlußblende) Das neue Konzept bewegt das Herz.

Doch Männer träumen nicht nur von schnittigen Wagen, sondern auch von scharfen Klingen und geshapeten Bodies. An diesen Wunsch knüpft der Spot für den Mach3 von Gillette an, die auch in Deutschland gesendet wurde. Darin rasiert sich ein Düsenjägerpilot nackt vor dem Spiegel. Der deutsche Slogan für Gillette: Für das Beste im Mann, appelliert an den Traum von der Beförderung. Aber auch die Firma Sanyo kombiniert im Land der Samurai-Schwerter auf ihrem U-Bahn-Plakat messerscharf für ihren Rasierer: Der Siegertyp muß zuerst wie ein Sieger aussehen.

・ オトコの形。オトコの性能。 シェイプしたボディーに秘めた、カミソリ級の剃り味。 男を磨くシェーパー「T-SOLID」、SANYOから誕生。

- Das Aussehen des Mannes. Die Leistung des Mannes. Die Schärfe einer Rasiererklasse, verborgen im ,geshapeten“ body. T-Solid von Sanyo, ,stylt““ (poliert) den Mann.

Ein Wundertrunk schlägt in dieselbe Kerbe. Er wirbt mit einer siegreich jubelnden Football-Mannschaft. Die Verlierer knien im Schlamm.

・勝ちに、行け。チオビタドリンク 2000 .

- Siege! Tiovita Drink 2000.

Steigern läßt sich dieses befreiende Gefühl des Erfolgs nur durch ein männliches Gefährt. Für das starke Geschlecht kommt da nur das Motorrad in Frage. So heißt es in der Schlußblende des Südostasien-Roadmovie-Spots für die Yamaha DS 11 Tourenmaschine:

・男が、男であるために。

- Mann, um Mann zu sein. 
Für Männer reserviert ist auch der Dosenkaffee Pocca Coffee und der Koffein-Trunk von Nestlé.

・日本の男、目を覚ませ。 Japanischer Mann, Augen auf!

・男の味は、顔に出る。 Der männliche Geschmack huscht über das Gesicht.

Das Standardgetränk für Männer ist jedoch nicht Kaffee, sondern Bier. Asahi aktiviert mit seinem Plakat das Gefühl von Feierabend und von vollbrachter Leistung, für die man sich auch loben und belohnen darf. Wie der Werbetexter, der lieber Drehbuchautor geworden wäre. Der Text neben Schreibblock, Griffel, Glas und Flasche:

・いい仕事ができた、と自分を誉めたいときに 飲みたくなるビールが、いいビールなんだな。 一色伸幸・脚本家。Asahi.

- Wenn ich meine Arbeit gut erledigt habe und mich selbst belohnen will, will ich natürlich auch ein gutes Bier trinken. Isshiki Nobuyuki, Drehbuchautor. Asahi.

Noch weiter geht der Spot für den New Age Cedric von Nissan. Eine weiße, Respekt einflößende Führungskraft rückt vielsagend ihre Brille zurecht und steigt in ihre weiße Limousine ein. Der Sprecher liest die Einblendung vor:

- 私は流れをつくっていく。

- Ich bin (von jetzt an) der Trendsetter.

Dieselben Kanji und dieselben Argumente, wenngleich eher für den jüngeren, weniger konformen und schlankheitsbewußten Mann von heute benutzt die Werbung für das Produkt Beer Water. Im Spot trinkt ein gebräunter Mann mit Waschbrettbauch und nacktem Oberkörper im Liegestuhl sein Sommerbier.

- 晴れ男、飲む。自分流で、いこう。

- Das trinkt der „Sonnyboy“. ${ }^{32}$ Ich will meinen eigenen Stil.

32 Die japanischen Wörter hareotoko/hareonna bezeichnen Jungen/Mädchen, die immer gutes Wetter, d.h. gute Stimmung mitbringen. Ihr Gegenstück bilden ameotoko/ameonna, zu deutsch: Regenjunge/Regenmädchen, also Miesepeter. 
Ein Plakat in Shibuya für das harte, männliche Getränk Sherry 10 Special Reserve kokettiert schließlich mit der Rolle der Frauen beim Konsum harter alkoholischer Getränke: Ein junger, etwas ausgeflippter Mann stellt fest:

・ウイスキーを飲む男が好きだと言える女が好きだ。 薫るリザーブ、シェリー樽仕上げ。

- Ich mag Frauen, die sagen können, daß sie Männer mögen, die Whiskey trinken. Der duftende Reserve Sherry, im Faß gereift.

Auch die selbstbewußte, weibliche Zigarettenwerbung für Virginia Slims hat ein polares Gegenstück: die männliche Marke Hope. Ihre Kampagne erstreckte sich über zahlreiche Plakate und Anzeigen, Hauptdarsteller war ein ehemaliger Boxer. Auf einem stieg er cool mit Zigarette im Mundwinkel in ein Taxi.

・ホープの男。すんません。いちばん近い岬まで。

- Der Hope-Mann (Slogan:). T'schuldigung. Zum nächsten Kap.

In einer anderen Version greift er nach der Kugel auf der Kegelbahn. Auch der Slogan der Marke ist herb-männlich:

・一番重い玉はどれか。芯からずぶとい。

- Welche ist denn die schwerste Kugel? Kühn im innersten Kern.

Die Krönung der Kampagne war aber die Yakuza-Version. „Er“ steht mit Kampfhund breitbeinig auf der Wiese. Sein Boss sagt:

・弱いやつや、逃がしてやれや。

- Er ist ein schwacher Kerl, laß ihn gehen! (Vermutlich wird der Kampfhund den Rest erledigen ... )

Die japanische Werbung verleugnet also ihre kulturellen Wurzeln nicht. Sie kann auf starke Männer nicht verzichten, doch gleichzeitig nimmt sie sie mit Humor. Sie muß diese Bilder pflegen, weil sie realen Vorstellungen und Wünschen entsprechen, weil Selbst und Identität nicht denkbar sind ohne Körper und Geschlecht. Doch dieser Körperbezug läßt sich noch einmal steigern, und zwar erneut in Richtung Weiblichkeit. Indem die gierige Werbung die Ware und den Körper im Genuß präsentiert und die Bewegung des Essens ins Zentrum ihrer Bildsprache stellt, gelingt ihr zugleich der Sprung von der geschlechtlichen zur kulturellen Differenz. 


\section{6 oishii yôroppa (leckeres Europa): exklusives Essen in der japanischen Werbung}

\section{Lippenbekenntnisse der Werbung - zur oralen Geburt der Ware}

Die Zivilisierung der Körper in der modernen Gesellschaften mündet in Zivilisationskrankheiten, die sich vor allem auf der Haut der Individuen abzeichnen. Aber auch die zunehmenden Eß- und Ernährungsstörungen sind Einschläge der Macht in die Psychen der Individuen. Aus ihnen spricht eine Überlastung mit den polykontextuellen Anforderungen der funktionalen Differenzierung. Anthony Giddens hat diese historische Neuerung in der gegenwärtigen Welternährungslage benannt: Nicht der Hunger ist das Problem der reichen Gesellschaften, sondern die unendliche Auswahl an Speisen. ${ }^{33}$ Zum ersten Mal in der Geschichte wird breiten Schichten der Bevölkerung ihr Speiseplan nicht vom Lohn ihrer Arbeit diktiert. Doch ihre Befreiung aus der Unmündigkeit bedeutet zugleich eine selektive Überforderung und mündet häufig in Übergewicht und Bulimie. An diesem Punkt muß die Werbung als Luxusgut und informatives Geschenk, als Grenzgang zwischen satter Reproduktion und selektiver Lebensgestaltung, auf den Plan treten. Sie muß das Essen, den bloßen Konsum, als Genuß codieren. Und diesen Hauch der Exklusivität bezieht sie aus ihrem Lippenbekenntnis zu fremden Kulturen und ihren gezeichneten, ungezeichneten Körpern.

Bounty. Traumhaft exotisch! Im deutschen Spot für den gleichnamigen Schokoriegel benennt die Sprecherin mit erotischer Stimme die Formel der Werbung. Als das Mädchen hineinbeißt, sehen wir, was sie sieht: einen Strand, einen dunkelhäutigen Mann, eine fallende Kokosnuß. Wilde Bemalungen ziehen sich über ihre Haut, die sexuelle Anspielung ist nicht zu übersehen. Wieder zeichnet die Werbung bevorzugt weibliche Körper: Verona Feldbusch löffelte Rahmspinat, die Schwimmerin Franziska van Almsick naschte lila verpackte Süßigkeiten, und auch die wahrscheinlich längste Praline der Welt wurde erst im oralen Genuß negativ geboren. Die Werbung zeichnet nicht nur ungezeichnete Körper, sondern gebiert Waren (tanjô, Kapitel 4.2), sie vertauscht zu diesem Zweck Mund und Muttermund auf der Ebene der Zeichen. Idealtypisch faßte das die deutsche Werbung für die Süßigkeit Amicelli in ihrem Slogan zusammen: Alles, nur nicht männlich.

Die Liste der essenden Stars im deutschen Werbesystem läßt sich daher beliebig fortsetzen. ${ }^{34}$ Aber das japanische steht ihm in nichts nach.

33 Giddens 1997: 301.

34 Thomas Gottschalk verdrückt Gummibärchen, Guildo Horn vertilgt runde Nußecken, Stefan Raab nascht Haribo-Lakritze, Boris Becker schleckt 
Hemmungslos vergehen sich die nationalen Stars an den einfachen Speisen des Alltags. Fujiwara Norika empfiehlt das anregende Dosengetränk Dekitate, Hirosue Ryôko vernascht die Eispralinen Melty Kiss und Yamazaki Tsutomu prostet mit Sapporo-Bier. Der Fußballer Nakata Hidetoshi trinkt gesundes Switch mit natürlichen Ionen, der Sumoringer Konishiki Whiskey, der Schauspieler Oda Yûji schwört auf Ajinomoto Olivenöl und die Girlie-Group Speed auf McDonald's. Die Segmente Essen, Trinken, Rauchen verschlingen allein fast 20\% des japanischen Werbeetats, gefolgt von der Kosmetik mit über 9\%. Die Hälfte des Gesamtetats fließt in das Medium Fernsehen, doch von der Werbung für Nahrungs- und Genußmittel sind es drei Viertel. Sie Liegen mit ihren Investitionen in das Bildmedium deshalb noch vor dem Posten Pharmazeutika und Kosmetik (Abbildungen 5 und 6 im Anhang).

So hat denn auch der japanische Werbeforscher Yamaki Toshio die Hypothese aufgestellt: Je reicher eine Gesellschaft, desto stärker wirbt sie für billige Snacks, und desto weniger für teure Luxusprodukte. Die Entwicklungsländer träumen von Autos und Technik, die Schweiz, Deutschland und Japan aber von dem leckeren Appetithäppchen zwischendurch. Es gibt keinen empirischen Zusammenhang zwischen dem Umsatz einer Branche und ihrer Präsenz im Werbesystem. ${ }^{35}$ Eher scheinen sich die Industrien den Gesetzen der Werbemedien zu fügen, der Sprache der Bilder und der Filme. Und da das Auge mitißt, schaltet McDonald's in Japan konsequent nur noch Werbung im Fernsehen. In der Zeitung und im Radio kämen die appetitanregenden Farben Rot und Gelb nicht wirksam zur Geltung.

Von der japanischen Werbung läßt sich daher die orale Fixierung des Massenmediums idealtypisch ablesen. Z.B. aus dem Spot für Morinaga-Kekse. Ein junger Mann sitzt zuhause auf seinen Tatami-Matten. Seine Freundin verläßt das Haus mit der üblichen japanischen Floskel: itte kimasu. Daraufhin beginnt er, Kekse zu essen, schläft sogar mit einem Keks im Mund und ißt noch immer, als seine Freundin abends wieder mit der üblichen Floskel die Wohnung betritt: tadaima (Ich war lange fort.) Der Slogan sagt alles:

・飽きが、こない。

- Es kommt kein Überdruß auf.

Nutella, Johannes B. Kerner löffelt Joghurt, Jürgen Klinsmann trinkt ihn, Heidi Klum ißt billigen Salat (ohne Burger) und Iris Berben genießt Mon Chérie und schließlich die Kopfschmerztabletten.

35 Yamaki 1994: 59-62. 
Ein weiterer Höhepunkt der japanischen Nahrungsmittelwerbung war der schlecht ausgeleuchtete Fernsehspot für den Tomatensaft von Kagome. An einer befahrenen Landstraße steht ein junger Mann, reißt die Dose auf und gluckert ihren Inhalt in einem einzigen Zug in sich hinein. Der Sprecher:

・余計な味がしない。

- Kein bißchen Geschmack zugesetzt.

Die negative Geburt der Ware in der Werbung läßt sich unmittelbar am rituellen Gebrauch des japanischen Wortes tanjô (Geburt) in Japan nachweisen (Kapitel 4.2). Aber auch die Betonung des Mundes spiegelt sich unmittelbar im Gebrauch seines Kanji in den Werbeslogans. Dieses quadratische Zeichen für Mund findet sich täglich in Tausenden von Werbetexten, die auf den Geschmack ihres umworbenen Objekts hinweisen. Asahi-Bier schreibt:

-この味、幸口。

- Dieser Geschmack, einfach herzhaft.

Die Werbung rückt den oralen Genuß der Ware und ihre Geburt zwangsläufig in die Nähe sexueller Phantasie. In Frankreich verschlang die farbige Sängerin Grace Jones in einem hochgelobten Spot genüßlich einen Citroën CX. In Deutschland zwang die Werbung für das Eis Magnum einen jungen Liebhaber, sich vor den Automaten zwischen Kondom und Schokoeis zu entscheiden: Manchmal muß man Prioritäten setzen. In Japan flüsterte die feurige Fujiwara Norika in ihrem Werbespot für Java-Tea ein laszives tabete, nur zu übersetzen mit: Vernasch' mich! ${ }^{36}$ Und auch nach dem Genuß ist die Werbung um die Reinheit des Körpers besorgt und empfiehlt Kaugummi. Das Plakat für Xylish in der U-Bahn befiehlt sogar:

・歯と息に。噛メ、噛メ、噛メ。

- Für Zähne und Atem: Kauen! Kauen! Kauen!

Sogar das einschlägige Werbemagazin Kôkokuhihyô ist überwältigt von der oralen Lust der Werbung 10 Jahre nach dem Platzen der bubbleeconomy (die selbst als orale Kaugummi-Metapher zu lesen ist).

36 Manche Manga-Helden nutzen eine japanische Floskel, wenn sie ihre Süße vernaschen: itadakimasu (etwa: Ich nehme mir. Guten Appetit!) vorher, gochisôsama deshita (Es war sehr lecker!) hinterher. 
・もの食う人々。食う。食う。食う。とにかく食べるシーンと、 食べる音が CMからあふれてきた年だった。難しいリクツ抜 きで五感に訴え、それで売り上げを伸ばす商品も現れた。

- Menschen, die Sachen essen. Essen. Essen. Essen. Es war ein Jahr, in dem wir von Essensszenen und Eßgeräuschen aus den Werbespots überhäuft wurden. Es tauchten auch Waren auf, die ohne komplizierte Begründungen an die fünf Sinne appellierten, um den Verkauf zu steigern. ${ }^{37}$

Die orale Fixierung der Werbung bleibt aber nicht auf das Essen beschränkt. Die Fähigkeit zu beißen ist gerade in den rapide alternden Industriegesellschaften ein Synonym für Jugend, Frische und körperliche Unversehrtheit. Auch die zahlreichen Werbungen für Gebißreiniger, Gebißkleber, Zahnpflege und auch für Lippenstift sind daher nur semiotisch zu erklären. Dabei mutieren die weißen Zähne - wie die weiße Haut - zu einer weiteren Schreibfläche des ungezeichneten Körpers. Der Spot für die Zahncreme Ora2 markiert diesen Übergang:

・肌はつるつる。歯は?

- Die Haut ist zwar glatt. Aber die Zähne?

Der Schauspieler Oda Yûji, auch aktiv in der Werbung für das Mobiltelefonnetz von cdma1, macht sich stark für die Zahncreme Denta. Für den Spot blickt die Kamera durch den Badezimmerspiegel auf den bürstenden Schauspieler.

・歯グキのハレ・出血を防ぐ。フッ素配合で歯を強くし、 ムシ歯を予防する。歯グキのために。デンター。

- Bekämpft Zahnfleischschwellungen und Zahnfleischbluten. Macht die Zähne mit Fluor stark, verhindert Karies. Für das Zahnfleisch. Denta.

Mit ihren Lippenbekenntnissen landet die Werbung schließlich wieder beim weiblichen Körper. So engagierte Kanebo für seine neue T'Estimo 2000 Collection sogar drei nationale Grazien, um die Farben Fujiwara Red, Matsuyuki Red und Inamori Peach an die Frau zu bringen. Die Kampagne war multimedial angelegt, auf dem Plakat stand:

37 Kôkokuhihyô Nr. 222 vom Dezember 1998, S. 52. 
・く・ち・び・る・に透ける、輝く、ジュエリーヴェール。 輝きも、うるおいも、限りなくピュア。

T'Estimo 2000 Collection.

- Leuchtet durch die Lippen und glitzert: Jewelry Veil.

Glitzernd, feucht und unendlich rein. T'Estimo 2000 Collection.

Kosé ergänzt in seinem Glitzer-Lippenstift-Spot:

・光を塗る女。ルージュルーミナス。

- Frauen, die das Licht auftragen. Leuchtendes Rouge.

Die orale Fixierung des japanischen Werbesystems koppelt, bei Glitzerlicht betrachtet, Maternalität und Materialismus. Erst die orale Präsentation der Ware verleiht ihr Exklusivität, deshalb ihre Präferenz für Essen und Trinken. Doch diese die paradoxe Funktion der Werbung, industrielle Fließbandprodukte exklusiv zu verpacken, stellt sie vor ein sekundäres, informatives Ernährungsproblem. Übersättigung verdünnt den Geschmack. Gerade das homogene Japan muß daher seine Produkte kulturell dotieren. Und deshalb kann sich die japanische Werbung an ausländischen Stars und Motiven nicht sattsehen.

\section{Fremdkulturelle Dotierungen der japanischen Nahrungsmittelwerbung}

Der weiße, ausgewaschene Reis ist die Grundlage der japanischen Ernährung, die ideale Schreibfläche für kulturelle Dotierung. Sein erstes Zeichen ist die rote umebôshi, die saure Pflaume, die aus dem Reis eine japanische hinomaru-Flagge macht. Doch diese Flagge zeigt Japan in einer Perspektive von außen: von China aus. Japan definiert sich negative. So handhabt es auch ein Werbespot für Sake. Er zeigt Wasser, eine Quelle, Regen, einen Fluß. Und Kanji.

- 人、水、米。日本は西洋ではない。

- Menschen, Wasser, Reis. Japan ist nicht der Westen (Diesen Satz läßt der Sprecher diplomatisch aus).

Ein shintoistischer Spot von japanischer Reinheit. Die Selbstdefinition über Natur, Landschaft, Wasser, Reis und Stroh ist die Tatami-Basis der japanischen Kultur. Nahtlos an fügt sich der Spot für das Trinkwasser von Suntory: 
・神様がくれたサントリー南アルプスの天然水。

- Das natürliche Wasser von Suntory aus den südlichen (japanischen) Alpen, von den Göttern überreicht.

Und wie im Echo wirbt Asahi für sein Fuji-Bier. Die Schrift und die Dose erscheinen direkt vor dem heiligen Berg.

・うまさと、つよさと、清らかさと。 富士山の天然水 $100 \%$ 使用。誕生。

- Lecker, stark, klar. Zu 100\% natürliches Wasser vom Berg Fuji.

Immer wieder werden solche traditionellen Eindrücke Japans in sein Werbesystem eingestreut wie die altjapanische Grammatik in seine Zeitungssprache. Erneut tritt das Problem der Steigerung auf. Die Reinheit des japanischen Wassers kennt Grenzen. Überbieten können sich die japanischen Werbezeichen nur, wenn sie zugleich ihre kulturellen Grenzen überschreiten und sich andernorts bedienen. Radikal exerziert das die Werbung für die französischen Mineralwässer vor. Volvic resümiert die Körperphilosophie der japanischen Werbung (Kapitel 4.2) mit allen wichtigen Stichworten: Natur, Instinkt, Geburt, um dann das entscheidende Argument nachzuschieben. Auf dem Plakat nehmen sich fünf junge Japanerinnen mittels der Plastikflasche an der Hand.

・本能が、求めている。人は、自然から遠く離れてしまった。 人が今、自然を強く求めるのは、動物としての本能かもしれ ない。ボルヴィック。それは、自然から生まれた、自然のま まの水。カラダのずっと奥にある、本能が飲みたがっている。 本当のナチュラルミネラルウォーターです。

Volvic. Natural Mineral Water from France. 自然のままの水。

- Die Instinkte wecken das Verlangen. Die Menschen haben sich von der Natur entwöhnt. Wenn die Menschen jetzt wieder stark nach der Natur verlangen, dann sind es wohl ihre wilden Instinkte. Volvic. Mineralwasser, aus der Natur geboren, im natürlichen Zustand. Die Instinkte, tief im Innern des Körpers verborgen, wollen es trinken. Das wirkliche, natural mineral water. Volvic. Naturbelassenes Mineralwasser aus Frankreich.

Wie ein Echo liest sich die Werbung für Evian. Der zeigt ein blondes Mädchen mit Schnee in den Haaren, im Gesicht und auf dem Bauch.

・私を冷やす雪。フレンチアルプスから、エビアン。

- Schnee, der mich abkühlt. Aus den französischen Alpen. Evian. 
Wie alle Küchen der Welt, so braucht auch die japanische gelegentlich eine besondere Würze. Sie bezieht diese Exklusivität, zumal im Zuge der Globalisierung, aus der bewußten fremdkulturellen Kennzeichnung einzelner Zutaten. Und diese saugt sich erneut am Körper fest: an den Körpern von Fremden, an essenden, ausländischen Stars. Die Schweizer Tennisspielerin Martina Hingis beißt in einen Tennisball-Apfel für Balance Date, der US-Schauspieler Bruce Willis und der Golfer Tiger Woods trinken Dosenkaffee und der deutsche Fußballer Pierre Littbarski verspeist Deutschländer Würstchen. Wiederholt wurde die Vorliebe der japanischen Modejournale für ausländische Models nachgewiesen, aber am eindrücklichsten läßt sich die Globalisierung des japanischen Werbesystems an seiner gekünstelten Sprache festmachen. ${ }^{38}$

Schon aus der deutschen Werbung sind Anglizismen heute nicht mehr wegzudenken. Wurden sie noch in den 50er Jahren abgelehnt, werden sie heute bewußt als Stilmittel eingesetzt, speziell in der Werbung für Zigaretten, Alkohol, Mode, Reisen und Kosmetik. ${ }^{39}$ Und umso mehr in Japan. Hier liegt dank der integrativen Kraft der japanischen Sprache und Schrift der Anteil der Werbeanglizismen etwa doppelt so hoch wie in Deutschland. ${ }^{40}$ Insbesondere in die Produktbezeichnung (naming) der japanischen Zigaretten ist das Englische eingeschlagen. Blonde, hellhäutige, blauäugige Models voller Abenteuerlust und Freiheitsdrang werben für anglophone Marken wie Parliament, Mild Seven, Kent, Lark, Valiant, Frontier und Peace. Den I-Punkt aber setzt die Werbung für Caster1: Sie zeigt einen alten TEE-Dieselzug, der durch verschiedene europäische Landschaften und den Bahnhof Raisdorf gleitet.

In jüngster Zeit ist jedoch das Englische unter Druck geraten. Die Spots für den Toyota Vitz, für Fauchon Eiscreme und für KDD liefen komplett auf Französisch, und auch deutsche und italienische O-Töne nehmen zu. Zum einen hat offenbar Amerika - mit Ausnahme der Wolkenkratzer von New York - weniger internationale Zeichen von Kultur. Zum anderen lädt der amerikanische Werbestil und sein aggressiver Ton die japanischen Werber eher zur Parodie ein als zur Imitation. So z.B. in dem Werbespot für den Honda Life, in dem alle Beteiligten, das blonde Girl, der Hund, das Baby und die Nachbarinnen stereotyp und aufdringlich die Qualität des Produktes beteuern. Einen gewissen Wert gewinnt die japanische Werbung allenfalls den Ureinwohnern Amerikas ab. Die Werbung für den Dosenkaffee Kirin Fire zeigt einen jungen Japaner und einen alten Indianer beim Lagerfeuer im Canyon:

38 Goertzen 1995: 77-79.

39 Schütte 1996. Ebenso Dialekte der deutschen Sprache: Die Werbung für Red Bull setzt einen österreichischen Sprecher ein, die für Toblerone einen Schweizer. Ikea empfiehlt sich mit schwedischem Akzent.

40 Schütte 1996, Rinner-Kawai 1993. 
・「おまえのココロの真ん中で然える火を守れ」 ネイティブアメリカンの老人は言つた。 コーヒーは、火でもっとうまくなる。野性的な香ばしさ。

- Hüte das Feuer, das in der Mitte deines Herzens brennt, sagte der alte Indianer (amerikanische Eingeborene). Kaffee wird mit Feuer leckerer. Der Duft der Wildnis.

Europa, auch das gegenwärtige, rangiert aus Sicht der japanischen Werbung höher in der kulturellen Rangordnung. Die Firma Maxim wirbt mit einem französischen Straßencafé, Markisen und alten Hausfassaden für seine Mischung European Rich Taste. Auch die Eissorte Mövenpick bekommt dieses Etikett im japanischen Fernsehen aufgeklebt. Die populäre japanische Schauspielerin und Entertainerin Nishida Hikaru trifft sich in ihrem Werbespot für ein Curry-Gericht mit einer blonden europäischen Freundin zum Kochen.

・美味しいヨーロッパを閉じ込めた。

- Ich habe das leckere Europa hineingetan/eingefangen.

Innerhalb Europas bevorzugt Japan Frankreich und Italien, um kulturelle Elemente und Rezepte abzugreifen. Die großangelegte Werbekampagne für den Dosenkaffee Break steckte den französischen Action-Helden Jean Reno, der in dem Film „Wasabi“ seine Tochter Hirosue Ryôko aus den Fängen der Yakuza rettete, in das Outfit eines Wikingers. Als (armer) Teufel beglückt er seine leidenden, hart schuftenden Untertanen in der Hölle - und bedauert sich selbst als armen Angestellten. Obwohl er in diesem Spot französisch sprach, konnte ihn jeder männliche Japaner sofort verstehen. Die Untertitel lauten:

・確かに、地獄は大変だ。しかし、地獄の仕事はもつと大変だ。 しょせん雇われの身。オレは疲れた。(Seine Bedienstete:) Hi. Break. (Er trinkt aus der Dose): うまい。もつともつとコーヒ 一。(Einblendung:) 香りとキレ味。ブレイク新発売。 (Sprecher:) おかげで地獄は天国だ。

- Die Hölle ist zwar hart, aber noch härter ist die Arbeit in der Hölle. Ich bin ja nur ein armer Angestellter. Ich bin kaputt. (Seine Bedienstete:) Hi, Break. (Er trinkt:) Ah, lecker. Mehr Kaffee! (Einblendung:) Duft und pikanter Geschmack. Break, neu im Verkauf. (Sprecher:) Damit wird die Hölle zum Paradies. 
Auch französischer Wein ist ein heißbegehrtes Luxusgut in Japan. ${ }^{41}$ Das Werbeplakat für Bordeaux zeigt eine Japanerin mit vollem Glas in einem französischen Straßencafé, im Hintergrund lächelnde junge Franzosen. Der individualistische Appell wird kollektivistisch abgeschwächt:

・流行よりも、自分のスタイルでいく。 ボルドーで、集まろう。

- Ich folge nicht der Mode, sondern meinem eigenen Stil. Wir wollen uns mit Bordeaux zusammenfinden.

Italien steht für Wein und für Nudeln. Längst vertreibt die Firma Barilla auch in Japan. Die Werbung zeigt ein Paar, beide einander zugewandt. Sie essen eine Nudel in Form eines großen Herzens. Der Text:

・イタリア人は、パスタが好きなのではなく、バリラが好きな んです。イタリアで一番売れているパスタが、いま日本に本 格上陸。

- Die Italiener mögen keine Pasta, sondern Barilla. Die in Italien meisterverkaufte Pasta landet jetzt endlich auch in Japan.

Die Qualität des italienischen Essens goutiert auch der japanische Schauspieler Oda Yûji zum ersten Mal: Überraschend erhält er ein Geschenkset mit Olivenöl von Ajinomoto, packt es aus, kocht Nudeln mit Tomaten, kostet und stellt fest: Lecker! Danke! Die Einblendung:

・本物のイタリア料理のギフト。その顔が見たくて贈ります。

- Ein Geschenk aus echten italienischen Zutaten. Das schenke ich, weil ich dieses Gesicht sehen will.

Deutschland gilt (auch) in Japan als Land des Bieres. Insbesondere bayerische Motive vertreten daher in der Werbung Gesamtdeutschland. So zum Beispiel in dem Werbespot für das japanische Bier von Gingakôgen. Ein echter Braumeister mit Bart und Trachtenjacke empfiehlt das teure Bier von Gingakôgen in seinem Dialekt, beginnend mit den Worten: Aus Deutschland... Im folgenden prüft er mitten auf

41 In Deutschland ist es der französische Käse. Hier übertrug der Spot für „Géramont aus Fronkreisch“ diese kulturelle Herkunft in den jedem Deutschen verständlichen Akzent. Ein junges Paar mit einem schönen roten Citroën DS (der „Göttin“ DS bzw. déesse, über deren Haut Roland Barthes in den Mythen des Alltags schrieb) hat auf der Chaussée eine Panne. Ein alter, silberner Citroën-Laster kommt vorbei und schleppt sie ab. Sie genießen das Picknick im Wagen mit Géramont: Traumhaft verführerisch. 
dem Feld den jungen Weizen, sagt bedeutungsschwanger: komugi (Weizen), kostet am Ende das Bier und resümiert: gut. Der japanische Sprecher sekundiert:

・ビールの国ドイツでは、高級ビールは小麦を使って作ります。 小麦をつかった、日本の高級ビール。銀河高原ビール。

- In Deutschland, der Heimat des Bieres, braut man hochklassiges Bier mit Weizen. Ein japanisches Spitzenbier, mit Weizen gebraut: Gingakôgen-Bier.

Ein Prospekt für das Weißbier Prinzregent Luitpold ergänzt:

・本場ドイツより造りたての 美味しさをそのままご家庭へ！！

- Der leckere Geschmack, der gerade erst im deutschen Herkunftsland zubereitet wurde, direkt in Ihr Haus!!

Trinken die Deutschen in der japanischen Werbung bevorzugt Bier, so sind die Briten für den Tee zuständig. Die japanische Kampagne für den Dosentee Victoria bemüht mehr Fremdbilder als die Werbung für das Mint-Bonbon After Eight in Deutschland. Ein dezent gekleideter Gentleman mit Umbrella und Teddie-Kopf geht zu seinem Schneider. Im dunklen, holzgetäfelten Atelier wählt er einen neuen Stoff und besiegelt seine Bestellung per Handschlag. Der Sprecher hat im japanischen Spot einen distinguierten Cockney-Akzent:

・きちんとした紅茶なので、こう呼びます。

Victoria. English Black Tea.

- Weil dieser Schwarze Tee für vornehme Gentlemen (für das Establishment, mit understatement) sorgfältig zubereitet wurde, heißt er Victoria. Englischer Schwarzer Tee.

In einem weiteren Spot gondelt Teddie in seinem grünen Mini-Cabrio durch London und wird von einem langhaarigen Motorradfahrer überholt. Da wollen vier ältere Damen die Straße überqueren. Der Motorradfahrer heizt über den Zebrastreifen, Teddie hält an. Als die vier Ladies über die Straße gehen, erkennen wir: Das Bild zeigt das Cover des Beatles-Albums Abbey Road. Teddie läßt sich Zeit und schlürft einstweilen seinen Tee hinterm Steuer. Erneut hören wir den japanischen Werbespruch, natürlich mit Cockney-Akzent. Die Werbefigur wurde in dem Tokioter Stadtmagazin Pia mit allen typisch englischen Vorlieben vorgestellt. 
Nach dem Essen dürfen in Japan schließlich die kühlen Nordeuropäer für die Qualität des Anti-Karies-Kaugummis herhalten. Das Kaugummi Xylitol wirbt mit seiner finnischen Herkunft. Finnen sitzen im grünen Park, Professor Kauko Makinen (カウコ・マキネン教授) bemüht sich mit starkem Akzent auf Japanisch, der Text wird eingeblendet.

・キシリトールは、虫歯の原因になる酸を作りません。だから、 世界に広がっています。日本ではどうですか。(Schnitt nach Japan. Eine Gruppe Japaner antwortet:) 日本でも広がっていま す。

- Xylitol produziert keine kariesverursachende Säure. Deshalb breitet es sich über die Welt aus. Wie ist das in Japan? (Schnitt: Eine Gruppe Japaner antwortet:) In Japan auch!

In einem weiteren Spot rammt eine Finnin die Xylitol-Fahne im Trick in die japanische Hauptinsel Honshû. Dieser finnisch-japanische Spot eröffnet die Dimension „Welt“. Peter Stuyvesant warb schon vor Jahren mit dem Geschmack der großen weiten Welt, und auch das Becks-Bier fand erst als Spitzenpilsener von Welt zu dem grünen Segelschiff Alexander von Humboldt aus Bremen. Auch die japanische Werbung hat die Kategorie Welt nun integriert und rundet damit ihre semiotische Internationalisierung $\mathrm{ab}$. Eine Werbung für italienisches Wasser beginnt mit dem Wort Welt und argumentiert exakt wie Apollinaris in Deutschland: Aus dieser Quelle trinkt die Welt. Das Photo der Anzeige zeigt eine volle und eine leere Flasche, in der leeren Appetithäppchen. In der Ecke steht: Centenario S. Pellegrino 1899-1999. Der Text:

・世界のテーブルに、サンペレグリノの水。イタリア北部に湧 き出たアルプスの恵み。サンペレグリノは天然の炭酸を含ん だナチュラルミネラルウォーターです。そのマイルドな泡立 ちが食事中、お口をさわやかにリフレッシュし、世界中のす べての料理の味をおいしく引き立てます。

- San Pellegrino Wasser auf den Tisch der Welt. Eine Segnung, den Alpen in Norditalien entsprungen. San Pellegrino ist ein mit natürlicher Kohlensäure versetztes Mineralwasser. Dieses milde Sprudeln erfrischt den Mund während des Essens und verfeinert den Geschmack aller Speisen auf der ganzen Welt.

Auch Kanebo schlägt in seiner Werbung für Sensai Ex La Crème die Brücke nach Europa. Sie paßt am Flughafen Narita perfekt in den atmosphärischen Kontext: 
・製品をつくるというより、作品をつくる。 国境を越えた、ザ・クリーム。ヨーロッパ 9 カ国で発売され ています。Kanebo. For A Beautiful Human Life.

- Mehr als ein Produkt: ein Kunstwerk herstellen. La Créme hat die Grenzen überwunden. Sie wird auch in 9 Ländern Europas verkauft. Kanebo. For A Beautiful Human Life.

Sogar das Symbol der modernen japanischen Ernährung, die Nudelsuppe, ist inzwischen in der Welt angekommen. Die witzigen Werbespots von Cup Noodles (Hungry? Cup Noodles!) errangen Preise beim Werbefilmfestival in Cannes und wurden - eine große Ausnahme - auch in Deutschland gesendet. Die japanische Werbekampagne von 1999 spielte in New York (und bebilderte unabsichtlich auch Jean Baudrillards Buch über die Graffittis auf den New Yorker U-Bahnen: Kool Killer oder der Aufstand der Zeichen). Die Szenerie: eine Mauer, Sprayer, Graffittis und ein farbiger Jugendlicher, der die Cup Noodles standesgemäß aus der Pappe zu sich nimmt. Die Einblendung am Ende, gestanzt auf den Times Square:

・世界品質を、お届けします。Cup Noodles.

- Wir bieten die Qualität der ganzen Welt.

Das japanische Werbesystem erweist sich im Segment der Nahrungsmittelwerbung als unbegrenzte Schreibfläche von Interkulturalität. Eben deshalb wird sie nicht interkulturell standardisiert, sondern kultiviert Images und Beobachtungen zweiter Ordnung. Dieser Effekt läßt sich im Segment Autowerbung abschließend studieren.

\subsection{Werbung als kulturelle Beobachtung zweiter Ordnung}

Die mobile Landung internationaler Kampagnen in Japan

Für den Bereich der Printwerbung in Japan konnte Katharina Dallmann nachweisen, daß ausländische Unternehmen wesentlich intensiver Motive ihres Heimatlandes für Werbezwecke nutzen als japanische. Vor allem in der Werbung für Nahrungs- und Körperpflegemittel sowie für Bekleidung sollen weiße Models und Kulturstereotype ein internationales Image kreieren. ${ }^{42}$ Dieses Ergebnis gilt mutatis mutandis auch für die Fernsehwerbung. Nicht nur ausländische Models, Stars, Produkte und Sprachen sind dort gut vertreten, auch werden häufig komplette

42 Dallmann 1997: 195. 
Spots aus dem Ausland übernommen, z.B. die Werbefilme für Pantene-Pro-V und Vidal Sassoon, für den Drei-Klingen-Rasierer Mach 3 von Gillette, für Adidas, für den iMac, für Jack Daniels Whiskey und für Cisco Systems. ${ }^{43}$ Letztere Werbung für Internet-Software (Are You ready?) spielt aus Indien, Jamaika und den USA besonders viele fremdkulturelle Bilder ein und ist lediglich japanisch untertitelt. Die internationale Kampagne für Nescafé mit dem Slogan Open Up arbeitet nach demselben Muster. Lateinamerikaner, Afrikaner, weiße Europäer und Eskimos trinken den Pulverkaffee in verschiedenen Settings. Auch die Musik ist international dieselbe, lediglich die erste Textzeile ist ins Japanische übersetzt: Überwinde die Mauer in deinem Herzen (kokoro no kabewo koete)!

Die meisten spezifisch westlichen Vorstellungen von Warengenuß, d.h. von penetrativer Raumerfahrung à la Virilio, transportiert jedoch die Werbung für westeuropäische Automobile nach Japan. Da sie auf den Inseln mit strikter Geschwindigkeitsbegrenzung als teure Luxusgüter gelten, schöpfen sie aus einem besonderen Zeichenreservoir. So bevorzugt der schwedische Hersteller Volvo auch in Japan weiße Models und setzt auf das Argument Sicherheit. Eine Anzeige zeigt zwei weiße Männer und ein blondes Mädchen. Sogar der Text bemüht eckige Katakana-Anglizismen:

・安心の大きさは、父のボルボと同じです。 スタイリッシュ、アクティブ、スポーティ…

- Das Gefühl der Sicherheit ist (genau so groß wie) der Volvo meines Vaters. Stylish, aktiv, sporty...

Auch die Firma Saab übernimmt seine heimische Werbelinie, den Vergleich mit dem Flugzeug, nach Japan:

・車になった航空機。サーブ。

- Das Flugzeug, das ein Auto wurde. Saab.

Ein weltweit besonders homogenes Bild von Männlichkeit, Erfolg und Geschwindigkeit zapft die Werbung für Sportwagen in Japan an. So behält Audi in der Werbung für den TT sogar den deutschen Slogan in der japanischen Zeitungsanzeige bei: Vorsprung durch Technik. Auch der indianische Spurenleser, der den Audi Quattro an seinen Reifenabdrücken im Schnee erkennt, fand seinen Weg nach Japan. Vielleicht preschte er ja selbst im Audi TT durch die Wüste und dann über das

43 Über die rasante Zunahme ausländischer Spots in Japan freut sich auch das Fachmagazin Kôkokuhihyô: Nr. 233 vom Dezember 1999, S. 50-51. 
Wasser. Sogar den Slogan brachte er mit: Driven by Instinct. Der japanische Sprecher ergänzt nur noch lapidar:

- Audi TT. 上陸。 Landung des Audi TT.

BMW wirbt in der deutschen Werbung mit seinen Triebwerken, die keine normalsterblichen Motoren seien. Aber auch die Werbestrategie von BMW in Japan (und weltweit) ist einheitlich auf das Image des Sportwagens zugeschnitten. Der Slogan wurde komplett ins Japanische übersetzt: Freude am Fahren. Im TV-Spot für den 5er BMW fährt ein silberner Wagen zwischen den verglasten Wolkenkratzern hindurch. Der Wagen spiegelt sich darin, aber das Spiegelbild ist ein schwarzer, aufgemotzter Sportwagen. Ein japanisches Model schielt im Zwischenschnitt interessiert in Richtung der Limousine. Im Text fallen alle üblichen Stichworte: Der Wildheit, Eleganz und Geschmeidigkeit des weiblichen Autos steht die Intelligenz und Sportlichkeit seines männliches Fahrers gegenüber.

・エレガンスな姿の影に。熱くしなやかな野性がある。知性が 磨いたスポーティーサロン。BMW 5 シリーズ。駆け抜ける 歓び。Drive it!

- Der Schatten einer eleganten Form. Heiße und geschmeidige Wildheit. Ein sportlicher Raum, von Intelligenz gezeichnet. Die BMW 5er Serie. Freude am Fahren. Drive it!

Da fehlt nur noch das Motiv Freiheit. Das liefert die Werbung für den Z3 in Japan. Der Roadster ist rot, der Fahrer nicht zu sehen, die Straße weich gezeichnet. Der Text:

・ ニューZ 3 ロードスターがお連れします。ストレート 6 搭載。 洗練されたパワーがもたらす、より自由なオープン・エア・ ドライビング。ニューZ Z ロードスター 2.0, 登場。 BMW.Drive it. 駆け抜ける歓び。

- Der neue Z3 Roadster nimmt Sie mit. 6 Zylinder. Die veredelte Power ermöglicht ein Cabrio-Fahren mit allen Freiheiten. Drive it. BMW. Freude am Fahren.

BMW schöpft dabei aus einem weltweit gleichen Markenimage. Schon 1997 hat BMW eine solche globale Kampagne geschaltet, die Texte fast komplett in Englisch. Sie zielte nach Firmenangaben auf die 14 Millionen „Kosmopoliten“ weltweit, die internationale Geldelite. Ihre Bilder zeigten nur technische Motive, Landschaften und Menschen 
wurden ausgeblendet, die Textsprache war fast überall Englisch. ${ }^{44}$ Mit zum bayerischen Konzern geörte zwischenzeitlich die Firma Jaguar. Auch ihre Anzeigen in Japan betonen ihr globales Image. Wieder fallen alle üblichen Stichworte: Power, Vertrauen, Schönheit - und Welt.

・ 心ときめく試乗会です。

ミディアムサイズの新しいジャガーとして、いま世界中で注 目を集めているジャガーS-TYPE。いったいこの車がどんな 走る歓びを与えてくれるのか。ショールームから連れ出し、 そのスピード感のなかで確かめてください。最高出力 $243 \mathrm{ps}$ という余裕のパワー。世界最高水準の性能が生み出すダイナ ミズムと信頼性。いまあなたが乗っている車とは違う、性能 を超えたときめきがここにあります。あなたの大切な方とご 一緒に、ぜひどうぞ。 美しいミディアム JAGUAR S-TYPE 新登場。

- Eine herzerfreuende Einladung zur Probefahrt.

Das ist der neue mittelgroße Jaguar S, der jetzt weltweit auf sich aufmerksam macht. Was bereitet er nun für eine Freude beim Fahren? Probieren Sie es aus, holen Sie ihn aus dem Showroom und testen Sie das Gefühl der Geschwindigkeit. Die größte Power bei 243 PS. Dynamik und Vertrauen, hervorgebracht von der weltweit höchsten Effektivität. Hier finden Sie einen Genuß jenseits der Leistung, die Ihr bisheriger Wagen nicht hat. Bitte fahren Sie Probe mit einer Person Ihrer Wahl.

Der neue, schöne mittelgroße Jaguar S.

Und auch in der Sparte Geländewagen ist eine Internationalisierung der Werbestrategien zu beobachten. Ford reitet in seiner japanischen Werbung für den New Explorer in Wildwest-Manier durch den Text und lobt sich am Ende - nicht unähnlich der Werbung für Kirin Fire - als Real American.

・新しいエクスプローラーで、大自然を走るか、大都会を走る か。ワイルドに走るか、クールに走るか。アドベンチャーへ 走るか、アバンチュールヘ走るか。リアルアメリカン SUV. New Explorer 誕生。

- Sollen wir mit dem New Explorer durch die Natur fahren oder durch die Großstadt? Wild oder cool? Zum Abenteuer oder zum Liebesabenteuer? New Explorer, Real American SUV.

New Explorer (Geburt).

44 Weltweite Botschaft: Eine globale Imagekampagne soll die traditionellen Markenwerte verbreiten. In: Werben und Verkaufen vom Juni 1997. 
In einer weiteren Anzeige erscheint das Wort Abenteuer dann auch in Kanji. So können außer Autos auch die Erlebnisse durch den Geburtskanal gleiten.

・冒険に、乗ろう。新しいエクスプローラー誕生。

- Laßt uns ins Abenteuer einsteigen. Der neue Explorer.

Die zitierten Beispiele mögen dazu verleiten, die Hypothese von der kulturellen Standardisierung des Weltwerbesystems zu untermauern. Doch das Gegenteil trifft zu: Der häufige Anschluß der japanischen Werbung an internationale Kampagnen verdankt sich vielmehr der Offenheit der japanischen Kultur für fremde Elemente, ihrer Bereitschaft zur Kopie. Aus dem Ausland übernommene Werbestrategien haben in Japan den Status von Zitaten und lassen sich nur in diskreten Produktsegmenten interkulturell annähern, eben bei Sport- und Geländewagen. Oft engen auch die Kosten auf dem japanischen Medienmarkt den Spielraum ein. Das japanische Werbesystem ist sensibel sowohl für die Möglichkeiten, als auch für die Grenzen interkultureller Standardisierung. Das zeigt deutlich auch die gegenseitige Wahrnehmung von Deutschland und Japan im Massenmedium Werbung.

Interkulturelle Images: Deutschland in der japanischen Werbung (und umgekehrt)

In seiner Untersuchung zur Werbung japanischer Unternehmen in Deutschland hat Manabe Kazufumi festgestellt, daß hier japanische Produkte fast nie von Japanern präsentiert werden. In der Printwerbung wird nur äußerst selten das Japan-Image bemüht, japanische Zeichen und Worte sind mit Ausnahme des Firmennamens tabu. In der Fernsehwerbung treten zwar häufig Japaner auf: als Gruppen japanischer Touristen (Duplo-Werbung), als Sumo-Ringer (McDonald's), als fotografierende (spionierende?) Kunden (pit-stop) oder auch als Koch mit Stäbchen und Stirnband (Hengstenberg Sauerkraut). Aber fast immer dienen sie in den deutschen Spots als stereotype Statisten und fast nie präsentieren oder loben sie ein japanisches Produkt. Die japanischen Firmen passen ihre Werbung in Deutschland in aller Regel den kulturspezifischen Mustern an. ${ }^{45}$ Ganz anders verfahren dagegen die deutschen Hersteller in Japan. Um ihr positives Image optimal zu nutzen,

45 Manabe 1998: 73-86, 125. Er bezeichnet diese Methode japanisch als kakureminoshuhô (etwa: die Deckmäntelchen-Methode. kakuremino ist eine traditionelle japanische Regenjacke aus Stroh). Auch für den Bereich der Printwerbung läßt sich diese Tendenz belegen. Dallmann 1997: 198. 
exportieren sie gern ihre kompletten Werbespots und etikettieren deutsch. So endet z.B. der Spot für den Klebestreifen tesa-Film (Fußballfan reißt das Plakat seiner Mannschaft erst ab und will es dann wieder an die Mustertapete kleben) in Japan mit folgender Einblendung:

・ドイツ生まれの新・習慣。

- Die neue Gewohnheit aus Deutschland.

Eine noch klarere Sprache spricht das Plakat für die Haarpflege von Wella in Japan. Auch hier darf der Hinweis auf den Herstellungsort (Geburtsort) der Ware nicht fehlen. Eine weiße, blonde und blauäugige Frau lächelt dem Betrachter zu:

・ドイツで生まれた、へアケアのエキスパート。ウエラ。

- Der Hair-Care-Experte aus Deutschland (in D. geboren). Wella.

Für zwei Produkte wird der Hinweis auf Deutschland schließlich völlig unvermeidbar: in der Werbung für Bier (vgl. Kapitel 4.6) und für Autos. Schon der Autoverleiher Avis wirbt in einem japanischen Reiseprospekt mit einem urdeutschen Signet: dem dicken Stern auf der Motorhaube.

・ドイツが誇るランドマーク ... すぐにあなたのお手許に。

- Das Zeichen (landmark), auf das Deutschland stolz ist ... sofort zu Ihren Diensten.

Aber auch die deutsche Hausmarke Volkswagen befriedigt die Erwartungen der japanischen Medienkonsumenten. Die Bilder des Spots für den VW Passat wurden (samt Hamburger Kennzeichen) aus Deutschland übernommen, nur Musik und Text wurden kulturell adaptiert. Ein junger Mann projiziert einen Wagen als Hologramm in seine Wohnung, bewundert ihn, steigt dann ein und fährt los: eine meisterliche Kombination deutscher Ingenieurskunst mit japanischer Werbeargumentation.

・心高鳴る走りと確かな安全性。妥協を許さない。夢で終わら せないドイツ・エンジニーリングがここに。クラスを超えて 車を超えて Volkswagen Passat.

- Eine Stabilität, die das Herz höher schlagen läßt. Ohne Kompromisse. Deutsche Ingenieurskunst begnügt sich nicht mit dem Traum. Eine neue Klasse, ein neues Auto, Volkswagen Passat.

Und auch das deutsche Standardauto, der VW Golf, wird im japanischen Spot mit Motiven der westlichen Welt in Szene gesetzt. In einem Spot, 
der eigens für Japan in Europa produziert wurde, ziehen Motive der 80er Jahre am Zuschauer vorbei: Die Hochzeit von Lady Di, die amerikanische Raumfähre und der Fall der Berliner Mauer. Der Golf fährt durch die Lücke in der Berliner Mauer. Die Einblendung:

-Volkswagen Golf. 進化は終わらない。

- Volkswagen Golf. Die Evolution endet nie.

Und sogar der japanische Peugeot-Spot macht sich implizit das Image Frankreichs als Land der Mode zunutze.

・オシャレなだけでフランス人が買うわけありません。 プジョウ。

- Die Franzosen kaufen (ihn) nicht nur, weil er gut aussieht. Peugeot.

Die zitierten Beispiele zeigen, daß für das Weltwerbesystem kulturelle Images ein großes Kapital sind. Aber das japanische Werbesystem greift darauf nicht durch Übernahmen aus Deutschland zu. Gerade das positive Image Deutschlands erfordert es, Werbekampagnen speziell für Japan zuzuschneidern. Internationale Standardisierungen wie im Falle von BMW sind die Ausnahme. Und mehr noch: Gerade weil die Werbung diese kulturellen Images nutzen kann, kann sie sie auch abnutzen und erschöpfen. Diesen heilsamen Sättigungseffekt konnte der Werbeforscher Brian Moeran während seiner Feldforschung in einer japanischen Werbeagentur aus nächster Nähe erleben. Ein europäischer Hersteller (anonym, „PKW“ genannt) begann Anfang der 90er Jahre nach vielen Jahren Marktpräsenz in Japan, seine Produkte in einem japanischen Setting darzustellen. Auslöser dafür war eine zufällige Beobachtung (Belauschung) zweiter Ordnung:

\footnotetext{
„Although the Agency had already been handling the PKW account for several years, it had never before used a specifically Japanese scene to advertise the products of its European client. Yet a number of series made use of this idea. Why? For the very simple reason that the account director had overheard the PKW vice president saying that he thought that PKW should try to integrate itself more fully into the Japanese car market as a whole. In his opinion, there was no reason why the European car manufacturer should always appear so obviously, foreign“." “46
}

46 Moeran 1996: 58. 
Und diese kulturelle Sensibilisierung der Werbung ausländischer Hersteller in Japan nimmt zu, wie sich erneut anhand von Spots für deutsche Autos belegen läßt.

\section{Werbung als kulturelle Beobachtung zweiter Ordnung}

Die Firma Volkswagen hat für ihr Modell Golf IV einen weiteren Werbespot im japanischen Stil produzieren und senden lassen. Zwei japanische Wissenschaftler oder ,researcher" unterhalten sich in ihrer Rolle als sempai und kôhai (etwa: Meister und Schüler) über den neuen Wagen. Der sempai leistet sich den Luxus einer nachlässigen Grammatik, während der kôhai seine förmliche Sprache beibehält. Beide lugen durch ein Türfenster in einen laborartigen Raum, in dem der blaue Golf steht. Der 30 Sekunden-Spot beginnt und endet mit der Großaufnahme des Auges des Betrachters, in welches das VW-Zeichen eingestanzt (im Text: eingebrannt) ist.

- A：例のメーカーの車、届いたみたいですよ。

B: どうせたいしたことないんじゃないの。

(研究所内に入る)

$\mathrm{A}$ : 立体型ヘッドランプ。

$\mathrm{B}$ : フムフム。

$\mathrm{A}$ : すき間 $3 \mathrm{~mm}$ 。

B: モデル合成いいってこと。

（競って乗ろうとする）

私が先。サイドエアバッグだ。

A：レザーシート。カーナビ。

アナウンサー：「オールニューゴルフ誕生。画期的ですね。」

A：目に焼き付いちゃった。

- A: Das Auto von diesem einen Hersteller soll angekommen sein.

B: Ist bestimmt keine große Sache, oder? (gehen ins „Labor")

A: Die Lampen haben ein 3D-Design.

B: hmhm.

A: Die Türfuge ist nur $3 \mathrm{~mm}$ breit.

B: Alles gut verarbeitet. (drängelt sich vor beim Einsteigen)

Ich zuerst ... Der hat Seitenairbags.

A: Und Ledersitze. Und Satellitennavigation.

Sprecher: All New Golf (Geburt). Epochemachend, nicht wahr.

A: Den werde ich so schnell nicht vergessen.

(wörtlich: Der hat sich meinem geistigen Auge eingebrannt) 
Auch die Marke mit dem Stern zeigt sich mit ihrer Werbung in Japan flexibel und anpassungsfähig. Ihre Werbungen benötigen nicht immer den Hinweis auf Deutschland, weil jeder über die Herkunft des Produkts bescheid weiß. Gerade das gibt dem Hersteller die Chance, seine Spots dem japanischen Stil anzupassen. Berühmt wurde ein Plakat, auf dem eine nackte weiße Mutter mit Baby für die deutschen Karossen warb. Aber auch die Fernsehspots sind großenteils in einem sanften japanischen Stil gehalten (wie die in Kapitel 4.1 zitierten Traum-Spots) und arbeiteten bevorzugt mit dem Motiv Einkaufen. Das Schlendern, Stöbern und Bummeln ist im Japan der Großkaufhäuser und Geschäftspassagen sehr positiv besetzt, es gibt sogar einen eigenen Ausdruck dafür: burabura suru (und speziell für das Einkaufen im Tokioter Stadtteil Ginza: ginbura suru). Besonders humorvoll und ruhig kommt der Spot für die C-Klasse ohne Musik und mit weißem Hintergrund daher: Ein Japaner mit Einkaufsdrahtkorb spaziert um den Wagen herum. Hut, Brille, Bart, seine nackten Beine und sein nackter Oberkörper geben ihm das Aussehen eines nörgelnden Geizkragens. Skeptisch klopft er mit dem Finger gegen die Karosse und kostet sogar den Lack. Der Sprecher denkt für ihn:

・無理な買い物は、もうしたくない。こんな時代こそ メルセデスはどうだろう。それは長く乗る一台。

- Ich will kein nutzloses Zeug mehr kaufen. Wie wäre da (in so einer Zeit) ein Mercedes? Das ist ein Wagen, den ich lange fahren kann.

Die schönste Beobachtung zweiter Ordnung gelingt aber der japanischen Werbeagentur Hakuhodo im Auftrag der Firma Opel. Obwohl der Hersteller zum amerikanischen GM-Konzern gehört, präsentieren die japanischen Werber ihn als deutschen Autobauer. Doch diese Kampagne gibt sich mit dem eindimensionalen Hinweis auf Deutschland nicht zufrieden, sondern reflektiert gleichzeitig das Image der anderen deutschen Autofirmen in Japan. Ihr Slogan: chigau doitsu (die andere deutsche Marke), bezieht sich unmittelbar auf die deutsche Konkurrenz von Mercedes, BMW und VW. Hauptdarsteller der Spots ist eine vierköpfige deutsche „Opel-Familie“. Jedes Mitglied symbolisiert ein Opel-Modell $($ Vater $=$ Opel Omega, Mutter $=$ Opel Vectra, Sohn $=$ Opel Astra, Tochter $=$ Opel Vita), und sie alle haben Augenbrauen in Form des Opel-Blitzes. In dem Werbefilm, in dem sich alle dem japanischen Publikum auf Deutsch vorstellen, heißt es in der Synchronisation: 
・オペル家: 日本でのドイツ車イメージは?

母 : 真面目。息子 : 安全。高級。

娘：でも、それだけじゃないんじゃない?

アナウンサー：

「オペル家：こっちは一味違う素敵なドイツ。」 オペル家は主張します。違うドイツオペル。 ドイツのチャレンジング・スピリット。

- Die Opel-Familie: Wie ist das Deutschland-Image in Japan? Mutter: Zuverlässig, ernsthaft? Sohn: Sicher? Hochklassig? Tochter: Aber doch nicht nur das, oder?

Sprecher: Die Opel-Familie sagt: Hier ist ein tolles Deutschland, das vom allgemeinen Massengeschmack abweicht. Das behauptet die Opel-Familie. Das andere Deutschland (die andere deutsche Marke): Opel.

Einblendung: Aus Deutschland. Der Geist der Herausforderung.

Am Ende verbeugen sich alle vier simultan vor den Zuschauern - bis auf die temperamentvolle Vita, die stattdessen vielsagend winkt und von ihrer Mutter getadelt wird. In „ihrem“ Spot für den Opel Vita ist sie ganz in rot gekleidet und fährt einen roten Kleinwagen. Vier junge Japaner stellen ihr nach. Dieser Spot wiederholt zusätzlich die latente Identifikation von Frau und Auto in Japan.

Die zitierten Beispiele belegen eine zunehmende interkulturelle Flexibilität der Werbeindustrie in Japan. Widerlegt ist nicht nur die Standardisierungsthese, sondern auch die These der eindimensionalen kulturellen Abhängigkeit der Werbesysteme. Vielmehr beginnt die Werbung gerade in Japan, mit kulturellen Grenzen, Images und Stilen zu spielen. Die interkulturelle Kommunikation gelingt in der Werbung insoweit, als sie nicht mehr kulturelle Stereotype bemüht, sondern Images reflektiert. Wie das globalisierte Wirtschaftssystem und sein Management, so muß auch die Werbung die kommunikative Resistenz von Kulturen anerkennen. ${ }^{47}$ Doch sie begreift diese Grenze, die quer zur Systemgrenze liegt, zugleich als Chance, ihre kommunikative Kompetenz zu steigern. Interkulturelle Kommunikation als Grenzgang innerhalb der globalisierten Weltgesellschaft birgt daher eine zivilisierende Kraft: Die Werbung als Haut des Wirtschaftssystems macht es sensibel für den Durchlauf seiner eigenen Kommunikation durchs Subjekt. Die Verpackung des Wirtschaftssystems ist daher als monetäre Machtgrenze zu lesen.

47 Moosmüller 1997. 


\section{Fazit: Interkulturelle Lesungen der japanischen Werbung}

Das japanische Werbesystem kommuniziert interkulturell, weil es sich sensibel an die Denkweisen, Mentalitäten und Vorstellungen der Konsumenten anschmiegt. Es reflektiert, nutzt und verändert die kulturelle Differenz innerhalb des globalen Wirtschaftssystems. Indem gerade die japanische Werbung Waren und Wirtschaft verpackt, kreiert sie eine flexible Grenze zwischen diesem System und seiner Umwelt und daher zugleich die Grenze seiner theoretischen Beschreibung. Nicht Systemtheorie, sondern nur Medientheorie ist daher an das Phänomen der Werbung anschlußfähig. Weil die globale Ökonomie sich mit ihrer Werbung kulturell selbst beschriftet, ist ihre Latenz der Kommunikation umschreibbar in eine Kommunikation der Latenz.

Die Latenz in der Werbekommunikation ist unbestreitbar. Doch hinter ihr steckt mehr als eine bloße Ausblendungsregel (Kapitel 4.1). Denn die Werbung wagt als Massenmedium in aller Öffentlichkeit einen geheimen Grenzgang zwischen System und Lebenswelt. Nicht die unhintergehbaren Grenzen zwischen den Kulturen der Welt sind ihr Hauptthema, sondern die Grenzen zwischen Kulturen zweiter Ordnung: zwischen Systemtheorie und Subjekttheorie. Indem die Werbung Geschlechter- und kulturelle Differenzen integriert, legt sie eine Spur dorthin, der wir gefolgt sind.

Wenn die Werbung fungiert als massenmediales Komplement zum Kommunikationsmedium Geld, prallen in ihr materialistische Ökonomie und materielle Körperlatenz aufeinander. In dem Maße, wie die Ökonomie die Subjekte zeichnet, muß die Werbung gegenzeichnen. In dem $\mathrm{Maße}$, in dem die Theorie Individuen und Dividuen aus ihrem System ausschließt, muß die Werbung ungezeichnete Körper zeichnen. Und diese Körperfixierung der Werbung wurde hier in bezug auf die japanische Werbung nachgezeichnet: in der Geburt der Waren, auf der ungezeichneten, weißen Haut, in der Thematisierung des Selbst, in der Betonung des Geschlechts und der oralen Genüsse. Die Werbung gebiert ein natürliches, souveränes, körperlich genußfähiges Individuum auf der Ebene der Zeichen. Aber indem sie das Funktionssystem Ökonomie für die Konsumenten schön verpackt, offenbart sie zugleich deren Körperlatenz. Die paradoxe Zeichenakkumulation der Werbung ist daher zugleich eine Beschriftung und eine Umschrift des Funktionssystems Ökonomie.

Die globalisierte Weltgesellschaft ist nicht funktional differenziert, sondern komplex. Sie paßt nicht unter ein einziges Paradigma. Die symbolische Generalisierung ihres Kommunikationsmediums Geld zieht die Diabolik kultureller Entgrenzung wie einen Schatten mit sich. Die 
Massenmedien, insbesondere die Werbung, markieren die Machtgrenzen der Funktionssysteme und damit auch die theoretische Grenze zwischen binärem Schematismus und Widerspruch. Soziale Systeme, auch die „,immaterielle“, binäre Aktienökonomie der heutigen Weltwirtschaft, werden von Individuen aus Fleisch und Blut konstituiert. Das System kann sich nur von individuellen Bedürfnissen und Interessen abkoppeln, weil es Latenzen generiert, die dem Bewußtsein der Individuen und ihren Körpern eingeschrieben sind. Doch diese Latenzen sind nicht inkommunikabel, sondern lesbar. Nicht als symbiotischer Mechanismus, sondern als Widerspruch zwischen abstrakter Systemfunktion und individuellem Bedürfnis.

Die Diabolik der durchgreifenden symbolisch generalisierten und medienbasierten Kommunikation liegt gerade darin, daß sie automatisch auf kulturelle und individuelle Grenzen stößt, in deren Überschreitung latente Entwicklungsmöglichkeiten für Theorie und Gesellschaft liegen. Die innere kulturelle Komplexität der Weltgesellschaft ist höher als die reduzierte der Funktionssysteme, deshalb müssen sich letztere an den Kulturen und Individuen informativ bedienen. Zivilisation heißt daher in der reflexiven Moderne nicht mehr: Ein Beschreibungsmuster zur Selbstbeschreibung der sich selbst beschreibenden Zivilisation schreiben. Vielmehr ist zivilisiert, wer fragt: Wer zivilisiert wen? Die Werbung ist daher nur ein Schritt in Richtung dieser reflexiven Zivilisierung, weil sie - in der Verpackungskultur der dividualen Ökonomie mehr als irgend sonst - nach Kultur, Körper, Subjektivität und Individualität fragt. Damit endet ihre Umschrift. Die japanische Werbung kommuniziert interkulturell, weil sie den unmarked space markiert zwischen den Grenzen unserer Autonomie und unserem grenzenlosen Bedürfnis danach. 


\section{Literatur}

\section{Literatur zum theoretischen Teil (Kapitel 1 - 3.2)}

Abe, Kinya (1992): „Wesen und Wandel der Reziprozität in Deutschland und Japan“. In: Joachim Matthes (Hg.), Zwischen den Kulturen? Die Sozialwissenschaften vor dem Problem des Kulturvergleichs. Göttingen: Otto Schwartz, S. 239-248.

Blechinger, Verena (1998): Politische Korruption in Japan. Ursachen, Hintergründe, Reformversuche. Hamburg: Institut für Asienkunde.

Beck, Ulrich (1997): Was ist Globalisierung? Irrtümer des Globalismus - Antworten auf Globalisierung. Frankfurt a.M.: Suhrkamp.

Bohnen, Alfred (1994): „Die Systemtheorie und das Dogma von der Irreduzibilität des Sozialen“. Zeitschrift für Soziologie 23, S. 292-305.

Brumann, Christoph (1998): „Geld als Geschenk: Aspekte japanischer Beziehungsarithmetik“. In: Peter Pörtner/Angelika Ernst (Hg.), Die Rolle des Geldes in Japans Gesellschaft, Wirtschaft und Politik. Hamburg: Institut für Asienkunde, S. 77-91.

Coulmas, Florian (2000): Japanische Zeiten. Eine Ethnographie der Vergänglichkeit. Reinbek bei Hamburg: Kindler.

Deleuze, Gilles/Guattari, Félix (1974): Anti-Ödipus. Kapitalismus und Schizophrenie I. Frankfurt a.M.: Suhrkamp.

Deutschmann, Christoph (1998): „Theorien zur gesellschaftlichen Bedeutung des Geldes und deren Relevanz im Fall Japan“. In: Peter Pörtner/Angelika Ernst (Hg.), Die Rolle des Geldes in Japans Gesellschaft, Wirtschaft und Politik. Hamburg: Institut für Asienkunde, S. 11-24.

Deutschmann, Christoph (1999): Die Verheißung des absoluten Reichtums. Zur religiösen Natur des Kapitalismus. Frankfurt a.M.: Campus. 
Duerr, Hans Peter (1988): Nacktheit und Scham. Der Mythos vom Zivilisationsprozeß (Bd. 1). Frankfurt a.M.: Suhrkamp.

Duerr, Hans Peter (1990): Intimität. Der Mythos vom Zivilisationsprozeß (Bd. 2). Frankfurt a.M.: Suhrkamp.

Duerr, Hans Peter (1993): Obszönität und Gewalt. Der Mythos vom Zivilisationsprozeß (Bd. 3). Frankfurt a.M.: Suhrkamp.

Dux, Günter (1989): Die Zeit in der Geschichte. Ihre Entwicklungslogik vom Mythos zur Weltzeit. Frankfurt a.M.: Suhrkamp.

Dux, Günter (1992): Die Spur der Macht im Verhältnis der Geschlechter. Über den Ursprung der Ungleichheit zwischen Frau und Mann. Frankfurt a.M.: Suhrkamp.

Dux, Günter (1994): Geschlecht und Gesellschaft. Warum wir Lieben. Die romantische Liebe nach dem Verlust der Welt. Frankfurt a.M.: Suhrkamp.

Dux, Günter (2000): Historisch-genetische Theorie der Kultur. Instabile Welten. Zur prozessualen Logik im kulturellen Wandel. Weilerswist: Velbrück.

Elias, Norbert (1976): Über den Prozeß der Zivilisation (2 Bde). Frankfurt a.M.: Suhrkamp.

Elias, Norbert (1984): Über die Zeit. Frankfurt a.M.: Suhrkamp.

Ellrich, Lutz (1999): Verschriebene Fremdheit. Die Ethnographie kultureller Brüche bei Clifford Geertz und Stephen Greenblatt. Frankfurt a.M.: Campus.

Elschenbroich, Donata (1996): Anleitung zur Neugier. Grundlagen japanischer Erziehung. Frankfurt a.M.: Suhrkamp.

Fuchs, Peter (1992): Die Erreichbarkeit der Gesellschaft. Zur Konstruktion und Imagination gesellschaftlicher Einheit. Frankfurt a.M.: Suhrkamp.

Fuchs, Peter (1993): Moderne Kommunikation. Zur Theorie des operativen Displacements. Frankfurt a.M.: Suhrkamp.

Fuchs, Peter (1995): Liebe, Sex und solche Sachen. Zur Konstruktion moderner Intimsysteme. Konstanz: Universitätsverlag.

Fuchs, Peter (1999): „Japanische Kommunikation“. In: Peter Fuchs, Die Umschrift. Zwei kommunikationstheoretische Studien. Frankfurt a.M.: Suhrkamp, S. 47-117.

Ganßmann, Heiner (1996): Geld und Arbeit: Wirtschaftssoziologische Grundlagen einer Theorie der modernen Gesellschaft. Frankfurt a.M.: Suhrkamp.

Getreuer-Kargl, Ingrid (1997): „Geschlechterverhältnis und Modernisierung“. In: Ilse Lenz/Michiko Mae (Hg.), Getrennte Welten, gemeinsame Moderne? Geschlechterverhältnisse in Japan. Opladen: Westdeutscher Verlag, S. 19-58. 
Gössmann, Elisabeth (1997): „Neue Rollenmuster für Frau und Mann? Kontinuität und Wandel der Familie in den japanischen Fernsehdramen der Gegenwart“. In: Ilse Lenz/Michiko Mae (Hg.), Getrennte Welten, gemeinsame Moderne? Geschlechterverhältnisse in Japan. Opladen: Westdeutscher Verlag, S. 96-122.

Goux, Jean-Joseph (1975): Freud, Marx. Ökonomie und Symbolik. Frankfurt a.M.: Suhrkamp.

Guttandin, Friedhelm (1980): Genese und Kritik des Subjektbegriffs. Zur Selbstthematisierung der Menschen als Subjekte. Marburg: Guttandin und Hoppe.

Habermas, Jürgen (1962): Strukturwandel der Öffentlichkeit. Untersuchungen zu einer Kategorie der bürgerlichen Gesellschaft. Darmstadt: Luchterhand.

Habermas, Jürgen (1981): Theorie des kommunikativen Handelns (2 Bde). Frankfurt a.M.: Suhrkamp.

Haesler, Aldo J. (1995): Sociologie de l'argent et postmodernité. Recherche sur les conséquences sociales et culturelles de l'électronisation des flux monétaires. Genf: Librairie Droz.

Hahn, Alois (1993): „Handschrift und Tätowierung“. In: Hans Ulrich Gumbrecht/K. Ludwig Pfeiffer (Hg.), Schrift. München: Fink, S. 201-218.

Hamaguchi, Eshun (1990): „Ein Modell zur Selbstinterpretation der Japaner - ,Intersubjekt“ und ,Zwischensein““. In: Jens Heise (Hg.), Die kühle Seele. Selbstinterpretationen der japanischen Kultur. Frankfurt a.M.: Fischer, S. 138-147.

Hampe, Ruth (1995): Frau und Geburt im Kulturvergleich. Eine kunstund kulturanalytische Studie. Frankfurt a.M.: Peter Lang.

Harsch, Wolfgang (1995): Die psychoanalytische Geldtheorie. Frankfurt a.M.: Fischer.

Harsch, Wolfgang (2002): „Psychoanalyse des Geldes“. In: Geld (Studium Generale der Universität Heidelberg). Heidelberg, S. 97-112.

Heinsohn, Gunnar (1995): „Muß die abendländische Zivilisation auf immer unerklärbar bleiben? Patriarchat und Geldwirtschaft“. In: Waltraud Schelkle/Manfred Nitsch (Hg.), Rätsel Geld. Annäherungen aus ökonomischer, soziologischer und historischer Sicht. Marburg: Metropolis, S. 209-270.

Heinze, Ulrich (1999): „Der Stadt-Land-Quotient. Bruch, Schichtung und Selbstreferenz im japanischen Urbanraum“. Ästhetik und Kommunikation Nr. 30/106, Berlin, S. 59-65.

Heise, Jens/Pörtner, Peter (1995): Die Philosophie Japans. Von den Anfängen bis zur Gegenwart. Stuttgart: Alfred Kröner.

Honegger, Claudia (1987): „Hexenprozesse und ,Heimlichkeiten der 
Frauenzimmer': Geschlechtsspezifische Aspekte von Fremd- und Selbstthematisierung“، In: Alois Hahn/Volker Kapp (Hg.), Selbstthematisierung und Selbstzeugnis. Bekenntnis und Geständnis. Frankfurt a.M.: Suhrkamp, S. 95-109.

Immoos, Thomas (1991): „Das Land der mächtigen Frauen. Archaisches im Gegenwärtigen - Frauen in schamanistisch-kultischen Funktionen“. In: Elisabeth Gössmann (Hg.), Japan - ein Land der Frauen? München: Iudicium, S. 13-33.

Irigaray, Luce (1976): Waren, Körper, Sprache. Der ver-rückte Diskurs der Frauen. Berlin: Merve.

de Jong, Willemijn (1998): „Das Haus der Lio als weiblicher Körper. Ein Geschlechtskonstrukt in Variationen“. In: Susanne Schröter (Hg.), Körper und Identitäten. Ethnologische Ansätze zur Konstruktion von Geschlecht. Hamburg: Lit Verlag, S. 36-50.

Kersten, Joachim (1997): Gut und Geschlecht. Männlichkeit, Kultur und Kriminalität. Berlin: Walter de Gruyter.

Kimura, Bin (1995): Zwischen Mensch und Mensch. Strukturen japanischer Subjektivität. Darmstadt: Wissenschaftliche Buchgesellschaft.

Klossowski, Pierre (1998): Die lebende Münze. Berlin: Kadmos.

Künzler, Jan (1989): Medien und Gesellschaft. Die Medienkonzepte von Talcott Parsons, Jürgen Habermas und Niklas Luhmann. Stuttgart: Enke.

Kurnitzky, Horst (1974): Triebstruktur des Geldes. Ein Beitrag zur Theorie der Weiblichkeit. Berlin: Wagenbach.

Lenz, Ilse (1995): „Geschlechtersymmetrie als Geflecht von Frauenund Männermacht. $\mathrm{Zu}$ den Minangkabau in der vorkolonialen Epoche“. In: Ilse Lenz/Ute Luig (Hg.), Frauenmacht ohne Herrschaft. Geschlechterverhältnisse in nichtpatriarchalischen Gesellschaften. Frankfurt: Fischer, S. 302-329.

Leroi-Gourhan, André und Arlette (1995): Eine Reise zu den Ainu. Hokkaido 1938. Zürich: Ammann.

Luhmann, Niklas (1982): Liebe als Passion. Zur Codierung von Intimität. Frankfurt a.M.: Suhrkamp.

Luhmann, Niklas (1984): Soziale Systeme. Grundriß einer allgemeinen Theorie. Frankfurt a.M.: Suhrkamp.

Luhmann, Niklas (1988): Die Wirtschaft der Gesellschaft. Frankfurt a.M.: Suhrkamp.

Luhmann, Niklas (1996): Die Realität der Massenmedien. Opladen: Westdeutscher Verlag.

Luhmann, Niklas (1997): Die Gesellschaft der Gesellschaft. Frankfurt a.M.: Suhrkamp. 
Luig, Ute (1995): „Körpermetaphorik, Sexualität und Macht der Frauen. Das Beispiel der Baule in der Elfenbeinküste“. In: Ilse Lenz/Ute Luig (Hg.), Frauenmacht ohne Herrschaft. Geschlechterverhältnisse in nichtpatriarchalischen Gesellschaften. Frankfurt a.M.: Fischer, S. 276-297.

Marx, Karl (1973/1975/1975a): Das Kapital (3 Bde). Berlin: Dietz.

Mauss, Marcel (1975): Soziologie und Anthropologie (2 Bde). München: Hanser.

Merten, Klaus/Westerbarkey, Joachim (1994): „Public Opinion und Public Relations“. In: Klaus Merten/Siegried J. Schmidt/Siegfried Weischenberg (Hg.), Die Wirklichkeit der Medien. Eine Einführung in die Kommunikationswissenschaft. Opladen: Westdeutscher Verlag, S. $188-211$.

Nakane, Chie (1985): Die Struktur der japanischen Gesellschaft. Frankfurt a.M.: Suhrkamp.

Neckel, Sighard (1989): „Das Stellhölzchen der Macht. Zur Soziologie des politischen Skandals“. In: Rolf Ebbighausen/Sighard Neckel (Hg.), Anatomie des politischen Skandals. Frankfurt a.M.: Suhrkamp, S. 55-80.

Neckel, Sighard (1991): Status und Scham. Zur symbolischen Reproduktion sozialer Ungleichheit. Frankfurt a.M.: Campus.

Okonogi, Keigo: „Der Ajase-Komplex des Japaners“. In: Jens Heise (Hg.), Die kühle Seele. Selbstinterpretationen der japanischen Kultur. Frankfurt a.M.: Fischer, S. 30-79.

Pauer, Erich (1990): „Reich, Neu-Reich, Super-Reich. Reichtum in Japan gestern und heute“. In: Peter Pörtner (Hg.), Japan-Lesebuch II. Tübingen: Konkursbuch, S. 200-240.

Pauer, Erich (1998): „Zur Geschichte des Geldes sowie des Reichtums in Japan“. In: Peter Pörtner/Angelika Ernst (Hg.), Die Rolle des Geldes in Japans Gesellschaft, Wirtschaft und Politik. Hamburg: Institut für Asienkunde, S. 31-54.

Paul, Axel T. (2002): „Die Legitimität des Geldes“. In: Christoph Deutschmann (Hg.), Die gesellschaftliche Macht des Geldes (Leviathan Sonderheft 21). Opladen: Westdeutscher Verlag, S. 109-129.

Paul, Axel T. (2002a): „Money makes the World Go Round. Über die Dynamik des Geldes und die Grenzen der Systemtheorie“. Berliner Journal für Soziologie 12/2, S. 243-262.

Pörtner, Peter (1995): „Zwischen Mutter und Netzwerk - zur Sozialisation in Japan“. In: Breuninger-Kolleg (Hg.), Der japanische Erfolg. Voraussetzungen, Bedingungen, Folgen. Stuttgart, S. 83-98.

Redelfs, Manfred (1996): Investigative Reporting in den USA. Strukturen eines Journalismus der Machtkontrolle. Opladen: Westdeutscher. 
Schaede, Ulrike (1990): „Die Vergangenheit des Futures. Was die findigen Tokugawa-Kaufleute ,im voraus“ taten“. In: Peter Pörtner (Hg.), Japan-Lesebuch II. Tübingen: Konkursbuch, S. 241-259.

Schlehe, Judith (1987): Das Blut der fremden Frauen. Menstruation in der anderen und in der eigenen Kultur. Frankfurt a.M.: Campus.

Schmidt, Siegried J. (1996): Die Welten der Medien. Grundlagen und Perspektiven der Medienbeobachtung. Braunschweig: Vieweg.

Schmidt, Siegfried J. (2000): Kalte Faszination. Medien, Kultur, Wissenschaft in der Mediengesellschaft. Weilerswist: Velbrück.

Schulte, Günter (1992): Kennen Sie Marx? Zur Kritik der proletarischen Vernunft. Frankfurt a.M.: Campus.

Schulte, Günter (1993): Der blinde Fleck in der Systemtheorie Niklas Luhmanns. Frankfurt a.M.: Campus.

Schwanitz, Dietrich (1987): „Selbstthematisierung im englischen Liebesroman“. In: Alois Hahn/Volker Kapp (Hg.), Selbstthematisierung und Selbstzeugnis. Bekenntnis und Geständnis. Frankfurt a.M.: Suhrkamp, S. 281-296.

Schwanitz, Dietrich (1990): Systemtheorie und Literatur. Ein neues Paradigma. Opladen: Westdeutscher Verlag.

Schwengel, Hermann (1987): „Simmel und Marx. Zwei Philosophien des Geldes, ein Schatten des Heiligen?“ In: Dietmar Kamper/Christoph Wulf (Hg.), Das Heilige. Seine Spur in der Moderne. Frankfurt a.M.: Athenäum, S. 464-490.

Sennett, Richard (1983): Verfall und Ende des öffentlichen Lebens. Die Tyrannei der Intimität. Frankfurt a.M.: Fischer.

Sennett, Richard (1991): Civitas. Die Großstadt und die Kultur des Unterschieds. Frankfurt a.M.: Fischer.

Sennett, Richard (1995): Fleisch und Stein. Der Körper und die Stadt in der westlichen Zivilisation. Berlin: Berlin Verlag.

Sennett, Richard (1998): Der flexible Mensch. Die Kultur des neuen Kapitalismus. Berlin: Berlin Verlag.

Shimada, Shingo (1994): Grenzgänge - Fremdgänge. Japan und Europa im Kulturvergleich. Frankfurt a.M.: Campus.

Shimada, Shingo/Gabbani, Sonja (1998): „Überlegungen zur Äquivalenz von Zeit und Geld“،. In: Peter Pörtner/Angelika Ernst (Hg.), Die Rolle des Geldes in Japans Gesellschaft, Wirtschaft und Politik. Hamburg: Institut für Asienkunde, S. 65-75.

Shimada, Shingo (2000): Die Erfindung Japans. Kulturelle Wechselwirkung und nationale Identitätskonstruktion. Frankfurt a.M.: Campus.

Simmel, Georg (1989, Erstausgabe 1901): Die Philosophie des Geldes (hg. von David P. Frisby und Klaus Christian Kröhnke). Frankfurt a.M.: Suhrkamp. 
Singer, Kurt (1920): Das Geld als Zeichen. Jena: Gustav Fischer.

Wagner, Gerhard/Zipprian, Heinz (1992): „Identität oder Differenz? Bemerkungen zu einer Aporie in Niklas Luhmanns Systemtheorie selbstreferenzieller Systeme“. Zeitschrift für Soziologie 21, S. 394-405.

Weber, Claudia (1989): „Traditionelle Rollen und Wandel der Familienstrukturen in Japan“. In: Deutsches Jugendinstitut (Hg.), Kinderfernsehen und Fernsehforschung in Japan und der Bundesrepublik Deutschland. München: Juventa, S. 91-106.

Weber, Claudia (1997): „Geschlechterordnung, Arbeitsmarktintegration und Familienform: Japan im Vergleich“. In: Ilse Lenz/Michiko Mae (Hg.), Getrennte Welten, gemeinsame Moderne? Geschlechterverhältnisse in Japan. Opladen: Westdeutscher Verlag, S. 59-77.

Yamazaki, Masakazu (1994): Individualism and the Japanese. An Alternative Approach to Cultural Comparison. Tokio: Japan Echo.

Yoshimi, Shunya (吉見俊哉) (1994): メディア時代の文化社会学 (Die Kultursoziologie des Medienzeitalters). Tokio: 新曜社.

Yoshimi, Shunya (吉見俊哉) (1996): リアリティ・トランジット. 情報 消費社会の現在 (Realitäten im Fluß. Zur Gegenwart der Informations- und Konsumgesellschaft). Tokio: 紀伊国屋書店.

Yoshimi, Shunya (2002): „Der semiotische Raum des modernen Tokio“. In: Ulrich Heinze (Hg.), Regenzeichen. Spuren nach Japan. Kulturrevolution Nr. 44, Essen: Klartext Verlag, S. 96-106.

Yuge, Naoko（弓削尚子）(2000): Vom „,wilden“ zum ,zivilisierten“ Geschlechterverhältnis. Die neue Blickrichtung in der anthropologischen Diskussion um 1800 (Deutsche Fassung der Dissertation an der Ochanomizu-Universität). Tokio. 


\section{Literatur zum empirischen Teil (Vorwort, Kapitel 3.3, Kapitel 4)}

Anzieu, Didier (1991): Das Haut-Ich. Frankfurt a.M.: Suhrkamp.

Appadurai, Arjun (1990): „Disjuncture and Difference in the Global Cultural Economy“. In: Mike Featherstone (Hg.), Global Culture. Nationalism, Globalization and Modernity. London: Sage, S. 295-310.

Assmann, Aleida (1993): „Pflug, Schwert, Feder. Kulturwerkzeuge als Herrschaftszeichen“. In: Hans Ulrich Gumbrecht/K. Ludwig Pfeiffer (Hg.), Schrift. München: Fink, S. 219-232.

Au, Hans/Wormuth, Mirko (1995): „Das neue chinesische Werbegesetz. Einführung und Übersetzung“. China Aktuell, Hamburg, S. 213-222.

Becher, Uta/Kessler, Martina (1991): „Der Werbemarkt in Ostdeutschland“. Media Perspektiven 7, S. 445-451.

Butterweck, Ursula (1995): Veränderungen russischer Werbeanzeigen anhand von Beispielen aus der Zeitschrift "Novye tovary“. Magisterarbeit (unveröff.), Freiburg i.Br.

Clammer, John (1995): „Consuming Bodies: Constructing and Representing the Female Body in Contemporary Japanese Print Media“. In: Brian Moeran/Lise Skov (Hg.), Women, Media and Consumption in Japan. Honolulu: University of Hawaii Press, S. 197-219.

Dallmann, Katharina M. (1997): Kultur und Werbung. Eine theoretische und empirische Analyse zum Einfluß kultureller Dimensionen auf die Konzeption und Gestaltung von Werbung am Beispiel deutscher und japanischer Zeitschriftenwerbung. Delmenhorst bei Bremen: S. Rieck.

Davis, Riccardo A. (1993): „Many languages - 1 ad message. YAR agency translates not only dialogue in ads, but also cultural images“. Advertising Age vom 20. September 1993, S. 50.

Dentsû (2000): Japan 1999 Marketing and Advertising Yearbook. Tokio.

Entwistle, Joanne (1997): „,Power Dressing“ and the Construction of the Career Woman“. In: Mica Nava/Andrew Blake/Ian MacRury/Barry Richards (Hg.), Buy This Book. Studies in advertising and consumption. London: Routledge, S. 311-323.

Falk, Pasi (1997): „The Benetton-Toscani Effect. Testing the limits of conventional advertising“. In: Mica Nava/Andrew Blake/Ian MacRury/Barry Richards (Hg.), Buy This Book. Studies in advertising and consumption. London: Routledge, S. 64-83.

Featherstone, Mike (1991): „The Body in Consumer Culture“. In: Mike Featherstone/Mike Hepworth/Bryan S. Turner (Hg.), The Body. Social Process and Cultural Theory, London: Sage, S. 170-196. 
Fields, George/Katahira, Hotaka/Wind, Jerry (2000): Leveraging Japan. Marketing to the New Asia. San Francisco.

Ford, John B./Voli, Patricia Kramer/Honeycutt, Earl D. Jr./Casey, Susan L. (1998): „Gender Role Portrayals in Japanese Advertising: A Magazine Content Analysis“. Journal of Advertising 27/1, S. 113-124.

Fowles, Jib (1996): Advertising and Popular Culture. London: Sage.

Fuchs, Wolfgang (1992): „Internationalisierung der Werbung und transkulturelle Kommunikation“. In: Horst Reimann (Hg.), Transkulturelle Kommunikation und Weltgesellschaft. Opladen: Westdeutscher Verlag, S. 305-315.

Gehrs, Oliver (1999): „Mehr Spots, weniger Wikung. Der Jugendwahn frißt seine Kinder: Werbeagenturen und Mediaplaner zweifeln, ob Comedy- und Talk-Sendungen das richtige Umfeld für ihre Produkte sind. Im Einheitsbrei rauschen Milliarden von Werbegeldern an den Konsumenten vorbei“. Der Spiegel Nr. 40, S. 186-188.

Giddens, Anthony (1997): Jenseits von Links und Rechts. Die Zukunft radikaler Demokratie. Frankfurt a.M.: Suhrkamp.

Görtzen, Ulrike (1995): Die Entwicklung der japanischen Werbewirtschaft in der Nachkriegszeit (1950-1990). Marburg: Japan Reihe.

Gould, Stephen J./Minowa, Yuko (1994): „,Are They Saying the Same Thing?' An Exploratory Study of Japanese and American Automobile Advertising“. In: Basil G. Englis (Hg.), Global and Multinational Advertising. Hillsdale (N.J.): Lawrence Erlbaum, S. 193-204.

Greenberg, Bradley S./Ku, Linlin/Li, Hairong (1992): „Parental Mediation of Childrens' Mass Media Behaviors in China, Japan, Korea, Taiwan, and the United States“. In: Felipe Korzenny/Stella TingToomey/Elizabeth Schiff (Hg.), Mass Media Effects Across Cultures. London: International and Intercultural Annual, S. 150-172.

Haehling von Lanzenauer, Natascha (1998): Werbung in Japan. Eine Untersuchung der Werbewirtschaft und Werbegestaltung unter besonderer Berücksichtigung von Unternehmenswerbung. Berlin (Dissertation: www.diss.fu-berlin.de/1999/40/ im Februar 2000).

Heinze, Ulrich (1994): „Werbung als Massenmedium des Wirtschaftssystems. Zur latenten Polarität im systemtheoretischen Medienbegriff“. Kulturrevolution Nr. 30, Essen: Klartext Verlag, S. 34-36.

Heinze, Ulrich (2001): „Werbung zeichnet ungezeichnete Körper im Reich der Zeichen - Japanische Dividuen und die Lust am maternellen Selbst". Ästhetik und Kommunikation 32/112, Berlin, S. 87-92.

Heinze, Ulrich (2002): „Radionutzung im Großraum Tokio. Kulturspezifische Merkmale des japanischen Hörverhaltens“. Kulturrevolution Nr. 44, Essen: Klartext Verlag, S. 113-120. 
Hendry, Joy (1992): „Individualism and individuality: Entry into a social world“. In: Roger Goodman/Kirsten Refsing (Hg.), Ideology and Practice in Modern Japan. London: Routledge, S. 55-71.

Hendry, Joy (1993): Wrapping Culture. Politeness, Presentation and Power in Japan and Other Societies. Oxford: Clarendon Press.

Herbig, Paul A. (1995): Marketing Japanese Style. Westport/USA: Quorum Books.

Hölscher, Barbara (1998): Lebensstile durch Werbung? Zur Soziologie der Lifestyle-Werbung. Opladen: Westdeutscher Verlag.

Hong, Junhao (1994): „,The Resurrection of Advertising in China. Developments, Problems, and Trends“. Asian Survey Vol. 34, S. 326-342.

Iwamoto, Toshihiko (岩本俊彦) (1997): 広告モード研究 (Forschungen zu Werbemethoden). Tokio: 倉成社.

Jobling, Paul: Keeping Mrs. Dawson Busy. Safe Sex, Gender and Pleasure in Condom Advertising since 1970. In: Mica Nava/Andrew Blake/Ian MacRury/Barry Richards (Hg.), Buy This Book. Studies in advertising and consumption. London: Routledge, S. 157-177.

Kashiwagi, Shigeaki (1988) (柏木重秋, Hg.): 広告概論 (Einführung in die Werbung). Tokio: ダイヤモンド社.

Kawasoe, Noriko Katharina (1999): „Der imaginierte Mann - Männerbilder in der japanischen Zeitschriftenwerbung“. Minikomi Nr. 2, Wien, S. 14-22.

Kishii, Tamotsu (1994): „Insider- and Outsider-Oriented Advertising. The Differences Between Japanese and Western Advertising“. In: Dentsû Marketing and Advertising Yearbook 1994, Tokio, S. 51-55.

Kloepfer, Rolf/Landbeck, Hanne (1991): Ästhetik der Werbung. Der Fernsehspot in Europa als Symptom neuer Macht. Frankfurt a.M.: Fischer.

Koivisto, Jussi V. (1997): Television Advertisements as Cultural Symbols. A Cross-Cultural Semiotic Analysis of a European and a Japanese Baby Napkin Advertisement. Helskinki School of Economics.

Kunkies-Schwientek, Inge (1990): Wege zum japanischen Markt unterschiedliche Markteintrittsstrategien deutscher Unternehmen in Japan. Berlin: Erich Schmidt.

Lewis, Reina/Rolley, Katrina (1997): „(Ad)Dressing the Dyke: Lesbian Looks and Lesbian Looking“. In: Mica Nava/Andrew Blake/Ian MacRury/Barry Richards (Hg.), Buy This Book. Studies in advertising and consumption. London: Routledge, S. 291-310.

Lindner, Rolf (1977): Das Gefühl von Freiheit und Abenteuer. Ideologie und Praxis der Werbung. Frankfurt a.M.: Campus.

Lipovetsky, Gilles (1983): L'ère du vide. Essais sur l'individualisme contemporain. Paris: Gallimard. 
Lipovetsky, Gilles (1987): „La pub sort ses griffes“. In: Gilles Lipovetsky, L'empire de l'éphémère. La mode et son destin dans les sociétés modernes. Paris: Gallimard, S. 218-241.

Löhr, Marc (2002): „Das Mediensystem Japans“. In: Hans-BredowInstitut (Hg.), Internationales Handbuch Medien 2002/03. BadenBaden: Nomos, S. 824-838.

Maletzke, Gerhard (1996): Interkulturelle Kommunikation. Zur Interaktion zwischen Menschen und verschiedenen Kulturen. Opladen: Westdeutscher Verlag.

Manabe, Kazufumi (真鍋一史) (1994): 広告の社会学 (Soziologie der Werbung). Tokio: 日経広告研究所.

Manabe, Kazufumi (真鍋一史) (1998): 国際イメージと広告. 国際広告. 国際イメージ.文化的ナショナリズム (Internationale Images und Werbung. Internationale Werbung. Internationales Image. Kultureller Nationalismus). Internationales Image. Kultureller Nationalismus). Tokio: 日経広告研究所.

March, Robert (1994): „Kommunikation mit japanischen Kunden“. In: Der ehrenwerte Kunde Japan. Marketing und Verkauf im Japan der 90er Jahre. Landsberg/Lech: Moderne Industrie, S. 189-201.

Matsushima, Hiromi (松島廣美) (1976/1998): 国際ネーミング.入門 からプロ課程まで (Internationales Naming. Einführung und Kurs für Profis). Tokio: 日刊工業新聞社.

Mayer, Hans/Heckelsberger, Udo (1992): „Die Werbewirkung von Anzeigen in West- und Ostdeutschland. Eine empirische Untersuchung am Beispiel von Anzeigen für Lord Extra“. GfK Jahrbuch der Absatz- und Verbrauchsforschung Nr. 2, S. 201-218.

Meffert, Sylvia (2001): Werbung und Kunst. Über ihre phasenweise Konvergenz in Deutschland von 1895 bis zur Gegenwart. Opladen: Westdeutscher Verlag.

Metzler, Manuel (1999): „Japanische Ordnungsprinzipien - einige Parallelen zwischen Schule und Unternehmen“. Asien 71 Nr. 4, S. 62-81.

Moeran, Brian (1991): Media and Advertising in Japan. Copenhagen: Nordic and Asian Studies.

Moeran, Brian (1996): A Japanese Advertising Agency. An Anthropology of Media and Markets. Honolulu: University of Hawaii Press.

Moeran, Brian (1996a): „In Pursuit of Perfection. The Discourse of Cars and Transposition of Signs in Two Advertising Campaigns“. In: John W. Treat (Hg.), Contemporary Japan and Popular Culture. Surrey: Curzon Press, S. 41-66.

Mooij, Marieke de (1996): Global Marketing and Advertising. Understanding Cultural Paradoxes. London: Sage. 
Moosmüller, Alois (1997): Kulturen in Interaktion. Deutsche und US-amerikanische Firmenentsandte in Japan. Münster: Waxmann.

Mori, Toshinori (森俊範)(1993): 広告維新。21 世紀のメディアに備えよ (Erneuerung der Werbung. Vorbereitung auf die Medien des 21. Jahrhunderts). Tokio: TBS ブリタニカ.

Müller, Stefan/Kornmeier, Martin (1994): Internationales Marketing Eine interkulturelle Perspektive. Dresden: Dresdner Beiträge zur Betriebswirtschaftslehre 1.

Müller, Stefan/Kornmeier, Martin (1996): „Grenzen der Standardisierung im Internationalen Marketing“. Jahrbuch der Absatz- und Verbrauchsforschung 1, S. 4-29.

Müller, Wendelin G. (1997): Interkulturelle Werbung. Heidelberg: Physica.

Müller, Wendelin G. (1998): „Verlust von Werbewirkung durch Standardisierung“. Absatzwirtschaft 9, S. 80-88.

Nagata, Hideo (永田英夫) (1993): 国際広告評評談義 (Kritik der internationalen Werbung). Tokio: 近代文藝社.

Nanba, Kôji (難波功士) (2000):「広告」への社会学 (Soziologie der „Werbung“"). Kyoto: 世界思想社.

Nickel, Volker (1996): „Der Ossi, wie er leibt und lebt“. werben \& verkaufen 40, S. 160-164.

Nixon, Sean (1997): „Advertising Executives as Modern Men: Masculinity and the UK advertising industry in the 1980s“. In: Mica Nava/Andrew Blake/Ian MacRury/Barry Richards (Hg.), Buy This Book. Studies in advertising and consumption. London: Routledge, S. 103-119.

Oettermann, Stephan (1982): „Heavily Tattooed“. In: Dietmar Kamper/ Christoph Wulf (Hg.): Die Wiederkehr des Körpers. Frankfurt a.M.: Suhrkamp, S. 335-349.

Ôishi, Junichi (大石準一) (1979/1991): 広告の社会心理 (Sozialpsychologie der Werbung). Kyoto：世界思想社.

Ôishi, Junichi (大石準一) (1994): 広告概論説 - 歴史と未来を探る (Einführung in die Werbung - Geschichte und Zukunft). Kyoto: 世 界思想社.

Riessland, Andreas (1997): „Sweet Spots. The Use of Cuteness in Japanese Advertising“. Jahrbuch des Deutschen Instituts für Japanstudien 9, Tokio, S. 129-154.

Rinner-Kawai, Yumiko (1993): „Die Sprache der Werbung in Deutschland und Japan. Werbeanglismus: Motivation und Auswirkungen“. Zeitschrift für Betriebswirtschaft 63/9, S. 923-932.

Rosenberger, Nancy (1995): „Antiphonal performances? Japanese women's magazines and women's voices“. In: Brian Moeran/Lise 
Skov (Hg.), Women, Media and Consumption in Japan. Honolulu: University of Hawaii Press, S. 143-169.

Roth, Klaus (1996) (Hg.): Mit der Differenz leben. Europäische Ethnologie und interkulturelle Kommunikation. Münster: Waxmann.

Saito, Yoshihiko/Ida, Mieko/Endo, Naoko (齋藤喜彦/井田美恵子/遠藤尚 子) (2000): テレビ・ラジオ視聴の現況 - 平成 11 年 11 月全国個人 視聴率調査から(The Present State of Radio and TV Audiences: from the National Individual Audience Ratings Survey Conducted in November, 1999). 放送研究と調査 (hôsô kenkyû to chôsa. The NHK Monthly Report on Broadcasting Research) 51/3, S. 60-71.

Satô, Takumi (佐藤卓己) (1998): 現代メディア史 (Aktuelle Mediengeschichte). Tokio: 岩波.

Schmidt, Siegfried J./Spieß, Brigitte (1994): Die Geburt der schönen Bilder. Fernsehwerbung aus der Sicht der Kreativen. Opladen: Westdeutscher Verlag.

Schmidt, Siegfried J./Spieß, Brigitte (1996): Die Kommerzialisierung der Kommunikation. Fernsehwerbung und sozialer Wandel 19561989. Frankfurt a.M.: Suhrkamp.

Schnierer, Thomas (1999): Soziologie der Werbung. Ein Überblick zum Forschungsstand einschließlich zentraler Aspekte der Werbepsychologie. Opladen: Leske und Budrich.

Schütte, Dagmar (1996): Das schöne Fremde. Anglo-amerikanische Einflüsse auf die Sprache der deutschen Zeitschriftenwerbung. Opladen: Westdeutscher Verlag.

Shao, J. (1995): „Irreführende Werbung als unlautere Wettbewerbshandlung im chinesischen UWG“، Gewerblicher Rechtsschutz und Urheberrecht (Internationaler Teil) 10, Weinheim, S. 752-756.

Song, T.B./Wong, Leo (1998): „Getting the Word Out. Advertising in China are growing as new media emerge“. The China Business Review 9-10, S. 22-25.

Spieß, Brigitte (1994): „Weiblichkeitsklischees in der Fernsehwerbung“. In: Klaus Merten/Siegfried J. Schmidt/Siegfried Weischenberg (Hg.), Die Wirklichkeit der Medien. Eine Einführung in die Kommunikationswissenschaft. Opladen: Westdeutscher Verlag, S. 408-426.

Tanaka, Hiroshi (1992): „Werbung in Japan“. Viertel-Jahresheft für Media- und Werbewirkung, Hamburg, S. 18-21.

Tanaka, Keiko (1990): „Intelligent elegance: Women in Japanese advertising“. In: Brian Moeran/Eyal Ben-Ari/James Valentine (Hg.): Unwrapping Japan. Society and Culture in Anthropological Perspective. Honolulu: University of Hawaii Press.

Tanaka, Keiko (1994): Advertising Language. A pragmatic approach to advertisements in Britain and Japan. London: Routledge. 
Taylor, Charles R./Miracle, Gordon E./Chang, Kyu Yeol (1994): „The Difficulty of Standardizing International Advertising: Some Propositions and Evidence from Japanese, Korean, and U.S. Television Advertising“. In: Basil G. Englis (Hg.), Global and Multinational Advertising. Hillsdale (N.J.): Lawrence Erlbaum, S. 171-191.

Treat, John Whittier (1995): „Yoshimoto Banana's Kitchen Or The Cultural Logic Of Japanese Consumerism“. In: Brian Moeran/Lise Skov (Hg.), Women, Media and Consumption in Japan. Honolulu: University of Hawaii Press, S. 274-298.

Uejô, Norio (植条則夫) (1993): 広告コピー概論 (Einführung in das Texten von Werbeslogans). Tokio: 宣伝会議.

Wacker, Gudrun (1991): Werbung in der VR China (1979-1989). Hamburg: Institut für Asienkunde.

Willems, Herbert/Kautt, York (1999): „Der Körper in der Werbung: Überlegungen zu den Sinnbezügen und Formen seiner Inszenierung“. Rundfunk und Fernsehen 4, S. 515-530.

Yamaki, Toshio (八巻俊雄) (1990): 広告国際比較とグローバル戦略。 広告でその国の文化がつかめる (Internationaler Vergleich von Werbung und globale Strategien. Wie man mithilfe der Werbung die Kultur eines Landes erfassen kann). Tokio: 産能大学出版部.

Yamaki, Toshio (八巻俊雄) (1994): 比較、世界のテレビ CM (Vergleich von Werbespots aus der ganzen Welt). Tokio: 日経広告研究所.

Yamamoto, Taketoshi (山本武利 (編) (1998, Hg.) 現代広告学を学ぶ人 のために (Für Leute, welche die aktuelle Werbung erlernen wollen). Kyoto: 世界思想社.

Yi, Chuang (1999): „Weiblichkeit in der Werbung: Das Frauenbild japanischer Frauenzeitschriften“. In: Minikomi 2, Wien, S. 5-13.

Zurstiege, G. (1998): Mannsbilder. Männlichkeit in der Werbung. Eine Untersuchung zur Darstellung von Männern in der Anzeigenwerbung der fünfziger, siebziger und neunziger Jahre.“ Opladen: Westdeutscher Verlag. 


\section{Anhang}

\section{Liste japanischer Schriftzeichen/Werbeglossar}

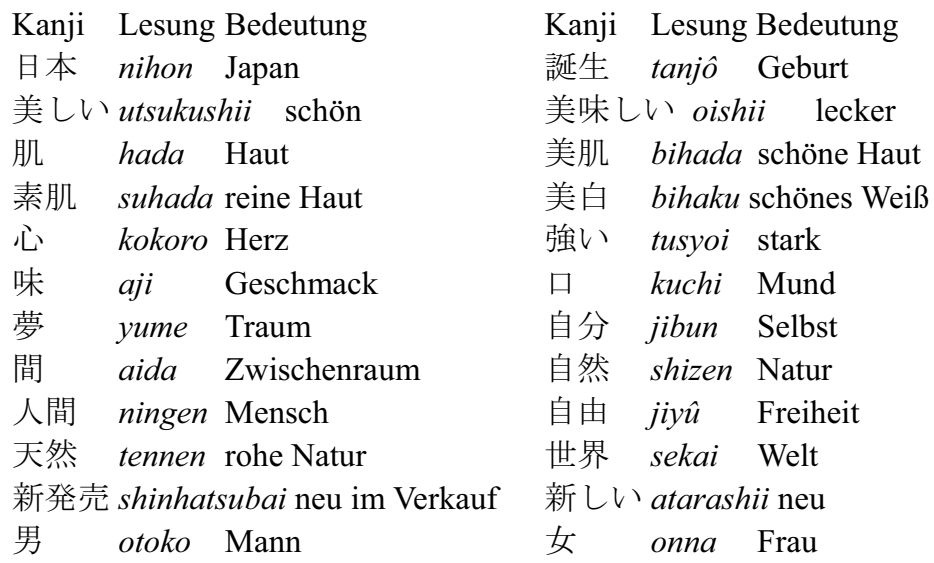

Die japanische Schrift nutzt die chinesischen Zeichen, die Kanji, sowie drei Alphabete. Das Standardalphabet ist das Hiragana (ひらがな), erkennbar an seiner runden Form. Die eckigen Katakana (カタカナ) werden vor allem für importierte Worte und ausländische Namen benutzt und heben sie im Werbe- oder Zeitungstext hervor. Schließlich garnieren die japanischen Werbetexter ihre Kreation oft noch mit den lateinischen Buchstaben (rômaji).

Textprobe:

[C-Klasse] の 夢をみましたね。3 秒で恋におちた。ビーチボーイに なった。ココロが踊りだす。地獄デ天国。BREAK ブレイク 新登場！ 


\section{Werbeausgaben nach Branchen und Mediamix in Japan und Deutschland}

- Bruttoausgaben in Japan 1999: 5.700 Mrd. $¥(1,15 \%$ des GDP).

- Bruttoausgaben in Japan 2000: 6,1102 Mrd. $¥(1,19 \%$ des GDP). Im Jahre 2001 stiegen sie nochmals auf 1,2\% des BSP.

- Bruttoausgaben in Deutschland 1999: 31,8 Mrd. DM (entsprechen $0,82 \%$ des GDP).

Abbildung 5 zeigt die Werbeausgaben nach Branchen in Deutschland und Japan im Jahre 1999. Demnach konzentrieren sich die Werbeausgaben in beiden Industrieländern auf dieselben Schwerpunkte. Der orale Konsum: Essen/Trinken/Tabak (plus Pharmazeutika), wird am meisten beworben, gefolgt von den Segmenten Kosmetik und Mode, Medien, Autos, Verkehr und Touristik. Die Putzmittel, die in der deutschen Fernsehwerbung besonders zubuche schlagen, nehmen vom Gesamtetat nur 2,6\% ein. Die Konzentration beider Werbesysteme auf den „oralen Konsum“ verstärkt sich noch, wenn man die Aufteilung der Werbeausgaben auf die vier Massenmedien Zeitung, Zeitschrift, Radio und Fernsehen (den Mediamix: Abbildungen 6 und 7) betrachtet.

Abbildung 5: Werbeausgaben nach Branchen im Jahre 1999 in Prozent in Japan und Deutschland

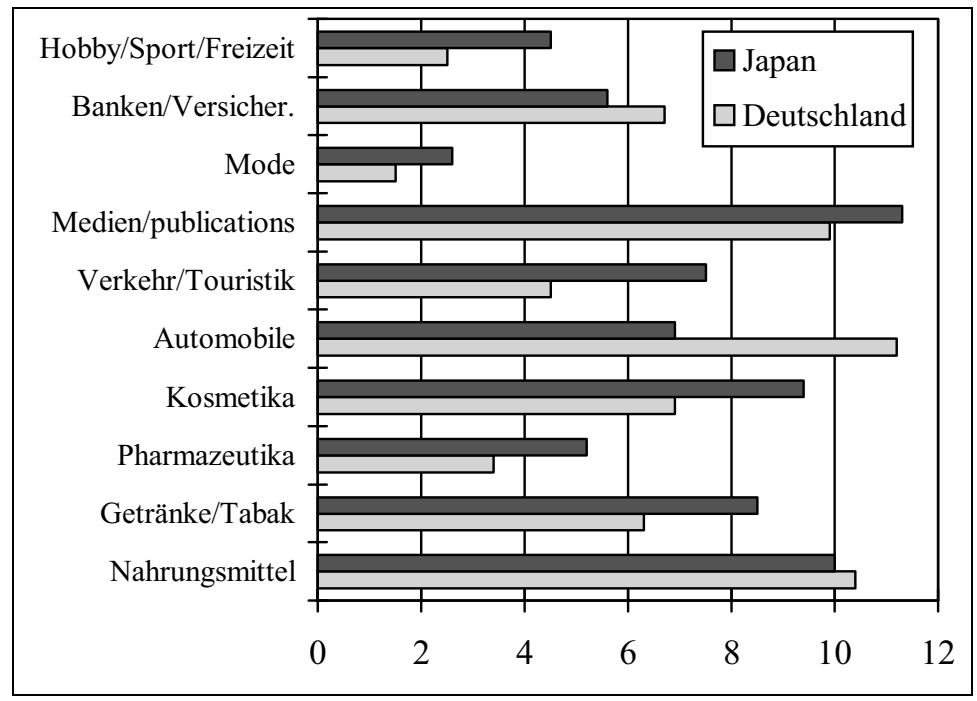

Quellen: http://co.guj.de/markt_media/werbetrend/ im November 2000 http://www.dentsu.co.jp/DOG/adex1999/index.html im Oktober 2000 
Abbildung 6: Mediamix der japanischen Werbung nach Branchen im Jahre 2001 in Prozent

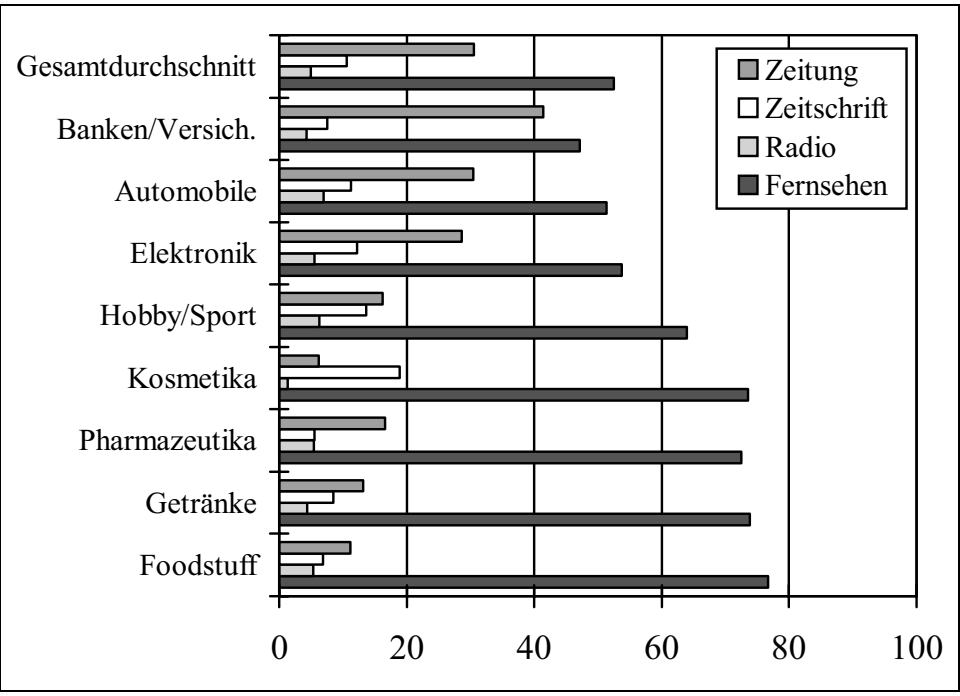

Quelle: Japan Almanac 2003

Abbildung 7: Mediamix der deutschen Werbung nach Branchen im Jahre 1999 in Prozent

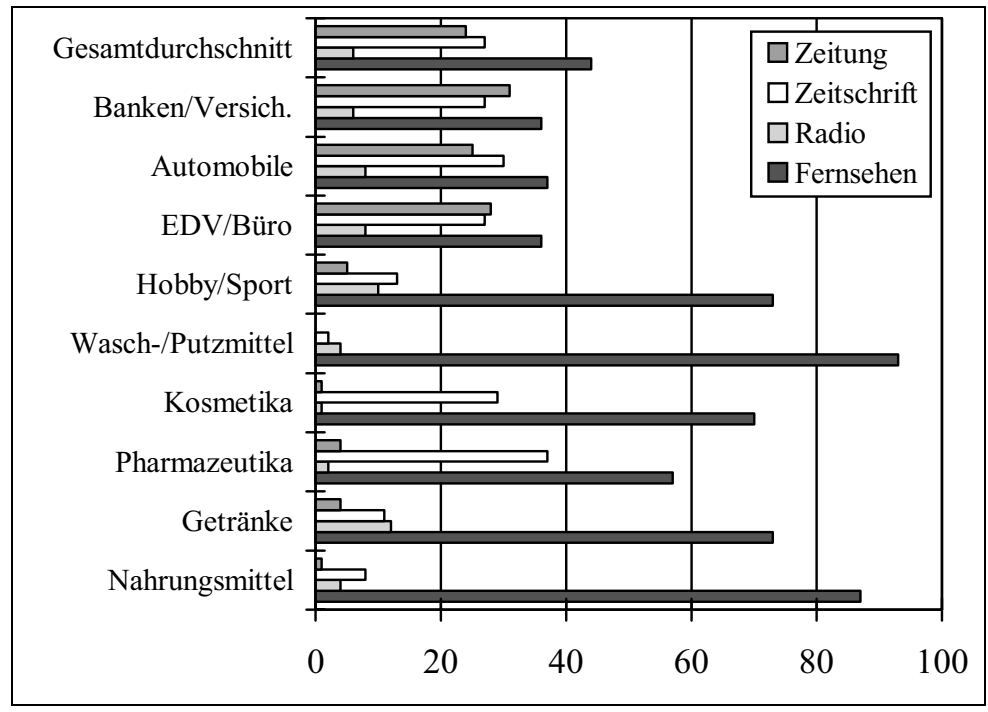

Quelle: http://co.guj.de/markt_media/werbetrend/ im November 2000 


\section{Bildanhang}

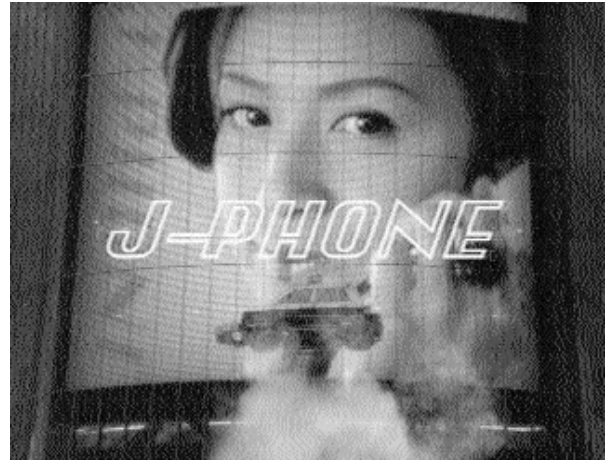

„Blade Runner“ in Shibuya. Das Topmodel Fujiwara Norika empfiehlt auf der Großbildleinwand des Tokioter Ringbahnhofs die Handies von J-Phone.

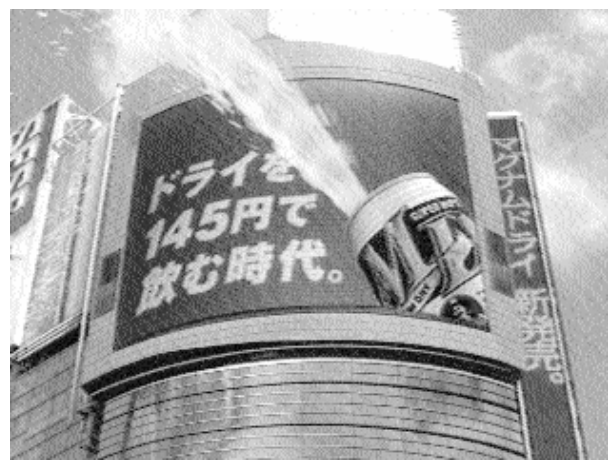

„Magnum Dry für nur 145 Yen!“ Billiges Bier für arme Angestellte. Davon träumt der japanische sarariiman nach getaner Arbeit.

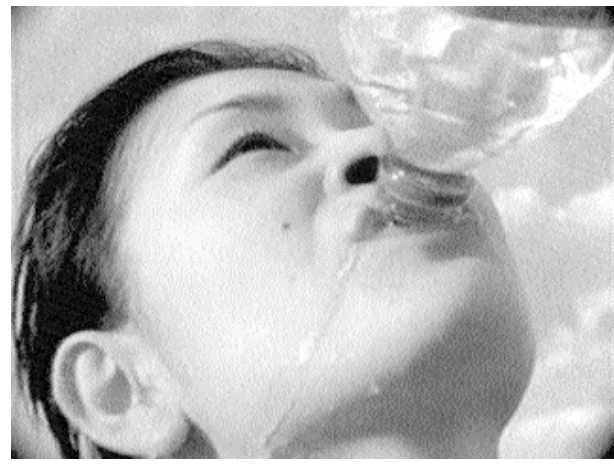

Volvic:

Oraler

Konsum aus

Frankreich. 


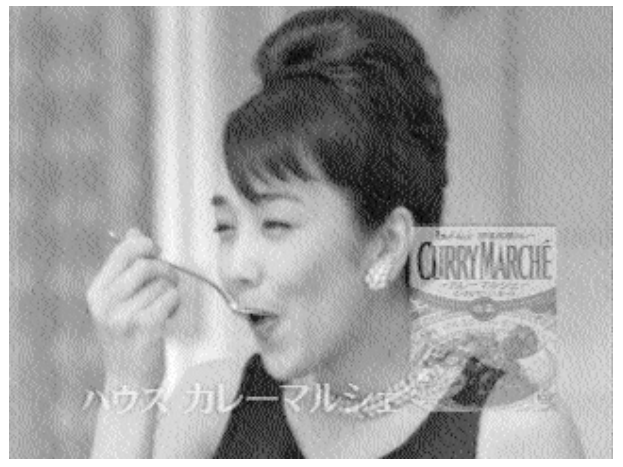

„Leckeres Europa

inklusive.“

Die Schauspielerin

Nishida Hikaru kostet

ein Curry-Gericht.

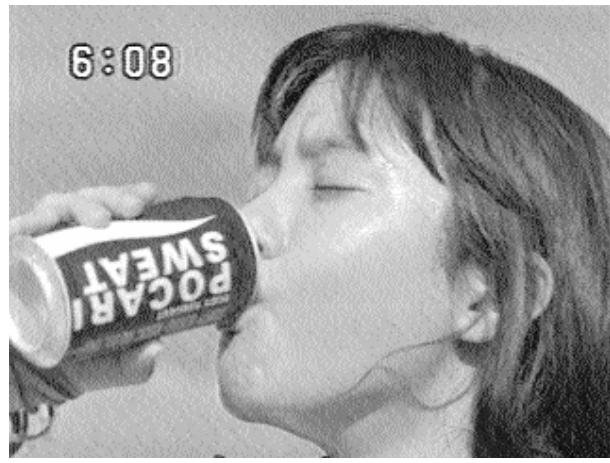

„Höre auf Deinen

Körper!"

Pocari Sweat ist mehr als ein Getränk.

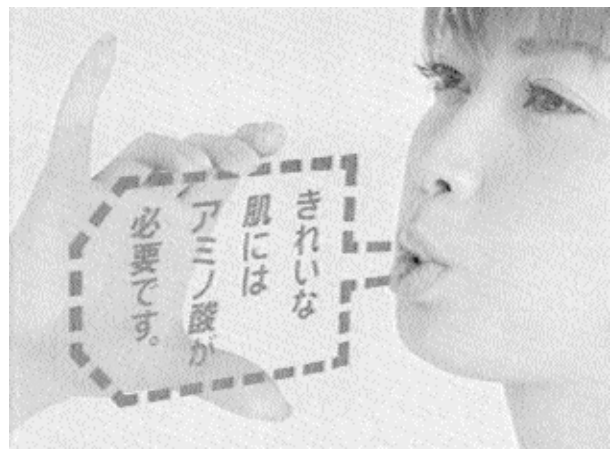

„Für schöne Haut

braucht man

Aminosäuren.“

Orale und taktile

Fixierungen der

japanischen Werbung. 


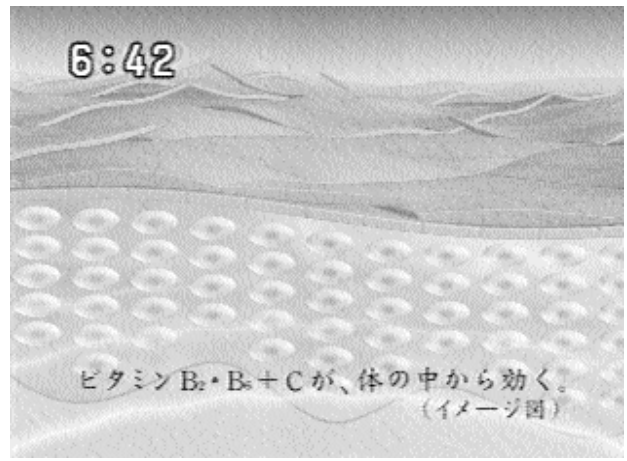

„Die Vitamine B2, B3 und $\mathrm{C}$ wirken aus dem Inneren des Körpers.“ Die Werbung geht in die Tiefe. Querschnitt durch die menschliche Haut.

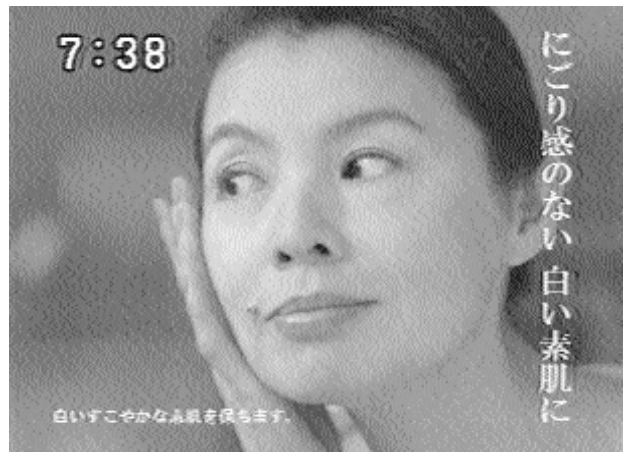

„Für eine weiße, natürliche Haut ohne jedes Gefühl von Unreinheit.“ TV-Spot für Grace Sofina.

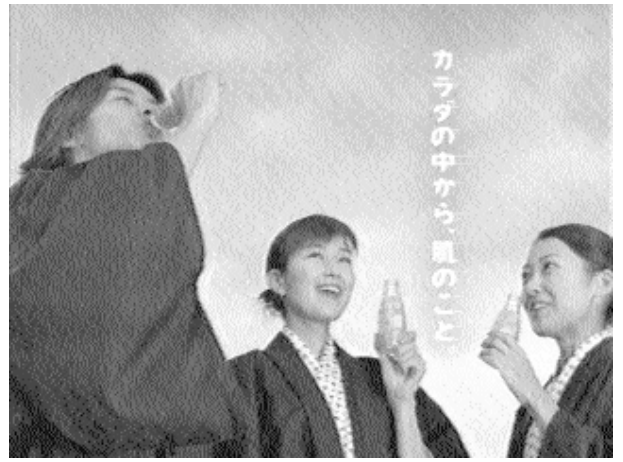

„Wirkt für die Haut aus dem Inneren des Körpers.“ TV-Spot für Pure-In. 


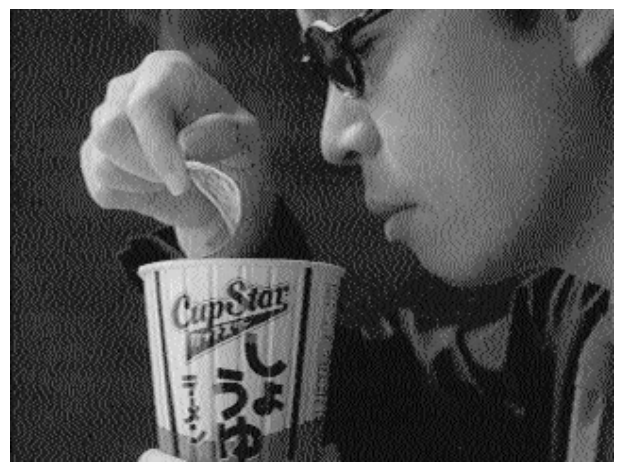

Japanisch 1:

Cup Noodles.

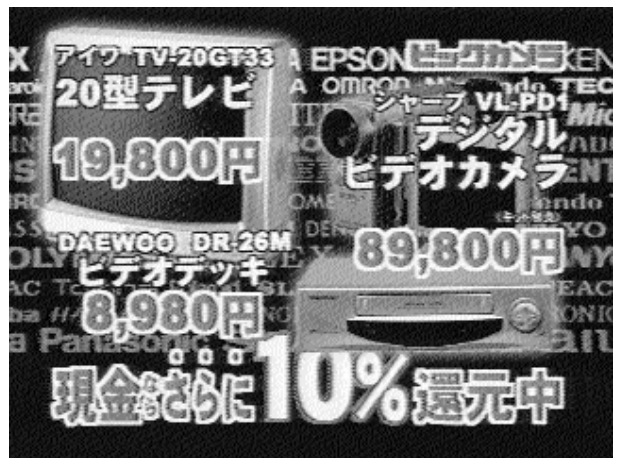

\section{Japanisch 2:}

Zeichenakkumulation

für das Elektronik-

Kaufhaus Big Camera.

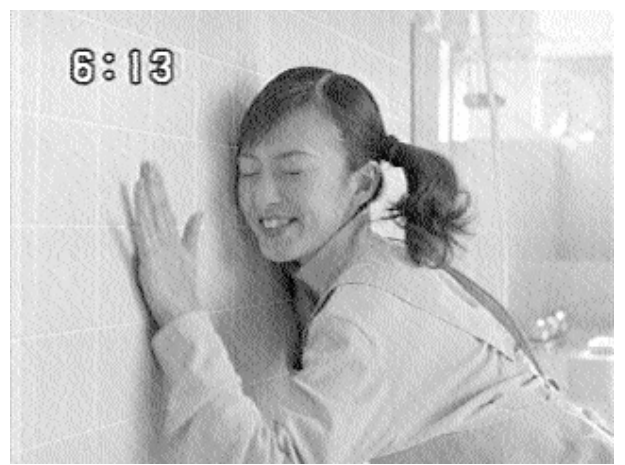

Japanisch 3:

Weiße Reinheit

bis in die Fugen. 


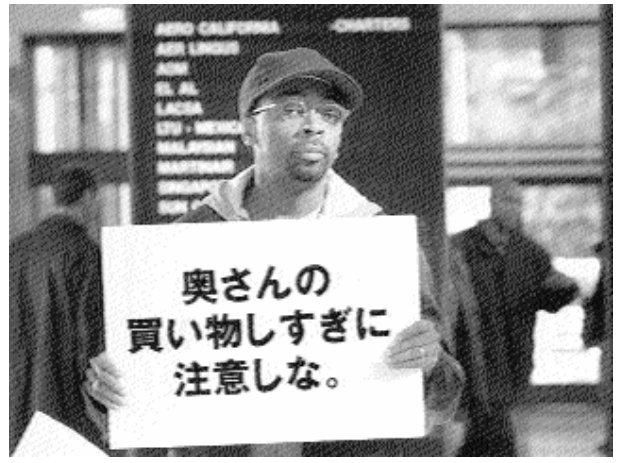

Amerikanisch 1:

„Paß’ auf, daß

deine Frau nicht zuviel

einkauft!“

Spike Lee empfiehlt

einen japanischen

Kleinwagen mit viel

Stauraum.

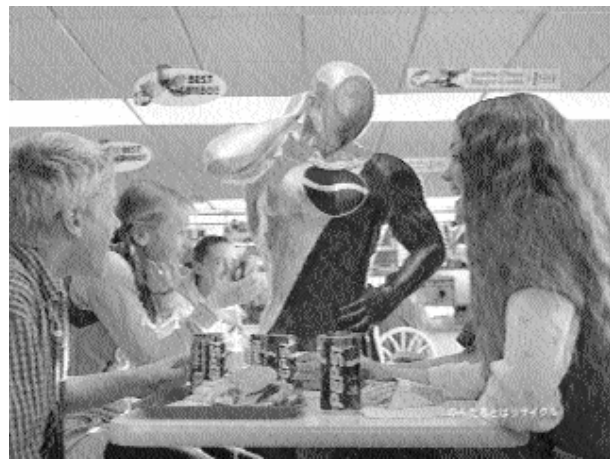

Amerikanisch 2:

Der Pepsi-Man versorgt die Teenager mit frischem Sirup.

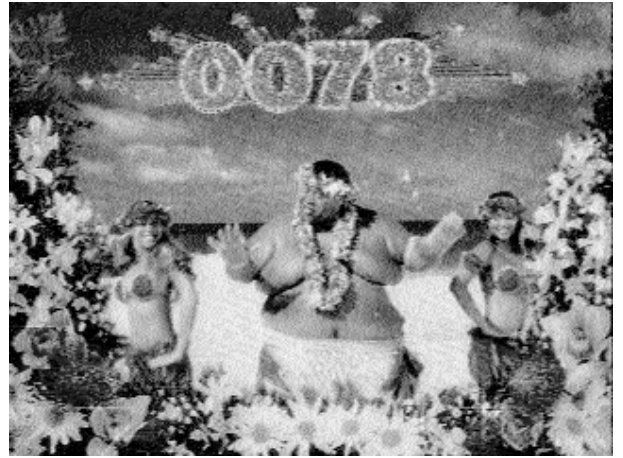

Amerikanisch 3:

Der Sumo-Ringer

Konishiki ruft seine

Mutter auf Hawaii

immer mit DDI an. 


\section{Die Neuerscheinungen dieser Reihe}

\section{Gabriele Dietze}

\section{Weiße Frauen in Bewegung}

Genealogien und Konkurrenzen von Race- und Genderpolitiken

Dezember 2006, 450 Seiten,

kart., ca. $31,80 €$,

ISBN: 3-89942-517-0

\section{Susanne Krasmann,}

Michael Volkmer (Hg.)

Michel Foucaults »Geschichte

der Gouvernementalität « in den Sozialwissenschaften

Internationale Beiträge

Dezember 2006, ca. 26o Seiten,

kart., ca. $26,80 €$,

ISBN: 3-89942-488-3

\section{Tatjana Zimenkova}

Die Praxis der Soziologie:

Ausbildung, Wissenschaft,

\section{Beratung}

Eine professionstheoretische

Untersuchung

Dezember 2006, ca. 300 Seiten,

kart., ca. $27,80 €$,

ISBN: 3-89942-519-7

Benjamin Jörissen

\section{Beobachtungen der Realität}

Die Frage nach der Wirklichkeit im Zeitalter der Neuen Medien

November 2006, 230 Seiten,

kart., ca. $24,80 €$,

ISBN: 3-89942-586-3

Reinhard Heil,

Andreas Kaminski,

Marcus Stippak,

Alexander Unger,

Marc Ziegler (Hg.)

\section{Tensions}

Technological and Aesthetic

(Trans)Formations of Society

November 2006, ca. 350 Seiten,

kart., ca. $31,80 €$,

ISBN: 3-89942-518-9

\section{Ulrike Gerhard \\ Global City Washington, D.C.}

Eine politische Stadtgeographie

Oktober 2006, 280 Seiten,

kart., ca. $26,80 €$,

ISBN: 3-89942-497-2

Heiner Keupp,

Joachim Hohl (Hg.)

Subjektdiskurse im

gesellschaftlichen Wandel

Zur Theorie des Subjekts

in der Spätmoderne

Oktober 2006, ca. 220 Seiten,

kart., ca. $25,80 €$,

ISBN: 3-89942-562-6

\section{Heiner Depner \\ Transnationale \\ Direktinvestitionen und \\ kulturelle Unterschiede}

Lieferanten und Joint Ventures deutscher Automobilzulieferer in China

Oktober 2006, ca. 210 Seiten,

kart., ca. $25,80 €$,

ISBN: 3-89942-567-7

\section{Sacha-Roger Szabo}

Rausch und Rummel

Attraktionen auf Jahrmärkten und in Vergnügungsparks.

Eine soziologische

Kulturgeschichte

Oktober 2006, 230 Seiten, kart., zahlr. Abb., ca. 26,80 € ISBN: 3-89942-566-9

Florian Feuser

Der hybride Raum

Chinesisch-deutsche

Zusammenarbeit in der VR China

Oktober 2006, ca. 320 Seiten,

kart., ca. $29,80 €$,

ISBN: 3-89942-581-2

Leseproben und weitere Informationen finden Sie unter: www.transcript-verlag.de 


\section{Die Neuerscheinungen dieser Reihe}

Christoph Wulf

Anthropologie kultureller Vielfalt

Interkulturelle Bildung in Zeiten der Globalisierung

September 2006, ca. 145 Seiten, kart., ca. $16,80 €$,

ISBN: 3-89942-574-X

Ingrid Jungwirth

Zum Identitätsdiskurs in den

Sozialwissenschaften

Eine postkolonial und queer informierte Kritik an George H. Mead, Erik H. Erikson und Erving Goffman

September 2006, ca. 300 Seiten, kart., ca. $29,80 €$,

ISBN: 3-89942-571-5

Martin Voss,

Birgit Peuker (Hg.)

Verschwindet die Natur?

Die Akteur-Netzwerk-Theorie in der umweltsoziologischen Diskussion

August 2006, ca. 180 Seiten, kart., ca. $22,80 €$,

ISBN: 3-89942-528-6

\section{Helen Schwenken}

Rechtlos, aber nicht

ohne Stimme

Politische Mobilisierungen um irreguläre Migration in die EU

August 2006, ca. 350 Seiten,

kart., $29,80 €$,

ISBN: 3-89942-516-2

Sebastian Linke

Darwins Erben in den Medien

Eine wissenschafts- und mediensoziologische Fallstudie zur Renaissance der

Soziobiologie

August 2006, ca. 240 Seiten,

kart., ca. $25,80 €$,

ISBN: 3-89942-542-1
Jochen Dreher,

Peter Stegmaier (Hg.)

Zur Unüberwindbarkeit

kultureller Differenz

Grundlagentheoretische

Reflexionen

August 2006, ca. 26o Seiten,

kart., ca. $25,80 €$,

ISBN: 3-89942-477-8

Ivo Mossig

Netzwerke der

Kulturökonomie

Lokale Knoten und globale

Verflechtungen der Film- und

Fernsehindustrie in

Deutschland und den USA

Juli 2006, 228 Seiten,

kart., $26,80 €$,

ISBN: 3-89942-523-5

Amalia Barboza,

Christoph Henning (Hg.)

Deutsch-jüdische

Wissenschaftsschicksale

Studien über Identitäts-

konstruktionen in der

Sozialwissenschaft

Juli 2006, ca. 28o Seiten,

kart., ca. $28,80 €$,

ISBN: 3-89942-502-2

Christian Kellermann

Die Organisation des

Washington Consensus

Der Internationale

Währungsfonds und seine Rolle in der internationalen

Finanzarchitektur

Juli 2006, 328 Seiten,

kart., $28,80 €$,

ISBN: 3-89942-553-7

\section{Leseproben und weitere Informationen finden Sie unter:}

www.transcript-verlag.de 


\section{Die Neuerscheinungen dieser Reihe}

Andrej Holm

Die Restrukturierung

des Raumes

Stadterneuerung der goer Jahre in Ostberlin: Interessen und

Machtverhältnisse

Juli 2006, ca. 300 Seiten,

kart., ca. $27,80 €$,

ISBN: 3-89942-521-9

\section{Martin Voss}

Symbolische Formen

Grundlagen und Elemente

einer Soziologie der

Katastrophe

Juli 2006, ca. 320 Seiten,

kart., ca. $27,80 €$,

ISBN: 3-89942-547-2

Christian Berndt,

Johannes Glückler (Hg.)

Denkanstöße zu einer

anderen Geographie der Ökonomie

Juli 2006, ca. 150 Seiten,

kart., ca. $15,80 €$,

ISBN: 3-89942-454-9

Mark Hillebrand, Paula Krüger, Andrea Lilge, Karen Struve

(Hg.)

\section{Willkürliche Grenzen}

Das Werk Pierre Bourdieus in interdisziplinärer Anwendung

Juli 2006, ca. 220 Seiten,

kart., ca. $23,80 €$,

ISBN: 3-89942-540-5

Renate Grau

Ästhetisches Engineering:

Wertschöpfung und

Verbreitung von

belletristischer Literatur

Eine Studie aus Sicht der

Akteur-Netzwerk-Theorie

Juli 2006, ca. 300 Seiten,

kart., ca. $32,80 €$,

ISBN: 3-89942-529-4
Ulrich Heinze

Hautkontakt der

Schriftsysteme

Japan im Zeichen der

Globalisierung: Geldflüsse und

Werbetexte

Juli 2006, 206 Seiten,

kart., $25,80 €$,

ISBN: 3-89942-513-8

Lutz Leisering, Petra Buhr,

Ute Traiser-Diop

Grundsicherung als globale

Herausforderung

Soziale Grundsicherungs-

systeme in Entwicklungs- und

Übergangsgesellschaften -

ein weltweiter Survey.

Mit einer Analyse westlicher

Grundsicherungsmodelle

Juli 2006, ca. 200 Seiten,

kart., ca. $18,80 €$,

ISBN: 3-89942-460-3

Wolf-Andreas Liebert,

Marc-Denis Weitze (Hg.)

Kontroversen als Schlüssel zur Wissenschaft?

Wissenskulturen in sprachlicher Interaktion

Juni 2006, 206 Seiten,

kart., $24,80 €$,

ISBN: 3-89942-448-4

Lutz Hieber, Paula-Irene Villa

Images von Gewicht

Soziale Bewegungen,

Queer Theory und Kunst

in den USA

Juni 2006, ca. 150 Seiten,

kart., ca. $16,80 €$,

ISBN: 3-89942-504-9

Leseproben und weitere Informationen finden Sie unter: www.transcript-verlag.de 


\section{Die Neuerscheinungen dieser Reihe}

Shingo Shimada,

Christian Tagsold

Alternde Gesellschaften im Vergleich

Solidarität und Pflege in

Deutschland und Japan

Juni 2006, 178 Seiten,

kart., $18,80 €$,

ISBN: $3-89942-476-X$

Andréa Belliger,

David J. Krieger (Hg.)

ANThology

Ein einführendes Handbuch

zur Akteur-Netzwerk-Theorie

Juni 2006, 584 Seiten,

kart., $29,80 €$,

ISBN: 3-89942-479-4

Max Miller

\section{Dissens}

Zur Theorie diskursiven und systemischen Lernens

Juni 2006, ca. 280 Seiten,

kart., ca. $27,80 €$,

ISBN: 3-89942-484-0

Martin Nonhoff

Politischer Diskurs

und Hegemonie

Das Projekt "Soziale

Marktwirtschaft"

Juni 2006, 424 Seiten,

kart., $29,80 €$,

ISBN: 3-89942-424-7

Niels C. Taubert

Produktive Anarchie?

Netzwerke freier

Softwareentwicklung

März 2006, 250 Seiten,

kart., $27,80 €$,

ISBN: 3-89942-418-2
Stephen Kalberg

Max Weber lesen

Februar 2006, 150 Seiten,

kart., $11,00 €$,

ISBN: 3-89942-445-X

Sina Farzin

Inklusion/Exklusion

Entwicklungen und Probleme

einer systemtheoretischen

Unterscheidung

Januar 2006, 124 Seiten,

kart., $13,80 €$,

ISBN: 3-89942-361-5

Sabine Brombach,

Bettina Wahrig (Hg.)

LebensBilder

Leben und Subjektivität

in neueren Ansätzen der

Gender Studies

Januar 2006, 308 Seiten,

kart., zahlr. z.T. farb. Abb., 26,80 €,

ISBN: 3-89942-334-8

Alexander Peine

Innovation und Paradigma

Epistemische Stile in

Innovationsprozessen

Januar 2006, 274 Seiten,

kart., $25,80 €$,

ISBN: $3-89942-458-1$

Matthias Otten

Interkulturelles Handeln

in der globalisierten

Hochschulbildung

Eine kultursoziologische Studie

Januar 2006, 318 Seiten,

kart., $28,80 €$,

ISBN: 3-89942-434-4

Leseproben und weitere Informationen finden Sie unter: www.transcript-verlag.de 